Gerenciamento de tags na arquitetura ChipCflow - uma máquina a fluxo de dados dinâmica

\author{
Bruno de Abreu Silva
}



SERVIÇO DE PÓS-GRADUAÇÃO DO ICMC-USP

Data de Depósito: 11/05/2011

Assinatura:

\section{Gerenciamento de tags na arquitetura ChipCflow - uma máquina a fluxo de dados dinâmica}

\section{Bruno de Abreu Silva}

Orientador: Prof. Dr. Jorge Luiz e Silva

Dissertação apresentada ao Instituto de Ciências Matemáticas e de Computação - ICMC-USP, como parte dos requisitos para obtenção do título de Mestre em Ciências - Ciências de Computação e Matemática Computacional. VERSÃO REVISADA.

USP - São Carlos

Maio/2011 
Ficha catalográfica elaborada pela Biblioteca Prof. Achille Bassi e Seção Técnica de Informática, ICMC/USP, com os dados fornecidos pelo(a) autor(a)

Silva, Bruno de Abreu
Gerenciamento de tags na arquitetura ChipCflow -
uma máquina a fluxo de dados dinâmica / Bruno de
Abreu Silva; orientador Jorge Luiz e Silva -- São
Carlos, 2011.
125 p.
Dissertação (Mestrado - Programa de Pós-Graduação en
Ciências de Computação e Matemática Computacional) --
Instituto de Ciências Matemáticas e de Computação,
Universidade de São Paulo, 2011.
1. Arquiteturas a fluxo de dados. 2. Arquiteturas
paralelas. 3. Sistemas de alto desempenho. I. Silva,
Jorge Luiz e, orient. II. Título.


Dedico esta dissertação a meus pais, Neuza e Gilson (in memoriam), cujos princípios têm sido norteadores para a minha vida; à minha irmã Alyne por todos os momentos alegres compartilhados e; para minha namorada Natália, que tem me dado apoio nos momentos mais dificeis. 


\section{AGRADECIMENTOS}

Dedico meus sinceros agradecimentos:

- ao Professor Doutor Jorge Luiz e Silva, pela orientação, incentivo e amizade;

- ao Maurício por todas as sugestões e críticas construtivas realizadas;

- à equipe do Projeto ChipCflow, em especial aos colegas Maykon, Joelmir e Antônio pelas discussões extremamente produtivas e momentos de descontração;

- ao Conselho Nacional de Desenvolvimento Científico e Tecnológico (CNPq) pelo apoio financeiro;

- a todos os colegas do Mestrado em Ciências de Computação e Matemática Computacional;

- para a secretaria de pós-graduação do ICMC-USP por todas as informações e serviços prestados;

- à minha namorada Natália por ter revisado o texto deste trabalho;

- para todos aqueles que direta ou indiretamente contribuíram para a realização deste trabalho. 


\section{RESUMO}

Nos últimos anos, percebeu-se uma crescente busca por softwares e arquiteturas alternativas. Essa busca acontece porque houve avanços na tecnologia do hardware e estes avanços devem ser complementados por inovações nas metodologias de projetos, testes e verificação para que haja um uso eficaz da tecnologia. Muitos dos softwares e arquiteturas alternativas, geralmente partem para modelos que exploram o paralelismo das aplicações, ao contrário do modelo de von Neumann. Dentre as arquiteturas alternativas de alto desempenho, tem-se a arquitetura a fluxo de dados. Nesse tipo de arquitetura, o processo de execução de programas é determinado pela disponibilidade dos dados. Logo, o paralelismo está embutido na própria natureza do sistema. O modelo a fluxo de dados possui a vantagem de expressar o paralelismo de maneira intrínseca, eliminando a necessidade de o programador explicitar em seu código os trechos onde deve haver paralelismo. As arquiteturas a fluxo de dados voltaram a ser um tema de pesquisa devido aos avanços do hardware, em particular, os avanços da Computação Reconfigurável e os FPGAs (Field-Programmable Gate Arrays). O projeto ChipCflow é uma ferramenta para execução de algoritmos usando o modelo a fluxo de dados dinâmico em FPGA. Este trabalho apresenta o formato para os tagged-tokens do ChipCflow, os operadores de manipulação das tags dos tokens e suas implementações a fim de que se tenha a PROVA-DE-CONCEITOS para tais operadores na arquitetura ChipCflow. 


\section{ABSTRACT}

The alternative architectures and softwares researches have been growing in the last years. These researches are happening due to the advance of hardware technology and such advances must be complemented by improvements on design methodologies, test and verification techniques in order to use technology effectively. Many of the alternative architectures and softwares, in general, explore the parallelism of applications, differently to von Neumann model. Among high performance alternative architectures, there is the Dataflow Architecture. In this kind of architecture, the execution of programs is determined by data availability, thus the parallelism is intrinsic in these systems. The dataflow architectures become again a highlighted research area due to hardware advances, in particular, the advances of Reconfigurable Computing and FPGAs (Field-Programmable Gate Arrays). ChipCflow project is a tool for execution of algorithms using dynamic dataflow graph in FPGA. The main goal in this module of the ChipCflow project is to define the tagged-token format, the iterative operators that will manipulate the tags of tokens and to implement them. 


\section{SUMÁRIO}

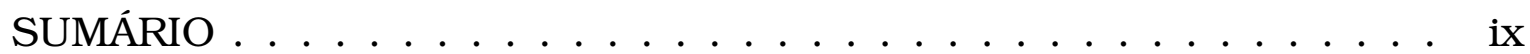

LISTA DE FIGURAS $\ldots \ldots \ldots \ldots \ldots$ xiii

LISTA DE TABELAS . . . . . . . . . . . . . . . . xvii

LISTA DE ABREVIATURAS . . . . . . . . . . . . . . . . xix

LISTA DE ALGORITMOS . . . . . . . . . . . . . . . . . . . . xxi

1 INTRODUÇÃO 1

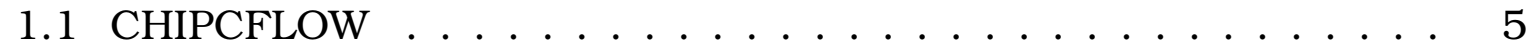

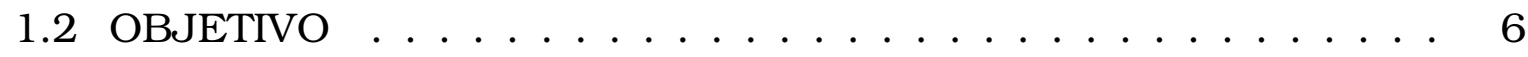

1.3 ORGANIZAÇÃO DA DISSERTAÇÃO . . . . . . . . . . . . . 7

2 COMPUTAÇÃO RECONFIGURÁVEL E FPGAs 9

2.1 CONSIDERAÇÕES INICIAIS $\ldots \ldots \ldots \ldots$

2.2 COMPUTAÇÃO RECONFIGURÁVEL . . . . . . . . . . . . . 9

2.3 FPGA - ELEMENTOS BÁSICOS . . . . . . . . . . . . . 11

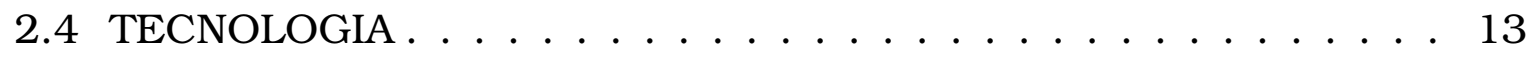

2.5 LOOK-UP TABLES . . . . . . . . . . . . . . . . . . . . 14

2.6 O BLOCO LÓGICO CONFIGURÁVEL DA XILINX $\ldots \ldots \ldots$

2.7 MATRIZ DE BLOCOS LÓGICOS DA ALTERA . . . . . . . . . . 15

2.8 ESTRUTURAS DE FPGAS . . . . . . . . . . . . . 16

2.9 FLUXO DE PROJETO EM FPGA . . . . . . . . . . . . . . 17

2.10 CONSIDERAÇÕES FINAIS $\ldots \ldots \ldots$

3 ARgUITETURAS A FLUXO DE DADOS 21

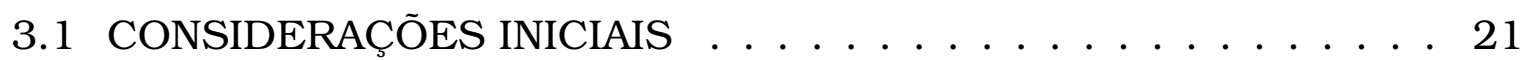

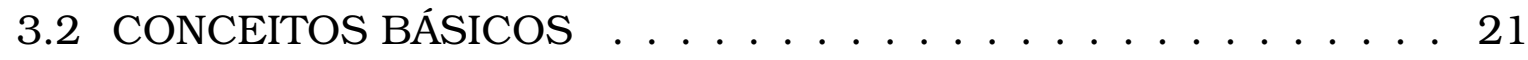

3.3 MÁQGUINA A FLUXO DE DADOS ESTÁTICA . . . . . . . . . . 27

3.4 MÁGUINA DE MANCHESTER . . . . . . . . . . . . . . . . 29

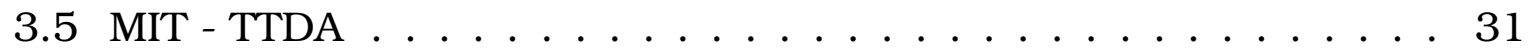

3.6 SPATIAL DATAFLOW $\ldots \ldots \ldots \ldots \ldots$ 


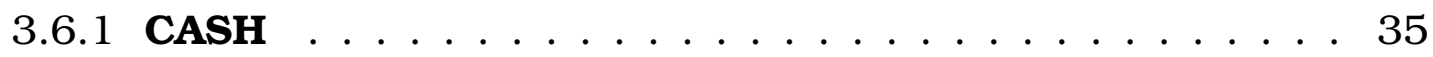

3.6 .2 CHiMPS $\ldots \ldots \ldots \ldots \ldots \ldots \ldots \ldots \ldots$

3.6 .3 WaveScalar . . . . . . . . . . . . . . . 37

3.7 CONSIDERAÇÕES FINAIS $\ldots \ldots \ldots \ldots$. . . . . . . . . 42

4 CHIPCFLOW

4.1 CONSIDERAÇÕES INICIAIS . . . . . . . . . . . . . 43

4.2 FASE PRÉ-CHIPCFLOW . . . . . . . . . . . . . . . 43

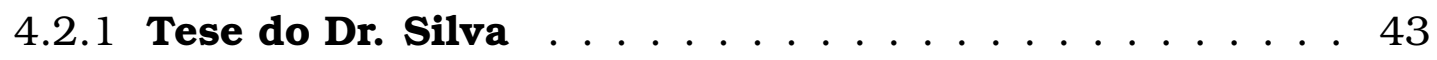

$4.2 .2 \operatorname{SPmm1} \ldots \ldots \ldots \ldots \ldots \ldots$

4.2 .3 O embrião do ChipCflow . . . . . . . . . . . . . . 45

4.3 PROPOSTA INICIAL DO PROJETO CHIPCFLOW . . . . . . . . 46

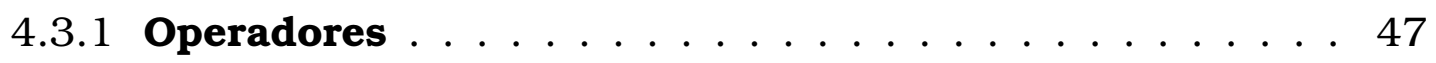

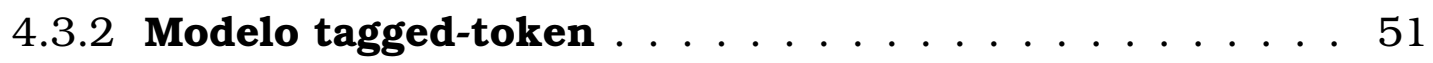

4.3 .3 Instâncias dos operadores . . . . . . . . . . . . 52

4.3 .4 Unidade de matching $\ldots \ldots \ldots \ldots \ldots$

4.3 .5 O compilador C para VHDL . . . . . . . . . . . . 54

4.3.6 Considerações sobre a proposta inicial do projeto ChipC-

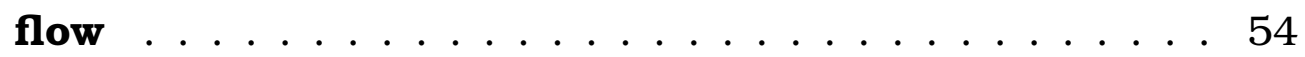

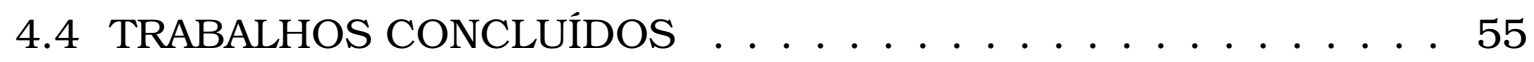

4.4.1 Operadores e grafo a fluxo de dados . . . . . . . . 55

4.4.2 Conversão $\mathbf{C}$ em grafo a fluxo de dados . . . . . . . 56

4.4.3 Instâncias em hardware parcialmente reconfigurável . . 62

4.4.4 Partição e protocolo de comunicação em DFG dinâmico 62

4.4.5 Considerações sobre os trabalhos concluídos . . . . . . 63

4.5 TRABALHOS EM ANDAMENTO . . . . . . . . . . . . . . 64

4.6 CONSIDERAÇÕES FINAIS . . . . . . . . . . . . 68

5 GERENCIAMENTO DE TAGS NA ARGUITETURA CHIPCFLOW 71

5.1 CONSIDERAÇÕES INICIAIS $\ldots \ldots \ldots \ldots \ldots \ldots \ldots \ldots$

5.2 TAGGED-TOKEN NA ARQUITETURA CHIPCFLOW . . . . . . . . 71

5.3 OPERADORES PARA GERENCIAMENTO DE TAGS NA ARGUITETURA CHIPCFLOW . . . . . . . . . . . . . 77

5.4 SOMA DE VETORES ELEMENTO POR ELEMENTO $\ldots . . . . . .84$

5.5 IMPLEMENTAÇÃO DOS OPERADORES PARA GERENCIAMENTO

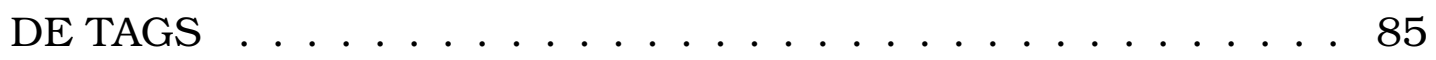

5.5 .1 Initial Tag Generator (ITG) . . . . . . . . . . . . . 86

5.5 .2 Tag Remover (TR) . . . . . . . . . . . . . . . . . 88

5.5 .3 New Iteration Generator (NIG) . . . . . . . . . . . . . 90

5.5.4 New Tag Manager (NTM) . . . . . . . . . . . . . . . 992

5.5 .5 New Tag Destructor (NTD) . . . . . . . . . . . . . 98 
5.5 .6 Old Tag Table (OTT) . . . . . . . . . . . . . . . . . . 102

5.5 .7 Testes de integração . . . . . . . . . . . . . 106

5.6 CONSIDERAÇÕES FINAIS $\ldots \ldots \ldots \ldots \ldots \ldots \ldots \ldots$

6 CONCLUSÕES E TRABALHOS FUTUROS 113

$\begin{array}{lr}\text { REFERÊNCIAS BIBLIOGRÁFICAS } & 119\end{array}$ 


\section{LISTA DE FIGURAS}

2.1 Flexibilidade $\mathrm{x}$ Desempenho (BOBDA, 2007) . . . . . . . 10

2.2 Estrutura de um FPGA (BOBDA, 2007) . . . . . . . . . . 13

2.3 Exemplo de LUT de duas entradas (BOBDA, 2007) $\ldots \ldots \ldots$

2.4 Bloco básico de FPGAs da Xilinx (BOBDA, 2007) . . . . . . . . 15

2.5 Bloco básico de FPGAs da Altera (BOBDA, 2007) . . . . . . . . 16

2.6 Estruturas básicas de um FPGA, adaptado de (BOBDA, 2007) . . 16

2.7 Fluxo de projeto em FPGA $\ldots \ldots \ldots \ldots$

3.1 Grafo a Fluxo de Dados. . . . . . . . . . . . . . . . . . 22

3.2 Exemplo de um grafo de uma construção condicional. . . . . . . 23

3.3 Problemas em grafos cíclicos. . . . . . . . . . . . . . . . 24

3.4 Métodos diferentes para tratar construções iterativas. . . . . . . . 25

3.5 Mecanismo Básico, adaptado de (DENNIS, 1980) . . . . . . . . 27

3.6 Célula de Instrução (DENNIS and MISUNAS, 1975) $\ldots \ldots$. . . . 28

3.7 Tipos de enlace (DENNIS and MISUNAS, 1975) . . . . . . . . 28

3.8 Tipos de operadores (DENNIS and MISUNAS, 1975) . . . . . . . 29

3.9 Máquina Manchester, adaptado de (GURD et al., 1985) . . . . . . 30

3.10 Operadores para linguagem a fluxo de dados (ARVIND, 2005) . 32

3.11 Instrução da TTDA, adaptado de (ARVIND and NIKHIL, 1990) . . 33

3.12 EP da TTDA, adaptado de (ARVIND and NIKHIL, 1990) . . . . . 34

3.13 Fluxo de compilação no modelo spatial dataflow (PUTNAM, 2009). 35

3.14 Fluxo de compilação no CASH (BUDIU, 2003). . . . . . . . . . 36

3.15Fluxo da ferramenta CHiMPS (PUTNAM et al., 2008) . . . . . . 37

3.16 Assembly do WaveScalar (SWANSON et al., 2007) . . . . . . . . 38

3.17 Controle no WaveScalar (SWANSON et al., 2007) . . . . . . . . . 39

3.18 Loops no WaveScalar (SWANSON et al., 2007) . . . . . . . . . 40

3.19WaveCache (SWANSON et al., 2007) . . . . . . . . . . . . 40 
3.20 Diagrama de um elemento de processamento do WaveScalar (SWANSON et al., 2007) . . . . . . . . . . . . . . . . . . 41

4.1 Máquina SPmm1 . . . . . . . . . . . . . . . . . . . . 44

4.2 Sistema de segurança doméstico. . . . . . . . . . . . . . . . 45

4.3 Proposta da Ferramenta ChipCflow . . . . . . . . . . . 48

4.4 Operadores do grafo a fluxo de dados do ChipCflow . . . . . . . 48

4.5 Blocos implementados para prova-de-conceitos para o protocolo

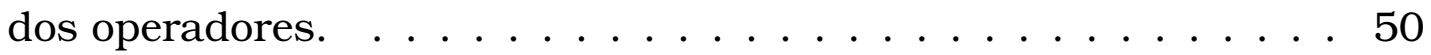

4.6 Grafo implementado para validar o protocolo dos operadores. . . 50

4.7 Construtores iterativos . . . . . . . . . . . . . 52

4.8 Instâncias diferentes para um operador $* \ldots \ldots \ldots$. . . . . 53

4.9 Diagrama Esquemático de um operador do ChipCflow . . . . . 56

4.10 Representação em binário para o Algoritmo $1 \ldots \ldots$. . . . 58

4.11 Formato de uma linha no mapeamento binário. . . . . . . . . . 59

$4.12 \mathrm{DFG}$ para um algoritmo com IF, FOR e WHILE . . . . . . . . . 59

4.130perador branch e suas instâncias. . . . . . . . . . . . . 65

4.14 Modelo para gerenciamento de memória. . . . . . . . . . . 65

4.15 Formato das instruções load e store. . . . . . . . . . . . . . . 66

4.16 Mnemônico e DFG de uma construção condicional. . . . . . . . 67

4.17 Objeto de estudo deste trabalho . . . . . . . . . . . . 69

5.1 Exemplo de um grafo de uma construção iterativa. . . . . . . . . 72

5.2 Exemplo de loops aninhados. . . . . . . . . . . . . . . . 73

5.3 Um for aninhado a outro. Tag indica somente nova iteração $\ldots 74$

5.4 Ativação de um grafo a partir de vários conjuntos de entradas. . . 76

5.5 Criação de tags iniciais utilizando o operador ITG. . . . . . . . . 78

5.6 Loop utilizando o operador NIG. . . . . . . . . . . . . . . . 79

5.7 Possível entrada de dados fora de ordem em um bloco. . . . . . . 79

5.8 Grafo onde um token deve recuperar sua tag antiga. . . . . . . . . 81

5.9 Soma de vetores elemento por elemento. . . . . . . . . . . . . . 84

5.10 Bloco esquemático do operador ITG e sua representação gráfica. . 86

5.11 Diagrama de estados do operador ITG. . . . . . . . . . . . 87

5.12 Simulação do operador ITG após síntese e place and route. . . . . 88

5.13 Bloco esquemático do operador TR e sua representação gráfica. . 88

5.14 Diagrama de estados do operador TR. . . . . . . . . . . 89

5.15Simulação do operador TR após síntese e place and route. . . . . 90

5.16Bloco esquemático do operador NIG e sua representação gráfica. 90

5.17 Diagrama de estados do operador NIG. . . . . . . . . . . . . . 91

5.18 Simulação do operador NIG após síntese e place and route. . . . . 92

5.19Bloco esquemático do operador NTM e sua representação gráfica. 93 
5.20 Diagrama de estados do operador NTM: recebimento dos dados de entrada. . . . . . . . . . . . . . . . . . . 94

5.21 Diagrama de estados do operador NTM: geração de tags novas e envio de dados à OTT. . . . . . . . . . . . . . . . . . . . . . . 95

5.22 Diagrama de estados do operador NTM: envio do resultado para a saída. . . . . . . . . . . . . . . . . . . 997

5.23 Simulação do operador NTM após síntese e place and route. . . . 99

5.24 Bloco esquemático do operador NTD e sua representação gráfica. 100

5.25 Diagrama de estados do operador NTD. . . . . . . . . . . . . 101

5.26 Simulação do operador NTD após síntese e place and route. . . . 103

5.27 Bloco esquemático da OTT e sua representação gráfica. . . . . . . 104

5.28 Diagrama de estados da OTT: Escrita. . . . . . . . . . . . 105

5.29 Diagrama de estados da OTT: Leitura. . . . . . . . . . . . . 106

5.30 Simulação da OTT após síntese e place and route. . . . . . . . . 107

5.31 Grafo de teste integrando ITG, NTM e TR. . . . . . . . . . . . 107

5.32 Simulação ITG, NTM e TR parte $1 . \ldots \ldots$. . . . . . . . 108

5.33 Simulação ITG, NTM e TR parte $2 . \ldots \ldots$. . . . . . . . 108

5.34 Grafo de teste integrando NTM, NIG, NTD e OTT. . . . . . . . . . . 109

5.35Simulação NTM, NIG, NTD e OTT. . . . . . . . . . . . . . . . . 110 


\section{LISTA DE TABELAS}

5.1 Resultados da síntese do operador ITG na Xilinx Spartan 3E 3s500efg320-4. . . . . . . . . . . . . . . . . 87

5.2 Resultados da síntese do operador TR na Spartan 3E 3s500efg3204. . . . . . . . . . . . . . . . . . . 89

5.3 Resultados da síntese do operador NIG na Xilinx Spartan 3E 3s500efg320-4. . . . . . . . . . . . . . . . . . 91

5.4 Resultados da síntese do operador NTM na Xilinx Spartan 3E 3s500efg320-4. . . . . . . . . . . . . . . . 98

5.5 Resultados da síntese do operador NTD na Xilinx Spartan 3E 3s500efg320-4. . . . . . . . . . . . . . . . 102

5.6 Resultados da síntese da OTT na Xilinx Spartan 3E 3s500efg320-4.105

6.1 Comparação de tags em arquiteturas tagged-token. . . . . . . . . 114 


\section{LISTA DE ABREVIATURAS}

ASIC - Application-Specific Integrated Circuit

CAD - Computer Aided Design

CASH - Compiler for Application-Specific Hardware

CLB - Configurable Logic Block

CPER - Computador Paralelo Estruturado Recursivamente

CPU - Central Processing Unit

CTL - CHiMPS Target Language

DFG - Dataflow Graph

EDA - Electronic Design Automation

EEPROM - Electrically-Erasable Programmable Read-Only Memory

EP - Elemento de Processamento

FEE - Faculdade de Engenharia Elétrica

FPGA - Field Programmable Gate Array

GPU - Graphical Processing Unit

HDL - Hardware Description Language

HDTV - High-Definition Television

ICMC - Instituto de Ciências Matemáticas e de Computação

ITG - Initial Tag Generator

LCR - Laboratório de Computação Reconfigurável

LUT - Look-up Table

MIT - Massachusetts Institute of Technology

MLA - Módulo de Lógica Adaptativo

NIG - New Iteration Generator

NTD - New Tag Destructors

NTM - New Tag Manager

OTT - Old Tag Table

RISC - Reduced Instruction Set Computer

RTR - Run-time Reconfiguration

SRAM - Static Random Access Memory

xix 
TR - Tag Remover

TTDA - Tagged-Token Dataflow Architecture

USP - Universidade de São Paulo

VHDL - VHSIC Hardware Description Language

VHSIC - Very High Speed Integrated Circuits

XOR - Exclusive-or 


\section{LISTA DE ALGORITMOS}

1 Exemplo de código a ser compilado . . . . . . . . . . . . . 57

2 Soma de vetores elemento por elemento . . . . . . . . . . 65 
Xxii 


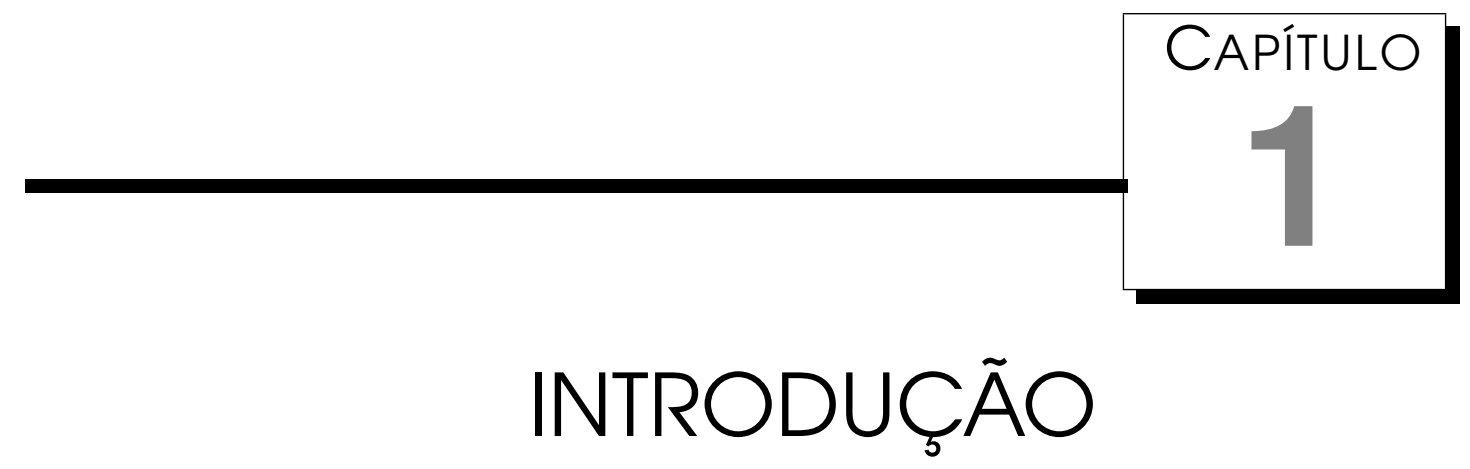

Entre a década de 1960 e a década de 1970, Gordon E. Moore, então presidente da Intel, "profetizou"que o número de transistores por chip dobraria a cada 18 meses (MOORE, 2000). Mas, aumentar simplesmente o número de transistores por chip não implica aumento no desempenho dos computadores. Então, desde que esta espécie de "meta"conhecida como Lei de Moore foi estabelecida, muitos esforços têm sido feitos pelos pesquisadores, engenheiros e fabricantes para acompanhar o ritmo intenso do mercado. Os computadores aumentaram sua complexidade durante os anos que se seguiram e uma das principais maneiras de se aumentar o desempenho era por meio de frequências de clock cada vez mais elevadas. Após cerca de trinta anos de Lei de Moore, já havia sintomas de que os dias da escalada do hardware, rumo a chips cada vez mais complexos, operando a frequências de clock cada vez mais altas, estavam chegando ao fim. De fato, muitas estruturas de um processador, como pipeline, precisam de sinais globais e, o problema é que fisicamente não há tempo suficiente para que os sinais se propaguem por todo chip em altas frequências de clock. Em $10 \mathrm{GHz}$, um sinal consegue cobrir menos do que $1 \%$ da superfície de um chip em um ciclo de clock, o que inviabiliza chips funcionando corretamente sob tais condições (AGARWAL et al., 2000).

Portanto, a migração para o paralelismo que está acontecendo na Computação não é somente mérito dos avanços em arquiteturas e softwares paralelos, mas também é fruto da impossibilidade de se continuar aumentando o desempenho por meio do modelo sequencial. Traduzir eficientemente os recursos de hardware disponíveis atualmente em desempenho na aplicação é um desafio aberto que os projetos superescalares convencionais não são capazes de resolver. Tais projetos são construídos sobre uma vasta estrutura de redes lentas 
de broadcast, buscas associativas, lógicas de controle complexas e estruturas centralizadas (SWANSON et al., 2007).

Alguém poderia perguntar o porquê de se aumentar cada vez mais o desempenho. Realmente, muitas aplicações parecem executar bem com as tecnologias atuais. Porém, muitas aplicações no futuro, inclusive aquelas voltadas para o mercado de massa, serão as consideradas supercomputing applications ou superapplications (KIRK and HWU, 2010). Por exemplo, aplicações de codificação e manipulação de áudio e vídeo para o padrão HDTV (High-Definition Television) demandarão maiores poderes computacionais, uma vez que processarão imagens em três dimensões. Além de outras funcionalidades que surgirão, como por exemplo, interfaces homem-máquina baseadas em voz e visão computacional, touch screen de alta resolução, entre outros. Além dessas aplicações, nas pesquisas biológicas em nível molecular, a Computação tem se tornado importante, pois é possivel simular as atividades da molécula, fazer medições e testar hipóteses em condições que seriam inimagináveis utilizando instrumentos tradicionais como o microscópio. O aumento do desempenho dos sistemas computacionais é essencial para que seja possível modelar grandes sistemas biológicos, aumentar o tempo da simulação do sistema e, ainda assim, obter os resultados em tempo aceitável. Estes avanços trariam benefícios para a ciência e para a medicina.

A resposta da Computação frente aos obstáculos impostos pelo desenvolvimento do modelo sequencial de apenas um core e a crescente demanda por alto desempenho foi partir para a busca de um modelo diametralmente oposto ao sequencial: o modelo paralelo baseado em arquiteturas multicore. E uma importante questão já se coloca no início da era multicore: como dividir as responsabilidades entre o programador, compilador e o hardware para descobrir e explorar o paralelismo existente em uma aplicação (SMITH et al., 2006).

Do lado do hardware, com o aumento do número de transistores, a complexidade de projeto aumenta exponencialmente (BUDIU, 2003). Embora a produtividade das equipes também aumente devido às melhorias das ferramentas CAD (Computer Aided Design), isso acontece a um passo mais lento. O resultado é uma crescente diferença de produtividade entre o que se tem (hardware com capacidade para muitos transistores) e o que se consegue extrair do hardware em termos de ganho em desempenho (capacidade de projeto). Poucas empresas conseguem diminuir esta diferença e o fazem com grandes equipes de projeto, teste, verificação e fabricação.

Três problemas contribuem com esta diferença: (1) disparidade entre computação e comunicação, ou seja, transistores rápidos, porém barramentos lentos; (2) o aumento da complexidade do circuito, levando a longos tempos de projeto e mais bugs e; (3) a decrescente confiabilidade do circuito causada 
pela miniaturização e limites das características do material. Esta diferença forçou os engenheiros a buscarem arquiteturas de processadores alternativas e mais escaláveis (SWANSON et al., 2007).

Neste contexto, duas alternativas emergiram para ultrapassar as barreiras enfrentadas pelos processadores superescalares tradicionais - as chamadas tiled architectures e as arquiteturas especializadas (PUTNAM, 2009). Tiled architectures usam um elemento de processamento pequeno e simples a fim de reduzir a complexidade do barramento. Este elemento de processamento é replicado pelo chip para reduzir o consumo de energia, fornecendo desempenho explorando o paralelismo e não por meio do aumento da velocidade do clock. Frequentemente, são usados mais elementos de processamento do que o estritamente necessário, fornecendo redundância e confiabilidade. Arquiteturas especializadas usam hardwares adaptados para um domínio particular de aplicação, como por exemplo as GPUs (Graphical Processing Unit), que são especializadas em aplicações gráficas. Estas arquiteturas oferecem desempenho melhor do que processadores superescalares nas aplicações que fazem parte de seu domínio, mas são ineficientes ou incapazes de executar aplicações que fazem parte de outros domínios (PUTNAM, 2009).

Estas duas alternativas oferecem melhorias de desempenho, tempo de resposta, consumo de energia, eficiência e tolerância a falhas. Entretanto, seu potencial somente poderá ser explorado se os desenvolvedores de software as adotarem. Esta adoção será mais fácil se eles continuarem usando seus próprios paradigmas e linguagens, no caso, as linguagens imperativas de altonível. Assim, arquiteturas que necessitam que o programador explicite o paralelismo do código, programe em baixo nível ou gerencie memórias distribuídas terão menor probabilidade de serem adotadas.

Uma tecnologia promissora que potencialmente possibilita um bom desempenho em um consumo de energia relativamente baixo é a Computação Reconfigurável baseada em FPGAs (Field-Programmable Gate Arrays). FPGA pode impulsionar o desempenho por fornecer várias formas de explorar o paralelismo. Entretanto, desenvolver sistemas em FPGAs requer conhecimentos de linguagens de descrição de hardware (HDL, do inglês Hardware Description Language) como, por exemplo, Verilog e VHDL (Very High-Speed Integrated Circuits $H D L$ ), conceitos de hardware como gerenciamento de clock, máquinas de estado, pipeline, etc. Apesar da promessa de aumentar o desempenho e diminuir o consumo de energia, o esforço necessário para aprender programação em FPGA faz com que a adoção desta tecnologia seja dificil, já que os desenvolvedores de sistemas computacionais de alto desempenho estão habituados a programar utilizando linguagens de alto nível.

Muitos pesquisadores exploraram formas de tornar a programação em FPGA 
mais fácil desenvolvendo linguagens baseadas em $\mathrm{C}$ para serem usadas no lugar das HDLs (MÖHL, 2005; ALTERA, 2007). Porém, muitas destas linguagens não suportam a linguagem $C$ por completo, fazendo com que boa parte do código precise ser reescrito e, apesar do esforço compensado pelo ganho de desempenho, a reescrita do código também é uma grande barreira para a adoção dos FPGAs (BOBDA, 2007). Outros pesquisadores utilizaram arquiteturas a fluxo de dados para converter ANSI-C para hardware reconfigurável (PUTNAM, 2009; BUDIU, 2003).

$\mathrm{Na}$ arquitetura a fluxo de dados, o processo de execução de programas é determinado pela disponibilidade dos dados. Logo, o paralelismo é natural neste modelo (DENNIS, 1974; DENNIS and MISUNAS, 1975) e não há a necessidade de o programador explicitar em seu código os trechos onde deve haver paralelismo.

Basicamente, existem dois tipos de arquitetura a fluxo de dados: estática e dinâmica. Em máquinas a fluxo de dados estáticas, cada instrução pode ter apenas um conjunto de dados sendo processados a cada instante. Já em máquinas dinâmicas, cada instrução pode ter vários conjuntos de dados sendo processados ao mesmo tempo. Por permitir vários conjuntos de dados sendo processados em uma mesma instrução, torna-se necessário um mecanismo para diferenciar os dados das diversas instâncias de uma instrução. Uma das principais maneiras de se fazer isto é utilizar o conceito de tagged-token. Esta ideia consiste em atribuir uma tag para diferenciar tais dados (tokens). Sistemas a fluxo de dados estáticos são menos poderosos que os sistemas dinâmicos, pois o paralelismo disponível em uma máquina a fluxo de dados dinâmica é maior do que o paralelismo de uma máquina a fluxo de dados estática (ARVIND and NIKHIL, 1990).

Nos anos 80, acreditava-se que a arquitetura a fluxo de dados substituiria os modelos tradicionais (JOHNSTON et al., 2004), porém os trabalhos do final desta mesma década e início de 90 deixaram claro que construir máquinas a fluxo de dados não é uma tarefa simples (SWANSON et al., 2003). As pesquisas em arquiteturas a fluxo de dados declinaram nessa época. Alega-se que a maior razão para esse declínio foi praticamente devido a problemas de hardware (JOHNSTON et al., 2004).

Entretanto, percebe-se novamente o interesse em pesquisas em arquiteturas a fluxo de dados. Esta renovação no interesse se deve à elegância do modelo; à transição para o paralelismo na computação; ao crescimento de áreas de aplicação que se prestam ao modelo a fluxo de dados, apresentando uma grande oportunidade para a programação a fluxo de dados (BHATTACHARYYA et al., 2008); às mudanças introduzidas pelos avanços da tecnologia e do hardware (BUDIU et al., 2005) e, de uma forma especial, pelos avanços dos FPGAs 
e da Computação Reconfigurável.

\subsection{CHIPCFLOW}

O projeto ChipCflow, coordenado pelo Prof. Dr. Jorge Luiz e Silva, está em desenvolvimento no Laboratório de Computação Reconfigurável (LCR) do Instituto de Ciências Matemáticas e de Computação - Universidade de São Paulo (ICMC - USP). O trabalho desta dissertação faz parte deste projeto. O projeto ChipCflow é motivado pela premissa de que desenvolvedores de sistemas computacionais de alto desempenho devem ser capazes de seguir um caminho fácil e familiar para acelerar suas aplicações explorando o paralelismo, sem abandonar as abstrações convencionais das linguagens de alto nível e o código existente. No ChipCflow, o objetivo geral é explorar um novo modelo computacional que não requer sincronização global, um novo método CAD objetivando fazer a ponte entre compilação de software e micro arquiteturas em dispositivos reconfiguráveis. As aplicações são escritas em linguagens de alto nível e são compiladas diretamente para descrições de hardware para serem descarregadas em plataformas reconfiguráveis. Os circuitos sintetizados possuem comunicação local, não possuem broadcast e nem controle global. É um compilador sem intervenção do programador (completamente automático) e explora paralelismo em nível de instrução e pipelining por meio de uma arquitetura a fluxo de dados.

No projeto ChipCflow, uma aplicação é escrita em linguagem C. Em seguida, um pré-compilador gera um DFG (Dataflow Graph) representado em uma linguagem intermediária. Um DFG é uma maneira de representar um programa a fluxo de dados. Logo após a geração do DFG, o grafo é convertido em código VHDL utilizando uma base de dados que já contém a implementação dos operadores básicos pré-definidos. O projeto ChipCflow utiliza o modelo a fluxo de dados dinâmico para extrair maior paralelismo das aplicações. Após gerar o código VHDL, o próximo passo é sintetizar e simular o hardware. Finalmente, o programa é carregado no FPGA e é executado direto em hardware. O projeto é descrito em detalhes no Capítulo 4.

Na maioria das máquinas a fluxo de dados, o hardware é uma coleção de elementos de processamento fixos e técnicas sofisticadas são usadas para distribuir o programa nestes elementos. Já no ChipCflow, para cada nova aplicação, um novo hardware específico é gerado. 


\subsection{OBJETIVO}

Vários módulos já foram realizados dentro do projeto ChipCflow (ASTOLFI, 2009; COSTA, 2009; CORREIA, 2009; SANCHES, 2010; JÚNIOR, 2011). Todos estes trabalhos estabeleceram bases para realizar o fluxo de dados estático. Entretanto, a ideia original do projeto ChipCflow é explorar o modelo a fluxo de dados dinâmico aplicado em uma ferramenta que traduz linguagens de alto nível diretamente para hardware reconfigurável (no caso, FPGA). As diferenças entre o modelo estático e o dinâmico incluem unidade de matching de dados, possibilidade de se ter várias instâncias dos operadores, dados com tags e operadores específicos para manipulação de tag. Todas estas estruturas estão sendo pesquisadas atualmente no projeto. No caso específico do trabalho desta dissertação, o objetivo é definir o formato para os taggedtokens, definir os operadores de manipulação das tags e implementá-los a fim de que se tenha a PROVA-DE-CONCEITOS para tais operadores da arquitetura ChipCflow considerando agora o modelo a fluxo de dados dinâmico.

Para colocar a máquina ChipCflow dinâmica em funcionamento, é necessário que todas as estruturas citadas (unidade de matching de dados, instâncias dos operadores, dados com tags e operadores específicos para manipulação de tag) estejam implementadas. Porém, com exceção das estruturas que são objeto deste trabalho, todas ainda estão em desenvolvimento. Portanto, está além do escopo deste trabalho executar a máquina ChipCflow dinâmica.

Os objetivos específicos do trabalho são:

- Desenvolver o modelo das tags para os tokens;

- Desenvolver o modelo dos operadores para manipulação de tags;

- Implementar e testar os operadores em VHDL.

Para o desenvolvimento do modelo das tags e dos operadores de manipulação, vários algoritmos e casos de estudo foram analisados e discutidos em reuniões do projeto ChipCflow. Nas discussões, buscou-se desenvolver um modelo formal que atendesse às necessidades e objetivos da máquina ChipCflow. Os operadores foram implementados em VHDL e sintetizados pela ferramenta ISE da Xilinx. O FPGA utilizado nas implementações foi o Spartan 3E 3s500efg320-4. Os operadores foram simulados e testados utilizando o ISim, também da Xilinx.

O resultado esperado com este trabalho é a possibilidade de explorar naturalmente todo o paralelismo de uma aplicação, sem necessidade de programação em baixo nível utilizando a arquitetura ChipCflow como alternativa ao modelo tradicional de arquiteturas multicore. 


\subsection{ORGANIZAÇÃO DA DISSERTAÇÃO}

Os próximos capítulos desta dissertação estão organizados da seguinte maneira: no capítulo 2 são descritos detalhes sobre os FPGAs e Computação Reconfigurável; no capítulo 3 são apresentadas as principais máquinas a fluxo de dados tradicionais e também algumas máquinas contemporâneas; no capítulo 4, o projeto ChipCflow é descrito em termos de arquitetura e funcionamento; no capítulo 5 são apresentados o modelo das tags e os operadores para sua manipulação, seguidos pela descrição dos resultados das implementações e testes; finalmente, a conclusão é apresentada no capítulo 6 seguida pelas referências bibliográficas. 


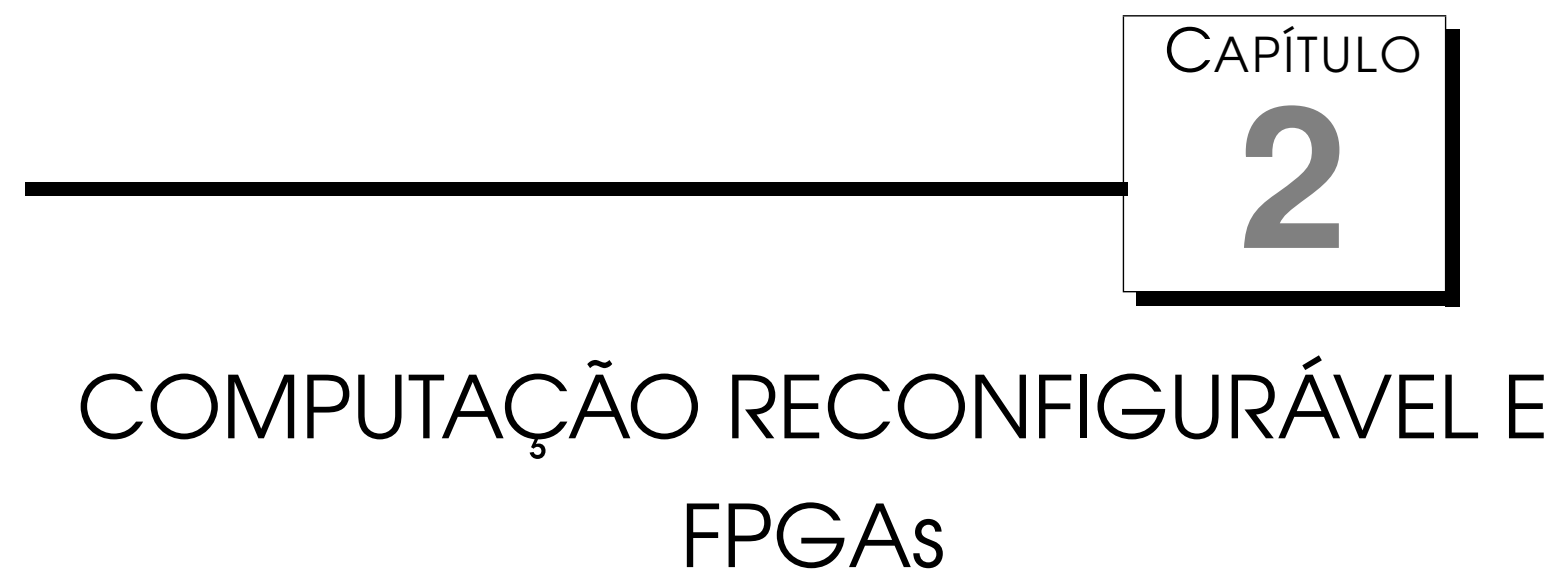

\subsection{CONSIDERAÇÕES INICIAIS}

Neste capítulo, será apresentado o conceito de Computação Reconfigurável e os FPGAs serão discutidos mais detalhadamente. Serão apresentados elementos básicos do FPGA, seguidos pela sua tecnologia de configuração. Logo em seguida, será apresentado o principal componente dos blocos lógicos dos FPGAs: as Look-up Tables. Depois, serão discutidos os blocos lógicos dos principais fabricantes de FPGAs atuais assim como as diferentes estruturas de FPGAs existentes. E por fim, é discutido o fluxo de projeto em um FPGA.

\subsection{COMPUTAÇÃO RECONFIGURÁVEL}

Segundo Bobda (2007), os vários processadores desenvolvidos para os mais variados sistemas podem ser classificados de acordo com o seu grau de flexibilidade: o grupo de computação de propósito geral que é baseado no paradigma de computação von Neumann; processadores de domínio específico, feito para uma classe de aplicações tendo em comum um grande número de características; e os processadores de aplicação específica (ASICs, do inglês ApplicationSpecific Integrated Circuits) feito para uma única aplicação. Os computadores de domínio específico possuem certo grau de flexibilidade, se comparado aos ASICs; e desempenho maior para as aplicações de seu domínio, se comparados com os processadores de propósito geral. 
Além da flexibilidade, os processadores podem ser classificados conforme seu desempenho. Os computadores de propósito geral, baseados no modelo de von Neumann, possuem alto grau de flexibilidade, pois podem executar um grande número de aplicações. Por outro lado, seu desempenho está restrito ao hardware que o suporta. Já os processadores ASICs possuem alto desempenho e baixa flexibilidade, por se tratar de um hardware desenvolvido especificamente para uma dada aplicação.

Na situação ideal, teríamos em um mesmo dispositivo a flexibilidade dos processadores de propósito geral e, ao mesmo tempo, o desempenho dos ASICs. É na tentativa de se aproximar dessa situação que surge a Computação Reconfigurável. Na definição encontrada em Bobda (2007), a Computação Reconfigurável é o estudo de computação usando dispositivos reconfiguráveis, ou seja, usando dispositivos de hardware que podem ter sua função alterada ao longo do tempo por meio de reconfigurações. A ideia é que para uma dada aplicação, o dispositivo tenha sua estrutura física modificada ao longo do tempo para que possa utilizar a melhor abordagem para acelerar a execução de tal aplicação. Os FPGAs são os dispositivos reconfiguráveis mais utilizados atualmente (BOBDA, 2007).

Na Figura 2.1, é descrita graficamente a relação desempenho/flexibilidade entre esses diferentes modelos de arquitetura.

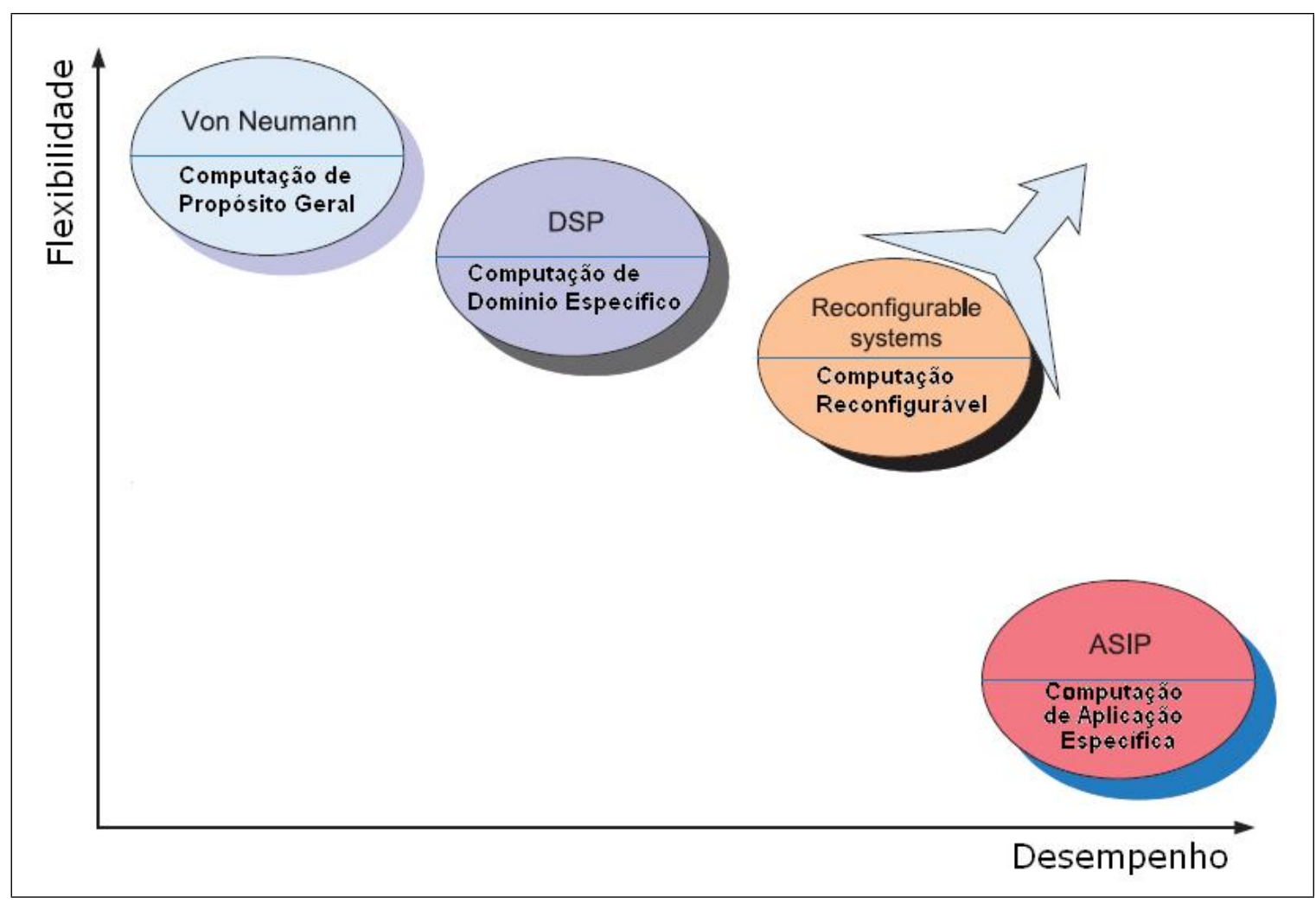

Figura 2.1: Flexibilidade x Desempenho (BOBDA, 2007)

A Computação Reconfigurável tem se tornado uma importante área de 
pesquisa em arquitetura de computadores e sistemas de software e avançou consideravelmente nos últimos anos, utilizando principalmente FPGAs como a base para sistemas reprogramáveis de alto desempenho (BOBDA, 2007; COMPTON and HAUCK, 2002; COMPTON et al., 2000).

Todas as aplicações potenciais de Computação Reconfigurável podem ser divididas em três categorias de acordo com o objetivo que se pretende atingir (SKLIAROVA and FERRARI, 2003). São elas:

- Aceleração de tarefas computacionalmente intensas;

- Emulação de hardware;

- Hardware Evolutivo.

Computação Reconfigurável ainda é uma área em desenvolvimento. Validar novos e diferentes tópicos em arquiteturas reconfiguráveis tem sido um dos desafios dos pesquisadores da área nos últimos 20 anos (BOBDA, 2007).

\subsection{FPGA - ELEMENTOS BÁSICOS}

Conforme descreve Hauck (1998), os FPGAs foram introduzidos em 1985 pela empresa Xilinx como uma nova tecnologia para implementação de lógica digital.

Inicialmente, os FPGAs não tinham velocidade nem capacidade, além de um alto custo por unidade se comparados aos FPGAs atuais. Então eram usados como dispositivos glue $\operatorname{logic}^{1}$ em sistemas que não exigiam velocidade e capacidade elevadas. Porém nos últimos anos, os FPGAs se desenvolveram e se tornaram a base de uma grande quantidade de sistemas reprogramáveis (HAUCK, 1998).

Vários computadores de alto desempenho atuais usam FPGAs como coprocessadores reconfiguráveis para aplicações como sensoriamento remoto, dinâmica molecular, bioinformática e criptografia. Além disso, muitos vendedores de computadores de alto desempenho possuem linhas de produtos de computação reconfigurável de alto desempenho, mostrando que os computadores reconfiguráveis de alto desempenho possuem um grande potencial (EL-GHAZAWI et al., 2008).

Os FPGAs foram empregados como um meio barato de prototipação e teste de soluções de hardware sem ter que recorrer aos longos e caros processos do projeto de ASIC, permitindo uma redução significativa do time-to-market (REDAELLI et al., 2008).

\footnotetext{
${ }^{1}$ Ou lógica de cola - circuito lógico simples utilizado para conectar dois circuitos, mesmo que sua interface não seja completamente compativel.
} 
A ampla utilização de FPGAs para sistemas reconfiguráveis se justifica por várias razões (MARTINS et al., 2003). São elas:

- Alta velocidade: é possível otimizar velocidade adequando e sintonizando os parâmetros críticos do sistema;

- Nível flexível de segurança: é relativamente fácil adequar as novas arquiteturas e sistemas a novos contextos e otimizações;

- Relação custo/desempenho: pode-se selecionar e projetar unidades funcionais, levando-se em conta o custo e o desempenho. Por exemplo, projetar poucas e lentas unidades aritméticas, ou rápidas e varias unidades;

- Moderação dos custos: o projeto com FPGAs é relativamente de baixo custo.

Segundo Bobda (2007), um FPGA pode ser classificado de acordo com a sua configurabilidade:

- Programável: O FPGA é programável se é possível programá-lo pelo menos uma vez, e todos os FPGAs são por definição programáveis ao menos uma vez;

- Reconfigurável: Nesse caso, o FPGA pode ser programado mais de uma vez;

- Parcialmente Reconfigurável: é possível reconfigurar o FPGA seletivamente, enquanto o resto dele permanece inativo, mas mantém sua configuração (VERONESI, 2005);

- Dinamicamente Reconfigurável: a reconfiguração dinâmica surgiu como uma técnica atrativa para minimizar o tempo de reconfiguração dos FPGAs (MERIBOUT and MOTOMURA, 2004). Nos dispositivos dinamicamente reconfiguráveis, a configuração pode ser atualizada seletivamente enquanto o FPGA estiver ativo (energizado e em operação). A reconfiguração dinâmica também é chamada de Run-time Reconfiguration (RTR) e on-the-fly reconfiguration.

Três elementos básicos compõem um FPGA: um conjunto de células lógicas programáveis, também chamados de blocos lógicos ou blocos lógicos reconfiguráveis; uma rede de interconexões programável e; um conjunto de células de entrada/saída em volta do dispositivo, conforme apresentado na Figura 2.2 .

Uma função implementada no FPGA é particionada em módulos, que são implementados nos blocos lógicos. Todos os três componentes básicos do FPGA podem ser programados pelo usuário e podem ser reprogramados uma ou várias vezes, dependendo da tecnologia. 


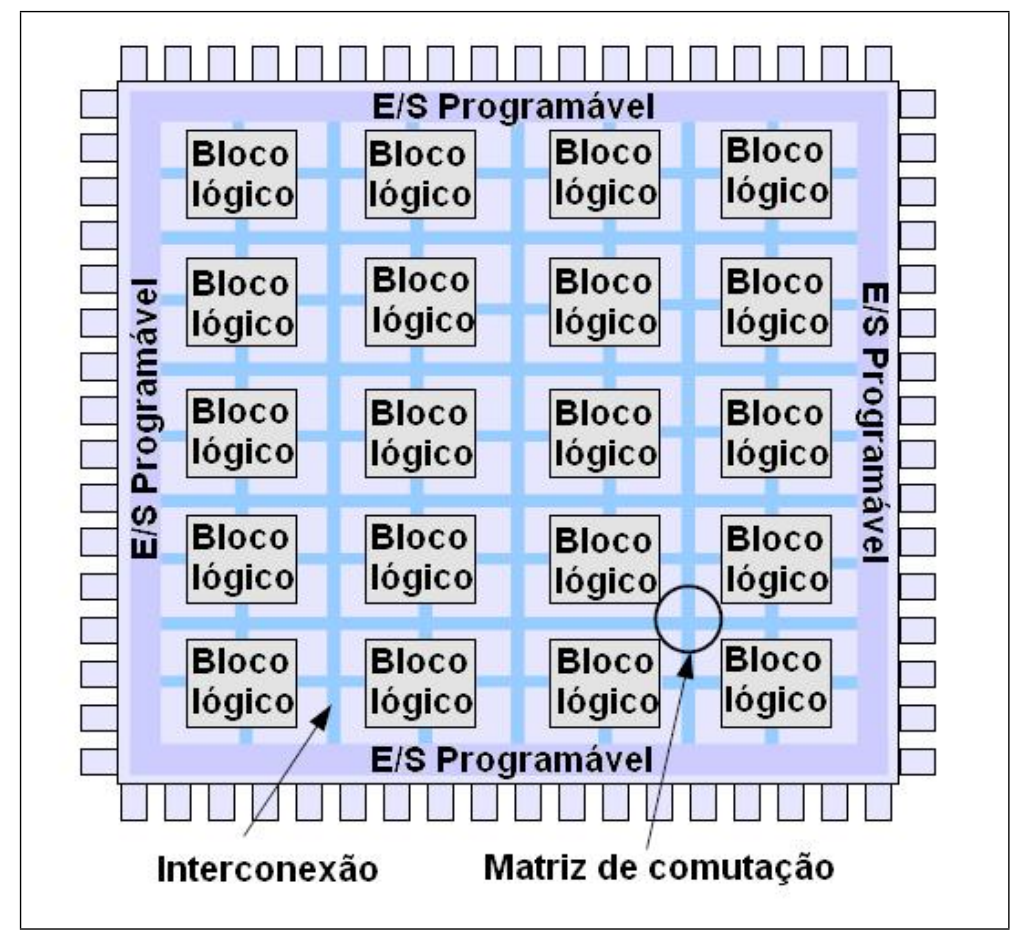

Figura 2.2: Estrutura de um FPGA (BOBDA, 2007)

\subsection{TECNOLOGIA}

A tecnologia é o que define como os blocos lógicos são feitos fisicamente. De acordo com Bobda (2007), as duas tecnologias básicas são antifuse e baseada em memória.

Na tecnologia antifuse, ao contrário do fuse, o circuito é normalmente aberto. No processo de gravação, aplica-se uma alta voltagem que causa derretimento do material dielétrico. Após esta operação, a ligação está feita. Os FPGAs baseados em antifuse não são aplicáveis a dispositivos que devem ser reprogramados frequentemente porque uma vez programado com a tecnologia antifuse, normalmente não é possível programar novamente.

As tecnologias baseadas em memória podem utilizar tipos de memória como SRAM (Static Random Access Memory), EEPROM (Electrically-Erasable Programmable Read-Only Memory) ou Flash. A seguir, será descrita a tecnologia baseada em SRAM, pois se trata do tipo mais comum utilizado em FPGAs atuais (BOBDA, 2007).

Em um FPGA baseado em SRAM, o estado dos blocos lógicos, os valores dos seus bits e interconexões são determinados pelo conteúdo da memória SRAM. A grande vantagem deste tipo de tecnologia é que os FPGAs podem ser programados indefinidamente. Basta alterar o conteúdo da SRAM para que o FPGA assuma uma nova função ou conexão. Além disso, torna-se possível realizar a reconfiguração dinâmica do FPGA. Por se tratar de um dispositivo 
volátil, é necessário um armazenamento externo ou dispositivos não voláteis para armazenar a configuração e carregar o FPGA quando esta for ligada.

Para implementar e reimplementar funções dinamicamente em um FPGA, os requisitos necessários são os geradores de função, que podem ser considerados como unidades básicas de computação no dispositivo. O tipo de gerador de função mais utilizado em FPGAs comerciais são as chamadas look-up tables.

\subsection{LOOK-UP TABLES}

Look-up tables (LUTs) são grupos de células de memória que armazenam, quando configuradas, todos os possíveis resultados de uma dada função dado um conjunto de valores de entrada. No caso específico dos FPGAs, uma LUT é um conjunto de células de memória SRAM para armazenar valores e um decodificador que é usado para acessar corretamente os endereços da SRAM de acordo com a entrada. No caso da implementação de funções complexas que não cabem em uma LUT, a função deve ser dividida em partes e estas partes são configuradas em diferentes LUTs. Então, por meio de várias interconexões é possível produzir a função completa. Na Figura 2.3, encontra-se o exemplo de uma LUT de duas entradas.

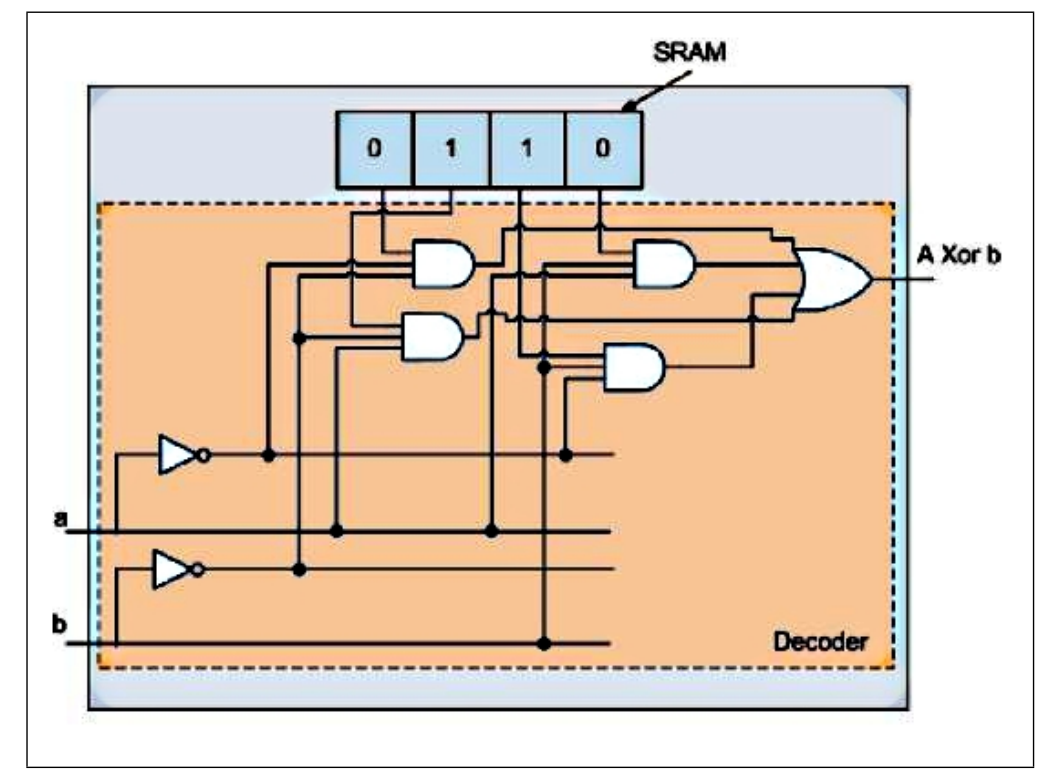

Figura 2.3: Exemplo de LUT de duas entradas (BOBDA, 2007)

Além da LUT, um FPGA normalmente possui outras estruturas que formam o seu bloco básico configurável. A seguir, serão apresentados alguns blocos básicos de FPGAs comerciais. 


\subsection{O BLOCO LÓGICO CONFIGURÁVEL DA XILINX}

O bloco lógico configurável dos FPGAs da Xilinx é formado por uma LUT com número variável de entradas a depender da família, um conjunto de multiplexadores, uma unidade lógico-aritmética e um elemento de armazenamento, como mostra a Figura 2.4.

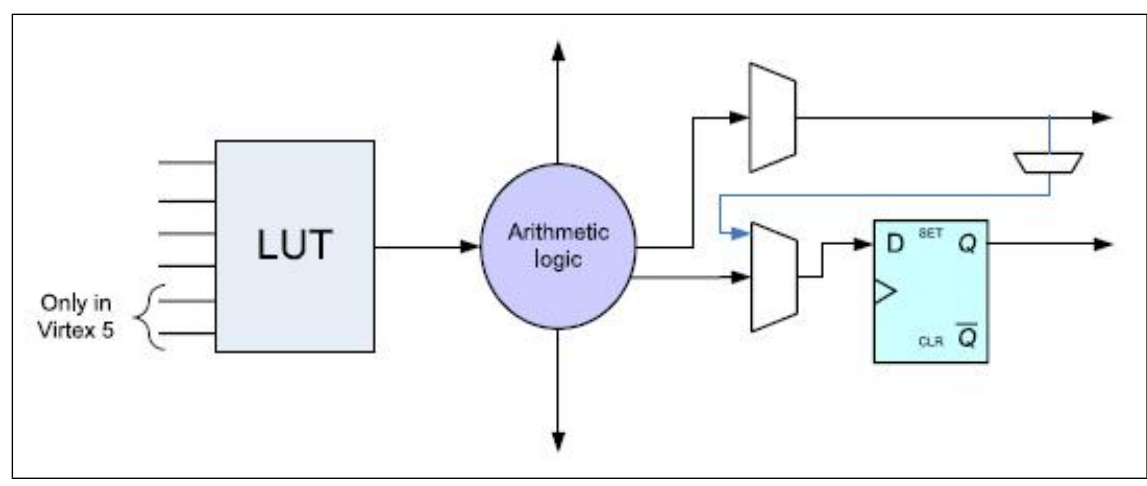

Figura 2.4: Bloco básico de FPGAs da Xilinx (BOBDA, 2007)

A LUT, como discutido acima, é usada para armazenar a configuração. Os multiplexadores selecionam as entradas corretas para a LUT, para o elemento de armazenamento e também para a saída correta do bloco. A unidade lógico-aritmética fornece alguns recursos como porta XOR (Exclusive Or) e encadeamento de carry mais rápido para construção de somadores mais rápidos e que economizam recursos da LUT.

Vários desses blocos básicos são agrupados em um elemento chamado de bloco lógico configurável, ou CLB (do inglês, Configurable Logic Block).

\subsection{MATRIZ DE BLOCOS LÓGICOS DA ALTERA}

A unidade de lógica básica da Altera é bem semelhante ao bloco básico da Xilinx e é chamada de elemento lógico. Um elemento lógico é formado por uma LUT, um flip-flop, multiplexador e unidade lógico-aritmética, conforme apresentado na Figura 2.5.

Porém, há casos, como no Stratix II da Altera, onde a unidade de computação básica é o chamado módulo de lógica adaptativo (MLA). Um MLA é formado por várias LUTs, flip-flops, somadores e multiplexadores.

Assim como nos FPGAs da Xilinx, as células lógicas básicas da Altera também são agrupadas formando elementos de computação de granulosidade grossa, que neste caso, são chamados de matriz de blocos lógicos. 


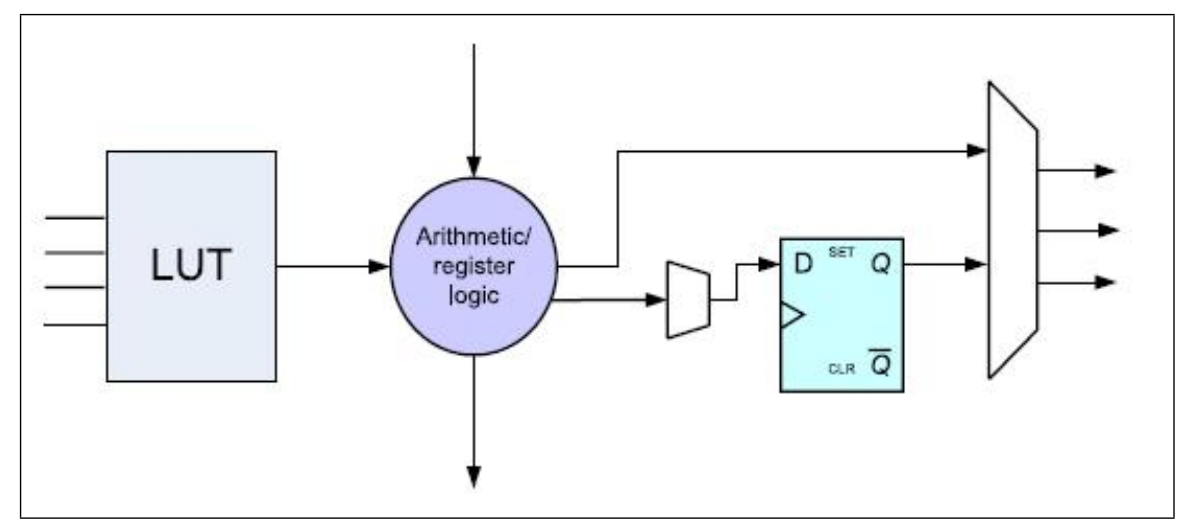

Figura 2.5: Bloco básico de FPGAs da Altera (BOBDA, 2007)

\subsection{ESTRUTURAS DE FPGAS}

Um FPGA é um conjunto de células lógicas programáveis localizadas em um dispositivo. A estrutura resultante difere de fabricante para fabricante. Porém, de acordo com o arranjo dos blocos lógicos e o paradigma de interconexão, os FPGAs podem ser classificados em quatro categorias: matriz simétrica, baseado em coluna, baseado em hierarquia e mar de portas, de acordo com a Figura 2.6.

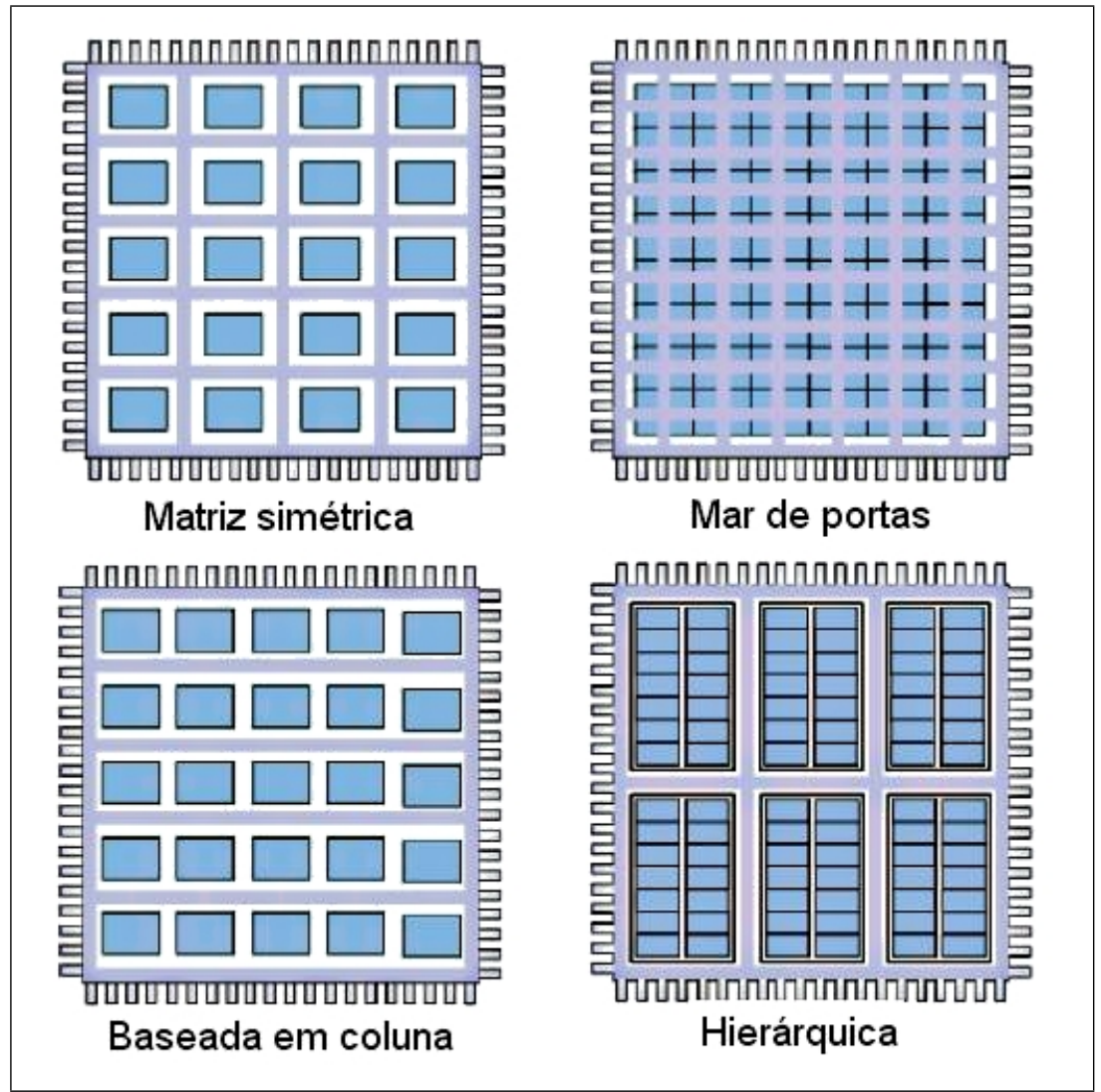

Figura 2.6: Estruturas básicas de um FPGA, adaptado de (BOBDA, 2007) 
Um FPGA baseado em matriz simétrica é formado por uma matriz bidimensional de blocos lógicos em um conjunto vertical e horizontal de linhas. Existem elementos de chaveamento nas intersecções das linhas verticais com as horizontais.

Um FPGA baseado em coluna divide os blocos lógicos em colunas, o espaço que fica entre os blocos lógicos é chamado de canal e é usado para roteamento.

Em FPGAs baseados em uma estrutura hierárquica, as macro células são colocadas de forma hierárquica no dispositivo. Os elementos de menor granulosidade pertencem a níveis mais baixos da hierarquia. Eles são agrupados para formar os elementos do próximo nível hierárquico. Como consta em Bobda (2007), cada elemento de um nível $i$ é formado por um dado número de elementos de nível $i-1$.

A estrutura mar de portas, assim como na matriz simétrica, possui macro células arranjadas numa matriz bidimensional. A diferença é que não existe espaço entre as macro células para roteamento.

\subsection{FLUXO DE PROJETO EM FPGA}

O fluxo de projeto em FPGAs é semelhante ao fluxo de projeto em ASICs. Os passos usuais estão descritos na Figura 2.7. O fluxo de projeto mostrado refere-se apenas a parte que deve ser implementada no FPGA. Quando existe projeto de software envolvido, o fluxo do projeto de software segue as abordagens tradicionais da Engenharia de Software.

O primeiro passo é o design entry. Neste passo, a descrição da função a ser implementada no FPGA pode ser feita por meio de um editor de diagrama esquemático ou uma linguagem de descrição de hardware ou em um editor de máquina finita de estados. No caso do diagrama esquemático, selecionam-se componentes já implementados em uma biblioteca e faz-se a conexão entre eles da maneira adequada, normalmente por meio de interface gráfica. O circuito final é constituído numa forma estrutural. Porém, para casos de circuitos maiores, torna-se mais difícil gerenciá-los graficamente. Para esses casos, uma linguagem de descrição de hardware pode ser usada para implementar o projeto tanto estrutural quanto comportamental do circuito.

O segundo passo, functional simulation, é simular o projeto para verificar sua funcionalidade e sua precisão. Para a realização dessas simulações, são construídos padrões de teste para as entradas do projeto e observa-se se a saída do circuito está de acordo com a funcionalidade desejada. A simulação normalmente é feita em software por ferramentas que simulam o comportamento dos componentes usados no projeto.

No terceiro passo, logic synthesis, como o circuito já teve sua funcionali- 


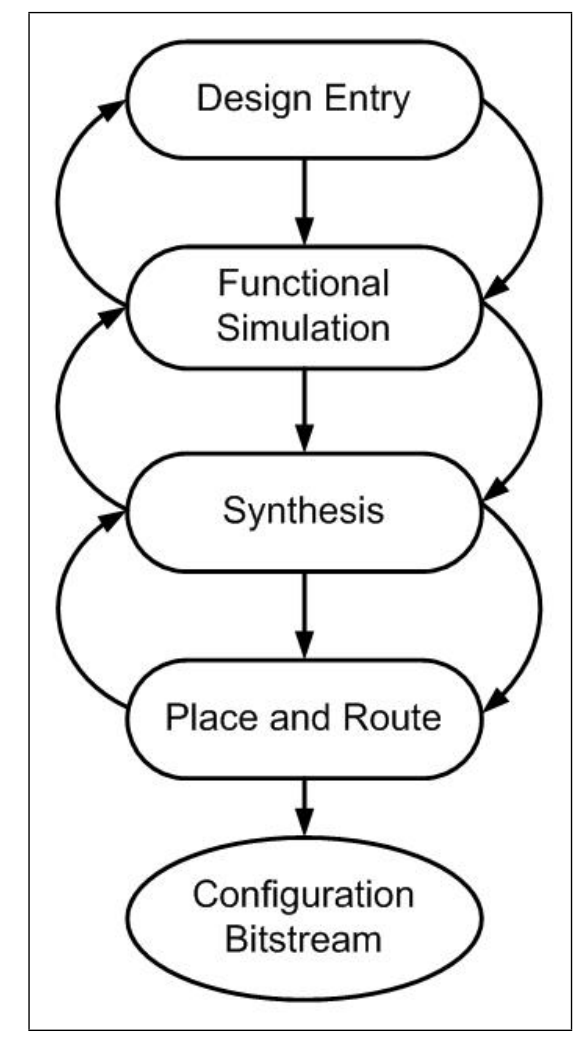

Figura 2.7: Fluxo de projeto em FPGA

dade verificada, pode-se partir para a síntese lógica. Nesse ponto, o projeto é compilado e otimizado. Primeiramente, independente de como o circuito foi descrito (diagrama esquemático ou linguagens de descrição de hardware), ele será traduzido em um conjunto de equações booleanas. Essa etapa também é feita por ferramentas que são normalmente fornecidas pelos próprios fabricantes dos FPGAs. A ferramenta então otimiza as equações booleanas e como resultado cria uma estrutura chamada de netlist. Uma netlist descreve os módulos usados para implementar as funções assim como suas interconexões.

O quarto passo é o chamado place and route. Após a geração da netlist, os operadores do FPGA (LUTs, flip-flops, multiplexadores, etc) devem ser alocados no FPGA e conectados através do roteamento. Estes dois passos também são feitos normalmente pelas ferramentas fornecidas pelo fabricante. Após este passo, o resultado é o bitstream. O bitstream fornece a descrição de todos os bits usados para configurar o FPGA.

Em cada etapa do fluxo de projeto é possível retroceder às etapas anteriores até que seja constatado que o projeto contempla todas as especificações e requisitos para determinado projeto. Após a etapa place and route, é possível simular o funcionamento lógico do projeto considerando a atribuição de todos os elementos físicos do FPGA e especificar restrições de tempo para determinados sinais. Essa simulação permite validar o projeto final com todas as suas restrições de tempo quando da atribuição do bitstream ao FPGA. 


\subsection{CONSIDERAÇÕES FINAIS}

Neste capítulo foram apresentados os conceitos básicos sobre Computação Reconfigurável e FPGA. Tais conceitos estão relacionados ao desenvolvimento de sistemas paralelos e de alto desempenho uma vez que FPGAs estão sendo utilizados em vários sistemas deste tipo. Porém, apesar de todo o esforço, o potencial dos FPGAs ainda não foi completamente explorado e pesquisas ainda devem ser feita em áreas como Compiladores, Arquiteturas de Computadores, Computação Paralela e Distribuída, entre outras áreas para que todo potencial seja eficientemente explorado. 


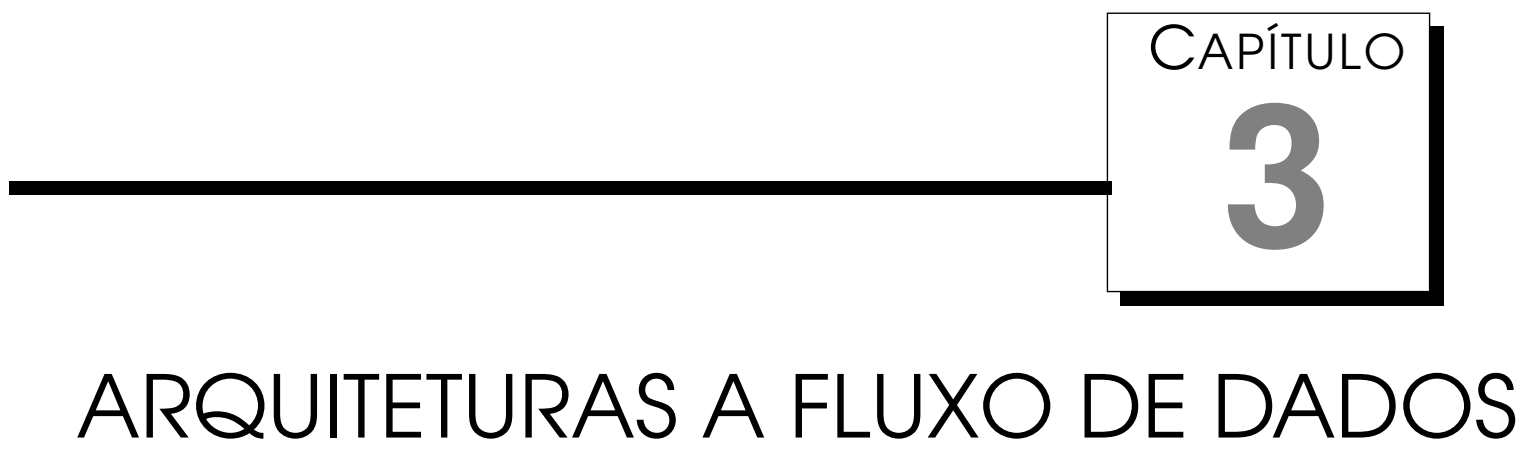

\subsection{CONSIDERAÇÕES INICIAIS}

Neste capítulo são apresentados os principais conceitos e trabalhos em máquinas a fluxo de dados. Primeiramente, são apresentados os conceitos básicos da área seguidos pelos três trabalhos iniciais mais influentes (máquina a fluxo de dados estática, máquina de Manchester e arquitetura a fluxo de dados tagged-token do MIT). Em seguida, serão apresentadas as principais máquinas a fluxo de dados atuais.

\subsection{CONCEITOS BÁSICOS}

O conceito de computação dirigida a dados ${ }^{1}$ é tão velho quanto a computação eletrônica (VEEN, 1986). Porém, foi a partir da década de 70 que as pesquisas em arquiteturas a fluxo de dados (dataflow) ganharam destaque no meio acadêmico devido aos estudos de programação concorrente juntamente com sistemas computacionais (DENNIS and MISUNAS, 1975).

Um programa em linguagem de máquina a fluxo de dados é descrito como um grafo direcionado $G=(V, A)$ (DFG), onde $V$ é o conjunto de operadores (nós) e $A$ é o conjunto de arcos. Estes operadores são ligados por arcos do conjunto $A$ do grafo $G$, que representam a dependência entre os dados. Os valores dos dados (tokens) trafegam pelos arcos. Um operador é ativado quando tokens estiverem presentes em todos os seus arcos de entrada. O operador

\footnotetext{
${ }^{1} \mathrm{O}$ termo dirigido a dados significa que a ativação de um processo é determinado apenas pela disponibilidade de seus dados de entrada.
} 
ativado então dispara, consome os tokens de entrada, realiza sua computação específica e envia o resultado pelo arco de saída (DENNIS and MISUNAS, 1975; VEEN, 1986; JOHNSTON et al., 2004). A utilização de grafo a fluxo de dados como linguagem de uma máquina a fluxo de dados levou a características e terminologias que se confundem com redes de Petri e teoria dos grafos (VEEN, 1986). Porém, uma explicação detalhada destes temas foge do escopo deste trabalho, além disso não é estritamente necessário o conhecimento destas áreas para o entendimento dos conceitos básicos das arquiteturas a fluxo de dados.

Para fins de ilustração, considere a seguinte expressão:

$$
a:=[(b+c) *(c+d)] /[(e+f) *(c+d)]
$$

Em uma máquina tradicional, baseada no modelo de von Neumann, essa expressão precisaria de sete passos sequenciais para ser concluída. Já em uma máquina a fluxo de dados, a expressão estaria concluída após três etapas, como descrito na Figura 3.1.

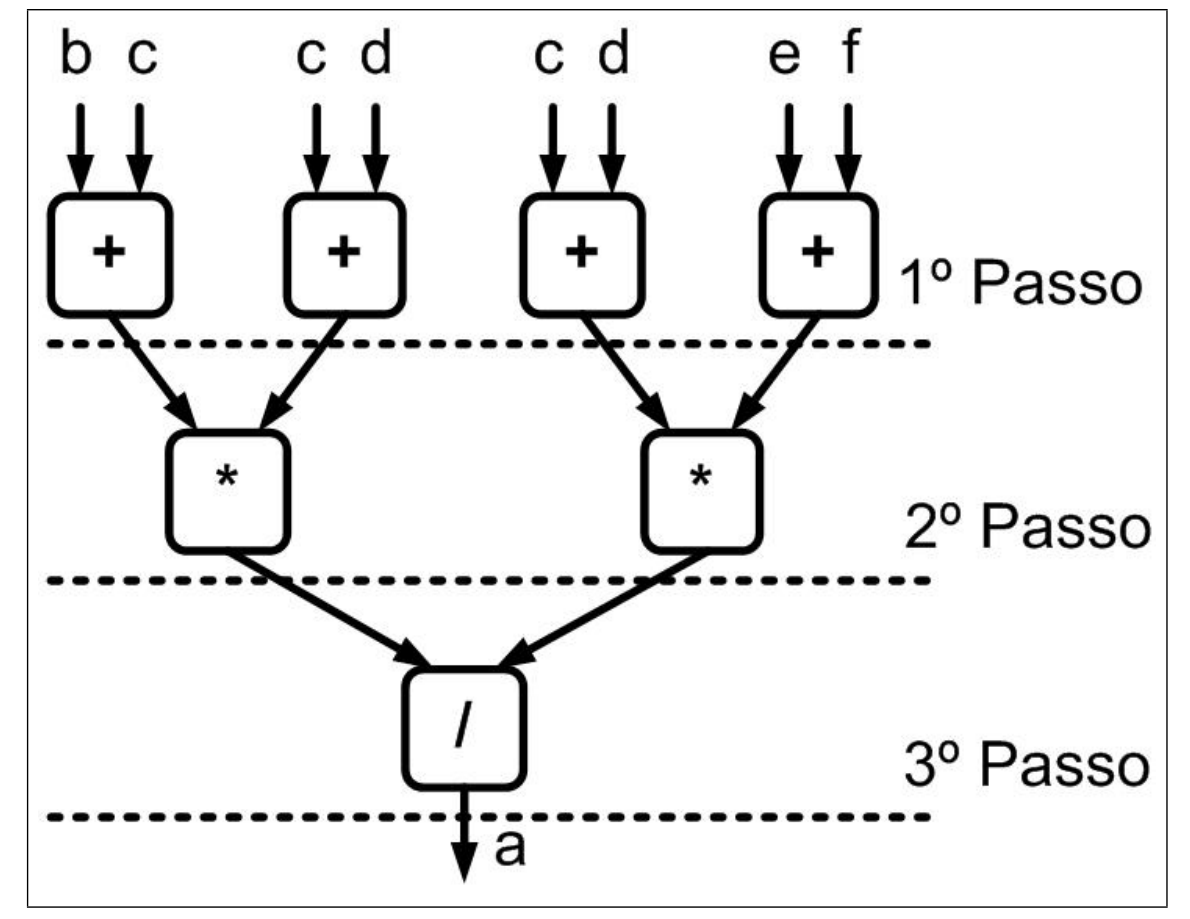

Figura 3.1: Grafo a Fluxo de Dados.

Na Figura 3.2, é mostrada uma implementação de uma construção condicional utilizando DFG. Execução condicional e de repetição necessitam de nós que implementam operações para permitir o branch controlado. O jump condicional de um programa a fluxo de controle é representado no DFG por nós de branch. Um nó de branch recebe como entrada um dado e um controle booleano e possui duas saídas. Se o controle for falso, o dado é enviado 
para uma saída. Se o controle for verdadeiro, o dado é enviado para a outra saída. Outro nó faz parte das construções condicionais e de repetição: o non deterministic merge. Este nó possui duas entradas e uma saída. A regra de disparo deste operador é diferente da regra dos demais operadores. Tal nó não necessita de todos os dados disponíveis para disparar. O dado que chegar primeiro será o dado enviado para a saída. A ideia é que chegue apenas um dado por execução como exemplificado na Figura 3.2.

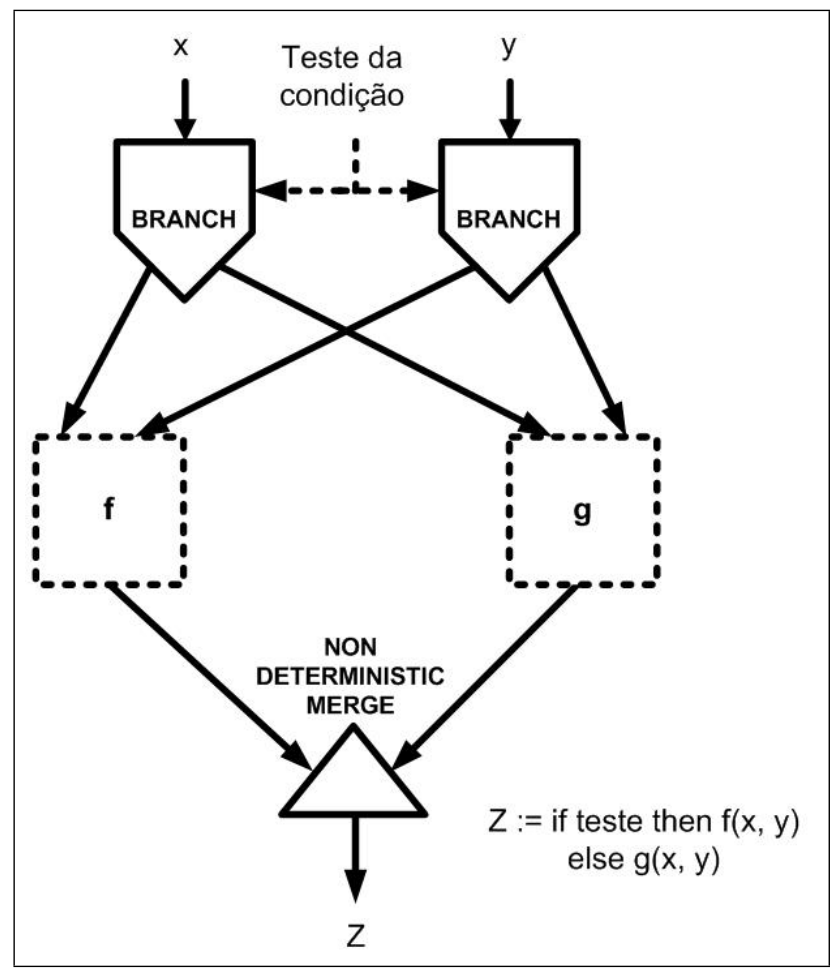

Figura 3.2: Exemplo de um grafo de uma construção condicional.

Como se pode perceber, uma das principais vantagens da máquina a fluxo de dados é que mais de uma instrução pode ser executada ao mesmo tempo, desde que estas instruções estejam em condições de disparo, ou seja, desde que todos os dados de entrada dessas instruções estejam presentes e que existam unidades de operação suficientes e disponiveis para a realização da operação. Este princípio simples é que fornece o potencial para execução de paralelismo massivo em nível de instrução (JOHNSTON et al., 2004).

Nas arquiteturas a fluxo de dados, a sincronização e o escalonamento das atividades concorrentes acontecem no nível do hardware (DENNIS, 1980). Assim, cada instrução é tratada como uma ação concorrente independente.

A implementação pura do modelo teórico da arquitetura a fluxo de dados é uma tarefa complexa por duas razões:

- Não é possível receber infinitos tokens ao mesmo tempo em uma máquina real, pois a memória é finita; 
- Não é possível processar infinitas instruções em paralelo, pois os elementos de processamento são finitos.

Isto significa que nenhuma implementação será exatamente igual ao modelo abstrato (JOHNSTON et al., 2004). Porém, existem duas formas de implementação que tentam se aproximar do modelo ideal: a estática e a dinâmica.

O que diferencia as máquinas a fluxo de dados estáticas das dinâmicas é a maneira como tratam as construções iterativas e grafos reentrantes (reentrância), ou seja, grafos que possuem ciclos.

A Figura 3.3 ilustra os problemas que podem acontecer em grafos cíclicos. O grafo descrito na Figura 3.3 (a) entrará em deadlock a menos que seja possível iniciar com um dado no arco de retorno. Já o grafo da Figura 3.3 (b) nunca irá acabar a execução. Embora estes exemplos não sejam casos reais, estes problemas de fato podem acontecer em qualquer grafo cíclico. Para evitar estes problemas, algumas medidas devem ser tomadas.

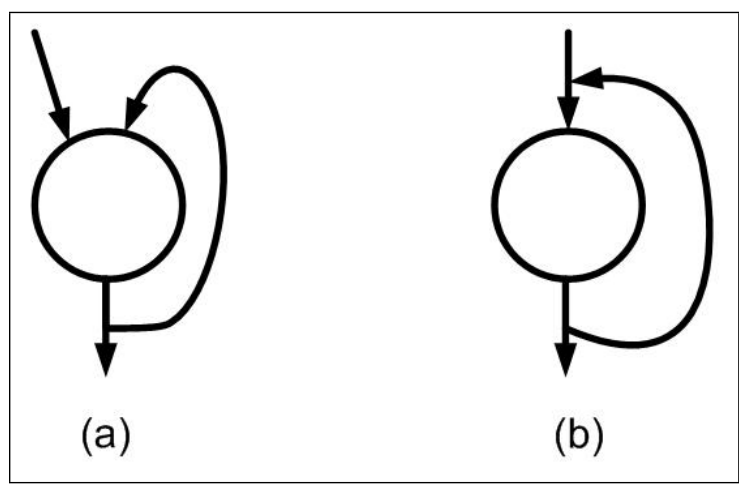

Figura 3.3: Problemas em grafos cíclicos.

Em máquinas estáticas, pode-se usar o método do bloqueio (lock method) ou reconhecimento (acknowledge method). Já em máquinas dinâmicas, existem os métodos code-copying e tagged-token.

A Figura 3.4 ilustra os métodos lock, acknowledge e tagged-token. Como pode ser visto na Figura 3.4 (a), o método lock usa instruções compostas, como o branch e non deterministic merge no grafo. A regra de ativação do branch assegura que ele não irá disparar antes que o subgrafo reentrante $g$ tenha liberado os dois tokens de saída. Como $g$ envia todas as suas saídas para o non deterministic merge, os tokens da próxima iteração podem seguramente ser enviados para o mesmo subgrafo. Já no grafo mostrado na Figura 3.4 (b), há um exemplo de um grafo que pode gerar comportamento inadequado. Neste caso não existem instruções compostas, portanto os ciclos para $x$ e $y$ podem executar em tempos diferentes. Considerando que o bloco $h$ seja um elemento atrasador, os valores de $x$ irão chegar ao operador de decisão mais rapidamente do que os valores de $y$. Sendo assim, seria impossível para 


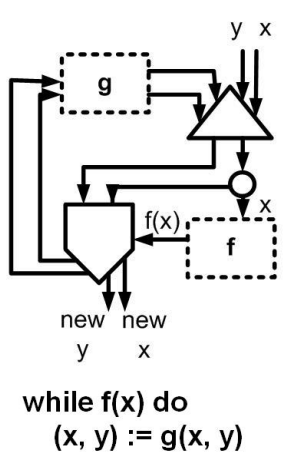

(a)

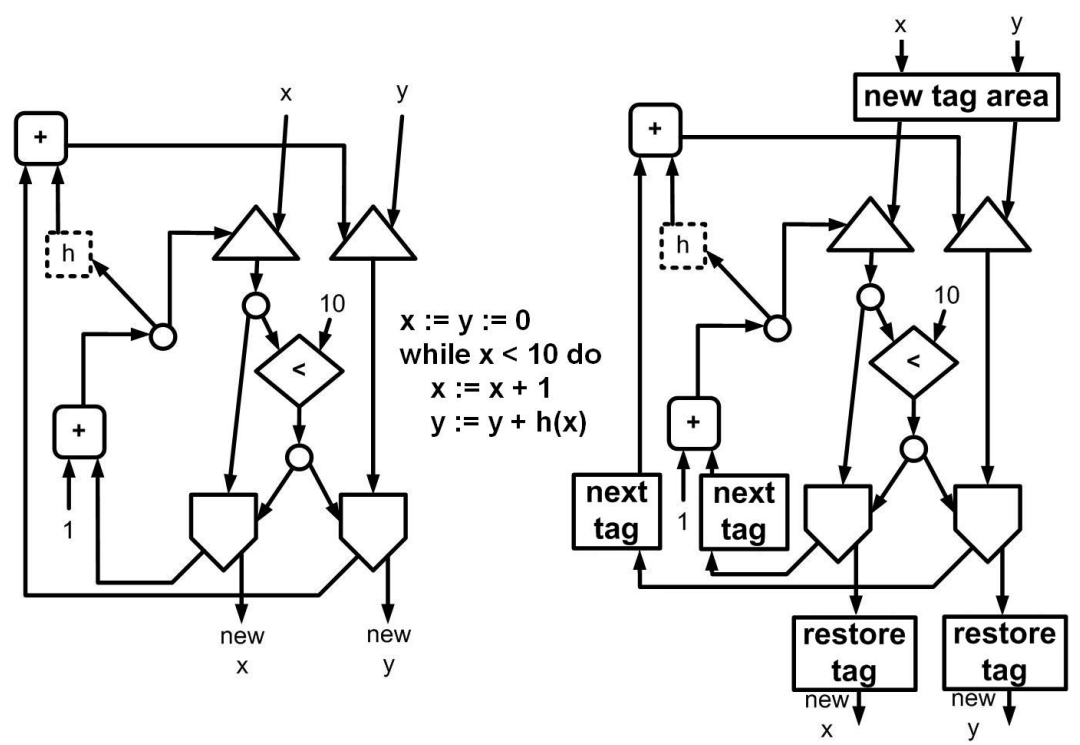

(b)

(c)

Figura 3.4: Métodos diferentes para tratar construções iterativas.

o operador de decisão saber qual valor de $x$ deve ser usado para cada valor de $y$. Portanto, esta é uma maneira não segura de se implementar loops pois dados de diferentes iterações podem se misturar e gerar resultados incorretos. Para que este grafo se torne seguro pode-se utilizar o método acknowledge. Para implementar este método basta adicionar arcos extras para realizar o acknowledge. Dessa forma, somente um dado pode estar em um arco em determinado momento e, assim, o grafo se torna seguro. Estes dois métodos restringem o paralelismo de um programa, porém o método acknowledge ainda permite maior paralelismo do que o método lock.

O método code copying pode atingir alto nivel de concorrência copiando subgrafos de um loop e executando as diferentes iterações em diferentes subgrafos. Entretanto, este método necessita que a máquina possua facilidades para criar novas instâncias de um subgrafo e para direcionar os dados para as instâncias apropriadas. Este método é semelhante à técnica de loop unrolling. Uma maneira mais interessante de tratar reentrância seria poder utilizar o mesmo subgrafo para executar todas as iterações de um loop. É possível fazer isto adicionando uma tag em cada dado para identificar para qual instância este dado deve ser direcionado. Neste caso, a regra de ativação de um nó é tal que o disparo ocorre somente se cada arco de entrada contém um token com tags idênticas. Este método, chamado tagged-token, torna o grafo seguro pois nunca há em uma entrada tokens com a mesma tag. A Figura 3.4 (c) ilustra um loop usando o método tagged-token. Como pode ser observado, este método introduz nós específicos no grafo para manipular tags. Ao entrar em loops aninhados, a tag de um token deve mudar, então uma new tag area é alocada no início do loop. Conforme as iterações são executadas, 
o bloco next tag gera tags associadas às novas interações. Finalmente, ao fim de um loop, a tag correspondente ao aninhamento externo é recuperada. Os métodos code copying e tagged-token permitem alto nível de concorrência, porém o code-copying necessita de uma quantidade extra de área, principalmente em implementações em hardware e tagged-token necessita espaço para armazenamento de tags.

Chamadas de procedimentos e funções introduzem problemas semelhantes aos problemas das construções iterativas. Os mesmos métodos podem ser utilizados para resolver ambos os casos (VEEN, 1986).

De acordo com os métodos apresentados, em máquinas a fluxo de dados estáticas apenas um dado pode estar em cada arco esperando dados parceiros. Já em máquinas dinâmicas, pode haver mais de um dado esperando por dados parceiros ao mesmo tempo em um determinado arco. Sistemas a fluxo de dados estáticos são menos poderosos que os sistemas dinâmicos, pois recursão, por exemplo, não pode ser manipulada por sistemas estáticos (GURD et al., 1985). Além disso, o paralelismo disponível em uma máquina a fluxo de dados dinâmica é maior do que o paralelismo de uma máquina a fluxo de dados estática (ARVIND and NIKHIL, 1990).

Desde o surgimento dos primeiros projetos em arquiteturas a fluxo de dados até atualmente, muitos trabalhos já foram desenvolvidos, como os trabalhos encontrados em (DENNIS and MISUNAS, 1975; DENNIS, 1980; DAVIS, 1978; SAKAI et al., 1989; SHIMADA et al., 1986; LEE et al., 1998; GURD et al., 1985; KISHI et al., 1983; GRAFE et al., 1989; SILVA, 1992; SANKARALINGAM et al., 2003; PAPADOPOULOS and CULLER, 1998; CULLER et al., 1991; SWANSON et al., 2007; BURGER et al., 2004) e outros.

Os primeiros projetos em arquiteturas a fluxo de dados foram desenvolvidos no MIT (Massachusetts Institute of Technology). Primeiramente, Dennis desenvolveu a representação de programas a fluxo de dados que posteriormente foi chamada de grafo a fluxo de dados ou em inglês dataflow graph DFG. Dennis e seu grupo de pesquisa desenvolveram pesquisas em máquinas a fluxo de dados estáticas (DENNIS, 1974; DENNIS and MISUNAS, 1975; DENNIS, 1980). Posteriormente, pesquisas em arquiteturas dinâmicas foram desenvolvidas nas máquinas tagged-token (ARVIND and NIKHIL, 1990) e Manchester (GURD et al., 1985). Estes três trabalhos são considerados os principais trabalhos básicos em arquiteturas a fluxo de dados e seus princípios influenciam muitos trabalhos da área (LEE and HURSON, 1993). 


\subsection{MÁQUINA A FLUXO DE DADOS ESTÁTICA}

A máquina a fluxo de dados estática, ou Static Dataflow Machine, foi desenvolvida por Jack Dennis e seu grupo de pesquisa no MIT. Entre as publicações que apresentam essa máquina pode-se citar (DENNIS and MISUNAS, 1975; DENNIS, 1980). O objetivo era construir um computador altamente paralelo, porém tal paralelismo deveria ser alcançado com o menor sacrifício possível. Buscou-se então por um modelo que conseguisse representar o paralelismo das aplicações de forma intrínseca.

O processador foi projetado para utilizar a linguagem a fluxo de dados como sua linguagem base, ou seja, utiliza os DFGs. O mecanismo básico para execução de instruções pode ser visto na Figura 3.5.

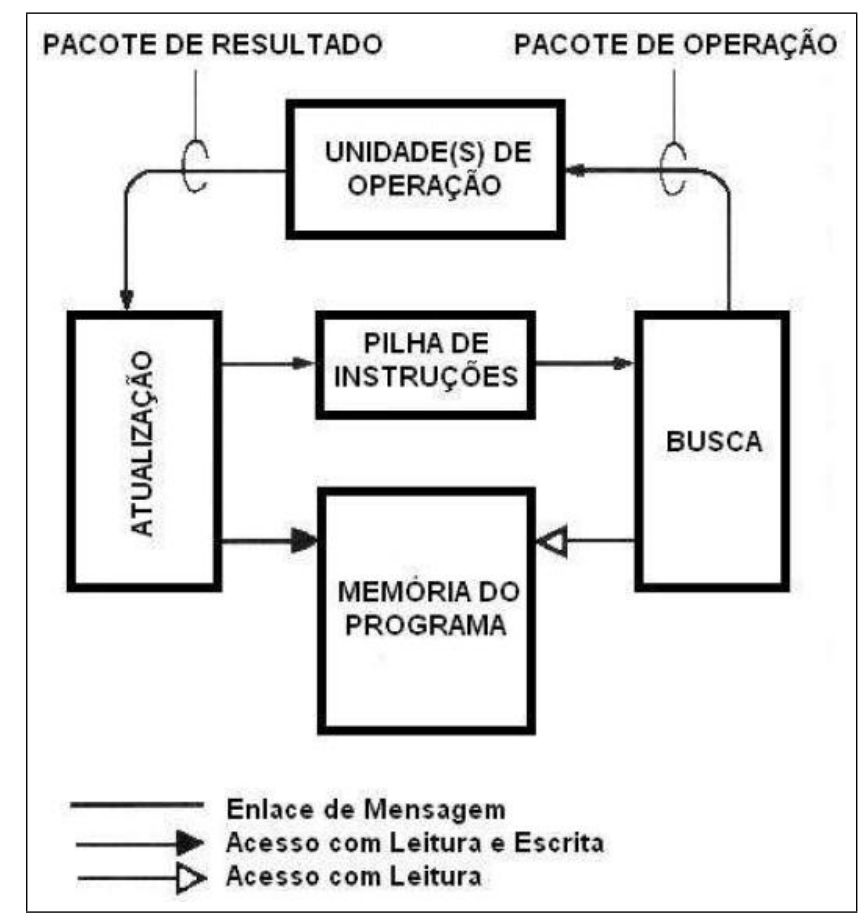

Figura 3.5: Mecanismo Básico, adaptado de (DENNIS, 1980)

O programa a ser executado é armazenado na memória do programa. A memória é organizada em células de instrução, cada célula corresponde a um operador (nó) do grafo a fluxo de dados. Cada célula de instrução, como mostra a Figura 3.6, é composta de três registradores. O primeiro registrador armazena uma instrução que especifica a operação a ser executada e os endereços dos registradores para os quais o resultado deve ser direcionado. O segundo e terceiro registrador armazenam os operandos que serão executados na instrução. Nos registradores de operandos há bits de presença que indicam se o dado já está disponível.

A unidade de atualização é responsável por verificar se há alguma instrução ativada. Se houver, a unidade de atualização envia para a unidade de busca 


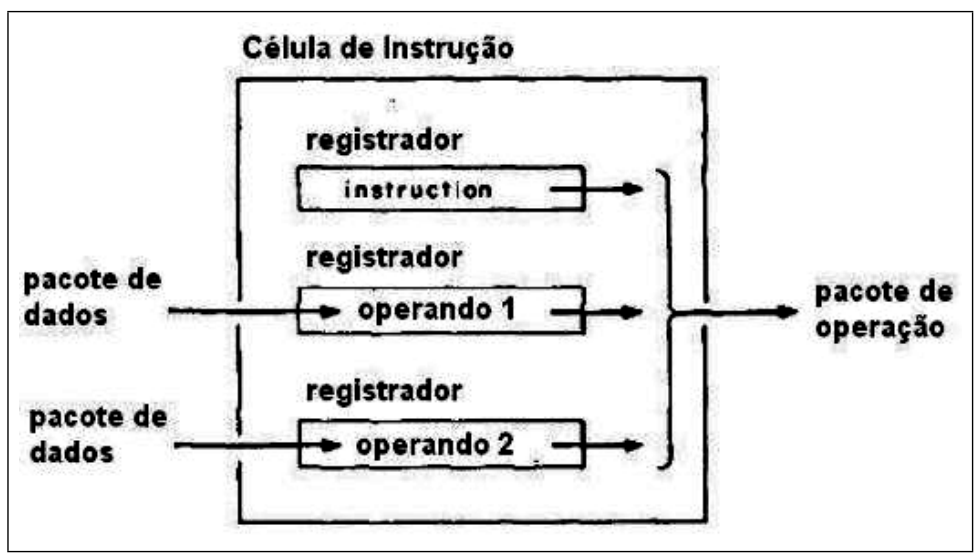

Figura 3.6: Célula de Instrução (DENNIS and MISUNAS, 1975)

o endereço da instrução. A unidade de busca então irá buscar e enviar um pacote de operação para a unidade de operação e também irá limpar os bits que indicam presença de dados na memória do programa.

Após o processamento dos dados na unidade de operação, o resultado é enviado para a unidade de atualização em forma de pacotes de dados. Esses pacotes consistem do valor computado e o endereço do registrador na memória para o qual o valor deverá ser entregue. A unidade de atualização envia o dado para o registrador correto da memória e verifica se mais alguma operação está pronta para ser executada, verificando-se os bits de presença.

A representação de condicionais e iterações na forma de fluxo de dados requer tipos adicionais de enlaces e operadores. Os tipos de enlaces e operadores para uma linguagem a fluxo de dados básica estão descritos nas Figuras 3.7 e 3.8 respectivamente. Os dados passam através dos enlaces de dados e os tokens transmitidos por enlaces de controle são chamados de tokens de controle e podem ser verdadeiros ou falsos. Um token de controle é gerado em um decider que, a partir dos dados de entrada, aplica um predicado e produz um token de controle verdadeiro ou falso no seu arco de saída.

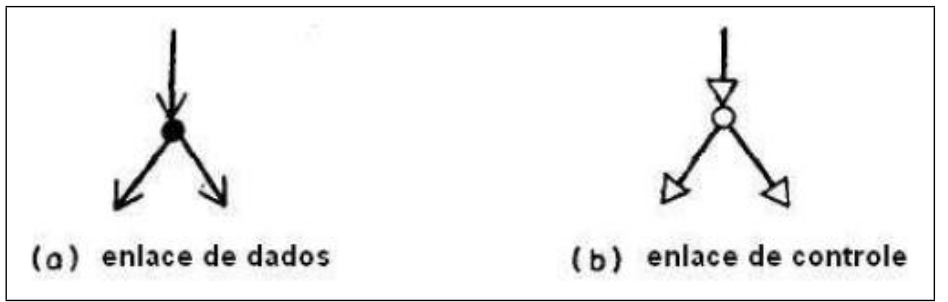

Figura 3.7: Tipos de enlace (DENNIS and MISUNAS, 1975)

O token de controle produzido em um operador decider pode ser combinado com outro token por meio do operador booleano, permitindo construir decisões a partir de decisões simples.

Um operador T-gate passa o token de dados da entrada para a saída quando 


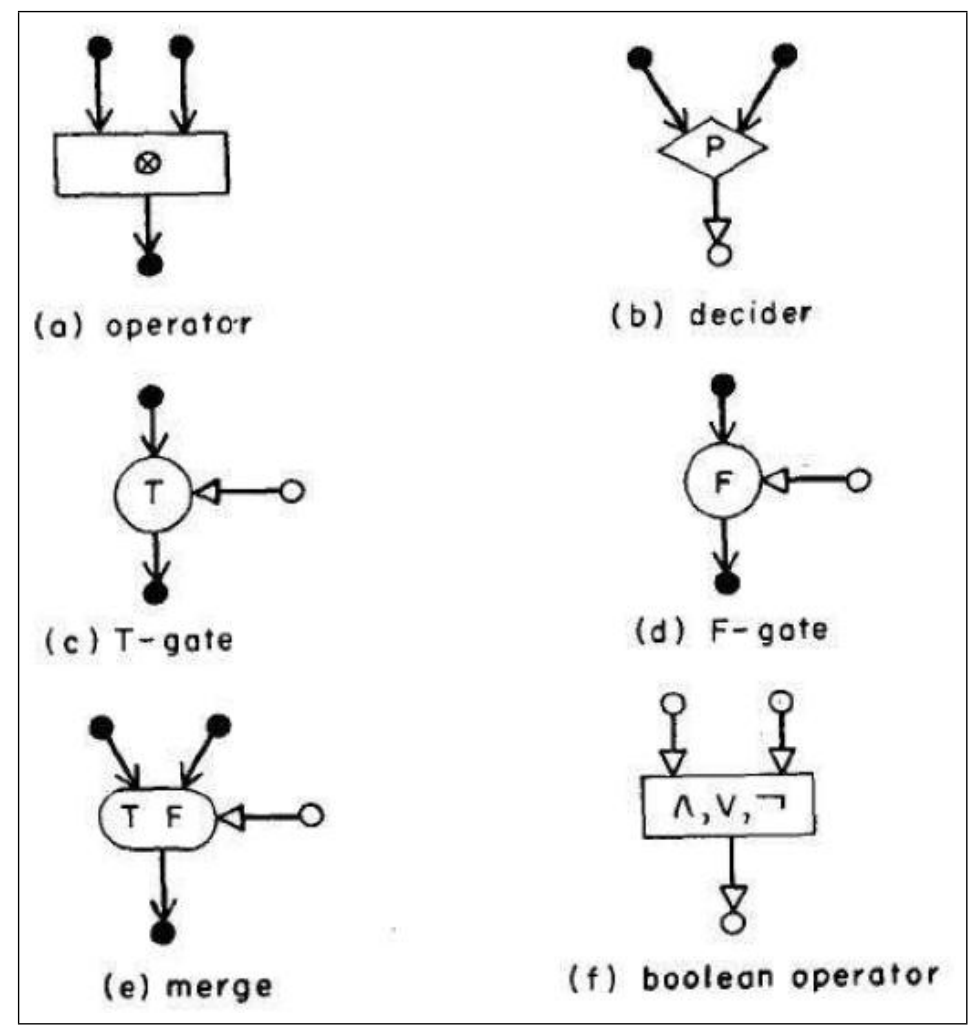

Figura 3.8: Tipos de operadores (DENNIS and MISUNAS, 1975)

recebe em seu arco de controle um token de valor verdadeiro. Se for falso, ele absorve o token mas não manda para a saída. Um operador F-gate funciona de modo análogo, porém envia o token de dados caso o token de controle for falso.

Um operador merge possui uma entrada de dados associada ao valor verdadeiro, uma associada ao valor falso e uma de controle. O operador passa para sua saída um token de dados da entrada correspondente ao valor do token de controle recebido.

O operador operator é responsável por realizar operações como adição, subtração, etc.

\subsection{MÁQUINA DE MANCHESTER}

No projeto Manchester, apresentado por Gurd et al. (1985), foi desenvolvido um processador a fluxo de dados baseado no etiquetamento dinâmico, do inglês dynamic tagging. Tags possuem iteration level para evitar confusões de operandos de diferentes iterações; activation name para procedimentos, funções recursivas, que necessitam de tags para gerar um ambiente paralelo análogo a uma pilha usada em implementações em linguagens sequenciais e; por fim, possui o index, que é usado para dizer qual parte de uma estrutura de dados o token faz parte, como o elemento de um vetor por exemplo. Os dados 
são transmitidos por arcos em pacotes etiquetados que formam os taggedtokens.

A estrutura do sistema a fluxo de dados Manchester pode ser vista na Figura 3.9. A estrutura básica é um anel de quatro módulos conectados a um sistema hospedeiro através de um módulo de chaveamento de entrada/saída. Os módulos operam independentemente e em pipeline. Os tokens são encapsulados em pacotes de dados que circulam pelo anel. Os tokens destinados a uma mesma instrução são pareados na unidade de matching. Esta unidade tem capacidade limitada, então a unidade de overflow é necessária quando programas com muitos dados estão sendo executados. Os tokens pareados e aqueles destinados a instruções com apenas uma entrada buscam a instrução apropriada na memória de instrução, que contem o código de máquina do programa a fluxo de dados. A instrução, juntamente com as suas entradas, é enviada para a unidade de processamento para execução. Este processo irá produzir novos tokens que irão circular de volta para a unidade de matching para ativar as instruções subsequentes. A fila de tokens segue o protocolo first-in-first-out e consome os tokens de acordo com o pipeline no anel. A chave de entrada/saída permite que programas e dados sejam carregados de um processador hospedeiro e permite que resultados sejam disponibilizados para inspeção externa.

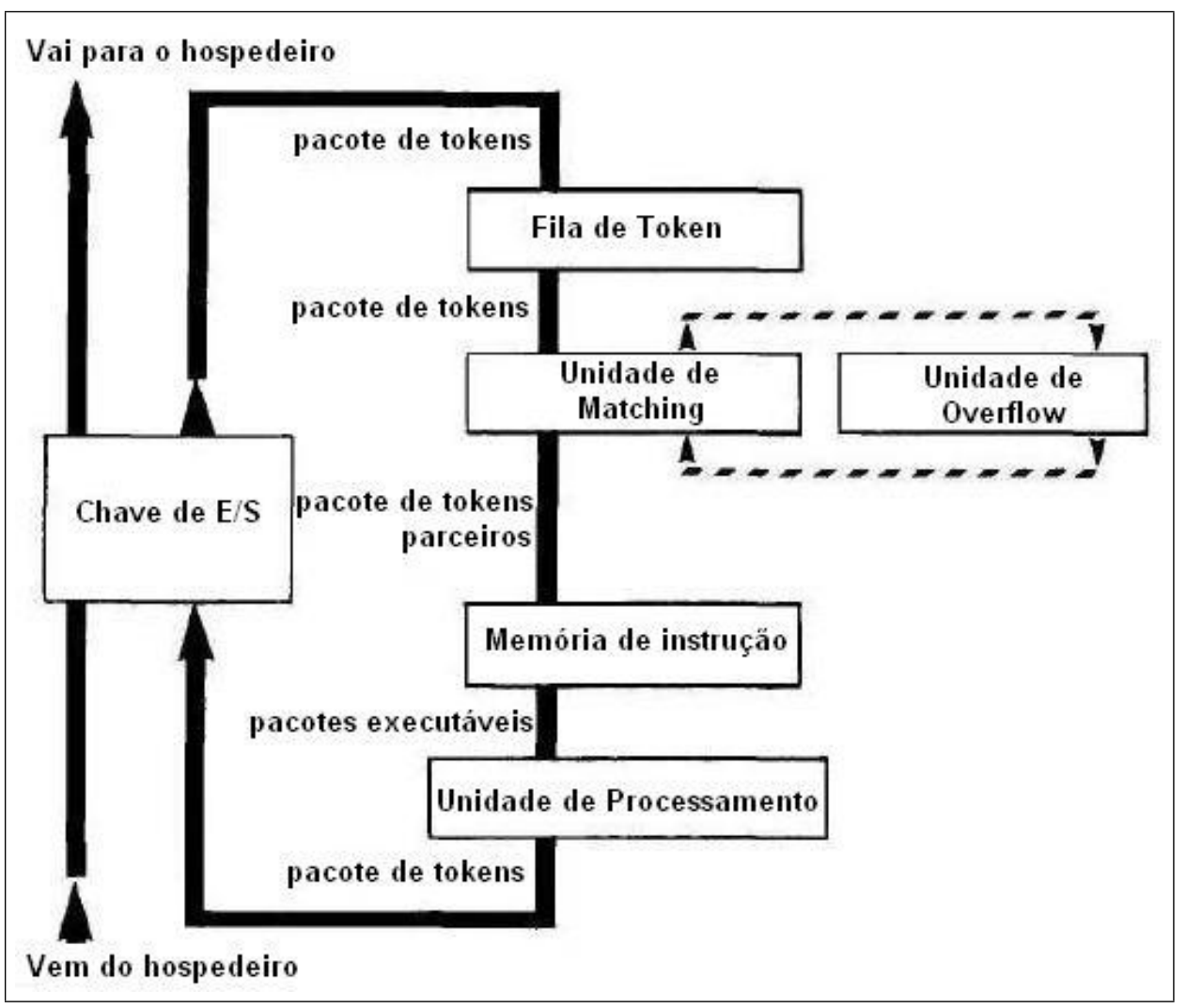

Figura 3.9: Máquina Manchester, adaptado de (GURD et al., 1985) 
A linguagem utilizada para a máquina Manchester também é baseada nos grafos a fluxo de dados. Segundo Gurd et al. (1985), os operadores básicos são:

- ADR - add floating-point values, adiciona valores de ponto flutuante;

- BRR - branch, desvio;

- DUP - explicit duplicate, duplica o token;

- CGR - compare floating point, compara ponto flutuante;

- ADL - add to iteration level, adiciona ao nível de iteração;

- MLR - multiply floating-point values, multiplica valores de ponto flutuante;

- OPT - send output to host processor, envia saída para processador hospedeiro;

- SIL - set iteration level, altera nível de iteração.

\subsection{MIT - TTDA}

O projeto MIT Tagged-Token Dataflow desenvolveu o MIT Tagged-Token Dataflow Architecture (TTDA) para realizar pesquisas em computação paralela de alto desempenho e de propósito geral. Utiliza uma linguagem chamada Id, que é uma linguagem de alto nível com paralelismo de granulosidade fina.

A TTDA utiliza a ideia de grafos a fluxo de dados proposta por Dennis (1974), como já foi apresentado anteriormente. Porém, a versão utilizada por Arvind e Nikhil (1990) é, na verdade, um grafo a fluxo de dados dinâmico. Para implementar o grafo a fluxo de dados dinâmico, utilizou-se o mesmo princípio da máquina Manchester: os tagged-tokens.

As tags têm quatro partes: invocation ID, iteration ID, code block e instruction adress. Invocation ID possui função semelhante ao activation name da máquina de Manchester. Iteration ID serve para indicar a qual iteração de um loop um dado pertence. $\mathrm{E}$ as duas últimas partes identificam o endereço da instrução de destino. Além destes campos que fazem parte do token, existe a porta de destino. Um operador de destino pode ter mais de uma entrada, então o destination port indica por qual porta o dado deve entrar.

Existem operadores específicos para manipular as tags. Os operador $D$ e $D^{-1}$ são usados em loops para incrementar o campo iteration ID. Para implementar loops aninhados e funções definidas pelo usuário, um operador adicional é requerido para atribuir invocation IDs únicos. O operador apply 
recebe um code block, um token como entrada e envia o token para este code block depois de atribuir uma nova invocation ID para ele e altera o valor da sua interation ID para zero. Existe um operador complementar para recuperar a tag original dos tokens resultantes para que eles possam retornar a níveis de aninhamento externos.

Posteriormente, Arvind (2005) apresentou um pequeno conjunto de operadores que podem ser utilizados para a definição de uma linguagem a fluxo de dados. Tais operadores se encontram na Figura 3.10.

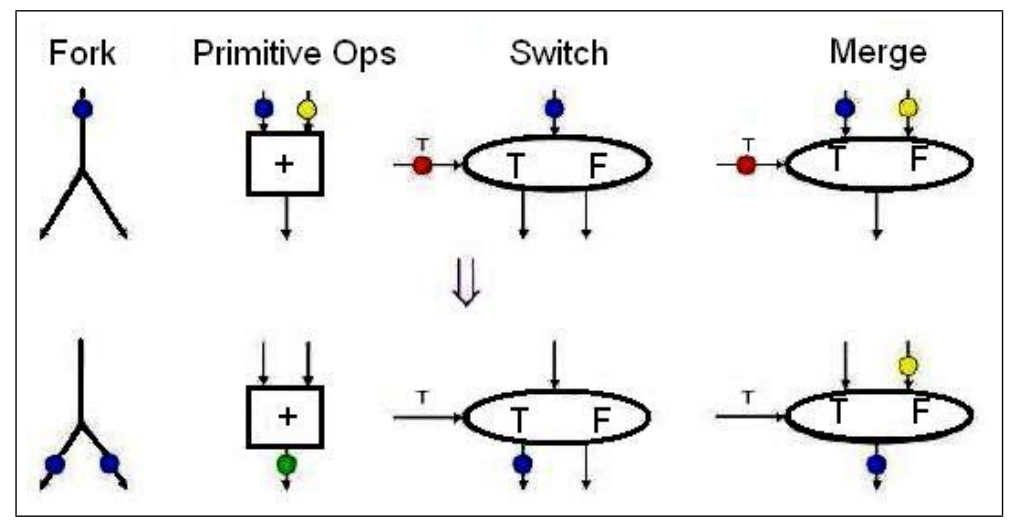

Figura 3.10: Operadores para linguagem a fluxo de dados (ARVIND, 2005)

O operador Fork recebe um token como entrada e o duplica em suas saídas. Na linguagem também são definidos os operadores primitivos como soma, subtração, multiplicação e divisão. Na Figura 3.10, os operadores primitivos estão representados pelo Primitive Ops. O operador switch recebe um token de dado e outro de controle nas suas entradas. O token de controle define para qual saída o token de dados será enviado. Já o operador merge recebe dois tokens de dados como entrada e a outra entrada, que é um token de controle, irá definir qual token de dados será enviado para a saída do operador.

A arquitetura possui uma quantia pré-definida de elementos de processamento (EPs) idênticos e unidades de armazenamento conectados em rede. As unidades de armazenamento são organizadas em um espaço de endereçamento global. Nessas unidades são armazenados os dados e os códigos que serão utilizados pelos elementos de processamento. Cada EP é um processador a fluxo de dados.

As instruções não possuem mais do que duas entradas. Assim cada instrução no grafo é codificada como mostra a Figura 3.11.

No campo Opcode, é descrito o tipo da operação. No campo literal/constante em um valor literal ou um deslocamento constante na memória (offset) é representado. Os campos destino armazenam o endereço das instruções sucessoras no grafo.

A arquitetura de um EP é descrita na Figura 3.12. O EP possui uma estru- 


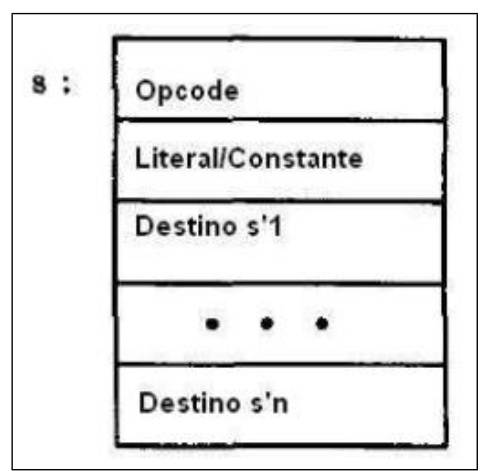

Figura 3.11: Instrução da TTDA, adaptado de (ARVIND and NIKHIL, 1990)

tura em pipeline, onde os tokens entram e atravessa os diferentes estágios do pipeline. O módulo Wait-Match é uma memória que possui vários tokens a espera de dados parceiros, ou seja, dados que possuem a mesma tag. Quando o dado parceiro chega, os dados vão para o módulo Instruction-Fetch, se o token vai para um operador de apenas uma entrada, ele passa direto para a módulo Instruction-Fetch. No módulo Instruction-Fetch, a tag dos dados que chegam definem qual instrução deverá ser buscada. Todas as informações necessárias para execução da instrução são reunidas neste estágio e posteriormente são mandadas para o próximo estágio. Os dois módulos ALU e Compute-Tag trabalham em paralelo. A $A L U$ é uma unidade lógico-aritmética convencional que pega os dados enviados, realiza a operação adequada e gera um resultado. Já o módulo Compute-Tag, fornece as tags corretas para os dados de saída. Tanto os resultados gerados quanto as tags geradas são enviadas para o módulo Form-Tokens. O módulo Form-Tokens constrói um token a partir da concatenação do resultado da operação com a tag gerada pelo módulo anterior. Finalmente, o módulo Control recebe tokens especiais para manipular qualquer estado dos EPs, por exemplo, armazenamento de valores constantes na memória e memória de programa. É neste módulo também que é possivel conectar-se com o "mundo externo", através de canais de entrada/saída.

No funcionamento global do sistema, um programa é dividido em várias partes que serão distribuídas entre os EPs. Então cada EP será responsável pela execução de um trecho do código.

\subsection{SPATIAL DATAFLOW}

Várias arquiteturas atuais são consideradas como tiled architectures. Este tipo de arquitetura é composto por vários elementos de processamento simples que são replicados ao longo do chip, diferentemente das arquiteturas tradicionais, que são baseadas em processadores monolíticos, complexos e de alto desempenho. Algumas dessas arquiteturas incorporam os conceitos 


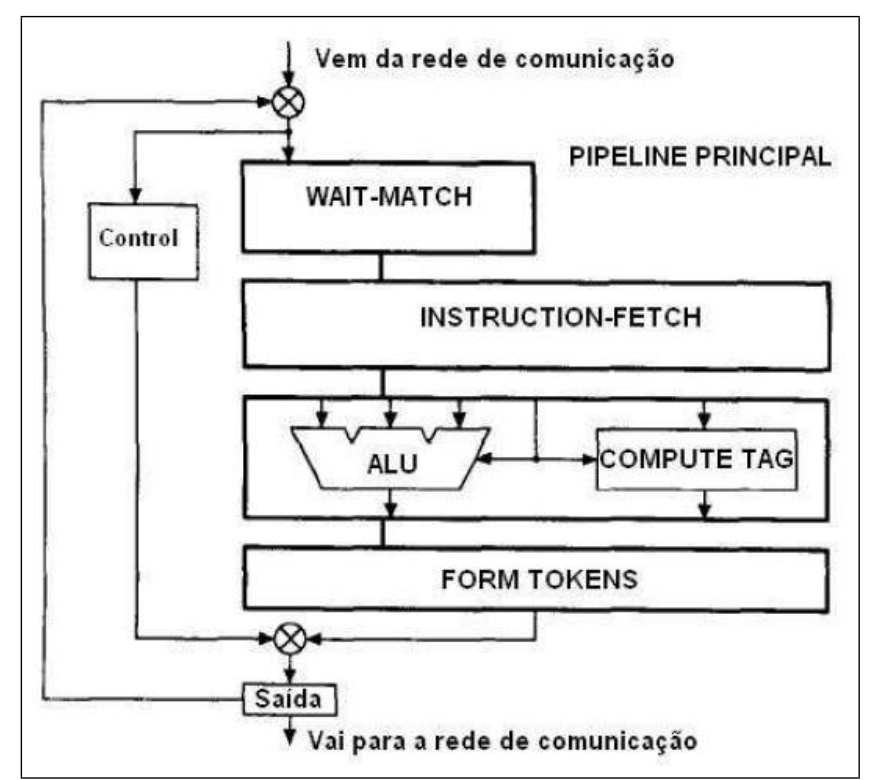

Figura 3.12: EP da TTDA, adaptado de (ARVIND and NIKHIL, 1990)

de processamento a fluxo de dados, como é o caso das máquinas Raw (LEE et al., 1998; TAYLOR et al., 2002), TRIPS (NAGARAJAN et al., 2001; BURGER et al., 2004; SANKARALINGAM et al., 2003; SANKARALINGAM et al., 2006; GEBHART et al., 2009; RANGANATHAN et al., 2009), Smart Memories (MAI et al., 2000), a Unidade de Controle a Fluxo de Dados para Compilação Pipeline Configurável a partir de programação C (CAPPELLI et al., 2004) e WaveScalar (SWANSON et al., 2003; SWANSON et al., 2007; PUTNAM, 2009). As máquinas Raw, Smart Memories, Unidade de Controle a Fluxo de Dados para Compilação Pipeline Configurável a partir de programação C e TRIPS são arquiteturas híbridas, pois apesar de incorporarem conceitos de processamento a fluxo de dados ainda são dependentes de um contador de programa para determinação da execução de instruções e para o acesso a memória.

Alguns trabalhos estão sendo baseados em um modelo conhecido como spatial dataflow ou spatial computation (PUTNAM, 2009; BUDIU, 2003). Tratase de um modelo arquitetural que é inerentemente escalável e distribuído. Neste modelo, para cada operador em um DFG, um elemento de processamento é atribuído (ou criado) para executar a instrução. Cada elemento de processamento executa de acordo com a regra tradicional das arquiteturas a fluxo de dados. Os elementos de processamento se comunicam apenas com os produtores dos seus dados de entrada e com os consumidores dos dados gerados nas suas saídas. A execução é puramente dirigida a dados, não existindo portanto contador de programa.

A Figura 3.13 apresenta um exemplo de spatial dataflow, iniciando com um código em $\mathrm{C}$ e mapeando-o em uma tiled architecture. De acordo com Putnam (2009), os primeiros três passos são comuns para todas as arquiteturas base- 
adas no modelo spatial dataflow. Primeiro, o código $\mathrm{C}$ é compilado em uma linguagem a fluxo de dados intermediária semelhante ao assembly convencional, porém com instruções específicas para montar estruturas condicionais e loops. Em seguida, o DFG é criado e cada instrução da linguagem intermediária se torna um nó, e as instruções que produzem dados são conectadas por um arco às instruções consumidoras.

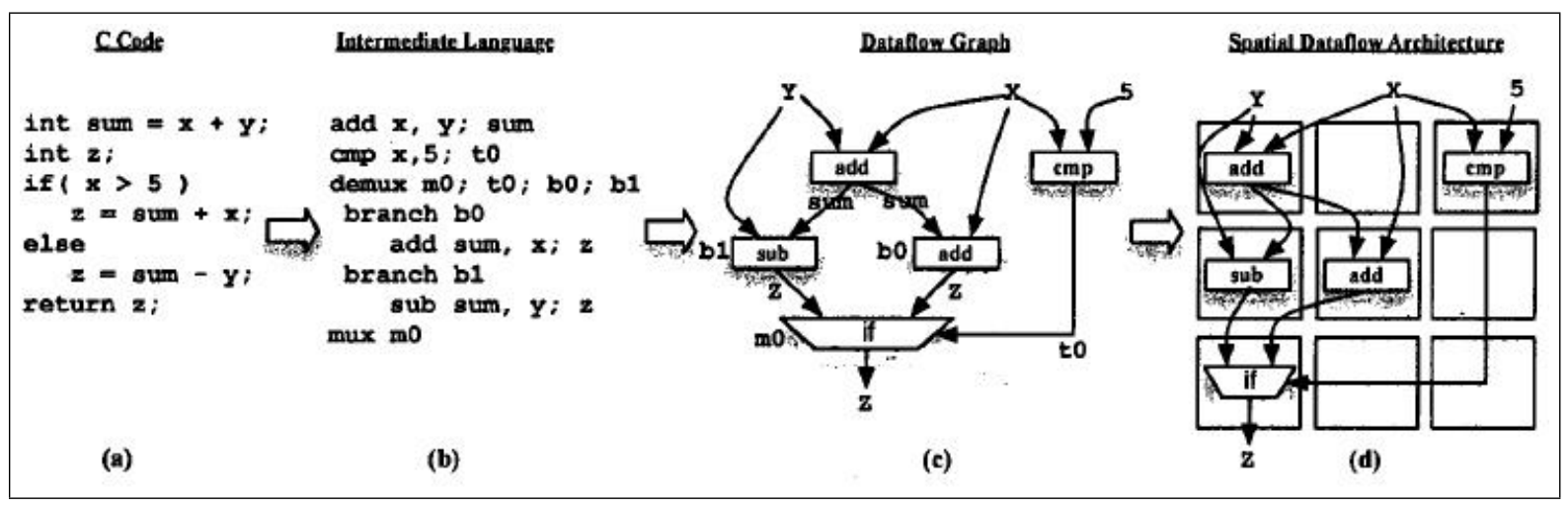

Figura 3.13: Fluxo de compilação no modelo spatial dataflow (PUTNAM, 2009).

O último passo, que é mapear o DFG em uma arquitetura alvo, é altamente dependente de qual arquitetura está sendo utilizada. Na Figura 3.13, utilizouse uma tiled architecture, mas poderia ser um ASIC ou um FPGA como em Budiu (2003).

Segundo Putnam (2009), as características do modelo spatial dataflow fazem com que seja adequado para resolver os desafios atuais do projeto de processadores superescalares, pois neste modelo não há comunicação global, os elementos de processamento são simples, o consumo de energia tende a ser mais eficiente, uma vez que os elementos de processamento são simples e somente aqueles que estão sendo utilizados necessitam estar energizados.

A seguir, serão descritas três arquiteturas baseadas no modelo spatial dataflow: CASH (BUDIU, 2003), CHiMPS e WaveScalar (PUTNAM, 2009).

\subsection{CASH}

No trabalho apresentado em Budiu (2003), é explorado um modelo computacional que não requer sincronização global, uma metodologia CAD objetivando fazer a ponte entre compilação de software e microarquiteturas. Aplicações são escritas em linguagem C e são compiladas diretamente para circuitos de hardware (ASICs) em uma arquitetura a fluxo de dados estática descrita na linguagem de descrição de hardware Verilog. Os circuitos sintetizados possuem comunicação local, sem broadcast e sem controle global. É um compilador sem intervenção do projetista (completamente automático) e explora 
paralelismo em nível de instrução e pipeline. O processo de tradução deste compilador é descrito na Figura 3.14.

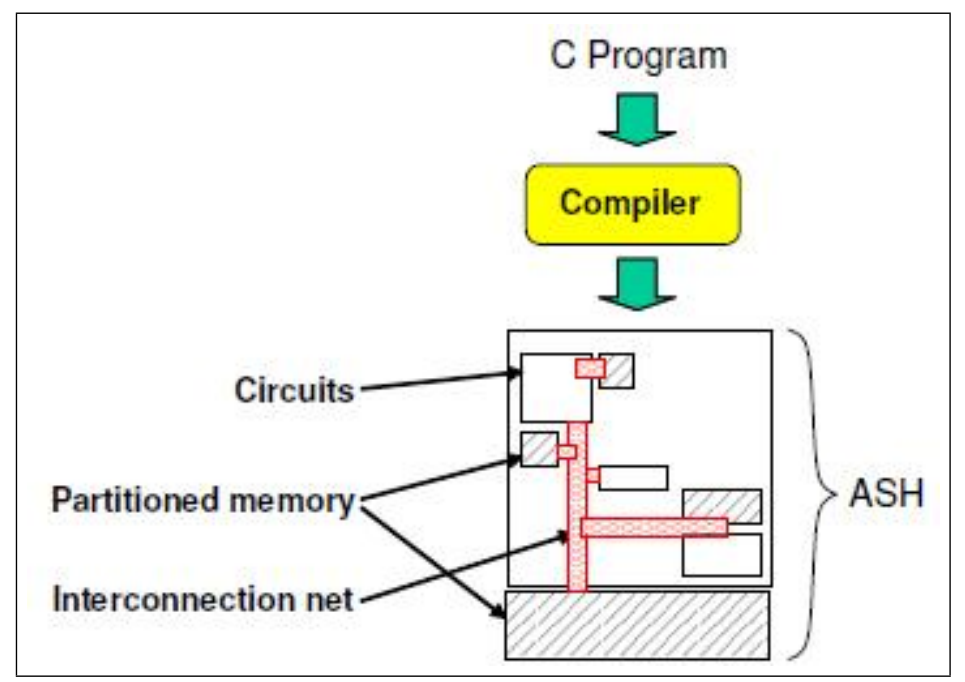

Figura 3.14: Fluxo de compilação no CASH (BUDIU, 2003).

$\mathrm{Na}$ arquitetura gerada pelo CASH (Compiler for Application-Specific Hardware), cada procedimento é traduzido em uma estrutura de hardware distinta; cada operação é sintetizada como uma unidade aritmética de hardware diferente e, como resultado, o circuito não compartilha recursos computacionais; todos os dados do programa são armazenados em uma única memória, acessivel através de hierarquia convencional de memória, incluindo filas de load-store e cache; o hardware sintetizado é uma máquina a fluxo de dados estática específica para a aplicação compilada.

Entre as conclusões apresentadas em Budiu (2003) sugere-se que spatial dataflow pode fornecer desempenho muito bom em programas data-intensive, que possuem alto grau de paralelismo em nível de instrução. Entretanto, algumas das vantagens das arquiteturas baseadas neste modelo podem ser também suas desvantagens quando se trata de programas control-intensive. Estes comportamentos sugerem que sistemas computacionais versáteis devem combinar as vantagens dos processadores específicos para códigos controlintensive e spatial dataflow para núcleos data-intensive.

\subsubsection{CHIMPS}

O CHiMPS é um compilador de aceleradores baseados em C para plataformas de computação híbridas CPU-FPGA (PUTNAM et al., 2008). O objetivo do CHiMPS é facilitar a programação de FPGAs para os desenvolvedores de computação de alto desempenho. Sua entrada é um código ANSI-C qualquer e automaticamente são gerados blocos VHDL para um FPGA. A CPU é utilizada para executar códigos que são sequenciais e as partes do programa que 
possuem maior paralelismo são executadas no FPGA. A Figura 3.15 ilustra o processo.

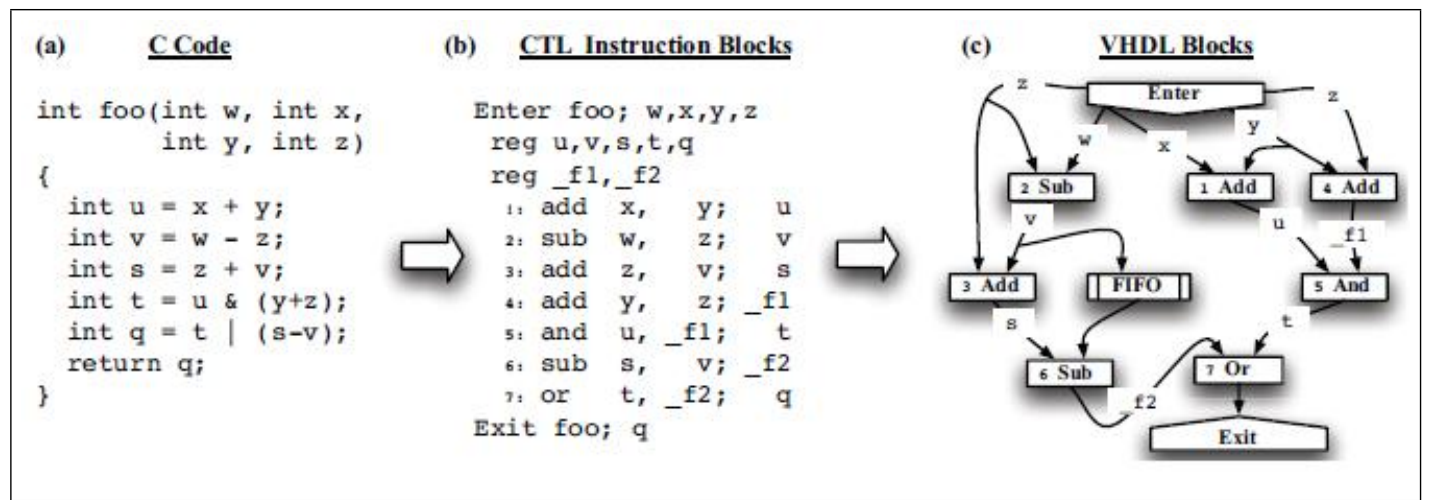

Figura 3.15: Fluxo da ferramenta CHiMPS (PUTNAM et al., 2008)

Cada instrução de código C na Figura 3.15 (a) é primeiro traduzida em uma linguagem estilo assembly chamada CHiMPS Target Language (CTL), mostrada em (b). Nesta linguagem, a maioria das instruções são similares ao padrão RISC e outras são instruções específicas para o fluxo de dados que são usadas na construção de comandos do tipo if/else, loops e breaks. Cada instrução CTL produz uma implementação em VHDL e os blocos VHDL são conectados para formar uma arquitetura de computação a fluxo de dados, mostrada em (c). A FIFO (estrutura de dados que utiliza o protocolo First In First Out para inserção e remoção de dados) é adicionada pelo compilador para melhorar o desempenho.

Cada bloco de instrução na arquitetura a fluxo de dados executa de acordo com a regra de disparo a fluxo de dados: uma instrução só pode ser executada quanto todas as suas entradas estão disponiveis. Os programas iniciam quando os dados chegam ao bloco de instrução enter. Não há contador de programa para ordenar instruções, então blocos de instruções independentes podem executar em paralelo. O fluxo de dados utilizado no CHiMPS é o estático.

\subsubsection{Wavescalar}

WaveScalar é um conjunto de instruções a fluxo de dados dinâmico com tagged-token e um modelo de execução projetado para utilizar processadores com baixa complexidade e alto desempenho formando uma tiled architecture.

As informações que compõem a tag dos dados no WaveScalar são instruction ID, thread ID e wave number. Cada elemento de processamento pode conter várias instruções para serem executadas. Então, para identificar quais dados devem ser executados em cada instrução, cada dado do sistema recebe 
um instruction ID com bits indicando a qual instrução um dado está associado. Thread ID serve para indicar a qual thread um dado pertence. Por fim, wave number serve para indicar a qual iteração um dado pertence durante a execução de loops.

No WaveScalar, é possivel executar aplicações convencionais de única thread, e também multi-threaded, no estilo pthread. Além disso, há um suporte eficaz para thread com granulosidade fina que pode consistir de apenas uma quantidade de instruções WaveScalar.

A seguir serão descritos aspectos do WaveScalar considerando execução de aplicações single-threaded. Mais informações podem ser encontradas em (SWANSON et al., 2007).

O WaveScalar representa programas como grafos a fluxo de dados. Como pode ser visto na Figura 3.16, o assembly do WaveScalar se assemelha ao assembly convencional, no estilo RISC (Reduced Instruction Set Computer). Porém, são diferentes em dois aspectos. Primeiro, apesar das arestas do grafo serem sintaticamente iguais a nomes de registradores, elas não correspondem a uma entidade arquitetural específica. Segundo, a ordem das instruções no código não afeta a sua execução, uma vez que a definição dessa ordem é feita de acordo com o fluxo de dados. Cada instrução possui um endereço único, que é usado em chamadas de funções. Além disso, labels também podem ser usados, assim como nos assemblies convencionais.

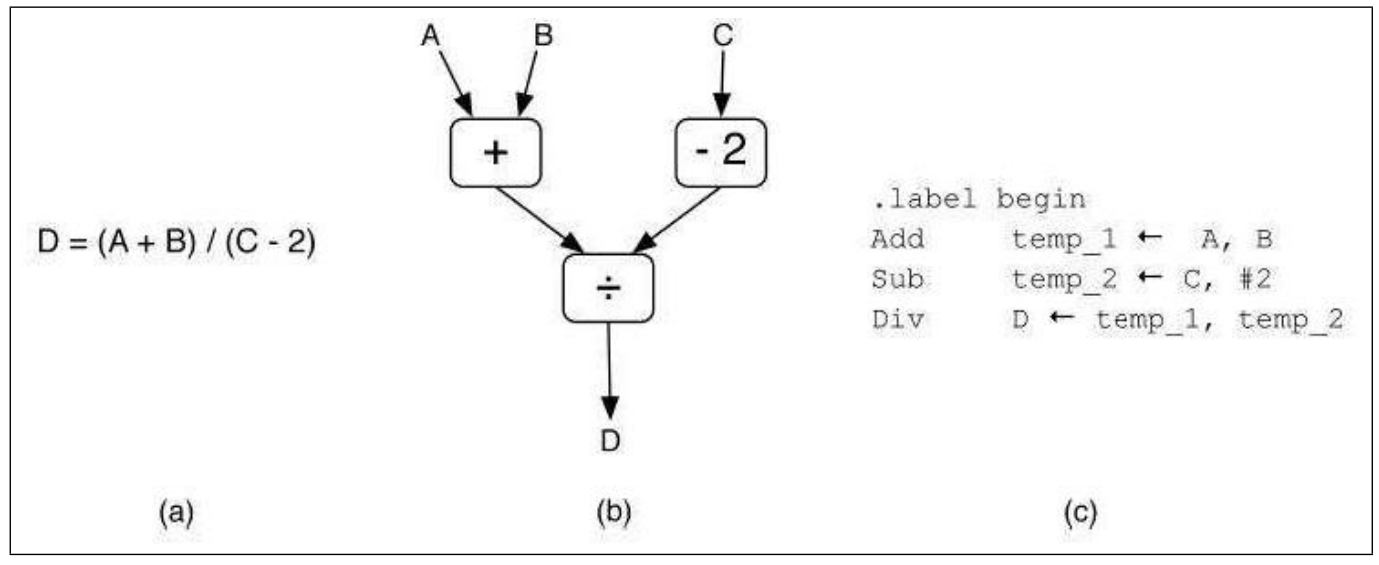

Figura 3.16: Assembly do WaveScalar (SWANSON et al., 2007)

Para viabilizar estruturas condicionais, o fluxo de controle é representado pela instrução STEER que guia os valores para seus caminhos corretos em função de valores booleanos. As instruções de predição também são usadas para o mesmo propósito, apesar de funcionarem de maneiras distintas, como mostra a Figura 3.17. Na parte (a) da figura, tem-se um trecho de código do tipo IF-THEN-ELSE. Na parte (b) da Figura, há um exemplo de como fica o DFG ao utilizar a instrução STEER (representada pelo triângulo nomeado 
de s) para implementar o código. Já na parte (c), utilizou-se a instrução de predição (representada pelo triângulo com o símbolo $\phi$ ). A instrução STEER recebe uma entrada de dados e outra de controle booleano. Dependendo do valor do controle, o dado da entrada será passado ou para uma saída ou para a outra saída. Já a instrução $\phi$, recebe duas entradas de dados e uma entrada de controle booleana irá determinar qual dos dados de entrada será enviado para a única saída.

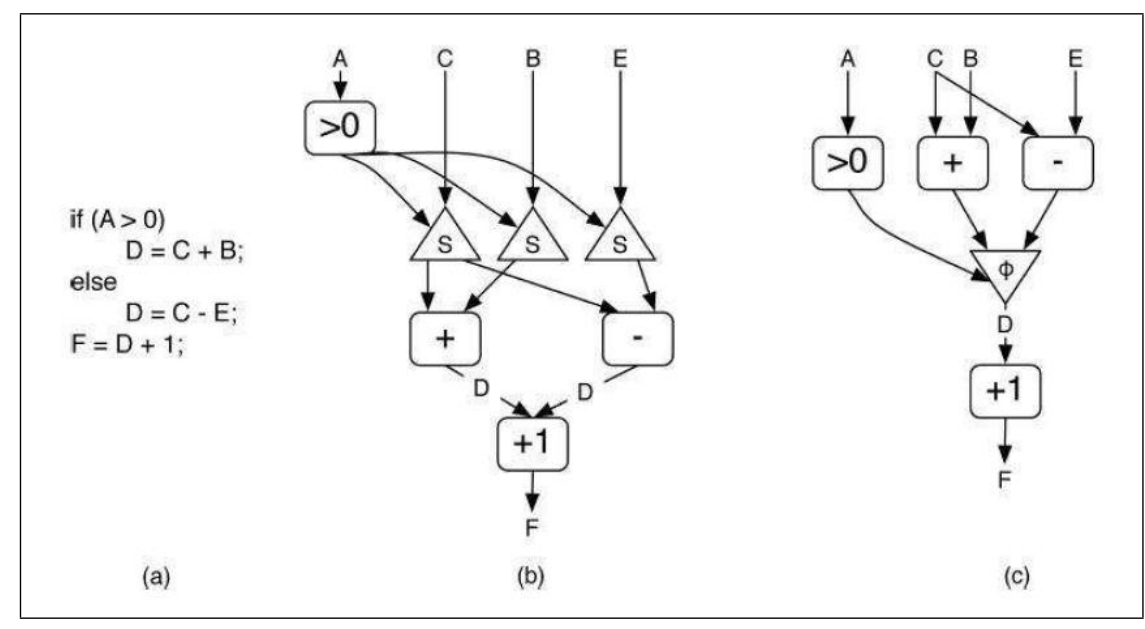

Figura 3.17: Controle no WaveScalar (SWANSON et al., 2007)

Já para a representação de estruturas iterativas, além da estrutura condicional, é necessário distinguir também as instâncias dinâmicas de valores de diferentes iterações de um loop. O WaveScalar é uma arquitetura a fluxo de dados dinâmica, e utiliza o princípio de tagged-token, porém, no WaveScalar, a parte da tag que identifica a qual iteração um dado pertence é chamada de wave number. Os wave numbers são atribuídos a porções do DFG determinadas em compilação, chamadas de waves. No topo de cada wave há um conjunto de instruções wave-advance, cada uma das quais incrementa o wave number dos valores que passam por ele. Os wave numbers permitem que instruções de diferentes iterações executem simultaneamente. A Figura 3.18 ilustra um algoritmo e sua implementação utilizando instruções do WaveScalar.

A arquitetura projetada para executar programas WaveScalar é uma tiledarchitecture chamada WaveCache. Na Figura 3.19, é apresentada a estrutura hierárquica das WaveCaches. Antes da execução do programa, a WaveCache mapeia as instruções do programa no seu conjunto de EPs (ou PEs, como estão referenciados na Figura 3.19). As instruções permanecem nos EPs por várias invocações, e conforme o working set de instruções modifica, a WaveCache remove as instruções não usadas e mapeia novas instruções nos lugares vagos. As instruções comunicam-se umas com as outras diretamente por meio de uma interconexão hierárquica, o que evita conexões longas e comunicação 


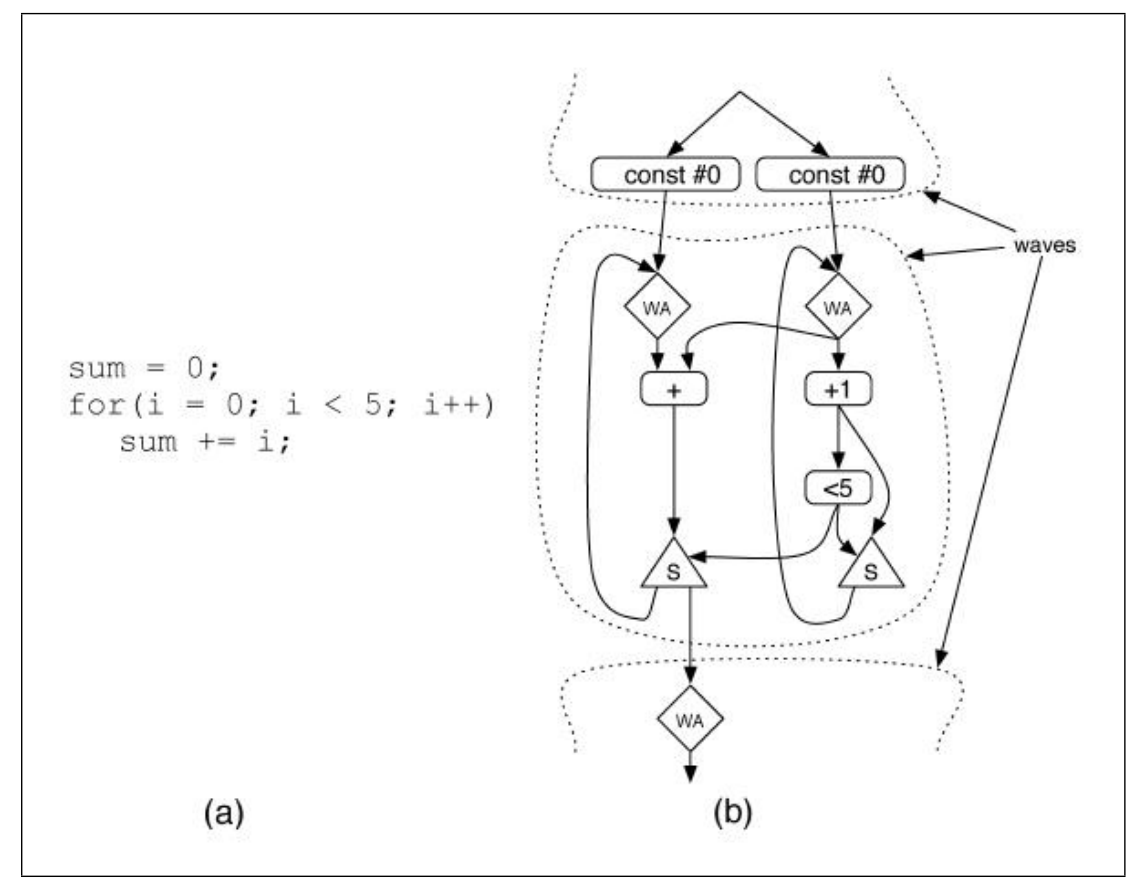

Figura 3.18: Loops no WaveScalar (SWANSON et al., 2007)

em broadcast, pois cada nivel da hierarquia usa uma estrutura de comunicação separada. A WaveCache engloba tudo que é necessário para executar um programa WaveScalar, exceto a memória principal.

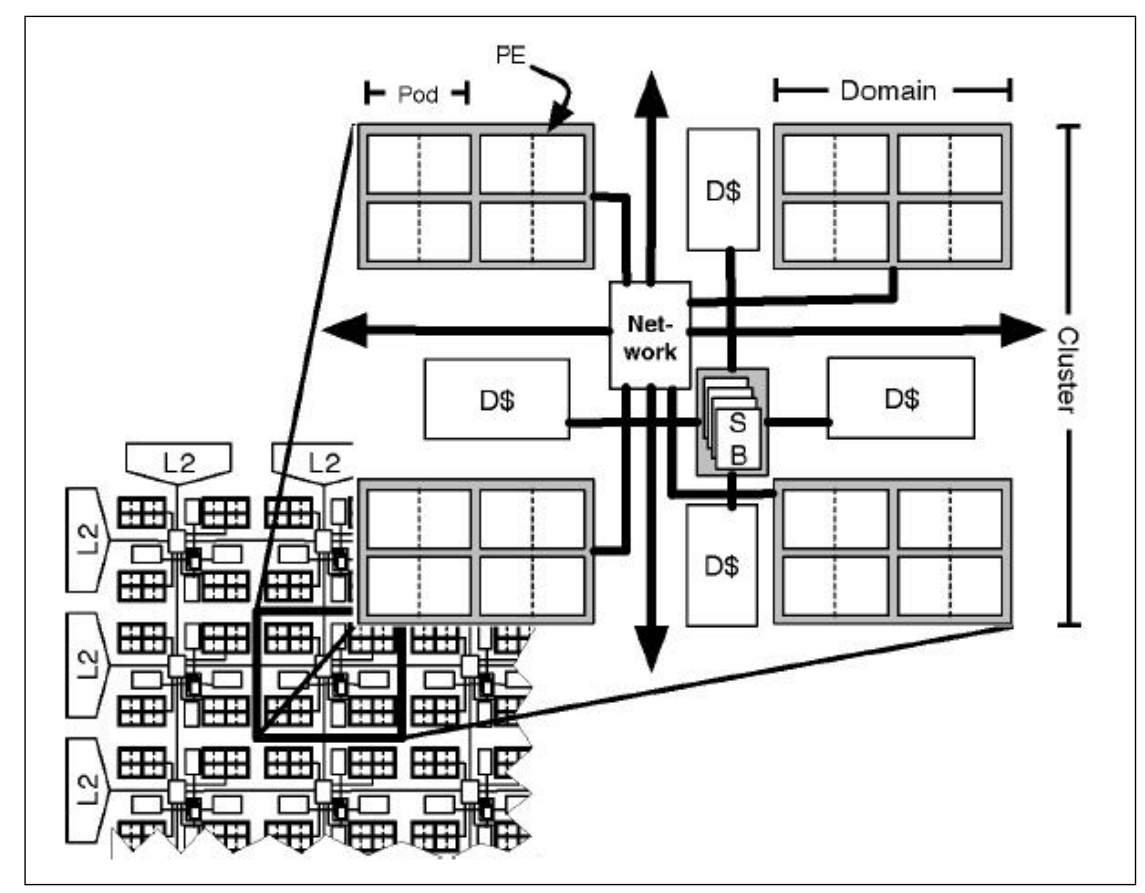

Figura 3.19: WaveCache (SWANSON et al., 2007)

Na WaveCache, cada tile é chamado de cluster. Um cluster contém quatro domínios idênticos, cada um com oito EPs idênticos.

Na Figura 3.20, é ilustrado o diagrama de um elemento de processamento 
do WaveScalar. Os EPs da arquitetura WaveScalar foram implementados com cinco estágios de pipeline descritos a seguir. Input: Os operandos chegam ao EP por meio de outro EP ou do mesmo, no caso de iterações; match: os operandos entram na tabela de matching, que irá determinar quais instruções já possuem todos os operandos e, portanto, estão prontas para executar; dispatch: o EP escolhe uma instrução da fila de execução, lê seus operandos pela tabela de matching, e os envia para o próximo estágio; execute: executa a instrução e envia os resultados para a fila de saída e/ou para a rede de comunicação local; output: uma saída de instrução é enviada para as instruções consumidoras por meio da rede de comunicação. Consumidores podem ser outros EPs ou o mesmo EP.

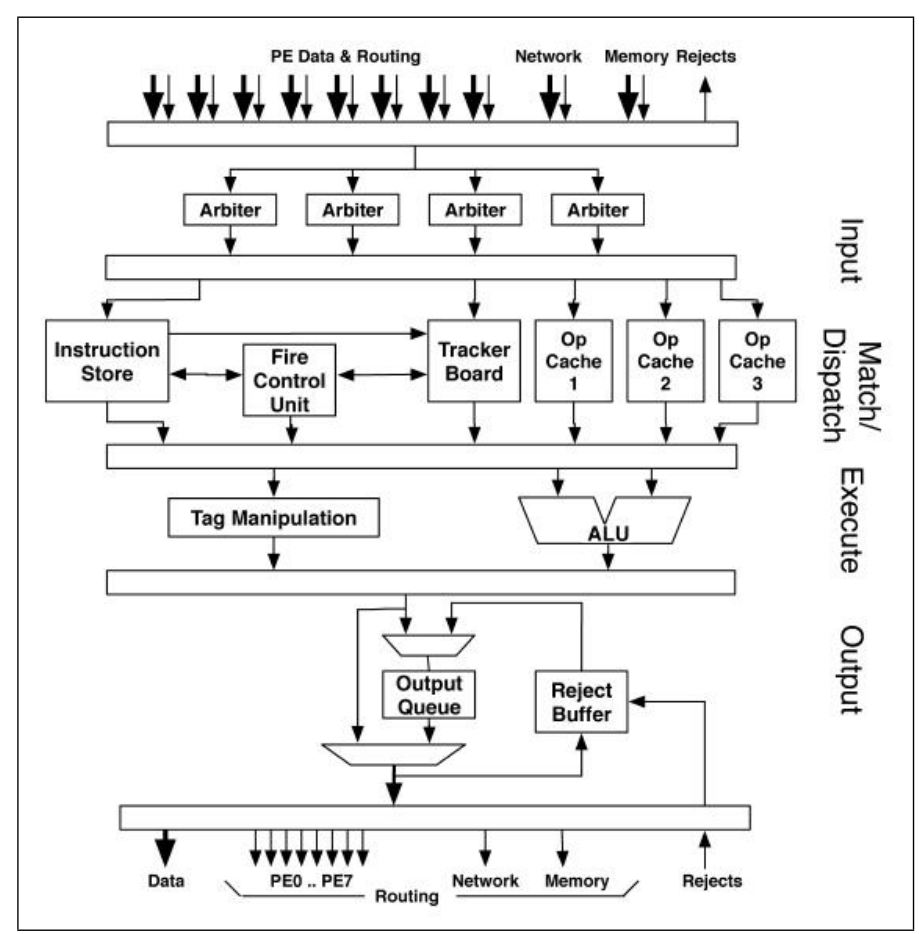

Figura 3.20: Diagrama de um elemento de processamento do WaveScalar (SWANSON et al., 2007) 


\subsection{CONSIDERAÇÕES FINAIS}

Neste capítulo, as principais máquinas a fluxo de dados foram discutidas. Primeiramente, foram apresentadas as máquinas consideradas como as máquinas que provaram conceitos que influenciaram muitas outras máquinas que vieram em seguida. Depois, falou-se um pouco sobre algumas máquinas que utilizam o conceito de processamento a fluxo de dados, o modelo arquitetural spatial dataflow e, posteriormente mais detalhes foram apresentados das máquinas CHiMPS, CASH e WaveScalar. Estas três máquinas executam linguagens imperativas em arquiteturas a fluxo de dados. Sendo assim, a adoção destas arquiteturas por desenvolvedores de sistemas paralelos de alto desempenho pode ser mais fácil, uma vez que não é necessário abandonar o legado de código existente em linguagens imperativas e nem aprender conceitos de baixo nível relacionados ao desenvolvimento de hardware. WaveScalar é a máquina que representa o estado da arte em máquinas a fluxo de dados dinâmicas baseadas em tagged-tokens. No próximo capítulo, o projeto ChipCflow será descrito. 
CAPÍTULO

\section{CHIPCFLOW}

\subsection{CONSIDERAÇÕES INICIAIS}

Este capítulo tem por objetivo explicar a origem do projeto ChipCflow, quais os trabalhos que já foram desenvolvidos até o momento, quais estão ainda em desenvolvimento e onde o trabalho desta dissertação de mestrado se enquadra no projeto.

\subsection{FASE PRÉ-CHIPCFLOW}

O objetivo desta seção é apresentar em ordem cronológica os trabalhos que contribuíram para que a proposta inicial do projeto ChipCflow fosse elaborada.

\subsection{Tese do Dr. Silva}

O primeiro trabalho que originou a inspiração para a criação do projeto ChipCflow foi a tese de doutorado do Professor Doutor Jorge Luiz e Silva (Dr. Silva) (SILVA, 1992), desenvolvida na Faculdade de Engenharia Elétrica da Universidade Estadual de Campinas (FEE - Unicamp). Nesta tese, foi proposta uma máquina para processamento a fluxo de dados tolerante a falhas em um computador paralelo estruturado recursivamente (CPER). E, com o objetivo de mostrar a viabilidade e eficiência da máquina paralela proposta, foi apresentado um simulador (FDSim) e uma análise estocástica.

A escolha de um computador paralelo estruturado recursivamente foi feita para obter alto desempenho de comunicação, já que um dos problemas críticos do processamento de programas a fluxo de dados citados na tese era a 
enorme demanda por comunicação de dados. Por seu barramento de comunicação ser organizado hierarquicamente, o CPER conseguia obter altas taxas de desempenho de comunicação. A estrutura básica do CPER é composta por um computador hospedeiro e um barramento paralelo integrando $N$ processadores para execução. Tais processadores também são interligados por uma rede em anel ponto-a-ponto. Além disso, o CPER apresenta alta confiabilidade por meio de tolerância a falhas devido a própria natureza da estrutura.

Com a utilização de um software básico apropriado, o CPER pode funcionar como uma máquina a fluxo de dados dinâmica utilizando tagged-token. Nesta tese, foram propostos um formato para as tags dos tokens, um conjunto de operadores para a manipulação destas tags, um carregador que servia para escalonar o DFG nos elementos de processamento e um conjunto de operadores básicos para representar programas em fluxo de dados.

\subsubsection{SPmm 1}

O SPmm1 foi um sistema paralelo multi-microcontrolador para aplicações de tempo real. Este sistema foi implementado utilizando os conceitos da tese do Dr. Silva. O SPmm1 possuía 30 CPUs organizadas em uma arquitetura hierárquica. Tal projeto foi concluído em dezembro de 1993 na Universidade Federal de São Carlos. A Figura 4.1 mostra algumas fotos deste sistema.

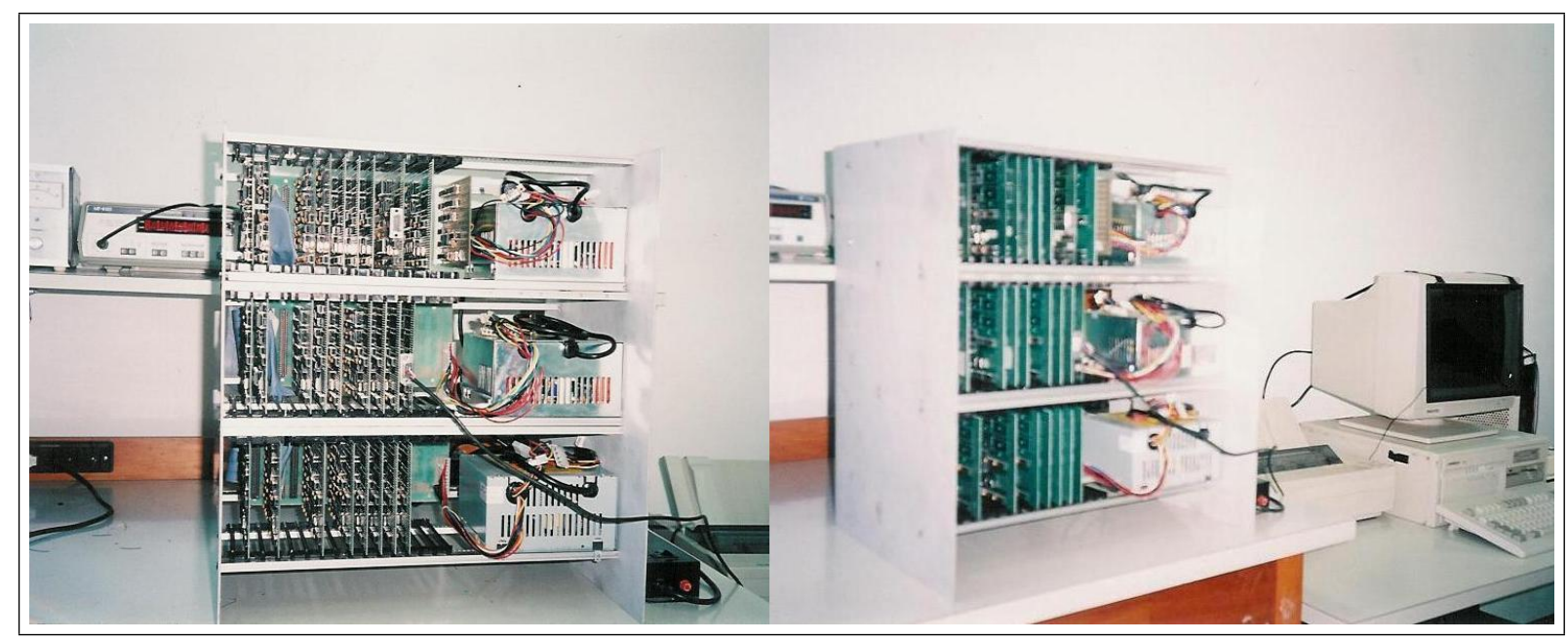

Figura 4.1: Máquina SPmm1

Após a realização da pesquisa com o sistema SPmm1, foi gerado um produto que era um sistema de segurança doméstica utilizando um microcontrolador 8051 em um sistema de aplicações embarcadas em 1994. Na Figura 4.2, são mostradas fotos deste sistema. 


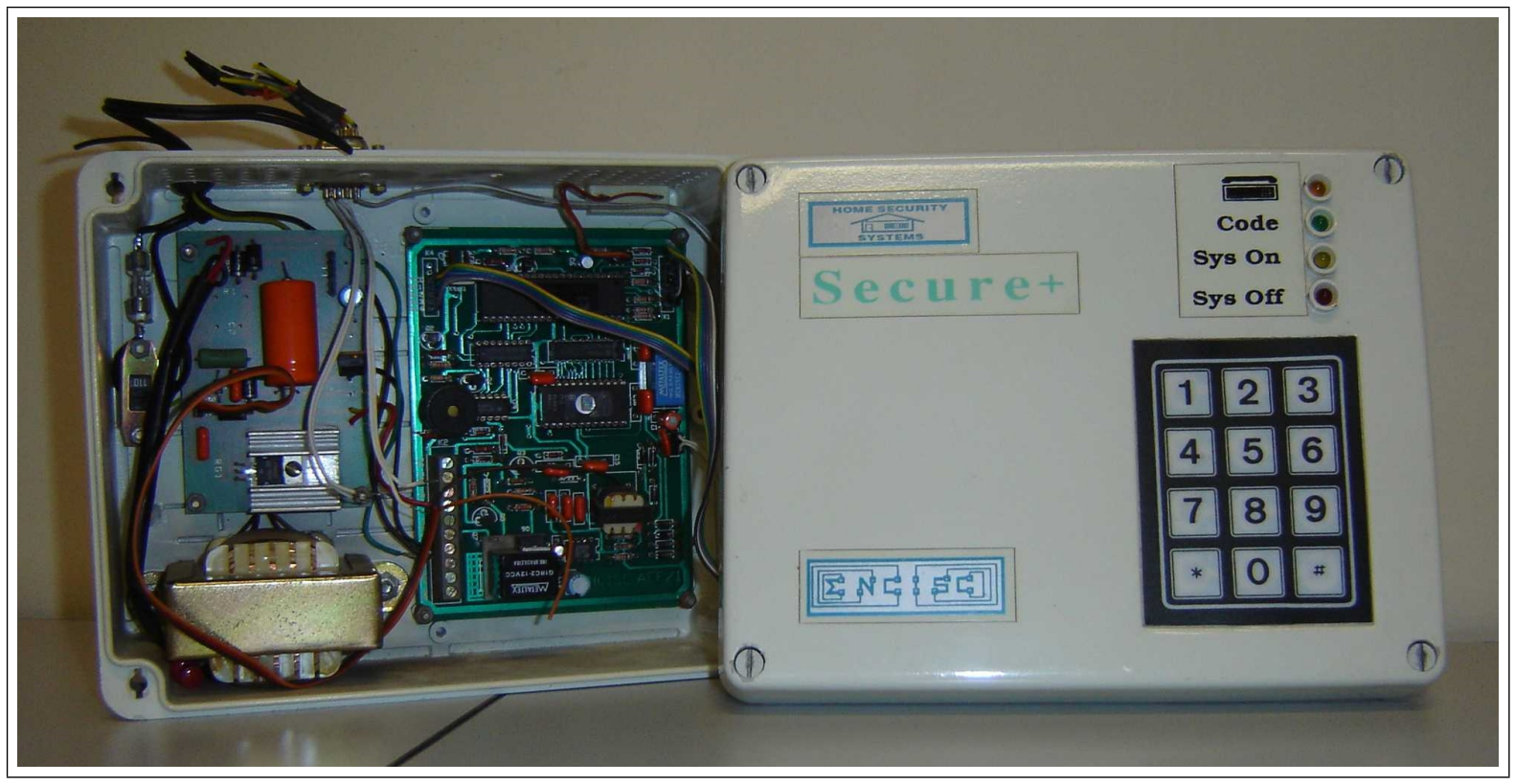

Figura 4.2: Sistema de segurança doméstico.

\subsubsection{O embrião do ChipCflow}

Um ano após a publicação da tese do Dr. Silva, um trabalho foi publicado por Ben Lee e A. R. Hurson discutindo os principais problemas da computação dirigida a fluxo de dados (LEE and HURSON, 1993). Nessa época, os ânimos dos pesquisadores em arquiteturas a fluxo de dados começaram a se dissipar, pois apesar da elegância do modelo, sua implementação apresentava um enorme desafio na prática.

Entretanto, uma nova perspectiva surgiu para as arquiteturas a fluxo de dados no momento em que os FPGAs se popularizaram. De um lado se tinha uma crescente demanda por capacidade computacional, flexibilidade dos sistemas, baixo consumo de energia e alta exploração do paralelismo. E de outro lado havia um emergente dispositivo reconfigurável paralelo, flexível, de baixo consumo e um modelo que explora naturalmente o paralelismo das aplicações. Da ideia de unir os FPGAs com o modelo a fluxo de dados dinâmico desenvolvido na tese do Dr. Silva é que surgiu, durante os anos de 2006 e 2007, três trabalhos que se tornaram o embrião do projeto ChipCflow.

O primeiro trabalho, apresentado em (SILVA and MARQUES, 2006), descreve o protocolo de comunicação para sincronizar os dados em um grafo a fluxo de dados implementado com o ISE 8.2i da Xilinx como parte da implementação de um modelo de grafo a fluxo de dados dinâmico, diretamente em hardware.

Já no segundo trabalho, (SILVA, 2006), é apresentado o modelo a fluxo de dados dinâmico (Dynamic Dataflow Model) em um hardware reconfigurável como um projeto de uma arquitetura que explora o paralelismo de forma 
natural usando as características de hardware parcialmente reconfigurável. Foi proposta então a utilização de um FPGA que suportasse reconfiguração parcial e dinâmica, no caso a Virtex II Pro da Xilinx. Este trabalho especificamente apresentou uma proposta para a unidade de matching de dados localizada dentro de cada operador. A intenção do modelo apresentado era, a partir de um código em $\mathrm{C}$, gerar o grafo a fluxo de dados dinâmico diretamente em hardware para partes do programa. E novas instâncias dos operadores seriam configuradas no FPGA em tempo de execução na medida em que fossem necessárias. A instância é uma réplica do operador, que é configurada dinamicamente no FPGA para executar a operação deste operador caso ele já esteja ocupado.

Finalmente no terceiro trabalho, apresentado em (ASTOLFI and SILVA, 2007), foram implementados em VHDL e simulados grafos de construções como if-else, while, for, do-while e switch. Porém, o fluxo de dados implementado foi o estático. O objetivo neste artigo era validar os grafos gerados para as diferentes construções presentes na programação imperativa. Por ser estático, não havia unidade de matching nem instâncias.

Estes três trabalhos realizados juntamente com as ideias herdadas da tese do Dr. Silva faziam parte de um mesmo modelo. Tal modelo deveria transformar partes de uma aplicação escrita em C em grafo a fluxo de dados dinâmico implementado diretamente em hardware utilizando reconfiguração parcial e dinâmica de FPGAs. Este hardware deveria possuir tagged-tokens, operadores para manipulação das tags, matching de dados, protocolo de comunicação dos operadores e instâncias para os operadores. Como estes trabalhos apenas apresentaram a ideia inicial e o modelo desta arquitetura a fluxo de dados dinâmico, foi justamente a proposta de implementação deste modelo é que foi chamada de projeto ChipCflow.

\subsection{PROPOSTA INICIAL DO PROJETO CHIPCFLOW}

O projeto ChipCflow propõe uma ferramenta de conversão de C para hardware. Trata-se, sob este ponto de vista, de um método de desenvolvimento ou um compilador para hardware a partir de linguagens de alto nível gerando hardware paralelo de alto desempenho. O ChipCflow também propõe uma máquina a fluxo de dados configurada em um dispositivo reconfigurável. Já deste ponto de vista, trata-se de uma arquitetura. Projeto ChipCflow e ferramenta ChipCflow se referem ao fluxo completo do ChipCflow, descrito na Figura 4.3.

A partir do programa de aplicação escrito originalmente na linguagem $C$, Figura 4.3 (a), se extrai os DFGs do programa de aplicação, Figura 4.3 (b) e (c), tendo como referencia para os operadores, uma base de DFGs a ser gerada 
especificamente para essa ferramenta (Figura 4.3 (d) (e). O DFG gerado já estará otimizado. O grafo então é convertido em VHDL, tendo como base todo o conjunto de operadores propostos para o ChipCflow, previamente implementados em VHDL. O código VHDL é então sintetizado e simulado em ferramenta EDA (Electronic Design Automation) comercial (Figura 4.3 (d)), em particular trabalha-se com o ISE da Xilinx no projeto ChipCflow, e o bitstream é então gerado para serem executados direto no hardware, Figura 4.3 (e).

Na Figura, as setas 1 e 2 representam um pré-compilador que juntos geram o arquivo de representação intermediária, estilo código em assembly, para o grafo a fluxo de dados gerado a partir da aplicação escrita originalmente em linguagem C. A seta 3 representa como o sistema ChipCflow gera a representação final do arquivo em VHDL, a partir de uma base de operadores já desenvolvidos em VHDL, para comporem a versão final do programa de aplicação, agora escrito em linguagem VHDL. Esse programa, em forma de arquivo VHDL, é inserido na ferramenta ISE, seta 4 na figura, que gera o bitstream para aquele arquivo, pronto para ser transferido e executado no FPGA (Na Figura 4.3 em particular foi descrita a ferramenta EDA da Xilinx (XILINX, 2011)).

A arquitetura do ChipCflow varia de acordo com cada aplicação, por isso o compilador utiliza um conjunto de operadores básicos e monta o que será de fato a arquitetura de uma dada aplicação. No hardware gerado, cada nó do grafo a fluxo de dados se torna um elemento de processamento real e cada vértice do grafo se torna em um canal de comunicação ponto-a-ponto entre dois elementos de processamento.

Nas próximas seções serão mostrados os detalhes da arquitetura e do princípio de funcionamento do modelo da máquina a fluxo de dados da ferramenta ChipCflow em sua proposta inicial.

\subsubsection{Operadores}

Os operadores básicos do grafo a fluxo de dados do ChipCflow são os mesmos apresentados em (SILVA, 1992).

Para que fosse possível representar um código escrito em linguagem de alto nível como $\mathrm{C}$ em um grafo a fluxo de dados, foi utilizado um conjunto de operadores: decisor ou decider, junção não-determinística ou non-deterministic merge, junção determinística ou deterministic merge, ramificação ou branch, cópia ou copy e operador ou operator. Por convenção, ao longo do texto, o nome dos operadores será mencionado em inglês. Os seis operadores e seus respectivos símbolos podem ser visualizados na Figura 4.4.

Os operadores branch, deterministic merge, non-deterministic merge e decider são usados para representar computações iterativas e condicionais no 
(a)

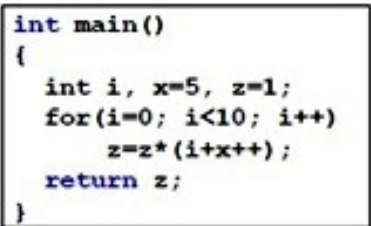

(b)

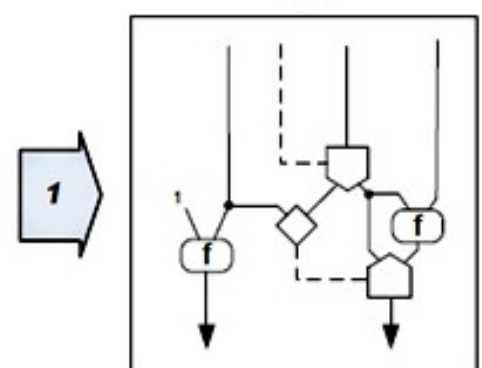

(c)

add $(a 1, a 2, s 1)$

add(b1,b2,s2)

If $(a 3, a 4, t 1)$

$\operatorname{copy}(\mathrm{t} 1, \mathrm{t} 2, \mathrm{t} 3)$

merge $(s 1, s 2, t 2, z 1)$

$\operatorname{branch}(z 1, t 3, z 2, z 3)$

add $(a 5,22,53)$

add $(a 6,23,54)$

ndmerge $(s 3,54,24)$

(d)
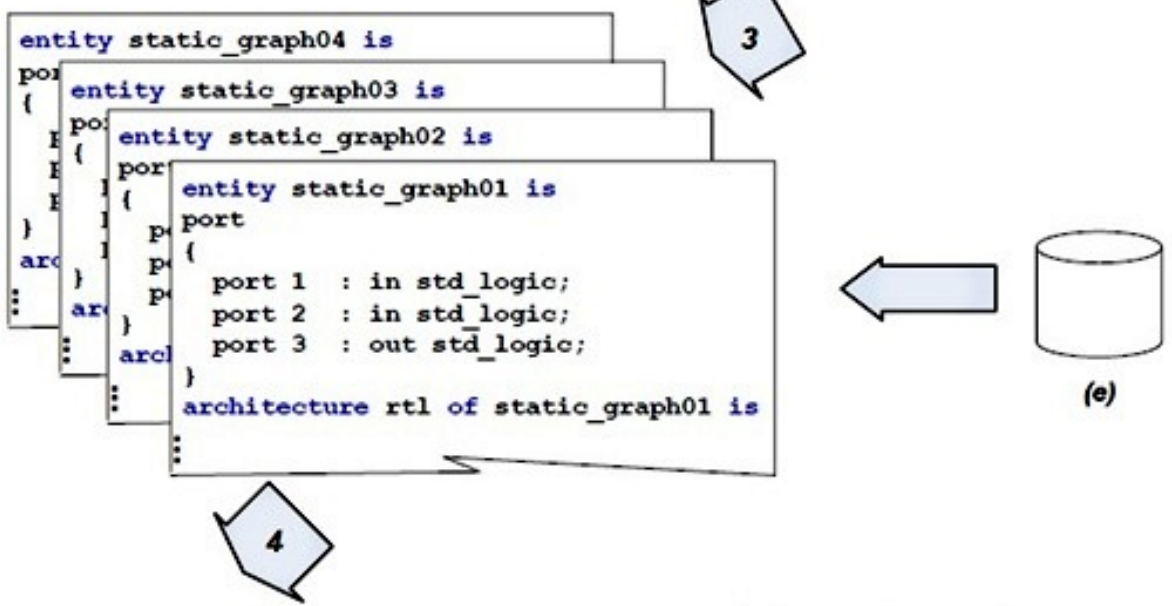

(e)

ISE DESIGN

SUITE 12

Unlock New Levels of Productivity

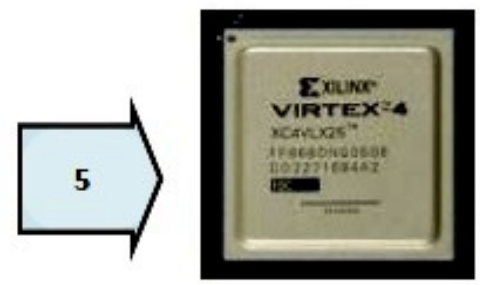

Figura 4.3: Proposta da Ferramenta ChipCflow
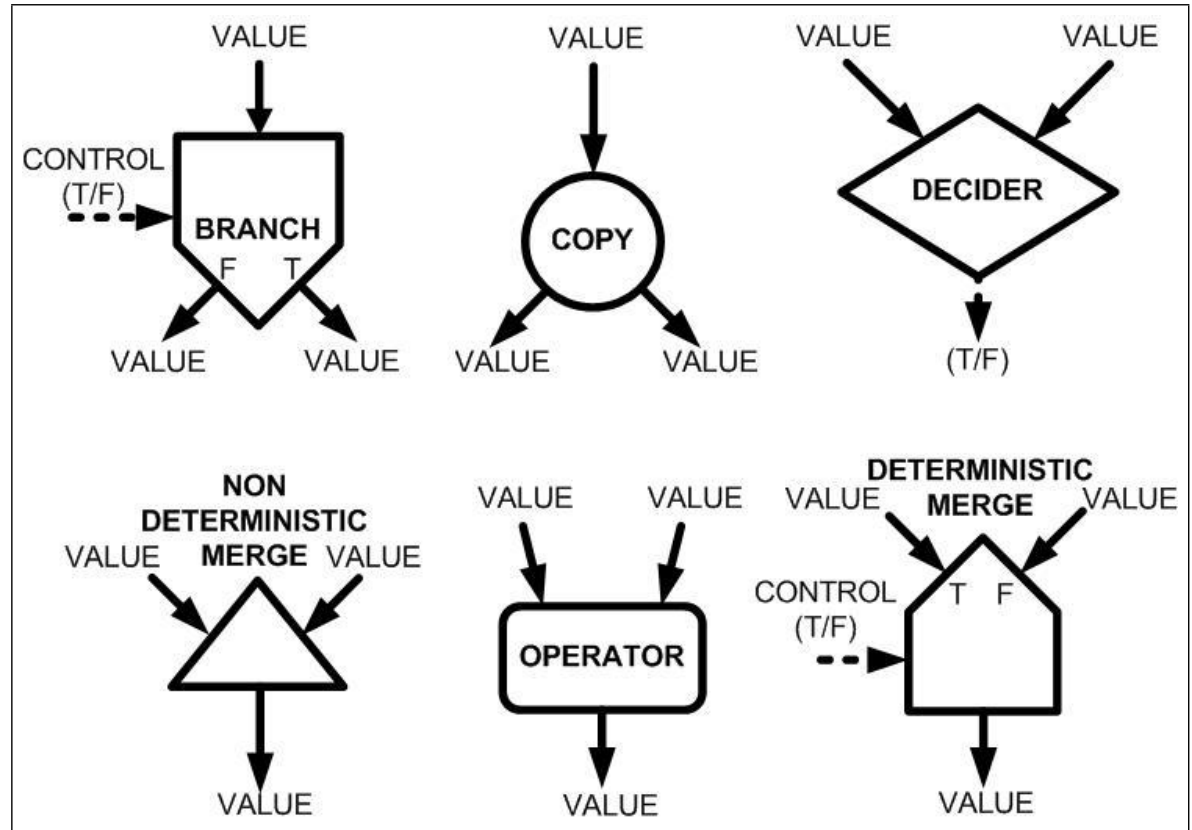

Figura 4.4: Operadores do grafo a fluxo de dados do ChipCflow 
grafo a fluxo de dados.

O operador branch copia o token absorvido pela entrada value de dados e, dependendo do valor recebido pela sua entrada de controle control, envia a cópia ou para o arco verdadeiro ou para o arco falso.

O operador copy recebe um token pela sua entrada value e duplica esse token. Em seguida, envia cada cópia para uma saída.

O operador decider recebe valores nas entradas do tipo value que são submetidos a uma função de teste. Essa função irá gerar um token de controle com valor booleano ( $T$ - true ou $F$-false) que será enviado pela saída do operador.

O operador deterministic merge possui um token de controle booleano que irá determinar qual dos dois dados recebidos pelas outras duas entradas será enviado pela saída. Já no caso do operador non-deterministic merge, não existe um token de controle. Nesse caso então, o dado que será enviado pela saída será o dado que chegar primeiro.

O operador operator recebe dois tokens, realiza alguma computação sobre eles e envia o resultado pela saída. Este operador é o responsável por realizar operações aritméticas, por exemplo. No caso então, existem vários operadores, cada um especializado na realização de um cálculo específico.

Para fazer as ligações entre os operadores em um grafo, existem dois tipos de enlace. O enlace de dados, que liga entradas e saídas para dados propriamente ditos e o enlace lógico representado por uma seta pontilhada, que liga entradas e saídas usadas para controle e seus valores são Booleanos.

Em (ASTOLFI and SILVA, 2007), todos os seis operadores foram implementados. Porém a implementação foi baseada em um fluxo de dados estático e todos os operadores foram sincronizados por um clock global a fim de facilitar a implementação. Neste trabalho, grafos a fluxo de dados de construções como if-else, while e switch foram simulados e validados utilizando-se o ISE 8.2i da Xilinx.

Os operadores recebem ou enviam tokens por meio do protocolo de handshake descrito em (SILVA and MARQUES, 2006). Portanto, para cada entrada ou saída de um operador, existe um par de sinais (ack e strobe) responsáveis pela implementação do protocolo.

Em (SILVA and MARQUES, 2006), um grafo com três operadores foi implementado para uma prova de conceitos inicial para o protocolo de comunicação entre os operadores. Na implementação deste trabalho, o token não possuía tag e o número de bits para os dados era 16. Um bloco chamado INDATA foi implementado para sincronizar os dados de entrada do grafo. Um operador de soma, chamado OPADD, foi implementado para somar dois dados de 16 bits. $\mathrm{E}$, por fim, foi implementado um operador para sincronizar a saída dos dados 
do grafo, chamado de AOUT. A Figura 4.5 mostra o diagrama de bloco destes três blocos.

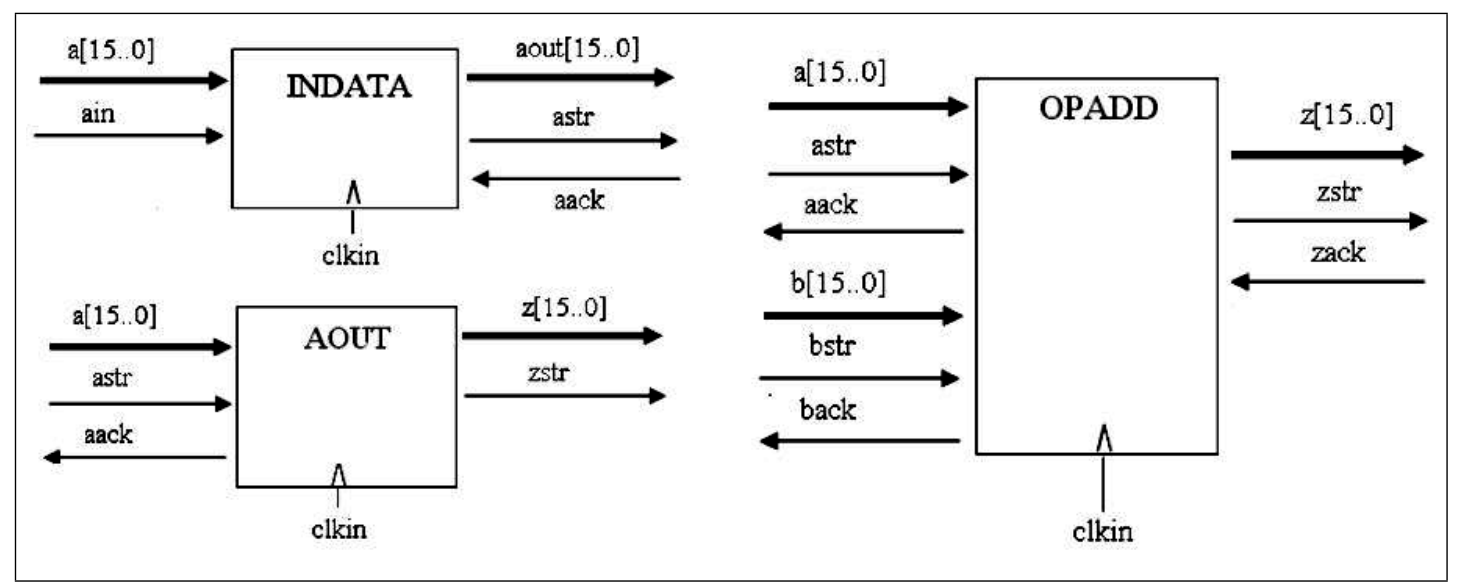

Figura 4.5: Blocos implementados para prova-de-conceitos para o protocolo dos operadores.

Então, para cada token de entrada, o protocolo de comunicação entre os operadores define que deve haver um par de sinais associados. Quando um token chega em um operador, um dos sinais vem do operador que enviou o token e serve para sinalizar que existe um novo token naquela entrada. $\mathrm{O}$ outro sinal então é utilizado para que o operador consumidor do token avise ao operador produtor que já recebeu adequadamente o token. Quando o token sai de um operador, o protocolo funciona de maneira análoga. Em outras palavras, este protocolo funciona como um handshake entre os operadores para cada token que deve ser enviado.

A Figura 4.6 apresenta o grafo com três operadores de soma implementados em (SILVA and MARQUES, 2006) para validar o protocolo de comunicação entre os operadores.

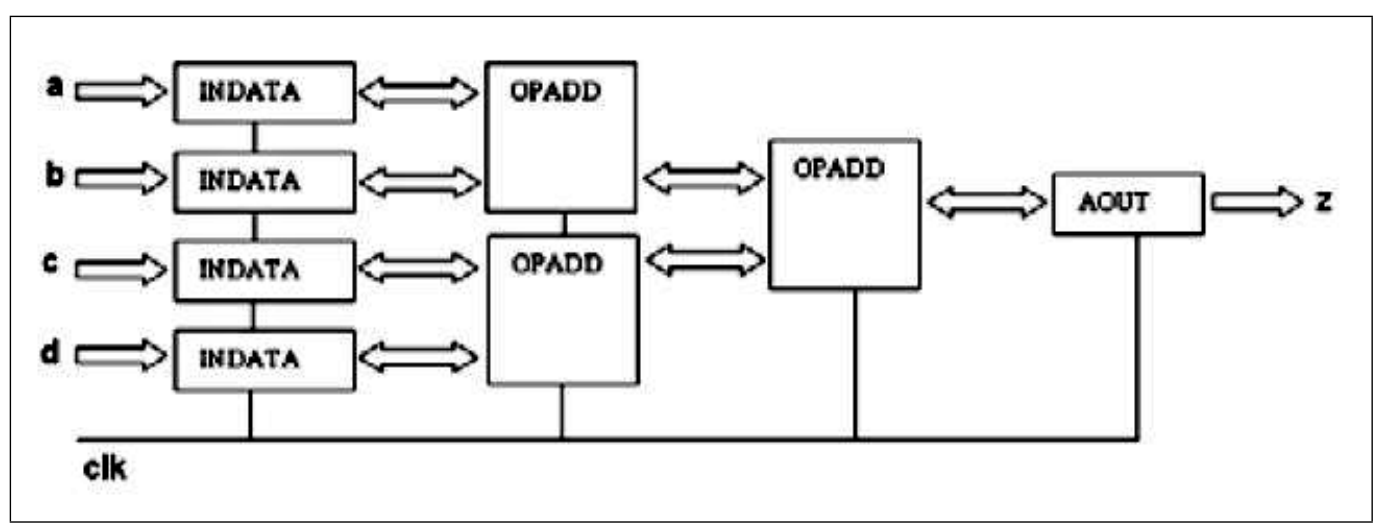

Figura 4.6: Grafo implementado para validar o protocolo dos operadores. 


\subsubsection{Modelo tagged-token}

Para permitir uma maior exploração do paralelismo, o fluxo de dados do ChipCflow é dinâmico e utiliza tagged-tokens. Cada token circulando pelos canais de comunicação possui, além do dado propriamente dito, sua tag. O formato da tag na proposta inicial do projeto ChipCflow é o mesmo descrito em (SILVA, 1992). Para cada execução de um programa é gerada uma tag representando uma ativação. Cada vez que se executa uma função, procedimento ou loop, uma nova tag é gerada e concatenada juntamente com o dado e suas tags anteriores. Para cada iteração do loop, a tag deve ser ajustada para indicar uma nova iteração. Como pode haver loops aninhados, é útil que a tag também contenha o nível de aninhamento. Ao final de um programa, função ou procedimento a parcela correspondente da tag é destruída. Segue abaixo o formato de um token no software a fluxo de dados do CPER.

$$
\begin{gathered}
\operatorname{tag}=<\text { nivel_de_aninhamento.ativacao.iteracao }> \\
\text { tag_anterior }=<\text { tag.tag....tag }> \\
\text { token }=<\text { tag.tag_anterior }, \text { dado }>
\end{gathered}
$$

Porém, implementar em hardware a concatenação das tags novas com as antigas não é tão simples quanto em um software ou em um simulador. Detalhes da implementação deste modelo em hardware reconfigurável não foram apresentados nesta proposta inicial.

Os operadores propostos para manipulação das tags no projeto ChipCflow são: New Tag Manager (NTM), New Iteration Generator (NIG) e New Tag Destructor (NTD). O funcionamento correto das construções iterativas (loops) só é garantido se o seu início ocorre somente quando todos os tokens de entrada do loop estão disponíveis (SILVA, 1992). Dessa forma, é possível gerar uma tag nova para todos os tokens que entram na estrutura e que possuem o mesmo tag anterior. O bloco responsável por gerar uma nova tag a um conjunto de dados e devolver esta tag ao conjunto de tags disponíveis é o New Tag Manager. O bloco responsável por ajustar a tag a cada iteração de um loop é o New Iteration Generator. O bloco New Tag Destructor elimina dos dados de saída a tag recebida pelo New Tag Manager e devolve ao bloco New Tag Manager. Na Figura 4.7 há um exemplo de um DFG com os construtores iterativos.

Além destes operadores específicos para gerenciar a criação, modificação e destruição das tags, existe ainda um modelo que é responsável por criar e destruir novas instâncias de um operador específico. Tal modelo é chamado de modelo de instâncias e o mesmo será detalhado a seguir. 


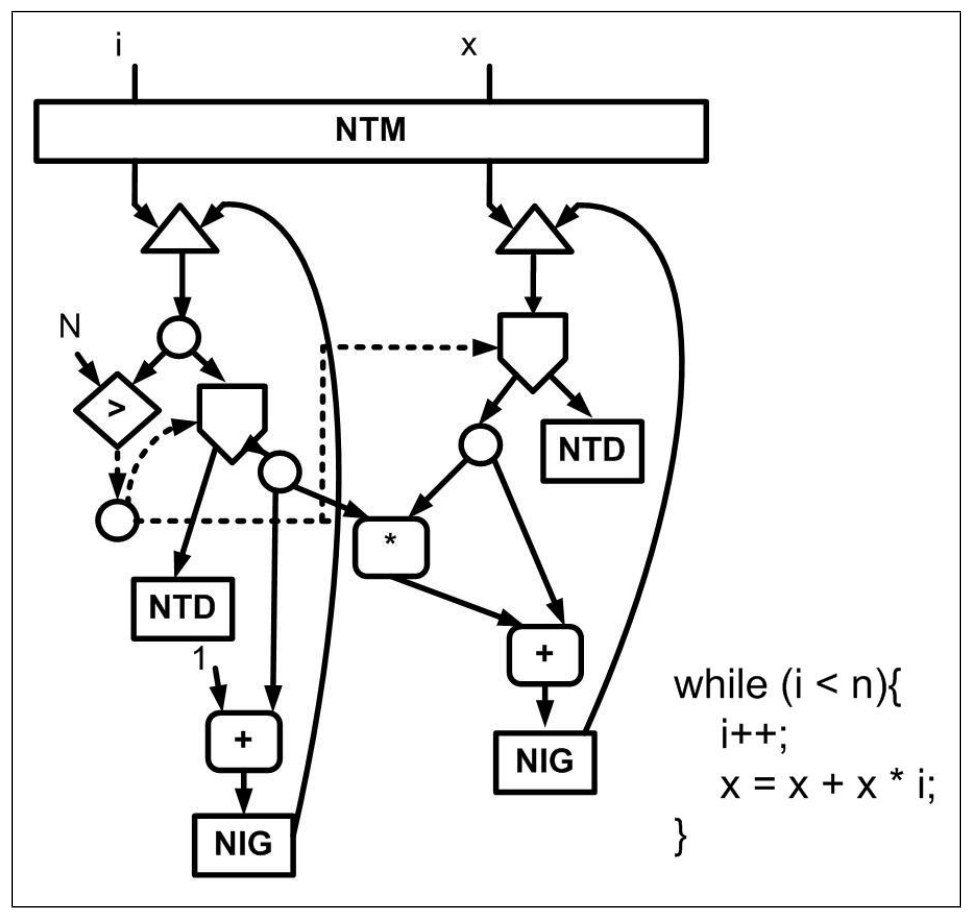

Figura 4.7: Construtores iterativos

\subsubsection{Instâncias dos operadores}

Como o modelo a fluxo de dados escolhido para o ChipCflow é o dinâmico, que permite a existência de mais de um dado por arco, a implementação do modelo é tal que novas instâncias dos operadores são geradas para cada dado que chegue em um mesmo arco. Assim, várias instâncias de um operador podem ser geradas, esperando por dados parceiros.

No modelo de instâncias, quando um token chega a um operador, e já existe um dado neste operador ou nas instâncias já criadas que não é seu parceiro, uma nova instância é criada para que esse token seja consumido. Dessa maneira, várias instâncias dos operadores podem ser criadas, cada uma esperando por seus parceiros, para posterior execução.

Na Figura 4.8, é descrita uma expressão que poderia estar dentro de um loop. Supondo que várias iterações do loop pudessem ser executadas paralelamente, vários tokens poderiam, por exemplo, chegar no operador de multiplicação que envolve a variável z. Dados com a mesma tag são chamados de dados parceiros e fazem parte de uma mesma iteração. Se os tokens da primeira iteração ainda estão sendo processados no operador quando chegar tokens da segunda iteração, o modelo de instâncias define que uma nova instância deve ser reconfigurada dinamicamente no FPGA para que os tokens da segunda iteração consigam executar paralelamente aos da primeira, e assim deve acontecer com todas as iterações.

Em termos de DFG, o modelo de instâncias nada mais é do que um pro- 


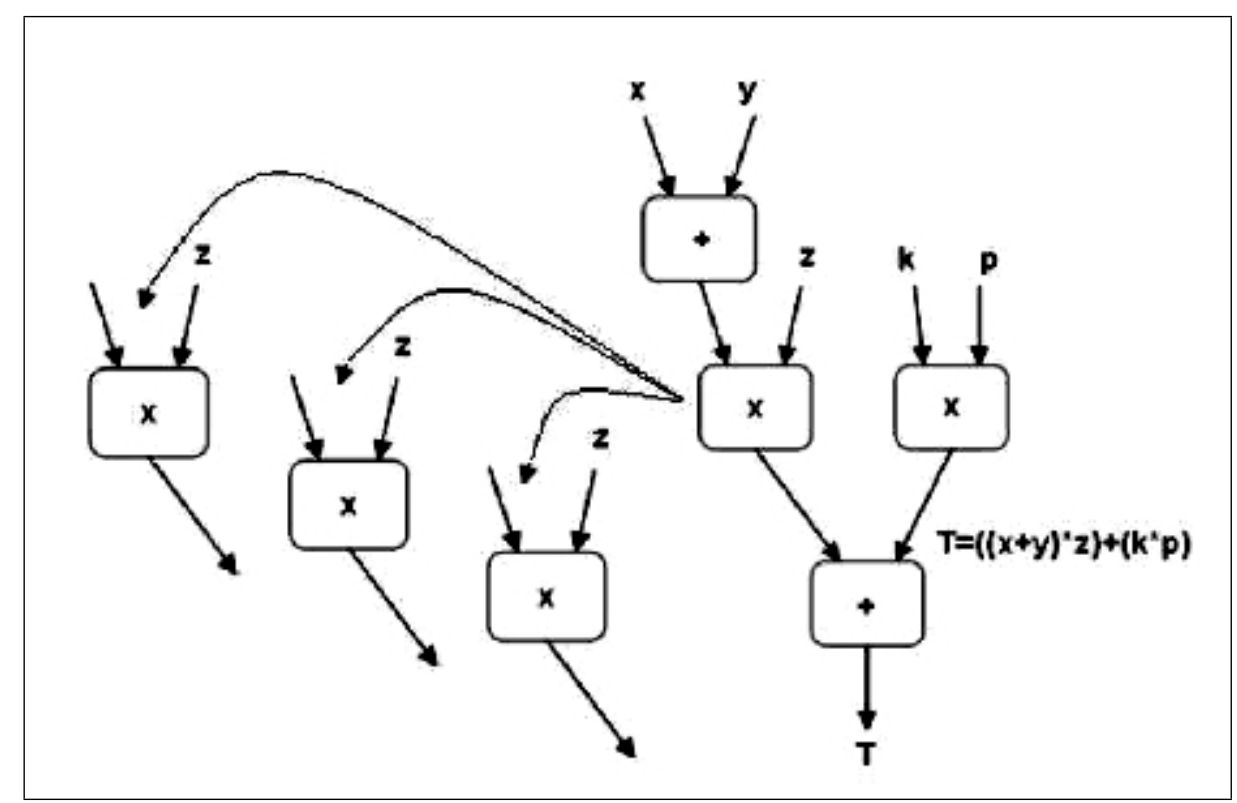

Figura 4.8: Instâncias diferentes para um operador *

cesso para inserir e remover subgrafos de um grafo. Para inserir um subgrafo é necessário saber onde os arcos desse subgrafo serão ligados e para remover o subgrafo precisa-se saber quais ligações serão desfeitas. Um subgrafo de um operador é concatenado tendo como pontos de concatenação os mesmos pontos de entrada e saída (arcos de dados) do operador. Dessa forma, as novas instâncias são ligadas paralelamente aos operadores originais.

Tão logo uma instância de um operador execute sua operação e envie o resultado, ela poderá ser destruída. Assim o modelo de instâncias remove a instância replicada de um operador.

Para que os dados executem nas instâncias corretas, com seus dados parceiros, deve-se verificar qual a tag dos dados e direcioná-los para a instância correta. A estrutura Matching de dados faz exatamente isso conforme será apresentado na seção seguinte.

\subsubsection{Unidade de matching}

A proposta inicial da unidade de matching foi feita em (SILVA, 2006). Seu objetivo é identificar os dados parceiros, a partir das tags de cada dado, que serão manipulados em alguma instância de um operador e sincronizá-los. O matching é acionado assim que um dado chega a um operador.

Com o intuito de acelerar o processo de matching, cada instância de um operador possui um circuito próprio para realizar o matching. Dessa forma, quando um dado chega a um operador, todas as instâncias verificam simultaneamente se aquele dado deve ser executado nela. Se uma instância possui um dado com a mesma tag, ela recebe o dado e caso já possua todos os dados 
necessários, realiza a operação e seus dados são retirados. Mas se não houver nenhuma instância com aquele dado, uma nova instância será criada para receber tal dado, que ficará a espera de seus dados parceiros.

Existe uma variável em cada operador que é usada para indicar se alguma instância recebeu o dado. Se nenhuma instância alterar o valor da variável, significa que não havia parceiros desse dado que chegou e uma nova instância deverá ser criada.

Os operadores básicos que possuem matching de dados são: branch, operator e deterministic merge, pois possuem mais de uma estrada. Tokens que não precisam de matching são enviados diretamente para o processamento dentro do operador. Tais tokens são chamados de by-pass.

Um circuito simples foi implementado em (SILVA, 2006) para identificar dados parceiros a partir da comparação de suas tags, porém sem instâncias. Como cada operador possui seu próprio circuito de matching de dados, as operações de matching dos diversos operadores podem ocorrer simultaneamente durante a execução do grafo.

\subsubsection{O compilador C para VHDL}

Os passos fundamentais do compilador da ferramenta ChipCflow podem ser divididos em dois: conversão de um código escrito em $\mathrm{C}$ em uma representação intermediária de um grafo a fluxo de dados e; conversão da representação intermediária em VHDL.

O primeiro passo de tradução do código em $\mathrm{C}$ para o modelo a fluxo de dados é uma pré-compilação que realiza análise léxica e sintática. Após essas análises, é gerado um grafo simbólico de dependências. Esse grafo é transformado em uma representação intermediária, que é o próprio grafo a fluxo de dados. O segundo passo tem como entrada o grafo do passo anterior e monta o código em VHDL utilizando módulos já pré-implementados dos operadores básicos da arquitetura ChipCflow.

\subsubsection{Considerações sobre a proposta inicial do projeto ChipC- flow}

Como foi apresentado nesta seção, alguns trabalhos prévios haviam sido realizados, porém, entre a proposta inicial e a implementação de alguns itens da proposta, realizados pelo próprio Dr. Silva, muitas questões do modelo teórico do ChipCflow ainda precisavam ser investigadas. Eram elas: Implementação de um compilador C para VHDL; validar a reconfiguração parcial e dinâmica de FPGAs para implementar o modelo de instâncias; implementar uma versão dos operadores básicos para o modelo a fluxo de dados dinâmico; 
implementar a unidade de matching; implementar os tagged-tokens e os operadores para suas manipulações e organização da memória no fluxo de dados.

A próxima seção irá apresentar os trabalhos que já foram concluídos dentro do projeto ChipCflow.

\subsection{TRABALHOS CONCLUÍDOS}

Três trabalhos do projeto ChipCflow foram concluídos no ano de 2009 . Os operadores básicos do ChipCflow foram implementados em um fluxo de dados estático e testou-se a execução do algoritmo de Fibonacci por Correia em (CORREIA, 2009). O primeiro compilador construído para a ferramenta ChipCflow pode ser encontrado em (COSTA, 2009). Estudos foram realizados por Astolfi em (ASTOLFI, 2009) sobre o modelo de instâncias e a reconfiguração parcial e dinâmica dos FPGAs. Em 2010 e 2011, mais dois trabalhos foram concluídos sobre reconfiguração parcial e dinâmica para implementação do modelo de instâncias: (SANCHES, 2010) e (JÚNIOR, 2011).

Os detalhes destes cinco trabalhos serão apresentados a seguir.

\subsection{Operadores e grafo a fluxo de dados}

O trabalho desenvolvido em (CORREIA, 2009) teve como objetivo o desenvolvimento dos operadores de máquinas a fluxo de dados propostos no projeto ChipCflow e sua execução em hardware por meio da implementação de grafos a fluxo de dados estáticos. Para poder executar os operadores em hardware foram construídos manualmente grafos a fluxo de dados estáticos e implementados na ferramenta ISE 8.2i da Xilinx.

Todos os seis operadores básicos foram implementados: branch, deterministic merge, non deterministic merge, decider, copy e operator. Os operadores foram implementados por meio de uma máquina finita de estados e em seguida convertidos para VHDL.

O estado inicial para cada operador é responsável em receber os dados de entrada do operador. Uma vez que os dados estão presentes, a execução acontece. Por fim, o resultado é enviado para a saída do operador. Os dados que circulam pelos operadores possuem 16 bits.

Os operadores seguem o protocolo de comunicação handshake como proposto em (SILVA and MARQUES, 2006). Todos os operadores possuem sinais de strobe (str) associados aos sinais de saída de dados. A função deles é indicar que os sinais de saída de um operador estão disponíveis para que o operador de destino os consuma. Os operadores também possuem sinais de reconhecimento (ack) cuja função é confirmar o recebimento de um dado ao operador que o produziu. Embora todos os operadores possuam sinais de clock, neste 
caso o clock é utilizado apenas para sincronismo interno diferentemente do que foi feito em (ASTOLFI and SILVA, 2007). Dessa forma, do ponto de vista macro, os operadores se comunicam de forma assíncrona.

Como exemplo, o operador de soma implementado é descrito na Figura 4.9.

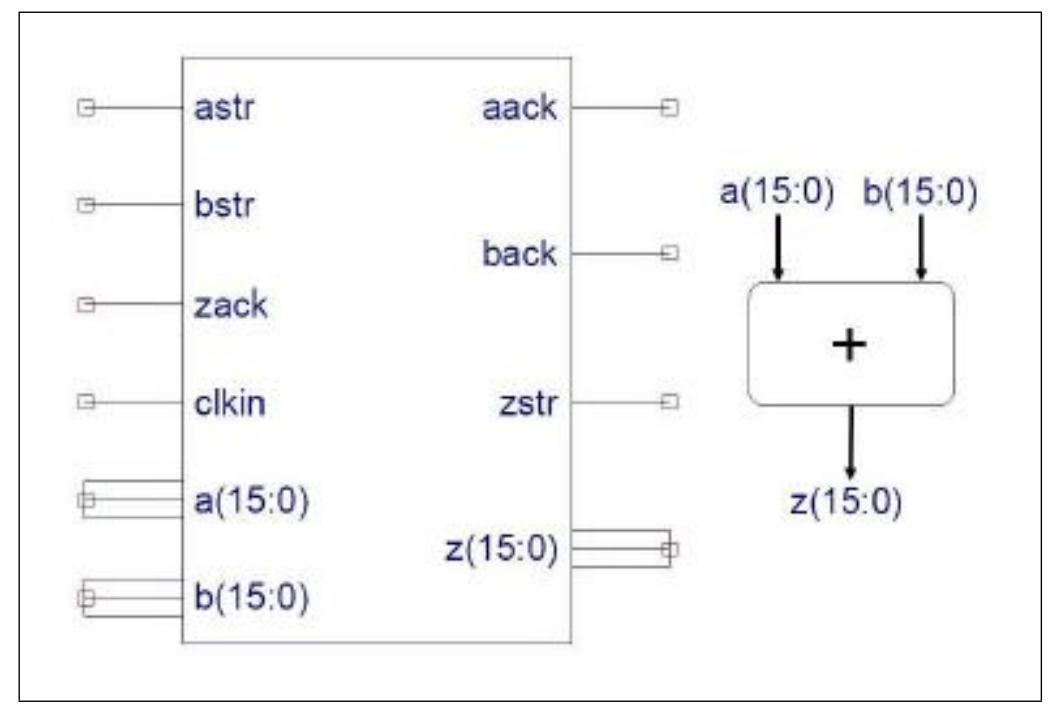

Figura 4.9: Diagrama Esquemático de um operador do ChipCflow

Conforme a Figura 4.9, o operador possui seis entradas astr, bstr, clkin, $a(15: 0), b(15: 0)$ e zack. O astr e bstr são usados para indicar ao operador atual que tem dado chegando através da entrada $a(15: 0)$ ou $b(15: 0)$, respectivamente. O clkin é um clock interno para o operador.

O operador tem quatro sinais de saída aack, back, zstr e z(15:0). O aack e back são usados para indicar ao operador prévio que o operador atual recebeu os dados através das entradas $a(15: 0)$ ou b(15:0), respectivamente. O zstr é usado para indicar ao próximo operador que um dado está sendo enviado para a sua entrada.

O trabalho também apresenta a implementação em hardware das construções if-else, while, switch, for e do-while utilizando a versão dos operadores implementados. Por fim, o trabalho apresenta a implementação de um grafo a fluxo de dados estático para o algoritmo de Fibonacci.

Este trabalho foi a primeira contribuição para o projeto ChipCflow. No momento em que este trabalho foi concluído, o primeiro compilador para o ChipCflow também já estava em fase de conclusão e é descrito a seguir.

\subsubsection{Conversão C em grafo a fluxo de dados}

Costa (2009) descreve o desenvolvimento de um compilador C para VHDL para o ChipCflow utilizando fluxo de dados estático. A ferramenta traduz partes de códigos escritos em $\mathrm{C} / \mathrm{C}++$ para o modelo a fluxo de dados. As partes que são traduzidas são aquelas consideradas mais intensas de uma dada 
aplicação sob o ponto de vista do processamento. Esta etapa de tradução do código em $\mathrm{C}$ para o modelo a fluxo de dados é uma pré-compilação que realiza análise léxica e sintática. Após essas análises, é gerado um grafo simbólico de dependências. Esse grafo é transformado em uma representação binária, que é o próprio grafo a fluxo de dados. Um exemplo de cadeia de bits é descrito na Figura 4.10 para o programa descrito no Algoritmo 1.

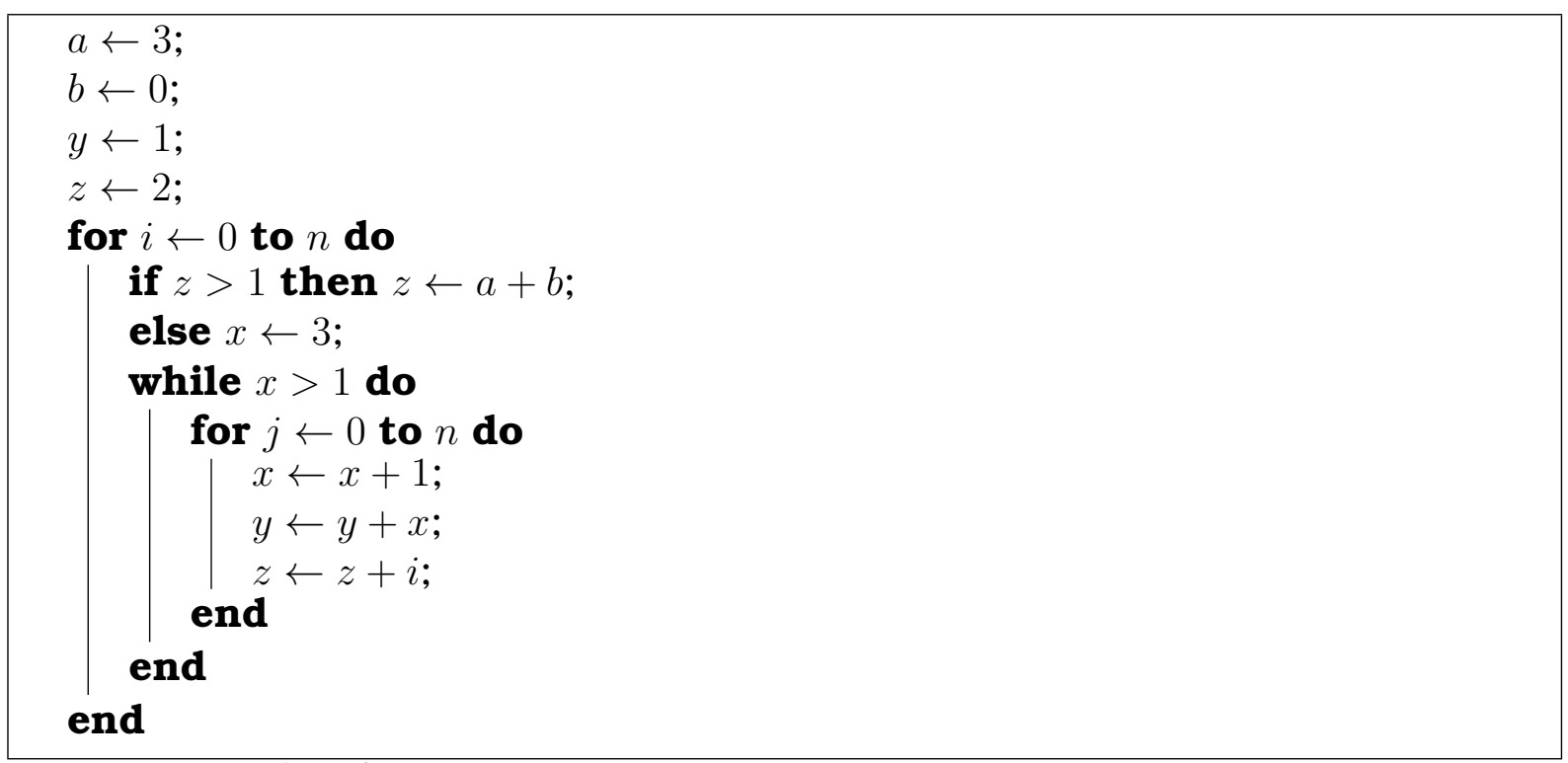

Algoritmo 1: Exemplo de código a ser compilado

Cada operador possui uma única sequência binária que o identifica e o mesmo ocorre com suas entradas e saídas. Tendo em mãos essa cadeia de bits que descreve o DFG, a etapa seguinte é transformar o DFG de binário para um código em VHDL. Para a montagem do código em VHDL, utilizam-se os operadores básicos do ChipCflow já previamente implementados. Finalmente, o hardware descrito em VHDL pode ser carregado em um FPGA para ser executado.

Para gerar o arquivo binário, foi definido um template para a cadeia de bits que representa um operador. A Figura 4.11 ilustra o template. Os primeiros quatro bits do pacote identificam o operador a fluxo de dados; os próximos três grupos de cinco bits identificam três entradas ( $a, b$ e $c$ ) do operador; e os dois últimos grupos de cinco bits identificam as duas saídas ( $s$ e $z$ ) do operador. Esta estrutura do pacote de bits é genérica, alguns operadores possuem menos entradas ou menos saídas (SILVA et al., 2009).

Como o próximo passo é transformar o arquivo binário em VHDL, um mapeamento é feito gerando as instâncias e suas interconexões que definem o código em VHDL correspondente ao grafo a fluxo de dados que será executado posteriormente na plataforma ISE da Xilinx.

Para o Algoritmo 1, temos o DFG como mostra a Figura 4.12.

Como mostra a Figura 4.12, o bloco representado na região 1 representa 


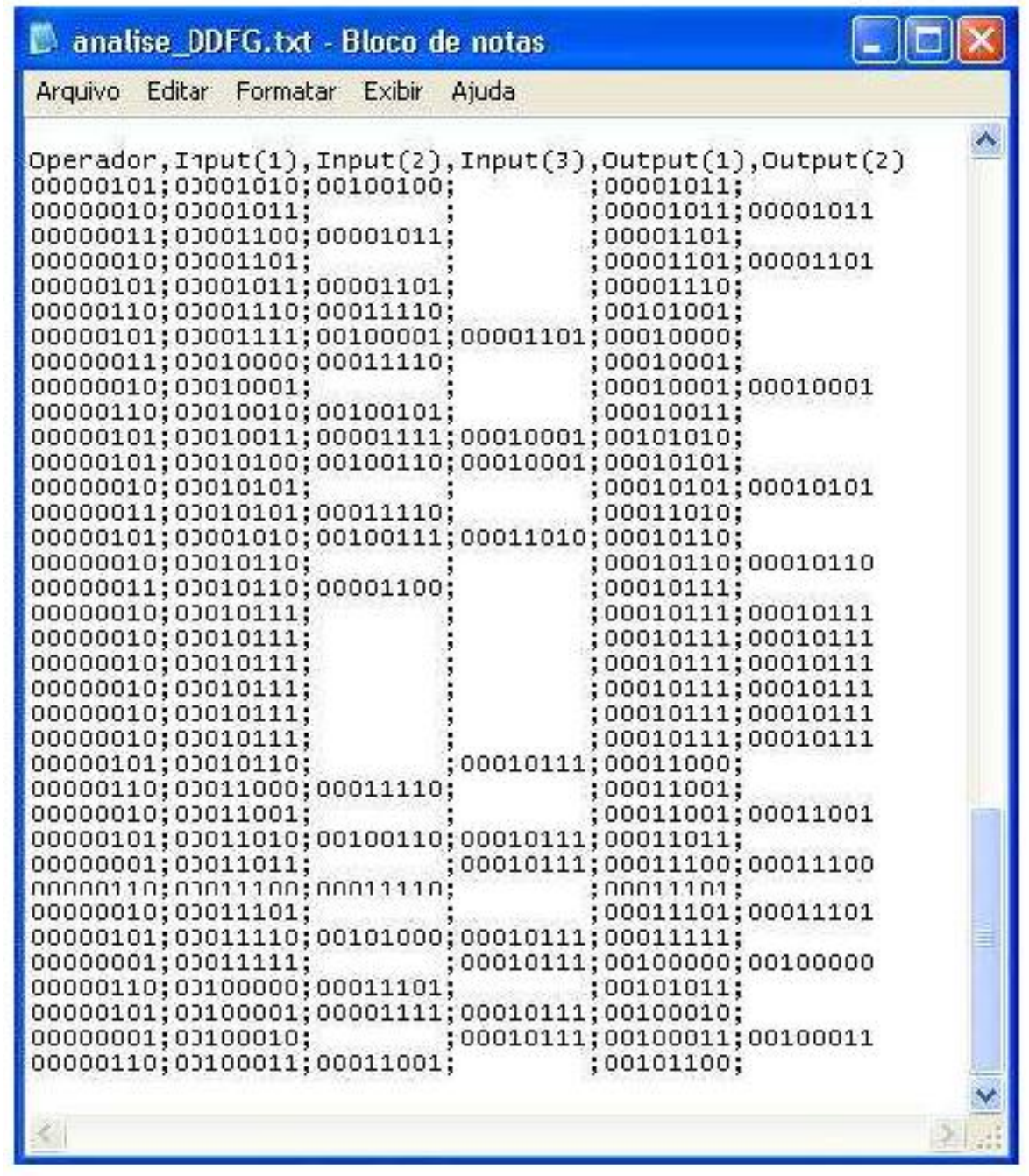

Figura 4.10: Representação em binário para o Algoritmo 1 


\section{\begin{tabular}{|l|l|l|l|l|l|}
\hline Operator & Input a & Input b & Input c & Output s & Output z \\
\hline
\end{tabular}}

Figura 4.11: Formato de uma linha no mapeamento binário.

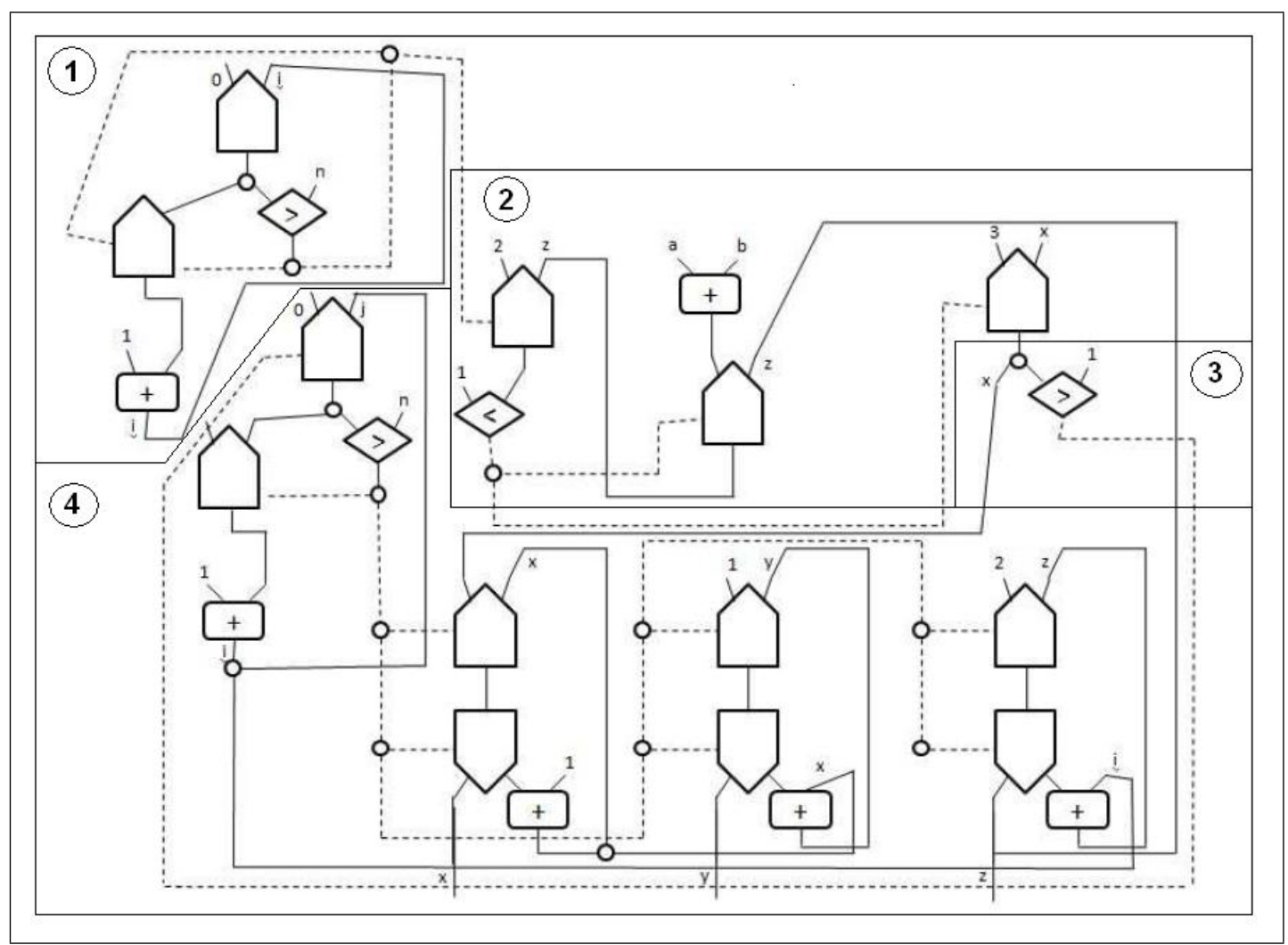

Figura 4.12: DFG para um algoritmo com IF, FOR e WHILE

o comando for mais externo do Algoritmo 1. A região 2 representa os comandos if-else, a região 3 representa o comando while e a região 4 representa o comando for interno ao comando while.

No último passo, que é a geração do código em VHDL, para o algoritmo mostrado temos o código em VHDL descrito na Listagem 4.1 e na Listagem 4.2 . 
Listagem 4.1: DFG em VHDL parte 1

library ieee; use ieee.std_logic_1164.a11; use

ieee.std_logic_arith.a11; use ieee.std_logic_signed.a11;

ENTITY circuito_final IS

port ( a : in std_logic_vector(31 downto 0$)$;

b : out std_logic_vector(31 downto 0$)$;

END;

ARCHITECTURE behavior OF circuito_final IS

Component merge_deterministic

port ( a: in std_logic_vector(31 downto 0$)$;

$\mathrm{b}$ : in std_logic_vector(31 downto 0$)$;

c: out std_logic_vector(31 downto 0$)$;

$z$ : out std_logic_vector(31 downto 0$)$

) ;

END Component;

Component copy

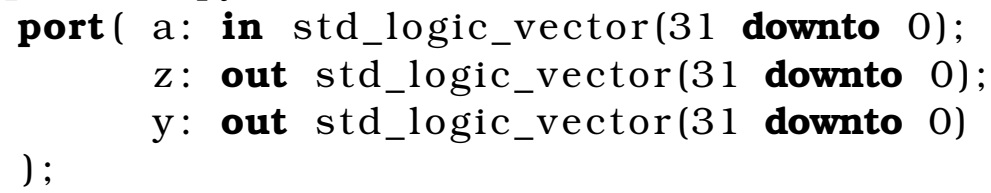

END Component;

Component decider

port ( $a$ : in std_logic_vector(31 downto 0$)$;

$\mathrm{b}$ : in std_logic_vector(31 downto 0$)$;

$z$ : out std_logic_vector(31 downto 0$)$

);

END Component;

Component operator

port ( a: in std_logic_vector(31 downto 0$)$;

b: in std_logic_vector(31 downto 0$)$;

$z$ : out std_logic_vector(31 downto 0$)$

);

END Component;

Component branch

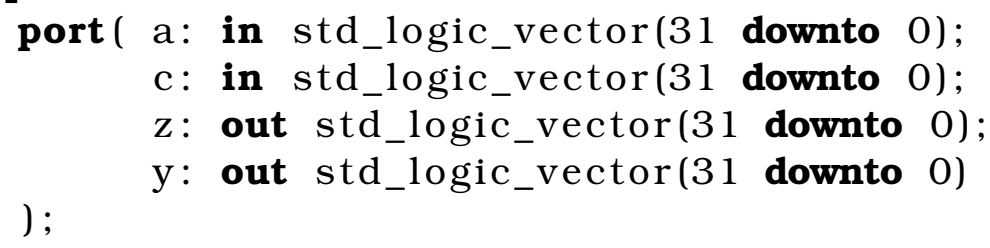

END Component;

signal i10, i36, i12, i30, i15, i33, i18, i37, i20,

i38, i39, i40, i11, i13, i14, i41, i16, i17, i19, i42,

i2 $1, \mathrm{i} 26, \mathrm{i} 22, \mathrm{i} 23, \mathrm{i} 24, \mathrm{i} 25, \mathrm{i} 27, \mathrm{i} 28, \mathrm{i} 29, \mathrm{i} 31, \mathrm{i} 32$,

i 43 , i34, i35, i44, i 111 , i 112 , i 131, i 132, i 171, i 172 ,

i2 $11, \mathrm{i} 212$, i221, i222, i231, i232, i231, i232,

i231, i232, i231, i232, i231, i232, i231, i232, i251,

i252, i291, i292 : std_logic_vector(31 downto 0); 
Listagem 4.2: DFG em VHDL parte 2

BEGIN

ul: merge_deterministic port map (i10,i36,i11);

u2: copy port map (i11, i111,i112);

u3: decider port map (i12,i111,i13);

u4: copy port map (i13,i131,i132) ;

u5: merge_deterministic port map (i112,i131,i14);

u6: operator port map (i14, i30, i41);

u7: merge_deterministic port map (i15,ii33,i132,i16);

u8: decider port map (i16,i30,i17);

u9: copy port map (i17, i171, i172);

u10: operator port map (i18,i37,i19);

u11: merge_deterministic port map (i19,i15,i171,i42);

u12: merge_deterministic port map (i20,i38,i172,i21);

u13: copy port map (i21,i211,i212);

u14: decider portmap(i211,i30,i26);

u15: merge_deterministic port map (i10,i39,i26,i22);

u16: copy port map (i22, i22 1, i222);

u17: decider port map (i221,i12,i23);

u18: copy port map (i23, i231, i232) ;

u19: copy port map $(i 23, i 231, i 232)$;

u20: copy port map (i23,i231,i232);

u21: copy port map (i23,i231,i232);

u22: copy port map (i23, i231, i232);

u23: copy port map (i23, i231, i232);

u24: merge_deterministic port map (i222,i231,i24);

u25: operator port map (i24, i30,i25);

u26: copy port map (i25, i251,i252);

u27: merge_deterministic port map (i26,i38,i232,i27);

u28: branch port map (i27, i233, i28, i28);

u29: operator port map (i28, i30,i29);

u30: copy port map (i29,i291,i292);

u31: merge_deterministic port map (i30,i40,i234,i31);

u32: branch port map (i31, i235, i32, i32);

u33: operator port map (i32, i291,i43);

u34: merge_deterministic port map $(i 33, i 15, i 236, i 34)$;

u35: branch port map $(\mathrm{i} 34, \mathrm{i} 237, \mathrm{i} 35, \mathrm{i} 35)$;

u36: operator port map $(\mathrm{i} 35, \mathrm{i} 251, \mathrm{i} 44)$;

END behavior; 
Uma série de questões não foram tratadas no compilador devido a complexidade apresentada no seu desenvolvimento. Os operadores NTM, NIG e NTD não faziam parte do processo de conversão C para VHDL, consequentemente não havia manipulação de tagged-tokens e sendo assim, o código $\mathrm{C}$ era convertido em grafo a fluxo de dados estático sem utilizar reconfiguração parcial e dinâmica. O código VHDL foi sintetizado na ferramenta ISE da Xilinx sem erros de compilação.

\subsubsection{Instâncias em hardware parcialmente reconfigurável}

O objetivo do trabalho apresentado em (ASTOLFI, 2009) foi o entendimento e domínio do processo de reconfiguração parcial e dinâmica em FPGAs aplicado ao modelo de instâncias da ferramenta ChipCflow. Apresentou-se uma prova de conceitos para o modelo de instâncias, utilizando recursos oferecidos pela reconfiguração parcial dinâmica, e como resultado foram gerados os bitstreams necessários para a programação parcial do FPGA, no caso um FPGA Virtex II da Xilinx. Tão logo fosse possivel, esta estrutura seria integrada às diferentes partes da ferramenta ChipCflow.

Durante o desenvolvimento desse módulo do projeto, algumas restrições foram identificadas para que ocorresse a reconfiguração das instâncias dos operadores conforme a proposta inicial do projeto ChipCflow. Naquele momento, a restrição mais significativa foi a forma como deveria ocorrer a reconfiguração, que no caso do FPGA Virtex II e sucessores implicava na reconfiguração de vários CLBs por unidade reconfigurável, superando em muito a quantidade de CLBs atribuídas para uma única instância de um operador.

Em razão desta restrição, decidiu-se pela elaboração de partições do grafo a fluxo de dados, para que, em função da reconfiguração, toda uma partição, ocupando grande parte dos CLBs considerados mínimos para uma reconfiguração, fosse reconfigurada resolvendo assim boa parte da restrição descrita.

O modelo de partição e comunicação entre as partições é descrito a seguir.

\subsubsection{Partição e protocolo de comunicação em DFG dinâmico}

O trabalho apresentado em (SANCHES, 2010) objetivou a obtenção de um modelo para o particionamento dos grafos a fluxo de dados dinâmicos e de um protocolo de comunicação entre suas partes, a fim de permitir sua implementação em arquiteturas dinamicamente reconfiguráveis, em especial em FPGAs Virtex da Xilinx.

Neste trabalho é proposta uma maneira de se particionar um grafo e poder reconfigurá-lo dinamicamente no FPGA e conseguir executá-lo corretamente. Além disso é proposto também um modelo e protocolo de comunicação entre 
as partições e como configurá-las no hardware adequadamente.

A implementação e validação destes modelos propostos foi realizada por Souza Júnior e apresentada em (JÚNIOR, 2011). Foram apresentadas algumas avaliações de desempenho para verificar se o overhead causado pela estrutura de partição e protocolo não comprometeria o projeto ChipCflow como um todo.

Para fazer a análise do overhead da reconfiguração das partições verificouse o tempo de execução entre o fluxo de dados puramente estático do algoritmo de Fibonacci e o tempo da execução utilizando a reconfiguração. Segundo Souza Júnior em (JÚNIOR, 2011), em alguns casos, o tempo de execução com reconfiguração chegou a ser seis vezes maior do que o tempo sem reconfiguração.

\subsubsection{Considerações sobre os trabalhos concluídos}

O primeiro trabalho (CORREIA, 2009) mostrou a viabilidade de se implementar em hardware os grafos a fluxo de dados das principais construções das linguagens imperativas. Embora o fluxo de dados ainda fosse estático, já utilizava o protocolo de comunicação dos operadores viabilizando uma implementação localmente síncrona mas globalmente assíncrona. Já o segundo trabalho (COSTA, 2009) apresentou um compilador C para grafo a fluxo de dados estático e mostrou que a construção de um compilador que contemplasse todas as questões envolvidas no projeto ChipCflow é uma tarefa complexa. Os outros trabalhos já concluídos (ASTOLFI, 2009; SANCHES, 2010; JÚNIOR, 2011) trabalharam no modelo de instâncias e a reconfiguração parcial e dinâmica de FPGAs. A conclusão destes trabalhos é que o modelo de instâncias como proposto inicialmente é inviável com as tecnologias de reconfiguração atuais. A proposta e implementação do modelo partição também mostraram que, mesmo ao se reconfigurar subgrafos em vez de instâncias, a reconfiguração parcial continua sendo inviável. Estes resultados sugerem que seja elaborado para o projeto ChipCflow outro modelo para implementação das instâncias dos operadores.

As primeiras implementações utilizaram fluxo de dados estático e sua utilização foi bem sucedida. Por outro lado, os trabalhos que utilizaram fluxo de dados dinâmico se apoiaram na reconfiguração parcial e dinâmica de FPGAs, que se mostrou inviável. Portanto, o ChipCflow ainda não possui um modelo que de fato utiliza fluxo de dados dinâmico e que seja viável em dispositivos reconfiguráveis. Os trabalhos que estão em andamento trabalham justamente nas questões que ainda necessitam ser investigadas para que se chegue de fato a uma arquitetura a fluxo de dados dinâmica para o projeto ChipCflow. 


\subsection{TRABALHOS EM ANDAMENTO}

Nesta seção, uma breve explicação sobre cada trabalho em andamento será feita a fim de se contextualizar o trabalho desta dissertação.

Um trabalho está sendo desenvolvido para definir a arquitetura dos operadores do fluxo de dados dinâmico. Cada operador deve ser formado por: um sistema de intercomunicação; o circuito para a realização do matching de dados; instâncias; e o controle de execução das instâncias. Operadores com apenas uma entrada, se houver uma instância desocupada, o dado é simplesmente enviado para a instância vazia.

Quando um token chega em uma entrada, uma série de testes é feita com sua tag: se o token chega na entrada A, por exemplo, os registradores correspondentes das outras entradas são testados para verificar se estão vazios. Se sim, o token A é armazenado no registrador A. Por outro lado, se algum registrador que não seja o A esteja ocupado, a tag do token A é comparada com o token que já estava armazenado. Se eles são parceiros, poderão ser processados assim que todos os parceiros chegarem. Caso eles não sejam parceiros, o token A será encaminhado para outra instância deste mesmo operador, caso haja alguma instância desocupada. Caso todas as instâncias estejam ocupadas, o grafo seguirá o protocolo handshake, não mandando o sinal de ack para o operador que enviou o token A.

Em (SILVA and LOPES, 2010) foi apresentado um operador branch, sua estrutura interna para o fluxo de dados dinâmico e suas instâncias. A Figura 4.13 mostra o diagrama do operador. Vale ressaltar ainda que este operador foi implementado de forma totalmente assíncrona, o que permitiu um ganho substancial na velocidade de execução do operador e suas instâncias. Este trabalho está em fase final de implementação. Neste modelo, o número de instâncias é fixo e é definido pelo compilador. Portanto, este novo modelo não utiliza reconfiguração parcial e dinâmica do FPGA.

Outro trabalho está sendo realizado com o objetivo de propor uma organização de memória para a arquitetura ChipCflow, uma vez que nenhum dos trabalhos desenvolvidos até então tratou esta questão. O relacionamento entre o grafo a fluxo de dados e a memória se dá por meio de duas instruções: load e store. Considerando o Algoritmo 2, uma proposta de organização de memória para este algoritmo pode ser vista na Figura 4.14.

Nesta proposta de organização de memória, cada variável possui um banco de memória localizado acima do gerenciador de memória. O gerenciador de memória é o intermediário entre as solicitações de load e store e os bancos de memória. As instruções de load e store se comunicam com o grafo a fluxo de dados solicitando e recebendo dados. 


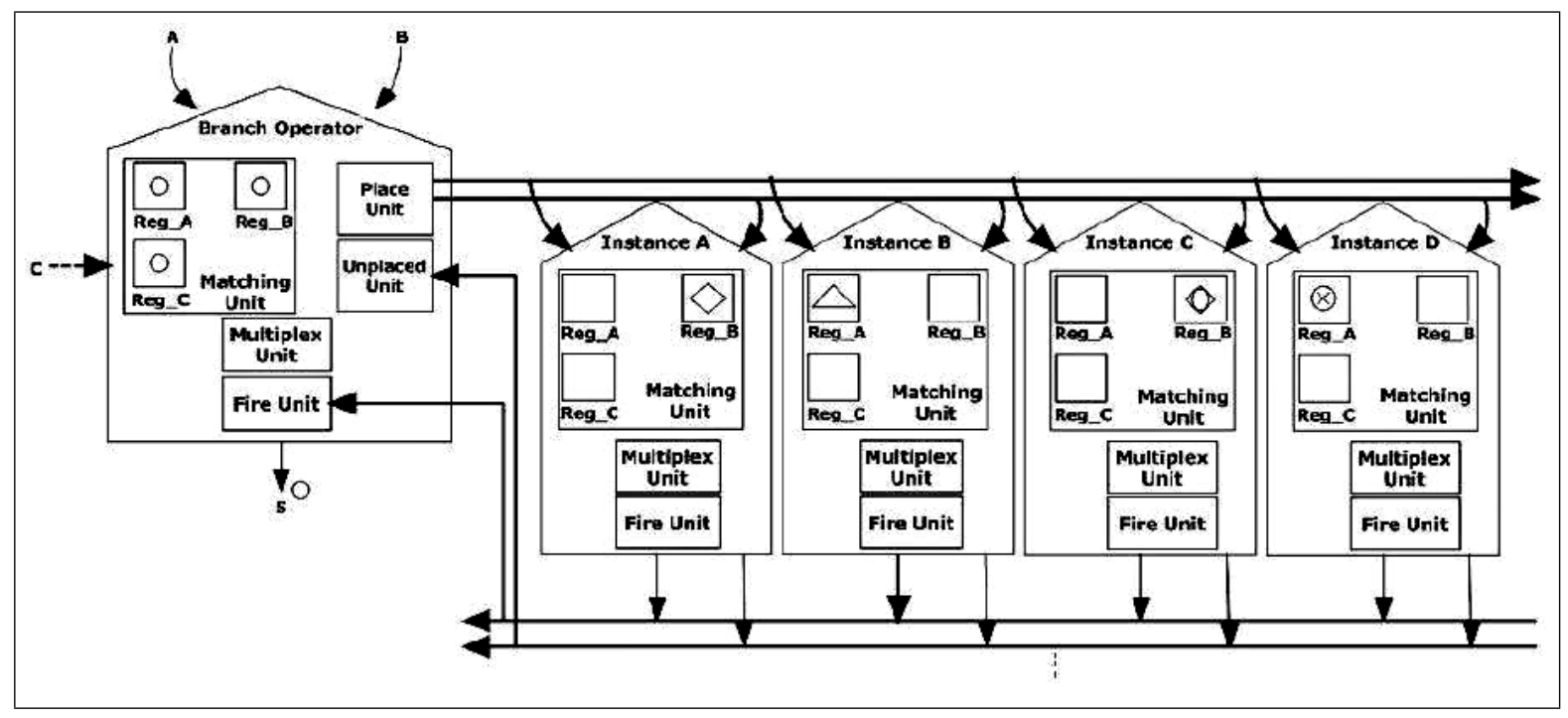

Figura 4.13: Operador branch e suas instâncias.

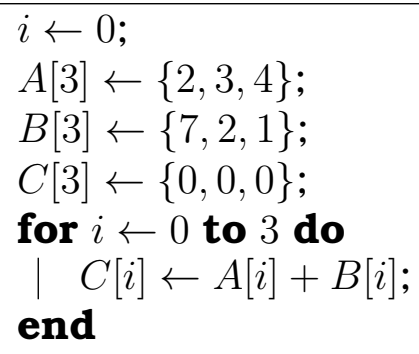

Algoritmo 2: Soma de vetores elemento por elemento

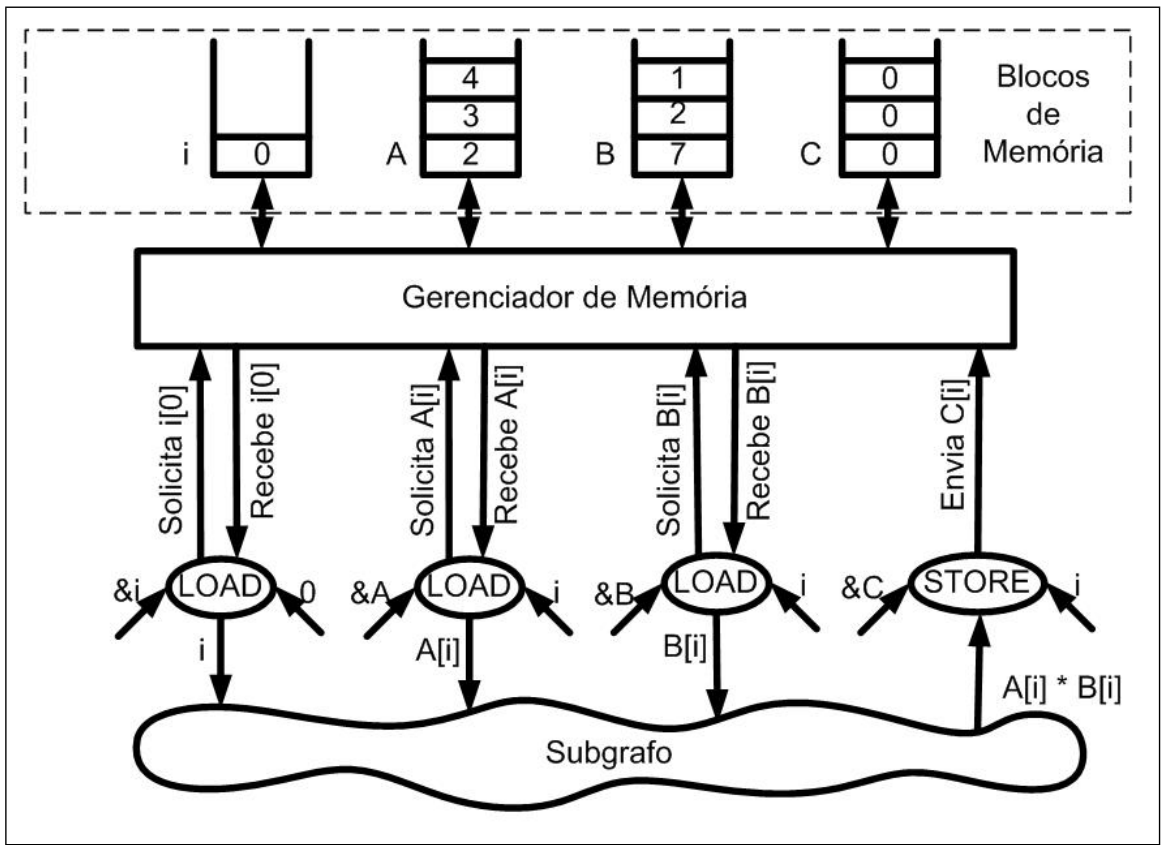

Figura 4.14: Modelo para gerenciamento de memória. 
A figura apresentada mostra um modelo teórico para as instruções de load e store. Segundo este modelo, a instrução de load recebe como entrada o endereço base da variável, representado por $(\& i, \& A, \& B$ ) na Figura 4.14; o deslocamento representado na Figura 4.14 como $(0, i)$, que pode ou não ser definido em tempo de execução pelo algoritmo; um canal para solicitar ao gerenciador o dado, na Figura 4.14 representado por (Solicita $i[0]$, Solicita $A[i]$, Solicita $B[i]$ ); um canal para receber este dado do gerenciador, na Figura 4.14 representado por (Recebe $i[0]$, Recebe $A[i]$, Recebe $B[i]$ ) e; um canal para devolver o dado lido para o grafo, representado na Figura 4.14 por (i, $A[i], B[i])$. Já o operador store recebe o dado que deverá ser armazenado em memória, na Figura 4.14 representado por $A[i] * B[i]$; o endereço base para armazenamento, na Figura 4.14 representado por $\& C$; o deslocamento, na Figura 4.14 representado por $i$ e; um canal para solicitar o armazenamento ao gerenciador, na Figura 4.14 representado por Envia $C[i]$. Estes operadores também seguem o protocolo de comunicação definido para os outros operadores.

Neste caso apresentado, quando matrizes de mais de uma dimensão necessitam utilizar operações de load e store, o cálculo do deslocamento deve ser feito no próprio grafo a fluxo de dados. Este fato introduz mais operadores no grafo e mais sinais de handshake gerando um atraso na execução. Portanto, para fins práticos, foi definido que os programas tratados pelo ChipCflow manipularão dados de até duas dimensões, apenas como provade-conceito. Sendo assim, uma versão mais específica para as instruções de load e store foi proposta e são ilustradas na Figura 4.15. Esta versão já calcula o deslocamento dentro do próprio operador, eliminando a necessidade de handshakes extras.

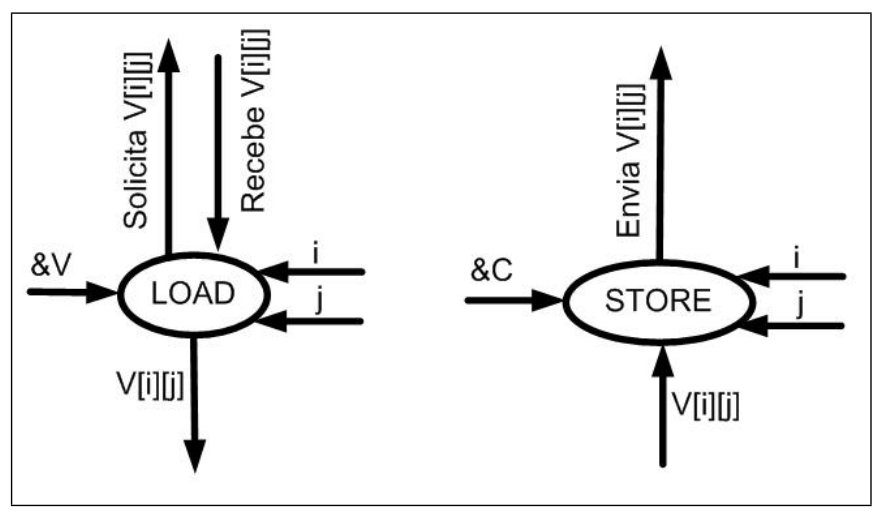

Figura 4.15: Formato das instruções load e store.

Embora não apareça na figura, todos os sinais, exceto o endereço base da variável, possuem o par de sinais para o protocolo de comunicação. O valor do endereço base é uma constante gerada pelo compilador ao criar o grafo a fluxo de dados. 
Quanto ao compilador, uma nova versão está sendo desenvolvida para o projeto ChipCflow. Este compilador será um compilador para fluxo de dados dinâmico, diferente do que já foi proposto. As principais diferenças entre o compilador estático para o compilador dinâmico estão nos operadores básicos, pois a implementação destes é consideravelmente diferente da implementação estática. Além disso, no compilador para fluxo de dados dinâmico pretendese utilizar uma representação intermediária baseada em mnemônicos em vez de código binário. A representação mnemônica possui uma série de vantagens sobre a binária (utilizada na primeira versão do compilador). Pode-se destacar: maior facilidade para entender o código gerado; facilidade para definir nomes de sinais mais intuitivos no código VHDL; facilidade para encontrar constantes e seus valores na representação; flexibilidade para definir diferentes tipos de vetores, constantes e variáveis; permite definição de labels e consequentemente a divisão do código em funções e procedimentos e permite que o grafo seja particionado na linguagem intermediária caso seja necessário fazer algum tipo de particionamento.

A representação mnemônica é semelhante a um código em assembly. Porém, neste caso a representação mnemônica representa um grafo a fluxo de dados em vez de representar um conjunto sequencial de instruções. Na Figura 4.16 é descrito um código em mnemônicos juntamente com seu respectivo DFG (SILVA, 2010).
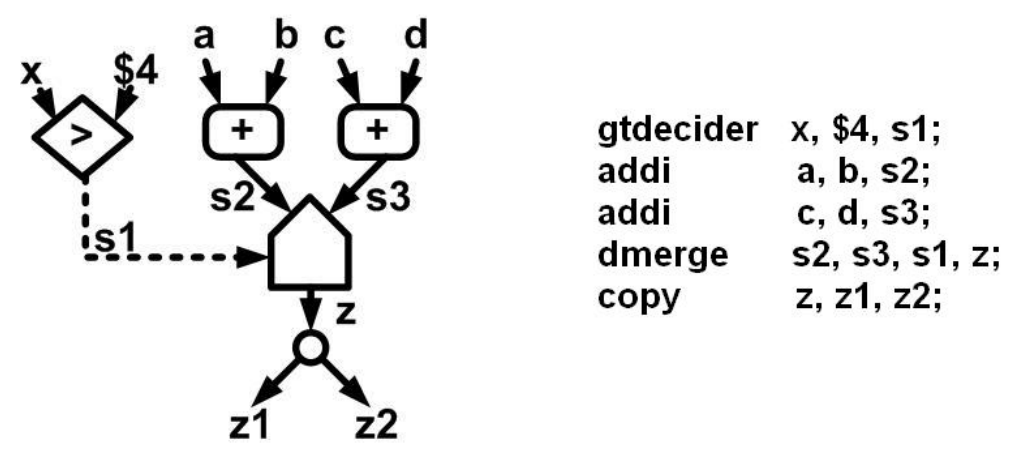

Figura 4.16: Mnemônico e DFG de uma construção condicional.

O compilador irá gerar um arquivo contendo o código na representação intermediária para em seguida convertê-lo em linguagem VHDL. Juntamente com essa descrição em VHDL, o compilador deverá gerar a estrutura de memória, também em VHDL, necessária para a aplicação compilada. Ou seja, o compilador irá definir a organização dos bancos de memória de acordo com a capacidade do dispositivo e de acordo com resultado de análises de dependências do código. E o compilador também irá gerar um arquivo contendo os valores iniciais para as variáveis que serão carregadas na memória.

Outra questão que ainda não foi tratada em nenhum trabalho é a validação do formato das tags dos tokens e a implementação dos operadores de manipu- 
lação destas tags. Na tese do Dr. Silva, foram propostos um formato de tags e alguns operadores para manipulação. Porém, este modelo não foi testado e verificado na prática, nem mesmo nos trabalhos anteriores ao ChipCflow. O trabalho desta dissertação investigou justamente esta questão e será descrita no Capítulo 5.

\subsection{CONSIDERAÇÕES FINAIS}

Neste capítulo uma ampla explicação do projeto ChipCflow foi feita, começando em sua história, seguida pelos trabalhos já concluídos e finalizando com os trabalhos em andamento. Atualmente, pesquisas com o modelo a fluxo de dados dinâmico do ChipCflow estão sendo investigadas. O fluxo geral da ferramenta continua sendo o mesmo, porém o compilador para o fluxo de dados dinâmico deve utilizar os operadores dinâmicos para a construção do DFG. Além disso, mudanças estão sendo feitas na arquitetura ChipCflow, em particular no modelo de instâncias.

No caso desta dissertação, a contribuição está na definição e implementação do gerenciamento, manipulação e formato das tags dos tokens do ChipCflow baseado em fluxo de dados dinâmico. No fluxo da ferramenta ChipCflow, este trabalho se enquadra no desenvolvimento da arquitetura ChipCflow e na geração de alguns módulos específicos em VHDL. De acordo com o apresentado na Figura 4.17 que representa o fluxo da ferramenta ChipCflow já apresentado anteriormente, após a definição do formato dos tagged-tokens, este trabalho irá apresentar a implementação dos operadores para gerenciamento das tags (criação, modificação, destruição). Estes operadores passarão a fazer parte do conjunto de módulos previamente implementados em VHDL, Figura 4.17 (e), que serão usados durante a compilação para montar o código VHDL completo do grafo a fluxo de dados dinâmico. 


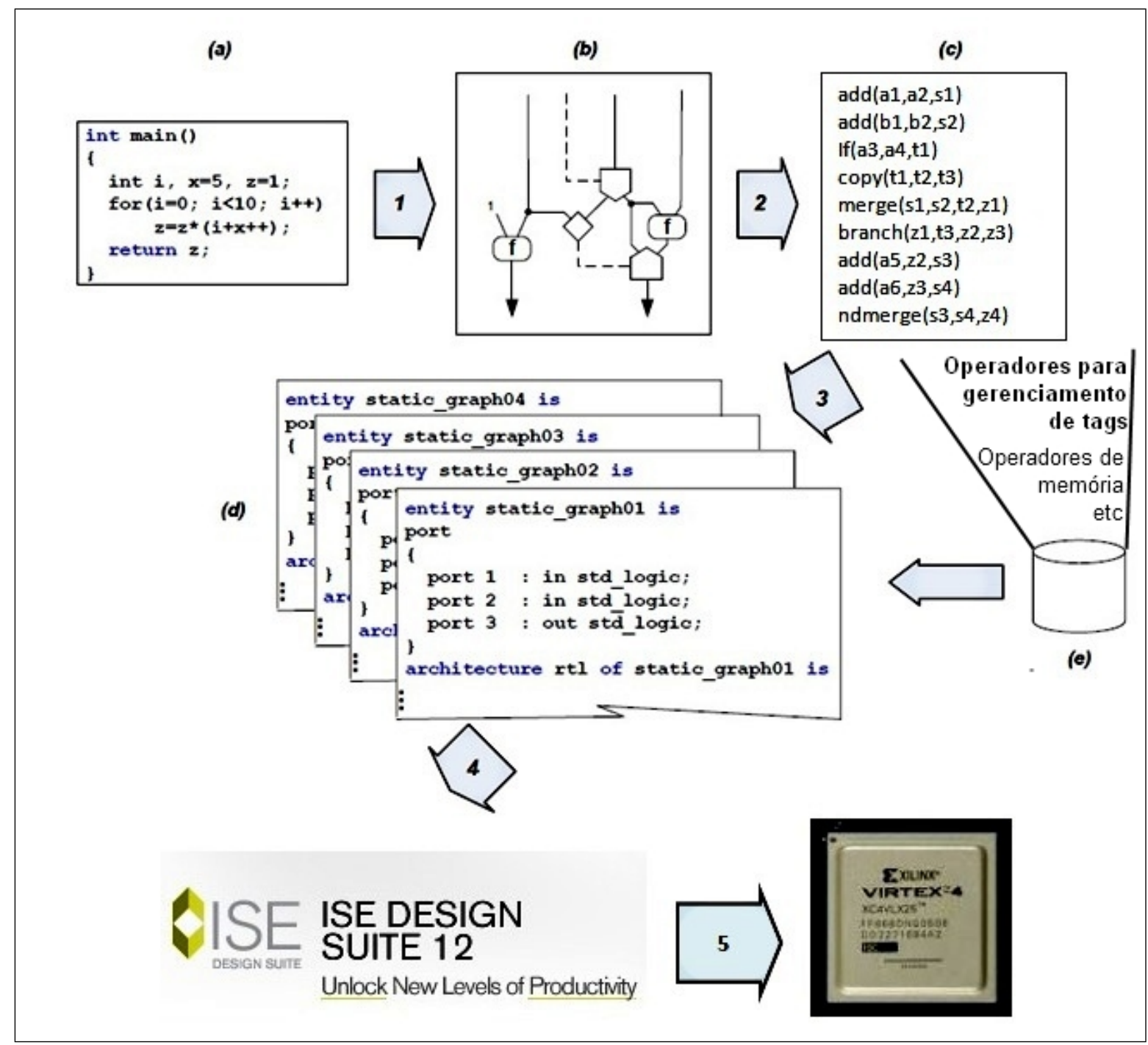

Figura 4.17: Objeto de estudo deste trabalho 


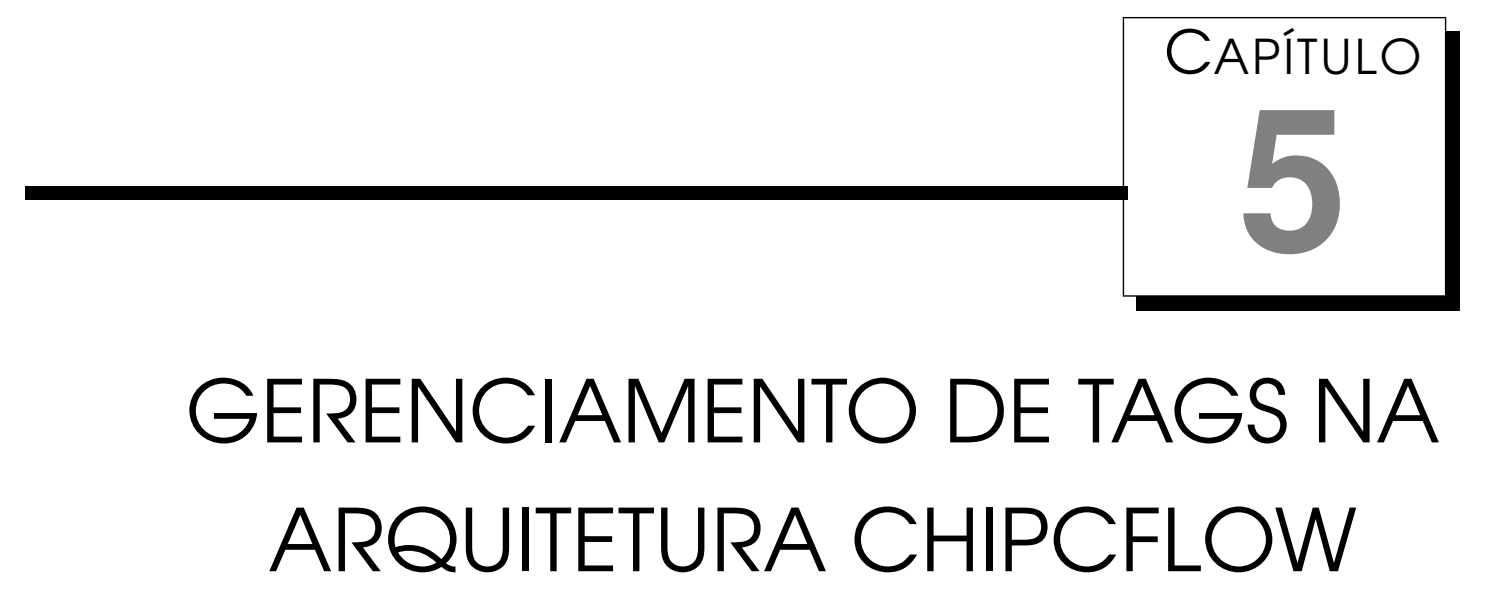

\subsection{CONSIDERAÇÕES INICIAIS}

Neste capítulo, é apresentado o desenvolvimento do trabalho desta dissertação. Inicialmente no texto é mostrada a necessidade da utilização de tagged-token na arquitetura ChipCflow e também quais informações devem fazer parte da tag. Logo em seguida, os operadores responsáveis por manipular e gerenciar as tags são descritos juntamente com um exemplo de um grafo a fluxo de dados utilizando todos os operadores. Finalmente, a implementação de cada operador, sua estrutura, simulação e testes de integração são apresentados.

\subsection{TAGGED-TOKEN NA ARQUITETURA CHIPCFLOW}

O modelo tagged-token para máquinas a fluxo de dados dinâmicas permite um maior paralelismo com relação a máquinas a fluxo de dados estáticas e ao mesmo tempo reaproveita partes de um mesmo grafo para as várias execuções, diferentemente do que ocorre ao se utilizar a técnica code copying. A ideia principal do modelo tagged-token é que a cada dado é associada uma tag e somente dados com a mesma tag são processados juntos em um determinado operador. Dados com a mesma tag são chamados de dados parceiros. Desta forma, a regra de disparo de um operador é a seguinte: um operador dispara somente quando todos os dados de entrada que possuem a mesma tag estão 
disponiveis nas suas entradas.

Dentro de um subgrafo referente a uma construção iterativa (loops, como for, while e repeat), dados de diferentes iterações podem circular ao mesmo tempo compartilhando os mesmos operadores. Considere o subgrafo $G_{1}$, mostrado na Figura 5.1. $G_{1}$ representa o código do for descrito de forma textual na figura. No modelo de execução a fluxo de dados, não se tem garantias sobre quanto tempo um dado vai levar para fluir através dos arcos do grafo. Supondo que $G_{1}$ recebeu tokens para suas entradas $i$ e $m$. Se a operação de multiplicação existente em $G_{1}$ levar muito tempo para executar, o lado esquerdo do grafo irá gerar vários valores para os arcos i_mult e decisão. Como os operadores ligados a estes arcos saberão qual valor recebido deverá ser utilizado para realizar os cálculos? Por exemplo, a última iteração de $i$ irá gerar um valor FALSE no arco decisão. Se o operador branch ligado a este arco aceitar este valor antes de realizar os cálculos das multiplicações, o resultado $m \_$final será produzido precipitadamente e o resultado final gerado estará errado. É necessário saber a qual iteração um dado pertence. Portanto, para que os dados sejam diferenciados, a primeira informação que a tag deve ter diz respeito a qual iteração de um loop um dado pertence em um determinado instante.

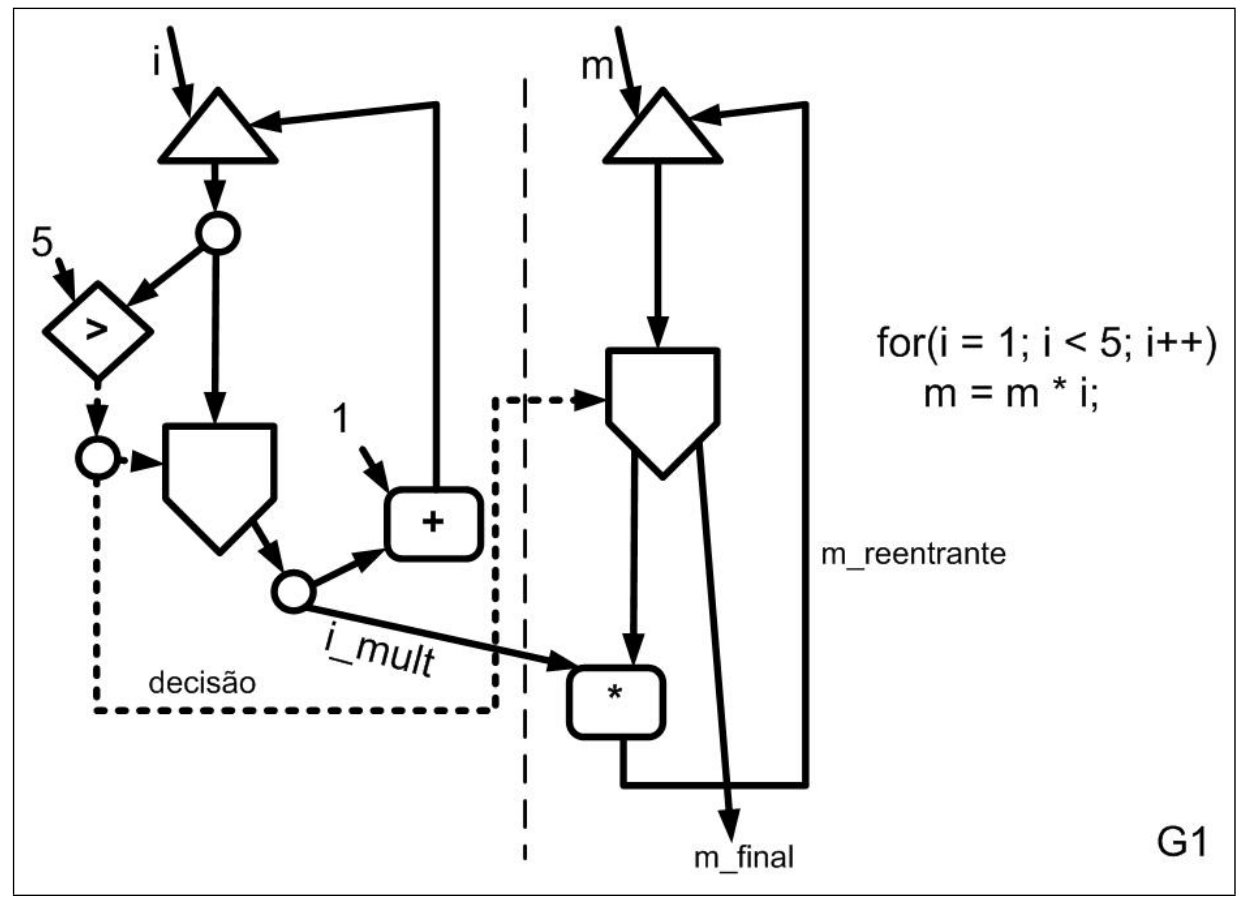

Figura 5.1: Exemplo de um grafo de uma construção iterativa.

Considere que este mesmo subgrafo $G_{1}$ esteja aninhado a outro for, como mostra a Figura 5.2. Qualquer construção iterativa (assim como qualquer grafo ou subgrafo) vista como uma "caixa preta", possui suas $x$ entradas e $y$ saídas. Cada entrada representa um dado que é utilizado para iniciar o processamento que é feito na construção iterativa e cada saída representa 
o resultado após o processamento dos dados de entrada. Um conjunto de entradas é definido como o conjunto de todos os dados das $n$ entradas do grafo necessários para a realização de algum processamento. Por exemplo, $i$ e $m$ são entradas de $G_{1}$. Se, para a primeira execução da construção iterativa, chegar na entrada $i$ um dado com valor igual a 1 e na entrada $m$ chegar um dado com valor igual a 2 o conjunto de entradas será $e_{0}=\{1,2\}$ e o conjunto de saídas relacionado a $e_{0}$ será $s_{0}=\{48\}$, que é o valor gerado no arco de saída $m$ final após processar o conjunto de entradas $e_{0}$. Para cada conjunto de entradas $e_{i} \in E$ haverá um processamento e haverá também um conjunto de saídas $s_{i} \in S$ relacionadas a $e_{i}$, onde $E$ representa o conjunto de todas as entradas possiveis e $S$ o conjunto de todas as saídas relacionadas a todas as entradas possíveis. Uma construção iterativa (assim como qualquer grafo ou subgrafo) é considerada ativada quando recebe um conjunto de entradas. Durante a execução de um programa a construção iterativa poderá ser ativada diversas vezes.

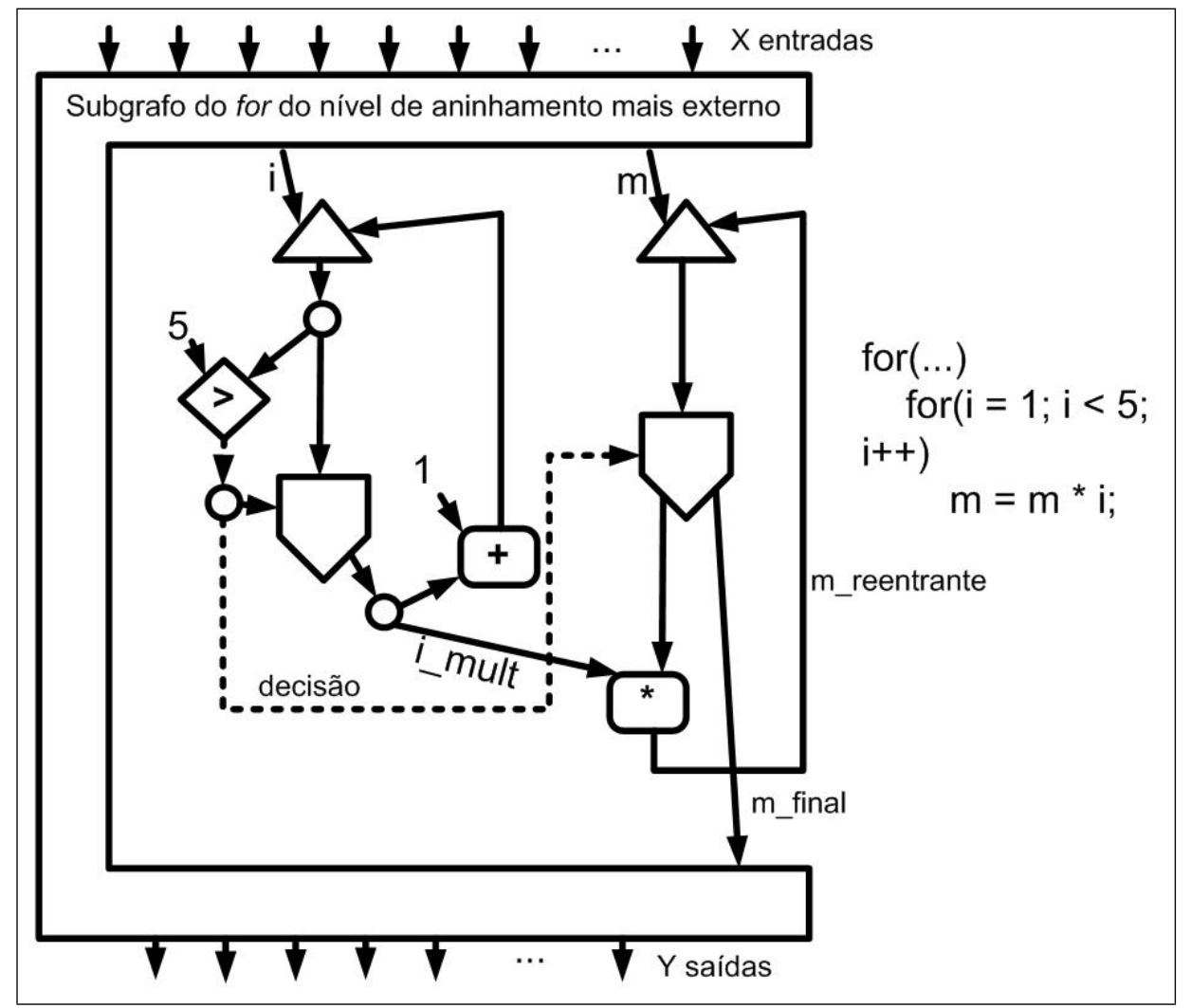

Figura 5.2: Exemplo de loops aninhados.

No caso de um loop dentro de outro loop, como é o caso da Figura 5.2, a cada geração de um novo dado $i$ e um novo dado $m$, consequência de uma nova iteração no loop externo, o subgrafo for no loop interno será ativado. Uma vez ativado, os dados desta ativação fluem normalmente pelo grafo, e por se tratar de um loop várias iterações sobre esses mesmos dados devem ocorrer. Da mesma forma, enquanto esses dados fluem pelo grafo no loop interno, novas 
ativações para $i$ e $m$ podem ser geradas pelos dados vindos do loop externo. A questão que se coloca aqui é como os operadores presentes no loop interno irão identificar se os dados que circulam no loop são da primeira, segunda ou qualquer outra ativação ou mesmo se o dado foi gerado em uma nova iteração dentro desse loop?

Na Figura 5.3, essa situação é ilustrada.

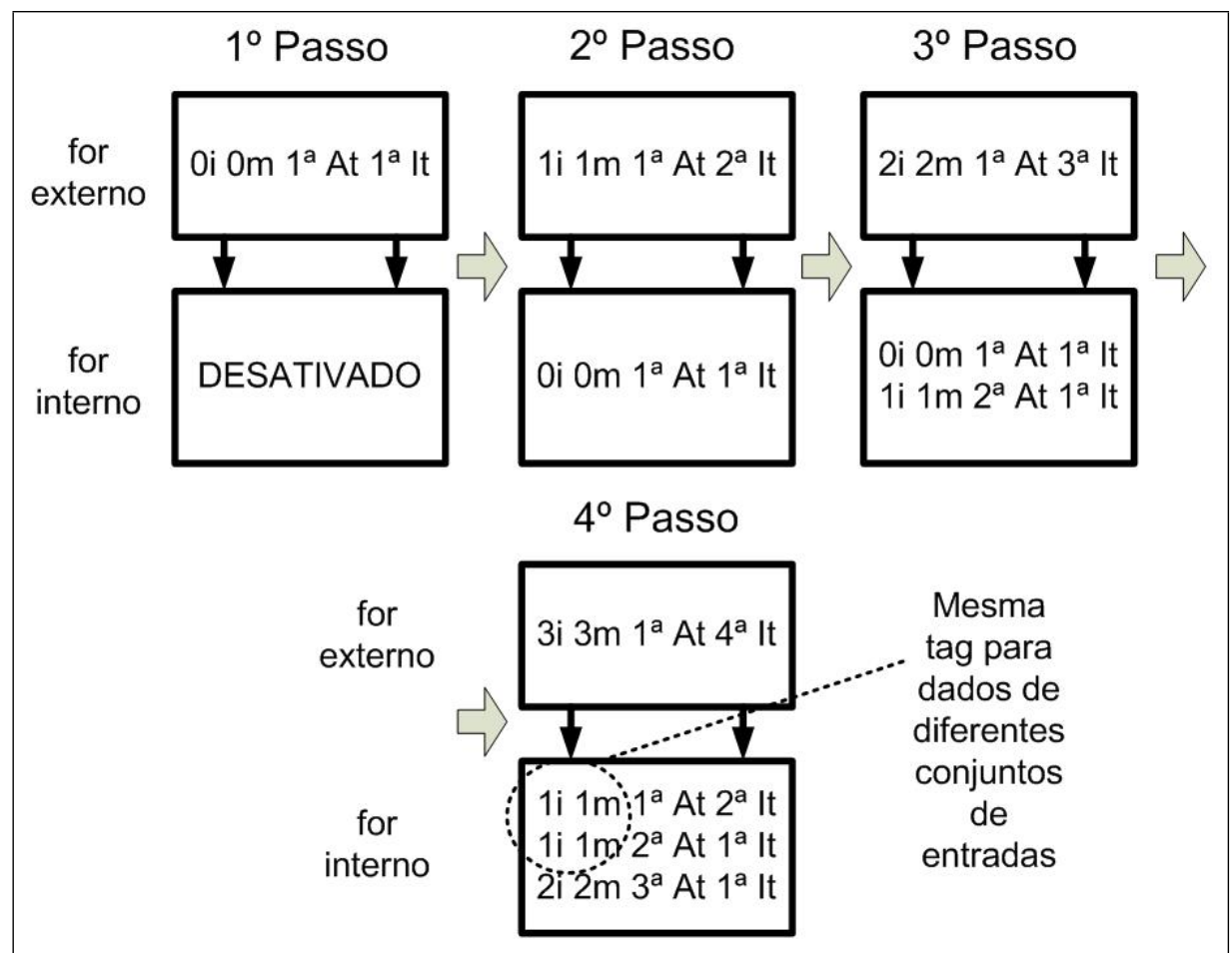

Figura 5.3: Um for aninhado a outro. Tag indica somente nova iteração

Nesta figura, cada retângulo representa um for e as setas verticais representam os arcos que ligam estes grafos. Dentro de cada retângulo contem informação se o for está sem dados (desativado) ou se ele está processando algum dado. As variáveis que passam pelos dois loops são $i$ e $m$. Do lado esquerdo de cada variável dentro do retângulo está sua tag atual. Além disso, para cada conjunto de dados processados, existe a informação que diz qual é a ativação (At) e a iteração atual (It) do conjunto. Na Figura 5.3, considerouse que a tag não seria alterada ao entrar no novo for, seria alterada apenas para indicar uma nova iteração. No primeiro passo, o for externo foi ativado apenas e está executando sua primeira iteração enquanto o for interno está desativado. No segundo passo, o for externo está em sua segunda iteração e o for interno já recebeu os dados da primeira iteração do for externo e iniciou sua primeira ativação. No terceiro passo, o for externo está em sua terceira iteração enquanto o for interno está processando a primeira iteração de sua primeira ativação e ao mesmo tempo processa também a primeira iteração de sua segunda ativação. No quarto e último passo, o for externo está em sua quarta iteração e o for interno está processando a segunda iteração da pri- 
meira ativação e por algum motivo, como uma operação mais lenta por exemplo, a segunda ativação ainda está na primeira iteração. Essa situação indica um problema, pois dados de diferentes conjuntos de entradas e de diferentes iterações passaram a ter a mesma tag. E seriam interpretados erroneamente como dados parceiros.

O problema apresentado pode ser solucionado diferenciando-se os dados das várias ativações possivieis de um subgrafo referente a uma construção iterativa. Para fazer esta diferenciação, a tag deve incluir mais uma informação além da iteração atual do dado. Mais especificamente, esta informação irá armazenar qual é a ativação do subgrafo que o dado faz parte em determinado momento. Ou seja, cada vez que um dado entrar em um subgrafo referente a um loop, um novo valor de ativação de subgrafo será atribuído ao dado para que este seja processado juntamente com os dados que fazem parte de seu conjunto de entradas. Novamente na Figura 5.3, considerando-se que a ativação faz parte da tag, os dados problemáticos não mais seriam considerados parceiros, pois são de ativações diferentes.

Para o exemplo apresentado, outro problema ainda é preciso ser resolvido que é: Como recuperar a tag que um token possuía antes de entrar no loop no momento em que o token deixa a construção iterativa? Para resolver este problema, não basta apenas definir uma tag para armazenar a ativação de subgrafo, é preciso ainda armazenar o antigo valor do campo iteração antes que esse valor receba zero para início das iterações nesse novo loop e também armazenar o valor antigo da ativação de subgrafo. Tão logo o loop seja executado para aquele dado, seu antigo valor de iteração e ativação de subgrafo é recuperado e atribuído à tag do token, podendo então esse dado sair do loop mais interno e voltar para o loop externo imediato. Deve haver então uma estrutura para realizar este armazenamento de tags antigas. Esta estrutura não faz parte da tag que circula pelo grafo juntamente com o token e será apresentada junto com os operadores para manipulação das tags.

Um grafo a fluxo de dados $G$ é visto como uma "caixa preta"com $n$ entradas e $m$ saídas. Supondo que o grafo $G$ faça parte de um programa que está sendo executado parte em uma CPU (Central Processing Unit) e parte em um FPGA conforme descrito na Figura 5.4. Por estar dentro de um loop, controlado pela variável $i$, o grafo $G$ receberá, ao longo do tempo, dez conjuntos de entradas. Antes que o grafo termine de processar os dados do conjunto $e_{i}$ é possível que cheguem à entrada do grafo dados do conjunto $e_{i+1}$. E antes que $e_{i+1}$ seja processado, pode chegar também $e_{i+2}$, ou seja, vários conjuntos de entradas podem estar sendo processados ao mesmo tempo e circulando no grafo compartilhando os mesmos operadores. Os dados que saem da CPU e entram no FPGA não possuem tag, mas são enviados na ordem correta para execução, 
ou seja, primeiro o conjunto de entradas $e_{0}$ é enviado, depois $e_{1}, e_{2}$ e assim por diante. Quando os dados vão sair do FPGA e retornar para a CPU, deve haver uma forma para que o programa em execução identifique quais são os conjuntos de saídas referentes aos conjuntos de entradas enviados. Como não é possível garantir qual será a ordem em que os dados sairão do grafo, deve haver mais um campo na tag responsável por armazenar qual é a ativação do grafo como um todo que determinado dado faz parte. Então, para cada conjunto de entradas $e_{i}$ do grafo principal será atribuída uma ativação de grafo $i$.

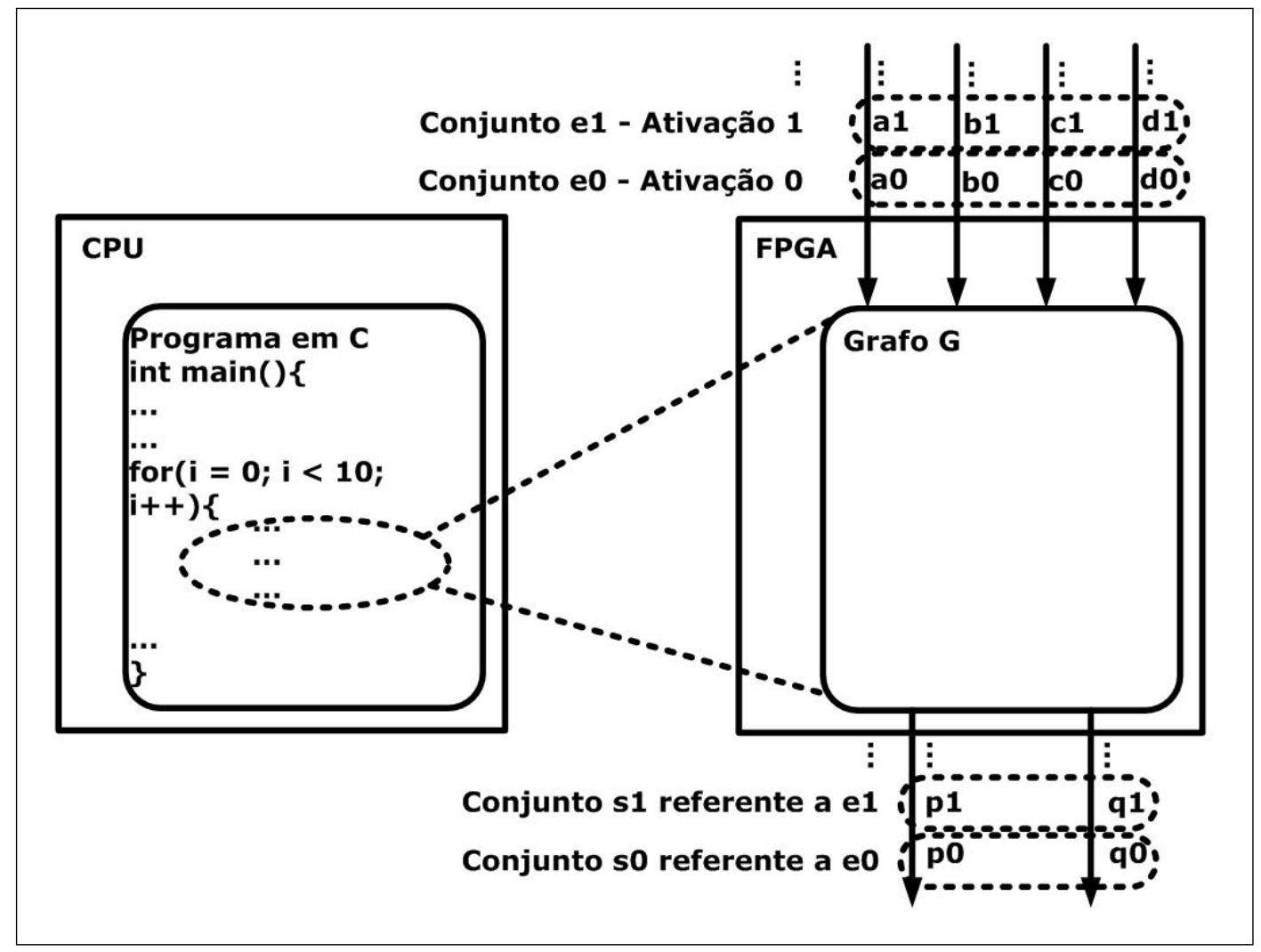

Figura 5.4: Ativação de um grafo a partir de vários conjuntos de entradas.

Considerando todos os casos apresentados, cada token então deverá conter uma tag associada que irá armazenar três informações: qual é a ativação de grafo (graph_act) que o dado pertence; qual é a ativação de subgrafo (subgraph_act) da construção iterativa na qual o dado está circulando em determinado instante e; qual é a iteração atual do dado (current_it), caso esteja em uma construção iterativa. O formato de um token é descrito da seguinte forma:

token $=<$ graph_act.subgraph_act.current_it,dado $>$

O conceito de tagged-token traz a necessidade de operadores específicos para realizar o gerenciamento das tags, ou seja, criar, manter, destruir e armazená-las durante a execução de um programa. Na próxima seção, os 
operadores necessários para o gerenciamento das tags na arquitetura ChipCflow serão apresentados.

\subsection{OPERADORES PARA GERENCIAMENTO DE TAGSNA ARQUITETURA CHIPCFLOW}

O compilador do ChipCflow recebe um código escrito em $\mathrm{C}$, gera um grafo a fluxo de dado descrito em VHDL, reserva endereços da memória para cada variável e preenche a memória com os valores iniciais declarados para cada variável. No começo da execução do programa, instruções de load previamente montadas pelo compilador irão carregar da memória os conjuntos de entradas e enviará para o grafo. Os dados carregados da memória não possuem tags. Caso o grafo seja parte de uma arquitetura híbrida CPU-FPGA como ilustrado na seção anterior, o dado sairá da CPU e irá para o grafo implementado no FPGA também sem tags. Dessa forma, essas tags devem ser geradas em tempo de execução quando os dados entram no grafo.

O operador responsável por criar uma tag inicial para cada dado que chega a um grafo é o Initial Tag Generator (ITG). Cada variável que entra no grafo deverá passar por um operador ITG. O ITG deve manter um registrador interno (graph_act_reg) que começa com zero armazenado e cada vez que um dado passar pelo ITG, o dado recebe em sua ativação de grafo o valor do registrador e este valor é incrementado logo em seguida. Para os campos ativação de subgrafo e iteração atual é atribuído zero. Formalmente tem-se:

$$
\begin{gathered}
I T G_{\text {entrada }}=<\text { dado }> \\
I T G_{\text {saida }}=<\text { graph_act_reg.0.0,dado }>
\end{gathered}
$$

Suponha um grafo que possui três entradas $A, B$ e $C$ e recebe dois conjuntos de entradas $e_{0}=\left\{a_{0}, b_{0}, c_{0}\right\}$ e $e_{1}=\left\{a_{1}, b_{1}, c_{1}\right\}$, conforme ilustrado na Figura 5.5. No grafo gerado pelo compilador, existirá um operador ITG ligado a cada entrada do grafo. Cada dado chega sem tag e após passar pelo ITG ele passa a circular no grafo juntamente com sua tag, representada na figura pelo retângulo de bordas arredondadas. Um elemento pertencente ao conjunto de entradas $e_{i+1}$ nunca deverá chegar ao grafo antes do elemento correspondente do conjunto $e_{i}$ a fim de que os dados de um mesmo conjunto de entradas sempre recebam o mesmo valor para a ativação do grafo. No caso, $a_{0}$ deve chegar antes de $a_{1}, b_{0}$ antes de $b_{1}$ e assim por diante. A garantia desta ordem ou é feita pelo compilador ao gerar o grafo e as operações de load iniciais ou é feita pelo software que se comunica com o grafo em uma arquitetura híbrida CPU-FPGA. 


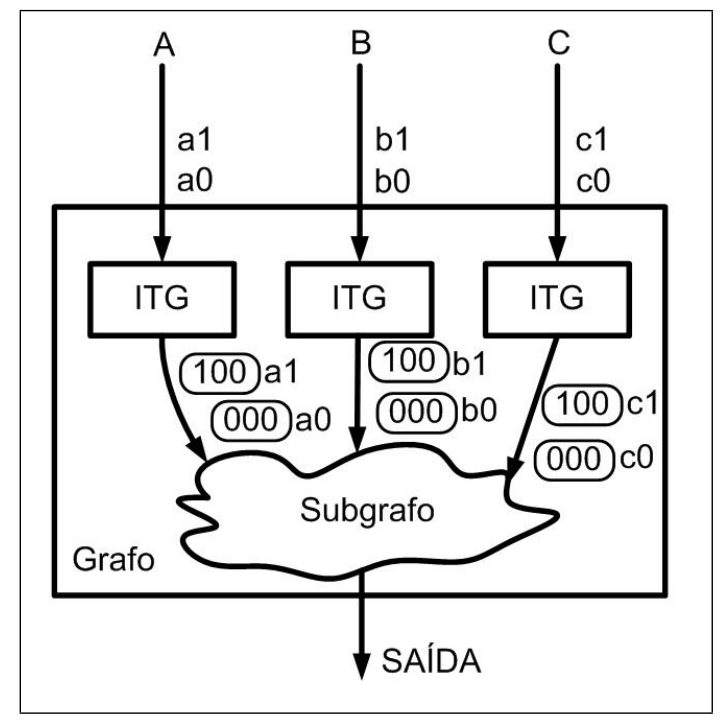

Figura 5.5: Criação de tags iniciais utilizando o operador ITG.

A saída de um grafo pode estar ligada em diferentes estruturas, como por exemplo, dispositivos de entrada e saída. Um dado que sai do grafo e vai para uma destas estruturas não necessita mais de sua tag, portanto ela deve ser removida. O operador responsável por remover a tag de um token é o Tag Remover (TR). Dados que passam pelo TR não voltam mais para o grafo. Formalmente, seu funcionamento em termos de entrada e saída pode ser descrito como:

$$
\begin{gathered}
T R_{\text {entrada }}=<\text { graph_act.subgraph_act.current_it,dado }> \\
T R_{\text {saida }}=<d a d o>
\end{gathered}
$$

Como mostrado na seção anterior, vários dados de diferentes iterações de uma construção iterativa podem estar circulando ao mesmo tempo em um grafo. Por isso, a tag dos dados deve ter um campo utilizado para armazenar qual é a iteração atual do dado. Consequentemente, ao final de cada iteração deve haver um operador que ajustará o campo da iteração atual da tag do dado que passar por ele. Tal operador é o New Iteration Generator (NIG). A Figura 5.6 mostra o mesmo for mais interno da Figura 5.1, porém utilizando o NIG para diferenciar as diversas iterações do loop.

Em termos de entrada e saída, o funcionamento do NIG pode ser descrito como:

$$
\begin{gathered}
N I G_{\text {entrada }}=<\text { graph_act.subgraph_act.current_it,dado }> \\
\left.N I G_{\text {saida }}=<\text { graph_act.subgraph_act.(current_it }+1\right), d a d o>
\end{gathered}
$$

Diferentemente do que acontece na entrada de um grafo, os dados que entram em uma construção iterativa podem não respeitar a ordem dos conjuntos 


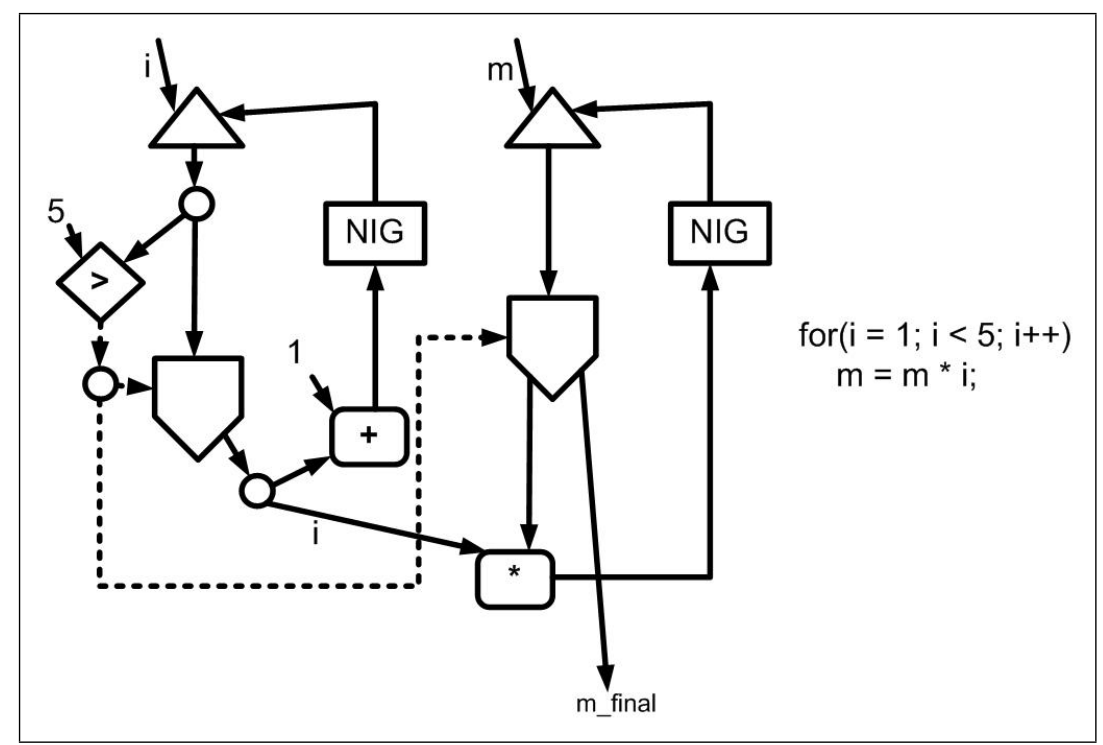

Figura 5.6: Loop utilizando o operador NIG.

de entradas. A Figura 5.7 ilustra este problema.

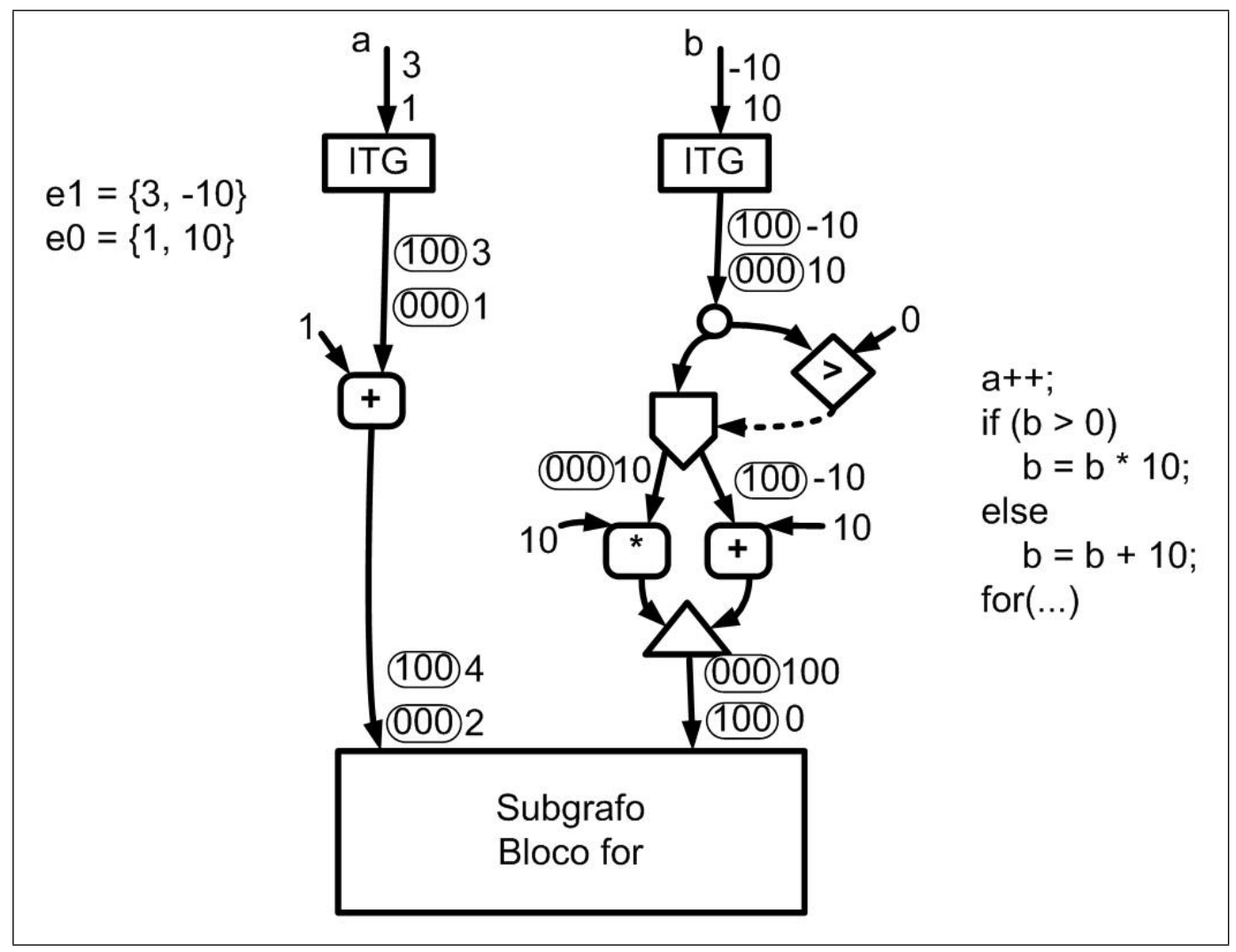

Figura 5.7: Possível entrada de dados fora de ordem em um bloco.

Inicialmente o grafo recebe um conjunto de entradas $e_{0}=\{1,10\}$ e logo em seguida recebe outro conjunto de entradas $e_{1}=\{3,-10\}$. Ao passar pelos operadores ITG, cada dado recebe sua tag, tornando-se $e_{0}=\{<0.0 .0,1\rangle,<$ $0.0 .0,10>\}$ e $\left.\left.e_{1}=\{<1.0 .0,3\rangle,<1.0 .0,-10\right\rangle\right\}$. O lado esquerdo do grafo, que é referente a entrada $a$, irá incrementar cada um dos valores e gerará em ordem os seguintes tokens na entrada do bloco for: $<0.0 .0,2>\mathrm{e}<1.0 .0,4>$. O lado 
problemático do grafo é o lado direito, que é referente ao processamento da entrada $b$. Quando o token $<$ 0.0.0, $10>$ passar pelo grafo, o operador de decisão irá redirecioná-lo para o operador de multiplicação. Já o token $<1.0 .0,-10\rangle$ será redirecionado para o operador de soma. Considerando que uma multiplicação leva muito mais tempo para executar do que uma soma, o token $<1.0 .0,-10>$ que após a soma se torna $<1.0 .0,0>$ chegará na entrada do bloco for antes do token $<0.0 .0,100>$, que virá do resultado da multiplicação. Suponha que existe um operador de gerenciamento de tags na entrada do bloco for e que ele recebe os dados fora de ordem e gera uma nova ativação de subgrafo para os mesmos. Neste caso, dados que faziam parte de diferentes conjuntos de entradas poderiam passar a fazer parte de um mesmo conjunto de entradas. Consequentemente, o processamento realizado pelo grafo provavelmente não seria o desejado. Para evitar que este problema aconteça, o operador de gerenciamento de tags posicionado na entrada de uma construção iterativa deve esperar que todos os dados com a mesma tag cheguem. Somente após isto, o operador deve atribuir uma nova ativação de subgrafo para estes dados e enviá-los para o processamento dentro da construção iterativa.

O operador responsável por atribuir uma nova ativação de subgrafo para um token é o New Tag Manager (NTM). E, para realizar esta tarefa, o NTM possui um registrador interno (subgraph_act_reg) que começa com zero armazenado e, para cada conjunto de entradas recebido, o NTM atribui o valor do registrador ao campo ativação de subgrafo dos tokens e incrementa o valor do registrador. Como mostrado acima, o NTM segue a regra de disparo que por definição qualquer operador de uma máquina a fluxo de dados dinâmica tagged-token deve seguir, uma vez que ele deve esperar que todas as entradas tenham recebido os dados com a mesma tag para realizar seu processamento. Além disso, o NTM deve atribuir zero para o campo iteração atual da tag, pois uma nova ativação de uma construção iterativa se inicia na iteração zero (zero neste caso representa a iteração inicial e não o valor da variável que controla a construção iterativa). Seu funcionamento em termos de entradas e saídas é descrito abaixo:

$$
\begin{gathered}
N T M_{\text {entrada }}=<\text { graph_act.subgraph_act.current_it,dado }> \\
N T M_{\text {saida }}=<\text { graph_act.new_subgraph_act.0,dado }>
\end{gathered}
$$

Como os dados que entram em um grafo sempre chegam em ordem, pode haver um ITG diferente relacionado com cada entrada. Porém no caso do NTM, deve haver um único operador para todas as entradas de uma construção iterativa para que seja possível atribuir o mesmo valor de ativação de subgrafo para todos os dados que possuem a mesma tag. Além dessas funcionalidades descritas, o NTM deve realizar mais uma tarefa que será detalhada a seguir. 
A Figura 5.8 ilustra um caso particular em que uma variável começa a ser processada em um determinado nível de aninhamento, depois entra em uma construção iterativa, é processada dentro desta construção e, por fim, a variável volta ao nível anterior para ser novamente processada.

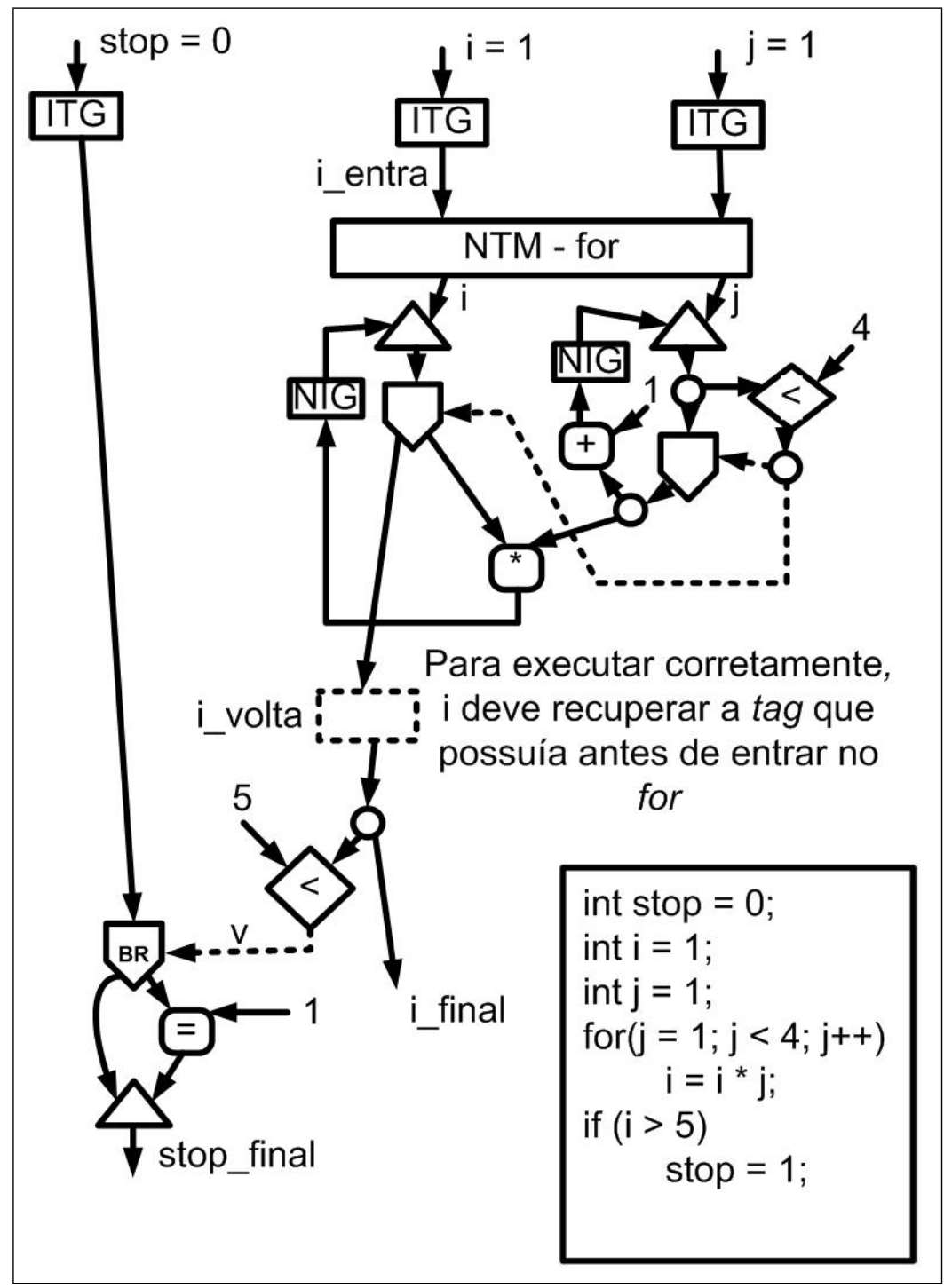

Figura 5.8: Grafo onde um token deve recuperar sua tag antiga.

No caso, o grafo da Figura 5.8 possui três variáveis de entrada: stop, $i$ e $j$. Como declarado no código, os valores recebidos na entrada do grafo são 0 para stop, 1 para $i$ e 1 para $j$. Todos os três dados entram em seus respectivos ITGs e se tornam stop $=<0.0 .0,0>, i=<0.0 .0,1>$ e $j=<0.0 .0,1>$. O token da variável stop ficará esperando que seu dado parceiro chegue no operador branch (BR) através do arco $v$. Os tokens $i$ e $j$ entram no NTM do for. O NTM então irá atribuir o valor de seu registrador interno (subgraph_act_reg) ao campo ativação de subgrafo dos tokens e atribui zero ao campo ativação atual. As tags se tornam $i=<0.0 .0,1>$ e $j=<0.0 .0,1>$. É o mesmo valor da tag anterior pois como é a primeira ativação deste subgrafo, o registrador interno do NTM valia zero. Note que este fato não gera problemas, pois quando 
novos conjuntos de entradas chegarem receberão tags diferentes do primeiro conjunto uma vez que o registrador interno incrementa seu valor para cada conjunto de entradas.

O for descrito no grafo irá executar três iterações. Os tokens $i$ e $j$ produzidos ao final da primeira, segunda e terceira iteração são, respectivamente:

$$
\begin{array}{ll}
i=<0.0 .1,1> & j=<0.0 .1,2> \\
i=<0.0 .2,2> & j=<0.0 .2,3> \\
i=<0.0 .3,6>\quad j=<0.0 .3,4>
\end{array}
$$

Então, a comparação $j<4$ retorna falso e o token $i$ vai para o arco $i \_v o l t a$. Neste momento, o token $i$ sai do for e volta para o nível de aninhamento anterior. Este token chega no operador de comparação $i>5$. Na arquitetura ChipCflow, as constantes ficam armazenadas em registradores e são parceiras de todos os tokens que chegam em algum operador do qual a constante é um dos operandos. A tag do resultado é a mesma do operando que possuia tag, no caso o token $i$. Então a comparação é feita e gera um token $v=<0.0 .3, V E R D A D E I R O>$. Tal token chega ao branch $B R$. Lembrando que o token stop $=<0.0 .0,0>$ está esperando seu dado parceiro, que no caso deveria ser justamente o token $v$. Porém, as tags de stop e $v$ não são iguais, pois ao entrar na construção iterativa a tag de $i$ (que foi quem gerou a tag de $v$ ) foi alterada. Para resolver este problema, deve haver um operador posicionado na saída da construção iterativa (na figura, é o retângulo com bordas em linhas pontilhadas) capaz de recuperar a tag que o token possuía antes de entrar na construção iterativa.

Uma tag antiga de um token é a tag que ele possuía antes de entrar em uma construção iterativa. O operador responsável por recuperar a tag antiga de um token que está saindo da construção iterativa para voltar para um nível de aninhamento anterior é o New Tag Destructor (NTD). Mais especificamente, as informações que devem ser recuperadas são ativação de subgrafo e iteração. Formalmente, em termos de entrada e saída, o funcionamento do NTD é:

$$
\begin{gathered}
N T D_{\text {entrada }}=<\text { graph_act.new_subgraph_act.current_it,dado>} \\
N T D_{\text {saida }}=<\text { graph_act.old_subgraph_act.old_it,dado}>
\end{gathered}
$$

Para ser possivel recuperar a tag antiga de um token, é necessário armazenála em alguma memória no momento em que o dado chega na construção iterativa. O operador NTD então consulta esta memória quando o token passar por ele e recupera a tag antiga. Esta memória é uma estrutura chamada Old Tag Table (OTT). A OTT armazena duas informações por conjunto de entradas: a 
tag antiga (representada pelos campos ativação de subgrafo e iteração atual) dos tokens e a tag nova (representada pelos campos ativação de grafo e ativação de subgrafo). Não é necessário armazenar na OTT qual é a nova iteração atual dos tokens, já que a iteração atual de todos os tokens é sempre ajustada para zero pelo NTM na entrada da construção iterativa.

O operador responsável por enviar as informações que serão salvas na OTT é o New Tag Manager (NTM), além de realizar as outras funções já explicadas anteriormente. O NTD consulta os valores das tags antigas na OTT por meio dos valores atuais das tags observando os campos ativação de grafo e ativação de subgrafo.

A OTT e o NTD existem apenas nos casos onde pelo menos um token que entra em uma construção iterativa necessita voltar para o nível de aninhamento anterior. Nos casos onde nenhuma variável volta a ser processada no nível anterior, não há necessidade de recuperar suas tags antigas.

Em resumo, existem cinco operadores responsáveis pelo gerenciamento de tags na arquitetura ChipCflow: Initial Tag Generator (ITG); Tag Remover (TR); New Tag Manager (NTM); New Tag Destructor (NTD); New Iteration Generator (NIG). Existe ainda uma estrutura auxiliar chamada Old Tag Table (OTT). O operador responsável por criar novas tags para os dados que entram em um grafo é o ITG. TR é responsável por remover as tags dos dados que saem do grafo. ITG e TR atuam no nível de ativação do grafo. O operador NTM é responsável por receber dados que farão parte de uma mesma ativação de uma construção iterativa e ajustar a ativação de subgrafo de suas tags. Guando um conjunto de entradas chega a um NTM, o NTM atribui novas tags para estes dados e envia para a OTT (caso ela exista) qual era a tag antiga dos dados e qual é a tag nova dos dados. A OTT então armazena os valores das tags antigas dos dados. Já o NTD é responsável por restaurar a tag que um dado possuía antes de entrar na construção iterativa atual (tag antiga). Este operador e a OTT são essenciais para permitir que um dado saia de uma construção iterativa em um aninhamento mais interno e volte para o bloco mais externo. O NTD consulta os valores das tags antigas na OTT por meio dos valores atuais das tags, observando os campos ativação de grafo e ativação de subgrafo. Os operadores NTM, NTD juntamente com a OTT atuam no nível de ativação de subgrafo. Por fim, o NIG é utilizado quando um bloco é referente a um loop. Cada dado que passa pelo NIG tem o campo da iteração atual ajustado para uma nova iteração do loop.

Na próxima seção, será apresentado um exemplo de um grafo utilizando todos os operadores de gerenciamento de tags. 


\subsection{SOMA DE VETORES ELEMENTO POR ELEMENTO}

Na Figura 5.9 é mostrado um DFG que utiliza todos os operadores de gerenciamento de tags propostos para a arquitetura ChipCflow.

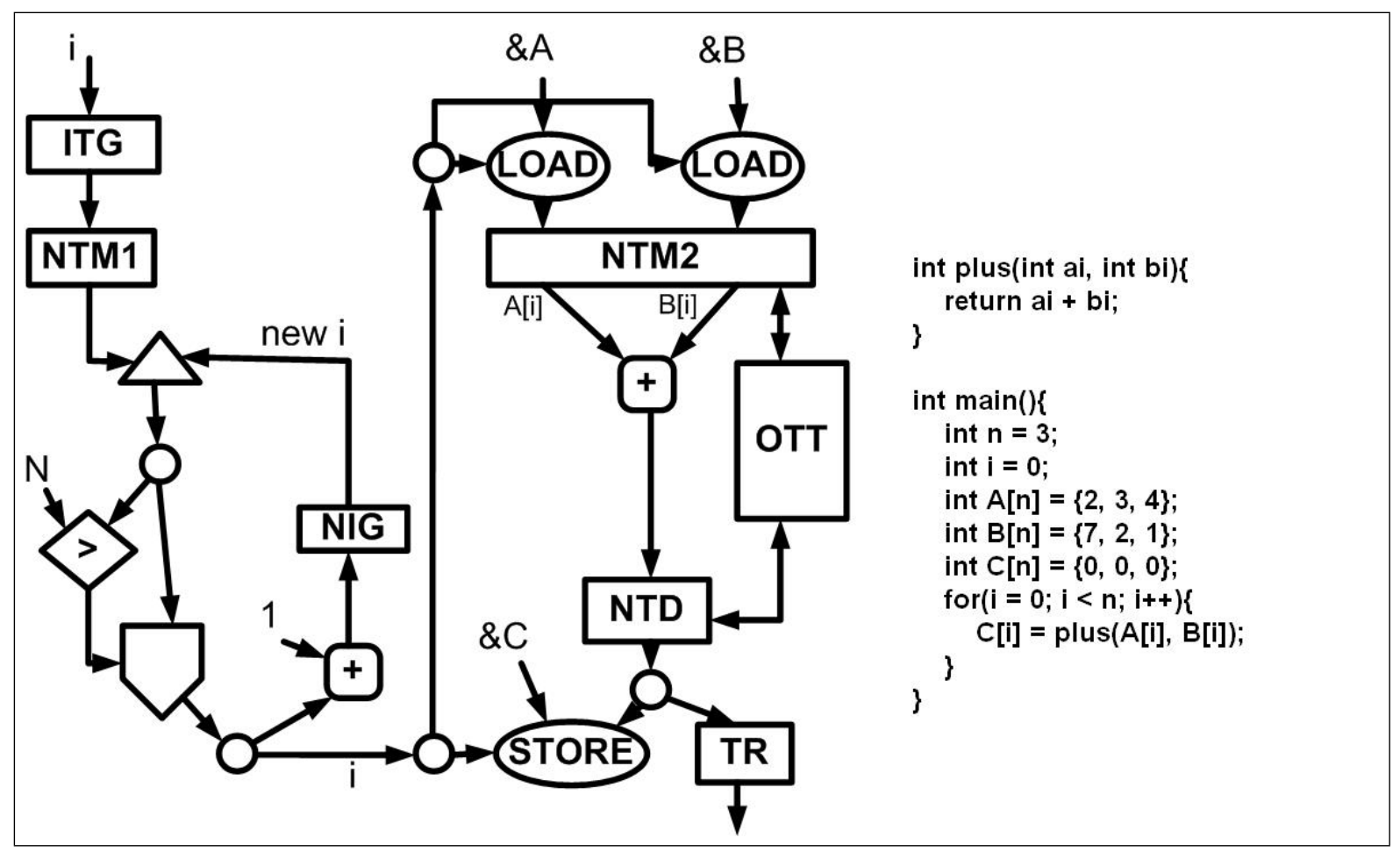

Figura 5.9: Soma de vetores elemento por elemento.

$\mathrm{O}$ código $\mathrm{C}$ relacionado ao DFG possui uma função chamada plus que recebe dois parâmetros e retorna a soma entre eles. A função principal do programa possui um loop que chama a função plus para cada elemento dos vetores $A$ e $B$ e armazena os resultados no vetor $C$. No início da execução do grafo, as constantes (endereço dos vetores $A, B$ e $C$; os valores das variáveis $i$ e $n$ ) são carregados da memória ou alocados em registradores pelo compilador. Todas as constantes estão esperando por seus dados parceiros enquanto $i$ entra no ITG e recebe sua tag inicial e se torna $<0.0 .0,0>$. Quando a variável $i$ entra no NTM1, sua ativação de subgrafo recebe o valor da ativação do NTM1, que é zero. O NTM1 é referente ao início do loop do código. Se a comparação lógica retorna VERDADEIRO, o operador de soma incrementa o valor de $i$, o NIG incrementa a parte da tag referente a iteração atual e o token se torna $<0.0 .1,1>$. Paralelamente ao incremento de $i$, a sua cópia chega nos operadores load e store do grafo. O store não executa ainda, pois falta o dado parceiro de $i$. Após a execução das instruções de load, $A[0]$ e $B[0]$ são enviados ao NTM2, que é referente ao início da função plus.

Depois que o NTM2 recebe $A[0]$ e $B[0]$, os valores dos tokens são $<0.0 .0,2>$ para $A[0] \mathrm{e}<0.0 .0,7>$ para $B[0]$. Suas tags antigas são associadas às novas e são armazenadas na OTT. Guando o resultado da soma entre $A[0]$ e $B[0]$ chega 
ao NTD, a tag antiga é recuperada, a instrução store recebe o parceiro que faltava e armazena o dado em $C[0]$. Ao mesmo tempo, uma cópia do resultado é enviado para o TR que remove a tag e envia o dado para algum dispositivo de entrada/saída. O ciclo de execução continua até que a comparação lógica entre $i$ e $n$ retorne FALSO.

Na próxima seção, a implementação em VHDL dos operadores para gerenciamento de tags na arquitetura ChipCflow será apresentada.

\subsection{IMPLEMENTAÇÃO DOS OPERADORES PARA GEREN- CIAMENTO DE TAGS}

Nesta seção, tem-se por objetivo apresentar a implementação em hardware dos operadores para gerenciamento de tags apresentados anteriormente, as respectivas formas de onda dos casos de teste do funcionamento de cada operador assim como de testes de integração dos operadores. Serão apresentados também os dados de síntese gerados pela ferramenta ISE 9.1i da Xilinx.

Os operadores foram implementados por meio de uma máquina finita de estados descrita em VHDL. Todos os operadores possuem um estado inicial que é responsável por receber os dados de entrada do operador. Assim que os dados de entrada são recebidos, muda-se de estado e a operação propriamente dita de cada operador é realizada. Ao final da operação, há um estado responsável por enviar o resultado através dos sinais de saída. Na implementação feita, um token possui 32 bits. Destes 32 bits, 16 são para o dado propriamente dito e 16 para a tag. Os campos ativação de grafo e ativação de subgrafo possuem 4 bits cada um e o campo iteração atual possui 8 bits. Tais valores para o tamanho dos campos foi escolhido arbitrariamente apenas para testes e para verificar o funcionamento dos operadores. No código VHDL, estes tamanhos foram definidos como constantes, desta forma para mudar os valores basta mudar apenas os valores no arquivo referente a declaração e inicialização de constantes.

Todos os operadores possuem um sinal de clock interno, porém a comunicação entre os operadores é feita de modo assíncrono, segundo um protocolo de handshake. Ou seja, para cada sinal de saída $s_{i}$ de um operador, existe um sinal, chamado strobe, que indica para o próximo operador que existe um dado na saída $s_{i}$ pronto para ser consumido. Os operadores também possuem sinais de reconhecimento relacionados as entradas. Tais sinais (ack) indicam ao operador anterior que determinado dado foi recebido. 


\subsubsection{Initial Tag Generator (ITG)}

O operador ITG, como apresentado, recebe um dado que não possui tag e gera uma tag inicial para o dado. O bloco esquemático do operador ITG juntamente com sua representação gráfica estão na Figura 5.10.

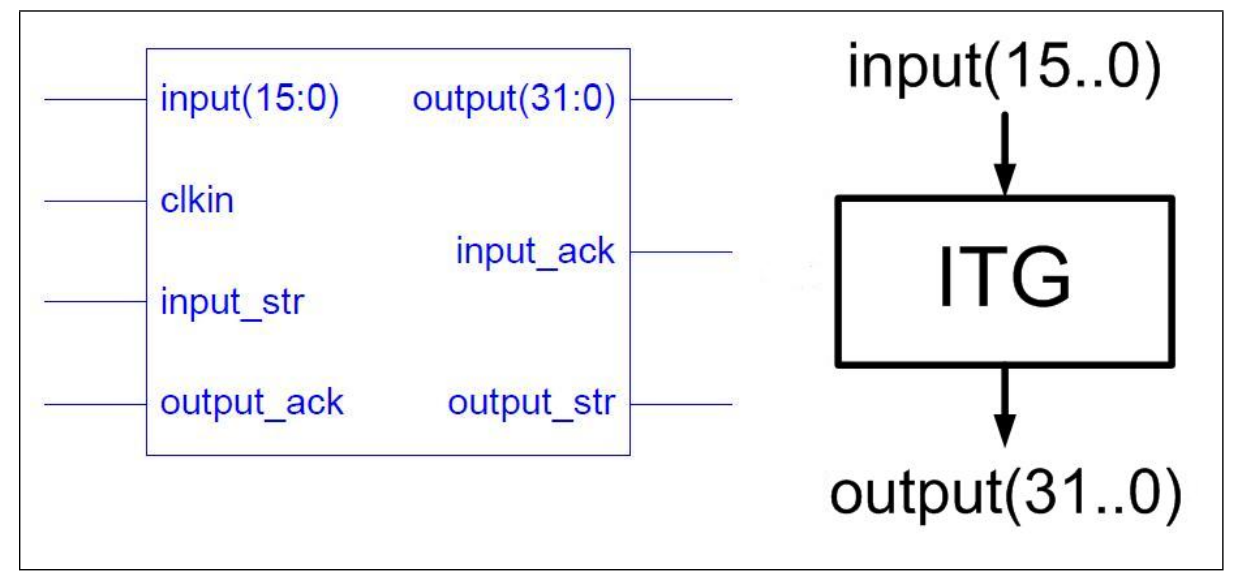

Figura 5.10: Bloco esquemático do operador ITG e sua representação gráfica.

Os sinais input, clkin, input_str e output_ack são sinais de entrada e os sinais output, input_ack e output_str são sinais de saída. O dado entra pelo sinal input e os sinais input_str e input_ack são os sinais de handshake para o sinal input. O resultado da operação é enviado para a saída output que possui os sinais de handshake output_str e output_ack. A Figura 5.11 apresenta o diagrama de estados do operador ITG.

Como pode ser visto, quando input_str for igual a 1 , o valor de input é armazenado em input_reg. Em seguida, output_ack não é igual a 1 pois este sinal é 1 quando o operador seguinte avisa que já recebeu o dado. Então, neste caso, a saída do ITG recebe o valor de graph_act_reg (que é um registrador que armazena quantas ativações do grafo em questão já ocorreram) para a tag e o valor de input_reg para o dado propriamente dito. Neste momento, o operador avisa por meio dos sinais de handshake que há um dado pronto em sua saída. Quando o operador seguinte indica por meio do sinal de output_ack que já recebeu o dado, o operador incrementa o valor de seu registrador interno e retorna ao estado inicial. Uma vez de volta ao estado inicial, o operador poderá receber novos dados. A Tabela 5.1 apresenta os dados da síntese do operador ITG.

A Figura 5.12 apresenta a simulação do operador ITG após a síntese e o place and route utilizando a ferramenta ISE da Xilinx. A Figura mostra o operador ITG recebendo primeiramente um dado igual a $<0000>h \mathrm{e}$, depois, igual $\mathrm{a}<A A A A>h$ (a letra $h$ após o token indica que os valores estão representados em hexadecimal). O dado recebe sua tag de acordo com o valor do registrador interno e o resultado é enviado para output. Os sinais de handshake também 


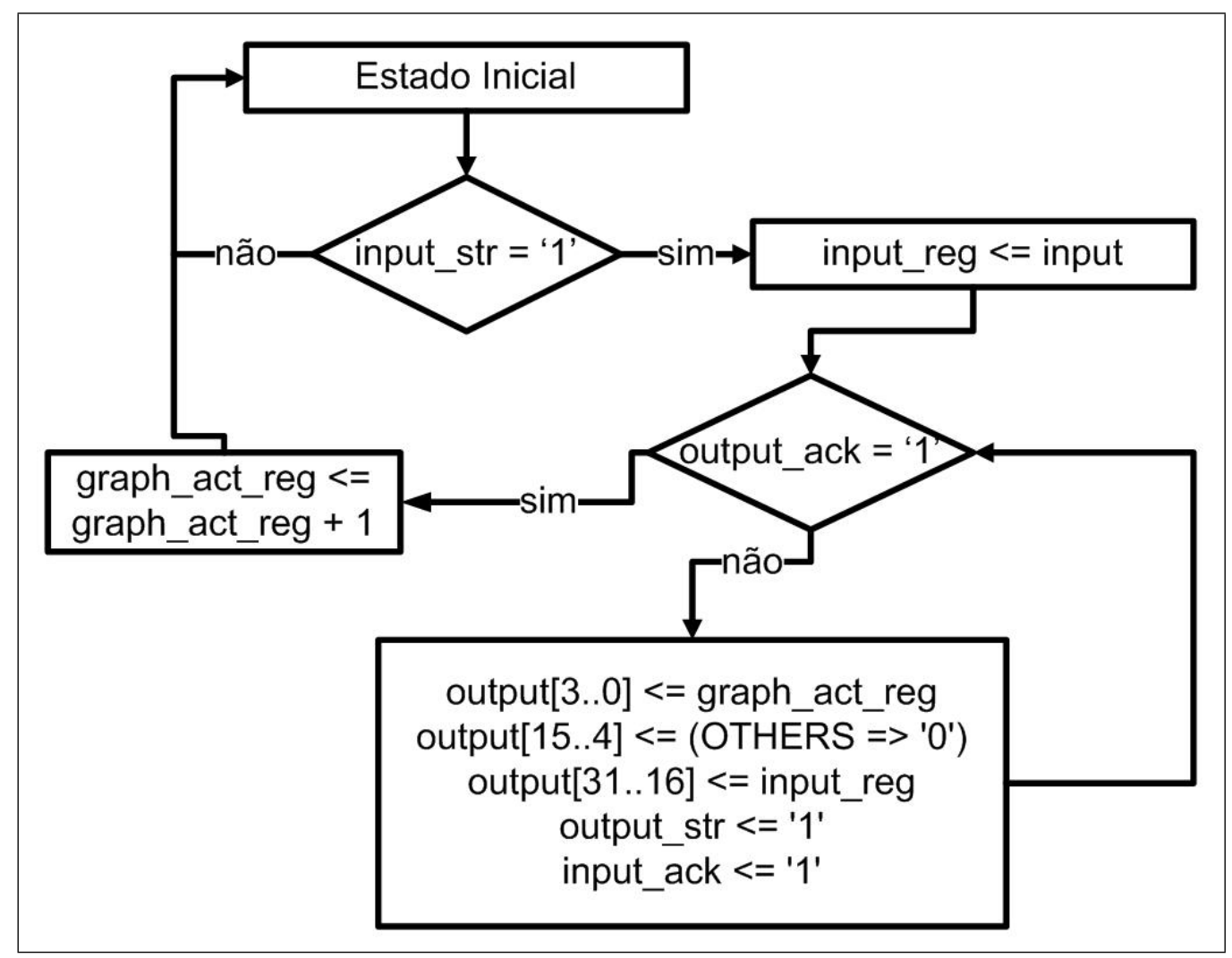

Figura 5.11: Diagrama de estados do operador ITG.

Tabela 5.1: Resultados da síntese do operador ITG na Xilinx Spartan 3E 3s500efg320-4.

\begin{tabular}{c|c} 
& Utilização dos Elementos do Dispositivo \\
\hline Operador & ITG \\
\hline Número de Slices & 43 de $4656(0 \%)$ \\
\hline Número de Slices FFs & 74 de $9312(0 \%)$ \\
\hline Número de LUTs de 4 entradas & 10 de $9312(0 \%)$ \\
\hline Número de bounded IOBs & 53 de $232(22 \%)$ \\
\hline Número de GCLKs & 1 de $24(4 \%)$ \\
\hline \hline Período Mínimo & $3.126 \mathrm{~ns}$ \\
\hline Frequência Máxima & $319.944 \mathrm{MHz}$ \\
\hline
\end{tabular}


podem ser visualizados na simulação. Após receberem as tags, os tokens passam a ser, respectivamente, $<0.0 .00,0000>h$ por ser a primeira ativação do grafo e $<1.0 .00, A A A A>h$ por ser a segunda a ativação do grafo.

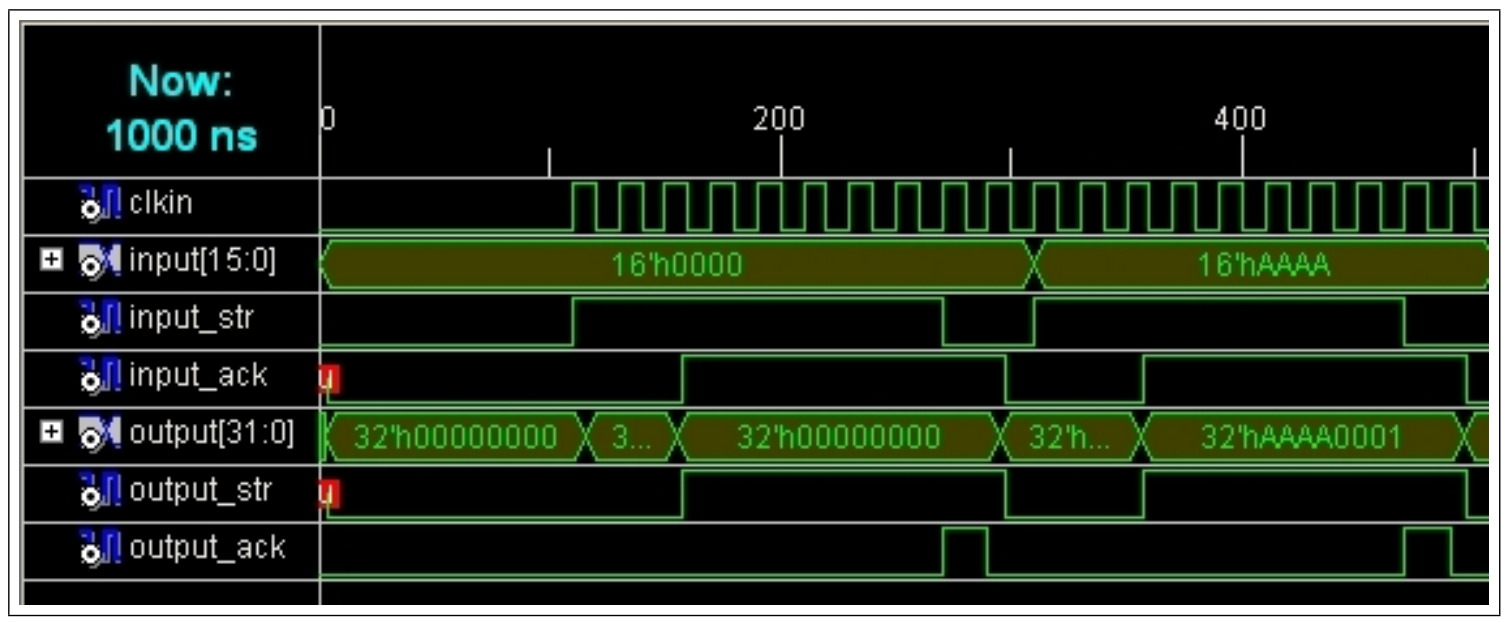

Figura 5.12: Simulação do operador ITG após síntese e place and route.

\subsubsection{Tag Remover (TR)}

O operador TR é responsável por remover a tag de um dado que está saindo de circulação no grafo. Seu bloco esquemático está na Figura 5.13 juntamente com sua representação gráfica.

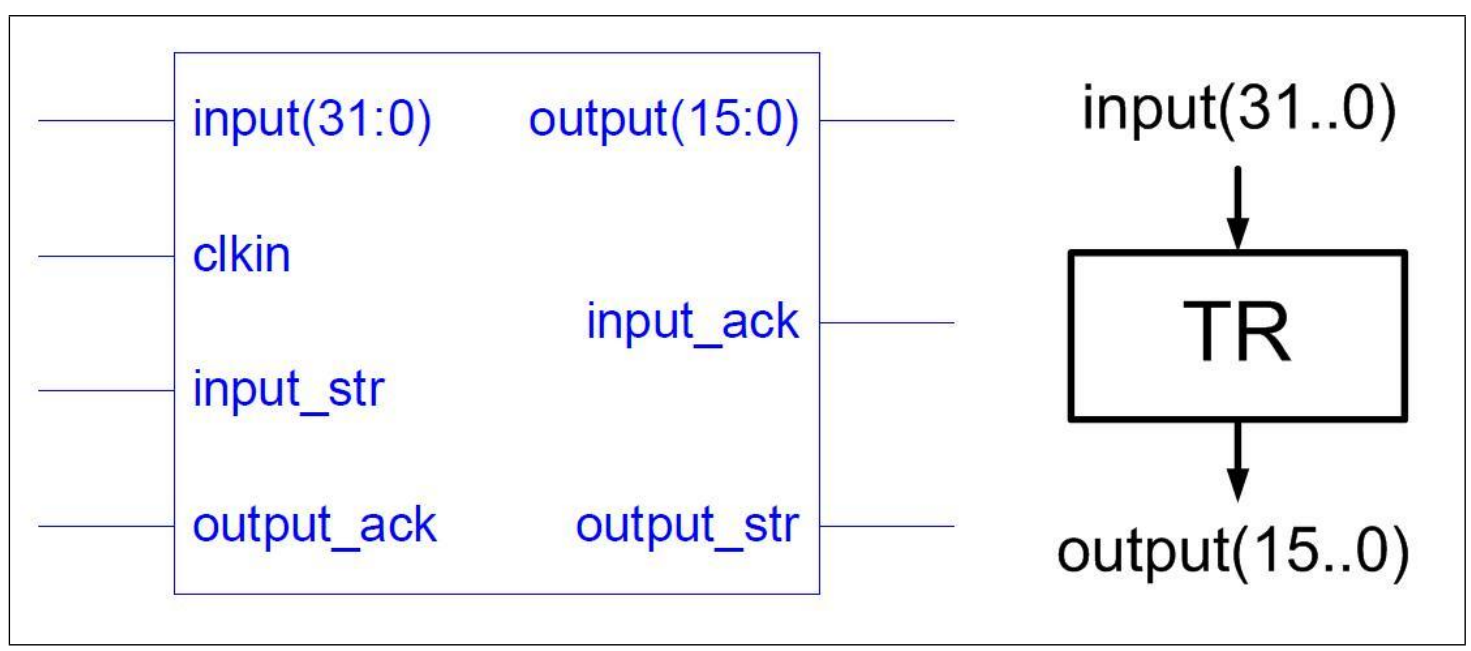

Figura 5.13: Bloco esquemático do operador TR e sua representação gráfica.

Os sinais input, clkin, input_str e output_ack são sinais de entrada e os sinais output, input_ack e output_str são sinais de saída. O dado entra pelo sinal input e os sinais input_str e input_ack são os sinais de handshake para o sinal input. O resultado da operação é enviado para a saída output que possui os sinais de handshake output_str e output_ack. A Figura 5.14 apresenta o diagrama de estados do operador TR. 


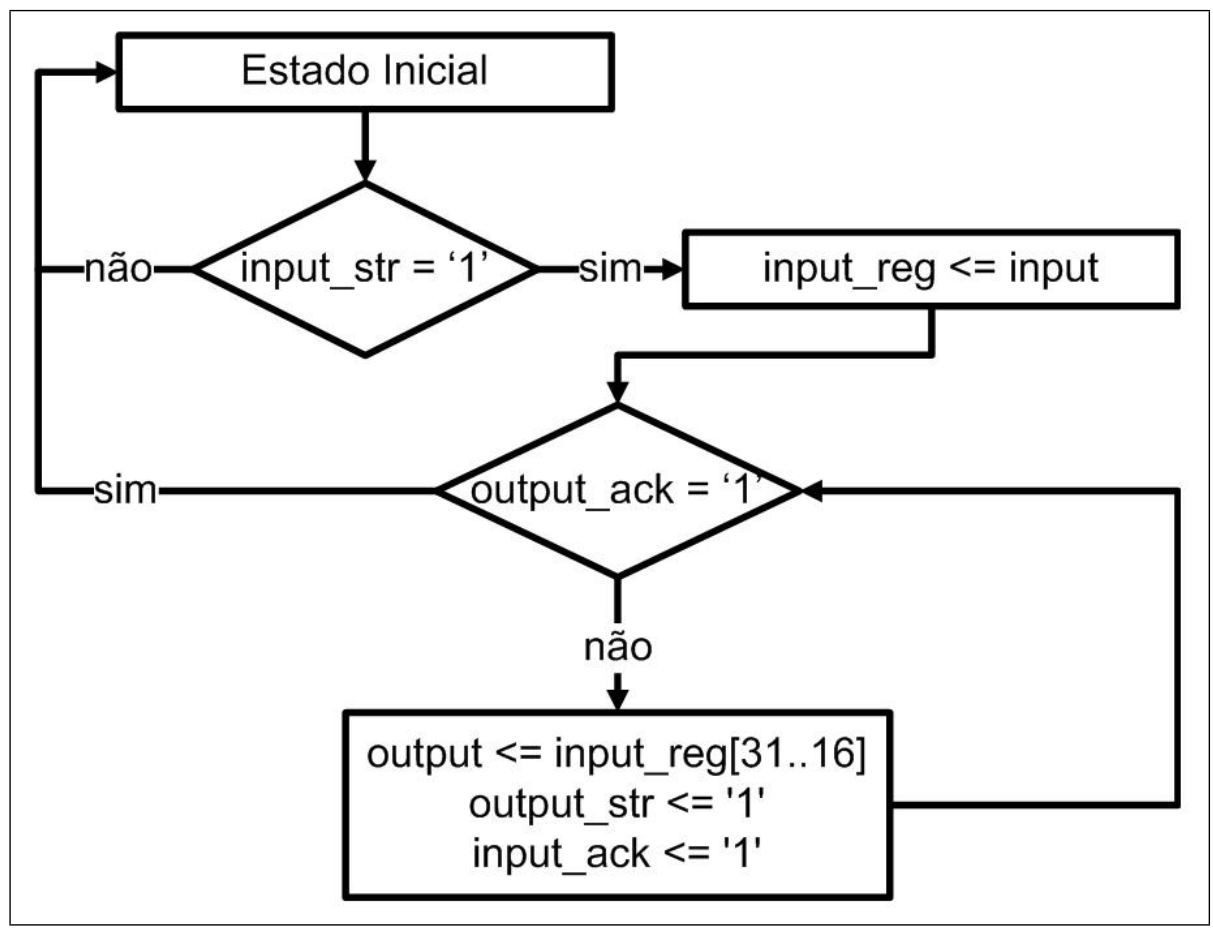

Figura 5.14: Diagrama de estados do operador TR.

Tabela 5.2: Resultados da síntese do operador TR na Spartan 3E 3s500efg3204.

Utilização dos Elementos do Dispositivo

\begin{tabular}{c|c}
\hline Operador & TR \\
\hline Número de Slices & 21 de $4656(0 \%)$ \\
\hline Número de Slices FFs & 35 de $9312(0 \%)$ \\
\hline Número de LUTs de 4 entradas & 4 de $9312(0 \%)$ \\
\hline Número de bounded IOBs & 37 de $232(15 \%)$ \\
\hline Número de GCLKs & 1 out of $24(4 \%)$ \\
\hline \hline Período Mínimo & $3.056 \mathrm{~ns}$ \\
\hline Frequência Máxima & $327.241 \mathrm{MHz}$ \\
\hline
\end{tabular}

De acordo com o diagrama de estados, quando input_str for igual a um, o valor recebido através da entrada input é armazenado em input_reg. O sinal output_ack vale zero uma vez que o dado ainda não foi enviado e portanto não pode ser recebido. Então, a saída do operador recebe o valor armazenado em input_reg porém sem a tag. Quando o operador seguinte receber o dado e enviar 1 para output_ack o operador TR volta ao seu estado inicial e está pronto para receber novos dados. A Tabela 5.2 apresenta os dados de síntese do operador TR.

A Figura 5.15 apresenta a simulação do operador TR após a síntese e o place and route utilizando a ferramenta ISE da Xilinx. A figura mostra o operador TR recebendo primeiramente um dado igual a $<0.0 .00, A A A A>h$ e depois igual a $<1.3 .02, A A A A>h$. O dado sem a sua respectiva tag é envi- 
ado para output. Os sinais de handshake também podem ser visualizados na simulação.

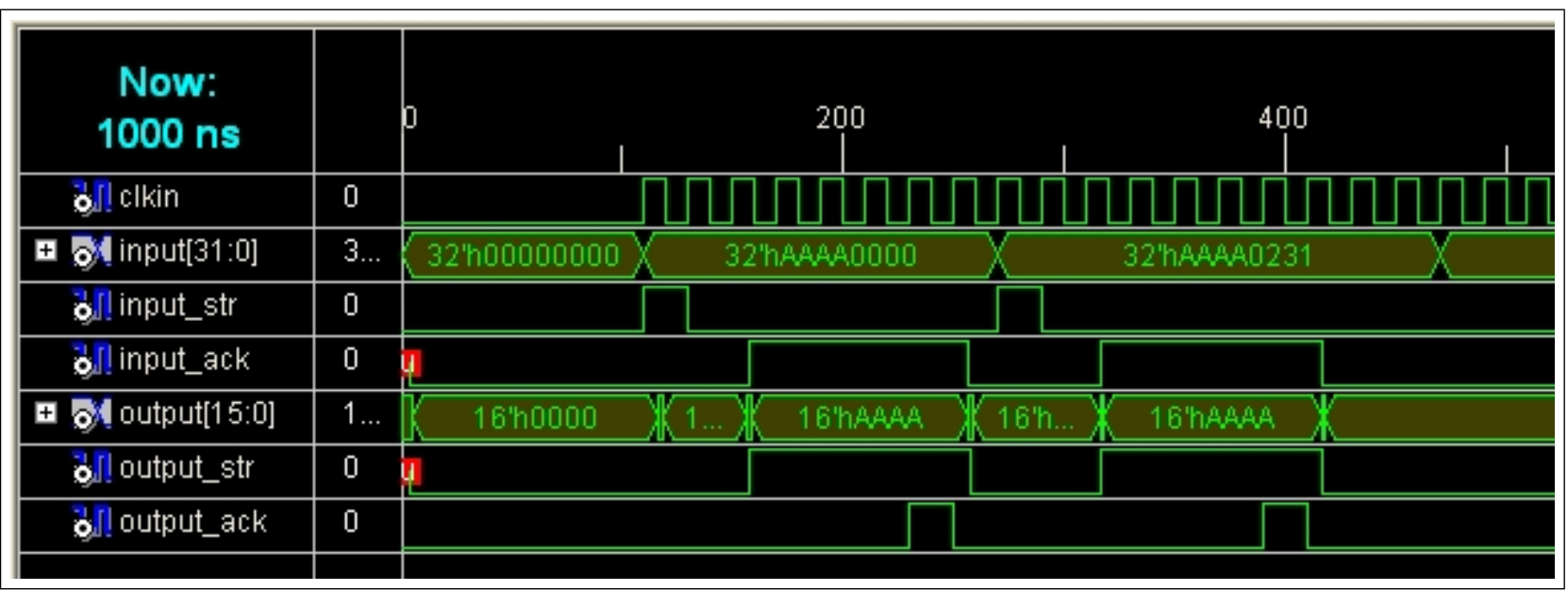

Figura 5.15: Simulação do operador TR após síntese e place and route.

\subsubsection{New Iteration Generator (NIG)}

O operador NIG é responsável por incrementar o campo iteração atual da tag de um dado que passa por ele. Seu bloco esquemático está na Figura 5.16 juntamente com sua representação gráfica.

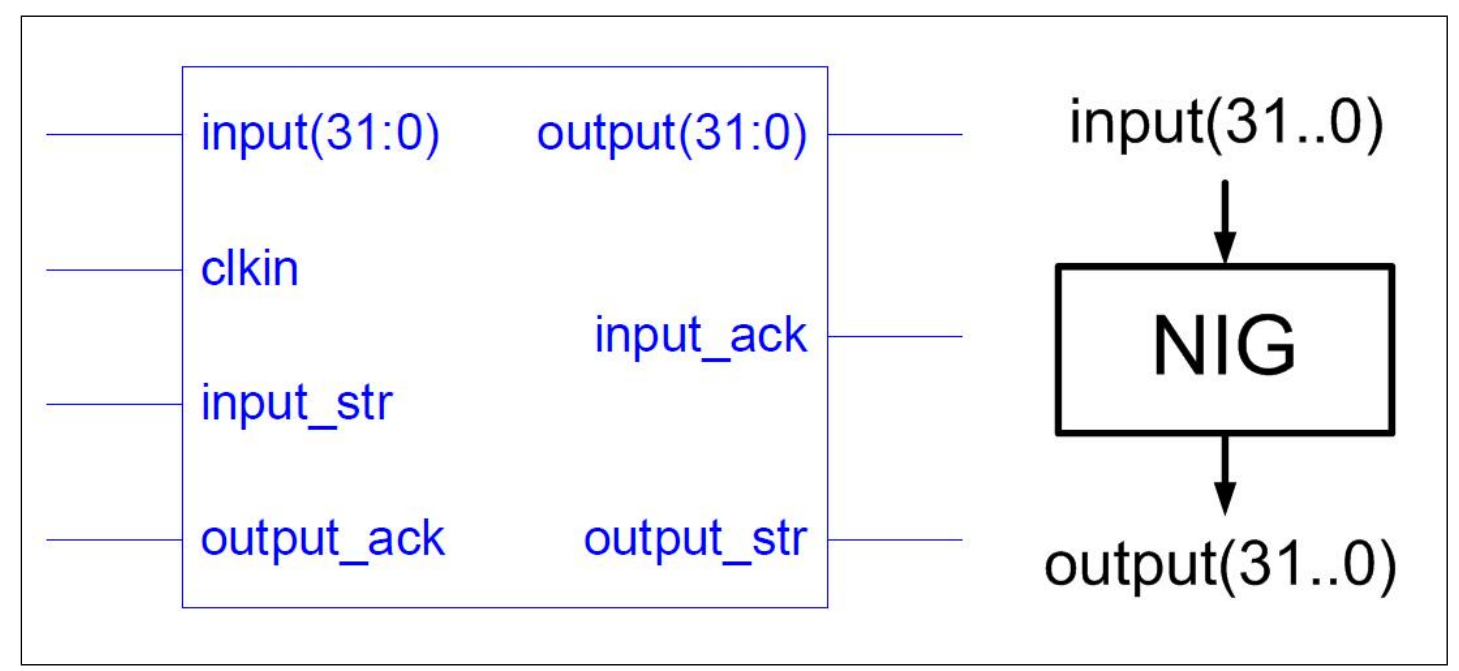

Figura 5.16: Bloco esquemático do operador NIG e sua representação gráfica.

Os sinais input, clkin, input_str e output_ack são sinais de entrada e os sinais output, input_ack e output_str são sinais de saída. O dado entra pelo sinal input e os sinais input_str e input_ack são os sinais de handshake para o sinal input. O resultado da operação é enviado para a saída output que possui os sinais de handshake output_str e output_ack. A Figura 5.17 apresenta o diagrama de estados do operador NIG. 


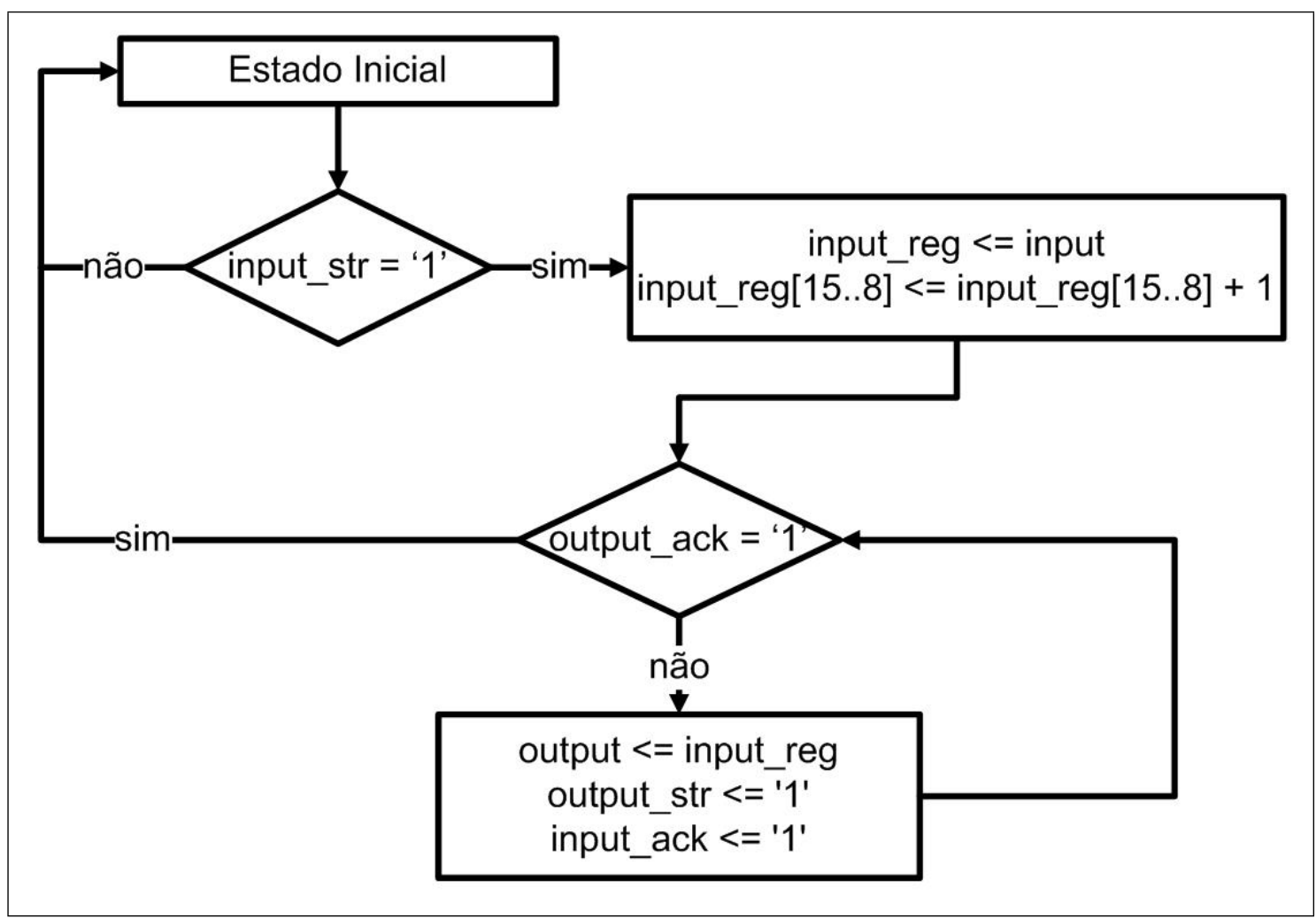

Figura 5.17: Diagrama de estados do operador NIG.

Como pode ser visto na figura, assim que input_str for igual a 1, o valor recebido em input é armazenado em input_reg. Logo em seguida o valor do campo da iteração atual é incrementado por meio da atribuição input_reg[15..8]<= input_reg[15..8] + 1. Como output_ack é igual a zero antes do envio do dado ao operador seguinte, o valor de input_reg é enviado para output e, assim que output_ack passa a valer 1, o operador volta ao seu estado inicial. A Tabela 5.3 apresenta os dados de síntese do operador NIG.

A Figura 5.18 apresenta a simulação do operador NIG após a síntese e o place and route utilizando a ferramenta ISE da Xilinx. A figura mostra o opera-

Tabela 5.3: Resultados da síntese do operador NIG na Xilinx Spartan 3E 3s500efg320-4.

\begin{tabular}{c|c} 
& Utilização dos Elementos do Dispositivo \\
\hline Operador & NIG \\
\hline Número de Slices & 46 de $4656(0 \%)$ \\
\hline Número de Slices FFs & 69 de $9312(0 \%)$ \\
\hline Número de LUTs de 4 entradas & 41 de $9312(0 \%)$ \\
\hline Número de bounded IOBs & 69 de $232(29 \%)$ \\
\hline Número de GCLKs & 1 out of $24(4 \%)$ \\
\hline \hline Período Mínimo & $4.390 \mathrm{~ns}$ \\
\hline Frequência Máxima & $227.788 \mathrm{MHz}$ \\
\hline
\end{tabular}


dor NIG recebendo primeiramente um dado igual a $<0.0 .00,0000>h$ e depois igual a $<0.0 .01,0000>h$. A ideia nesta simulação é mostrar um token que circula em um loop passando duas vezes pelo mesmo NIG. Então primeiro ele passa valendo $<0.0 .00,0000>h$ e sai do operador valendo $<0.0 .01,0000>h$, já com a iteração incrementada. Em seguida, este mesmo dado passa novamente pelo NIG e tem sua iteração atual novamente ajustada, passando a valer $<0.0 .02,0000>h$. Os sinais de handshake também podem ser visualizados na simulação.

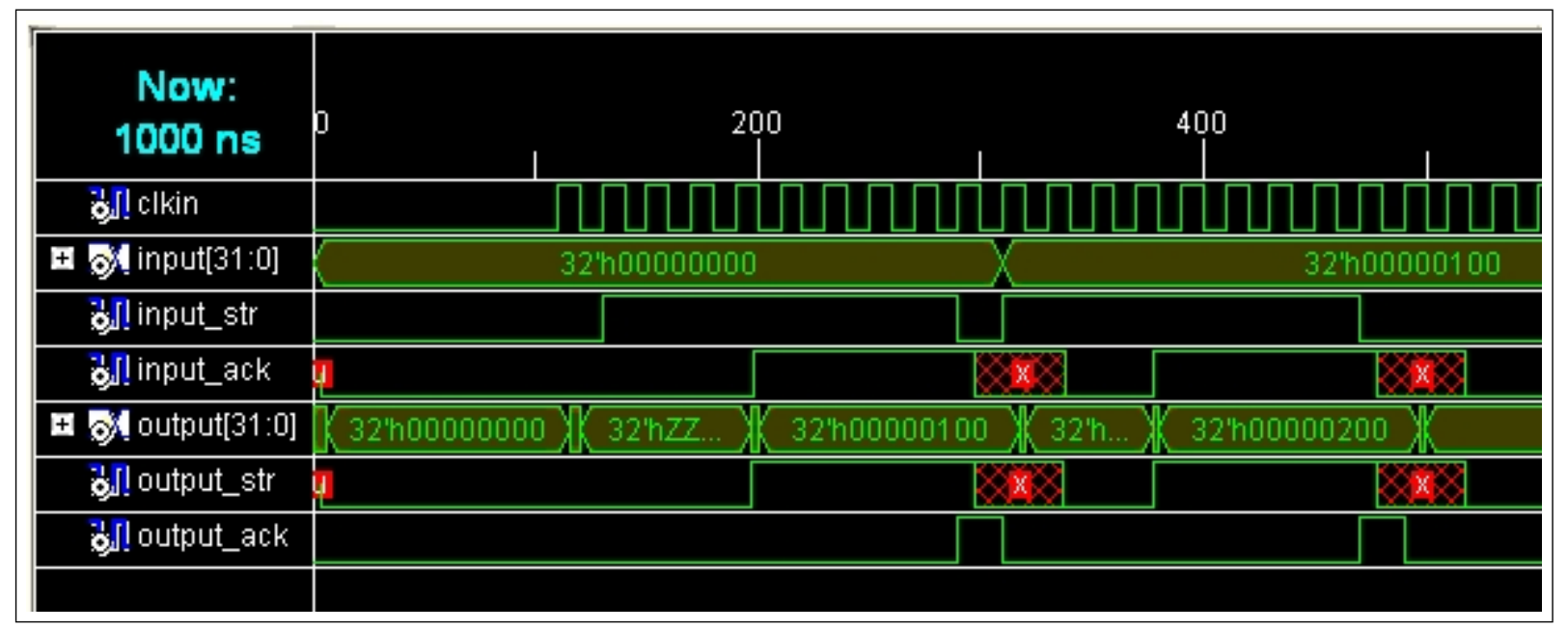

Figura 5.18: Simulação do operador NIG após síntese e place and route.

\subsubsection{New Tag Manager (NTM)}

O operador NTM recebe conjuntos de entradas, atribui uma nova ativação de subgrafo para as tags de cada conjunto de entrada, envia as tags antigas para a OTT (caso exista) e atribui zero para o campo iteração atual de cada tag. O NTM é utilizado no início de cada construção iterativa. A Figura 5.19 apresenta o bloco esquemático de um NTM com capacidade para receber três tokens para cada conjunto de entradas juntamente com sua representação gráfica.

Os sinais input, clkin, input_str, output_ack, newtag_ack e oldtag_ack são sinais de entrada e os sinais output, input_ack, output_str, newtag, newtag_str, oldtag e oldtag_str são sinais de saída. Os dados entram pelo sinal input e os sinais input_str e input_ack são os sinais de handshake para o sinal input. O NTM envia a nova tag para a OTT através da saída newtag seguindo o protocolo de comunicação por meio dos sinais newtag_str e newtag_ack e a tag antiga é enviada para a OTT através da saída oldtag utilizando os sinais oldtag_str e oldtag_ack para o protocolo de comunicação. O resultado da operação é enviado para a saída output que possui os sinais de handshake output_str e output_ack. No caso deste NTM, existem 96 bits para o sinal 


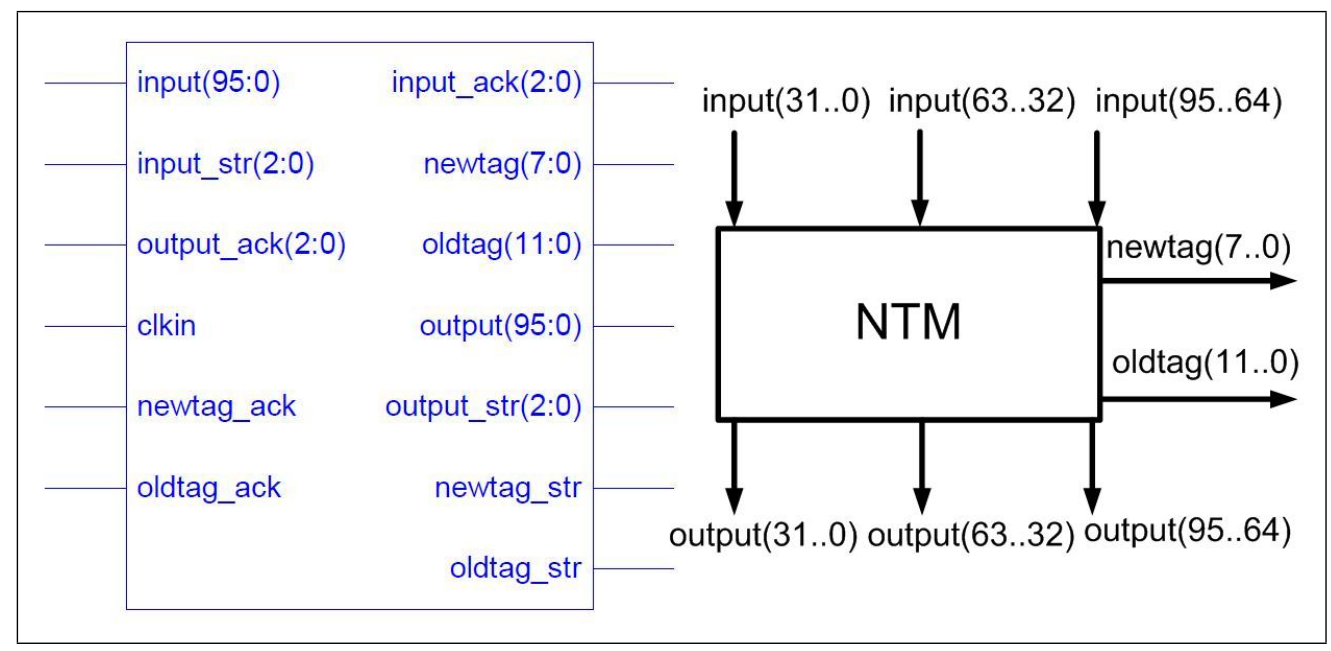

Figura 5.19: Bloco esquemático do operador NTM e sua representação gráfica.

input, ou seja, o NTM recebe três entradas de 32 bits, sendo que os bits de 0 a 31 são utilizados para a primeira entrada, de 32 a 63 é a segunda entrada e de 64 a 95 bits é a terceira entrada. Para cada uma das três entradas existe um par de sinais para a realização do handshake relacionado a entrada. Os bits de saída também estão divididos da mesma forma, gerando três saídas após a operação do NTM. O diagrama de estados do NTM apresentado, foi dividido em três figuras para uma melhor visualização. A Figura 5.20 apresenta o diagrama de estados do operador NTM relativo ao recebimento dos dados de entrada. A Figura 5.21 apresenta o processo de enviar a tag antiga e a nova tag para serem armazenadas na OTT. E por fim na Figura 5.22, é apresentado o processo para enviar os resultados para a saída do operador.

O recebimento dos dados de entrada funciona da seguinte maneira: há um vetor chamado rec_input responsável por armazenar quais dados de entrada já foram recebidos. O vetor possui o tamanho igual ao número de entradas do operador, no caso deste NTM, rec_input possui três posições. A partir do estado inicial, é feito um teste se cada posição de input_str é igual a 1, ou seja, se algum dado de entrada já está disponivel. A medida que os dados de entrada se tornam disponiveis, eles são armazenados em input_reg e a posição de rec_input referente a este dado recebe valor igual a 1. Após receber os dados de entrada, a máquina de estados realiza um conjunto de operações lógicas armazenando o resultado no registrador rec_and. Estas operações lógicas ( $\mathrm{E}$ lógico) resultarão em 1 caso todas as entradas tenham sido recebidas e armazenadas em suas respectivas partes de input_reg. Logo em seguida, há um teste para saber se rec_and é igual a 1. Se não é igual a 1, significa que ainda faltam entradas para serem recebidas e a máquina volta para o estado inicial. Se rec_and é igual a 1, rec_and, rec_input[0], rec_input[1] e rec_input[2] recebem zero e o operador passa para o próximo estágio, que é a geração de tags novas e envio de dados à OTT. 


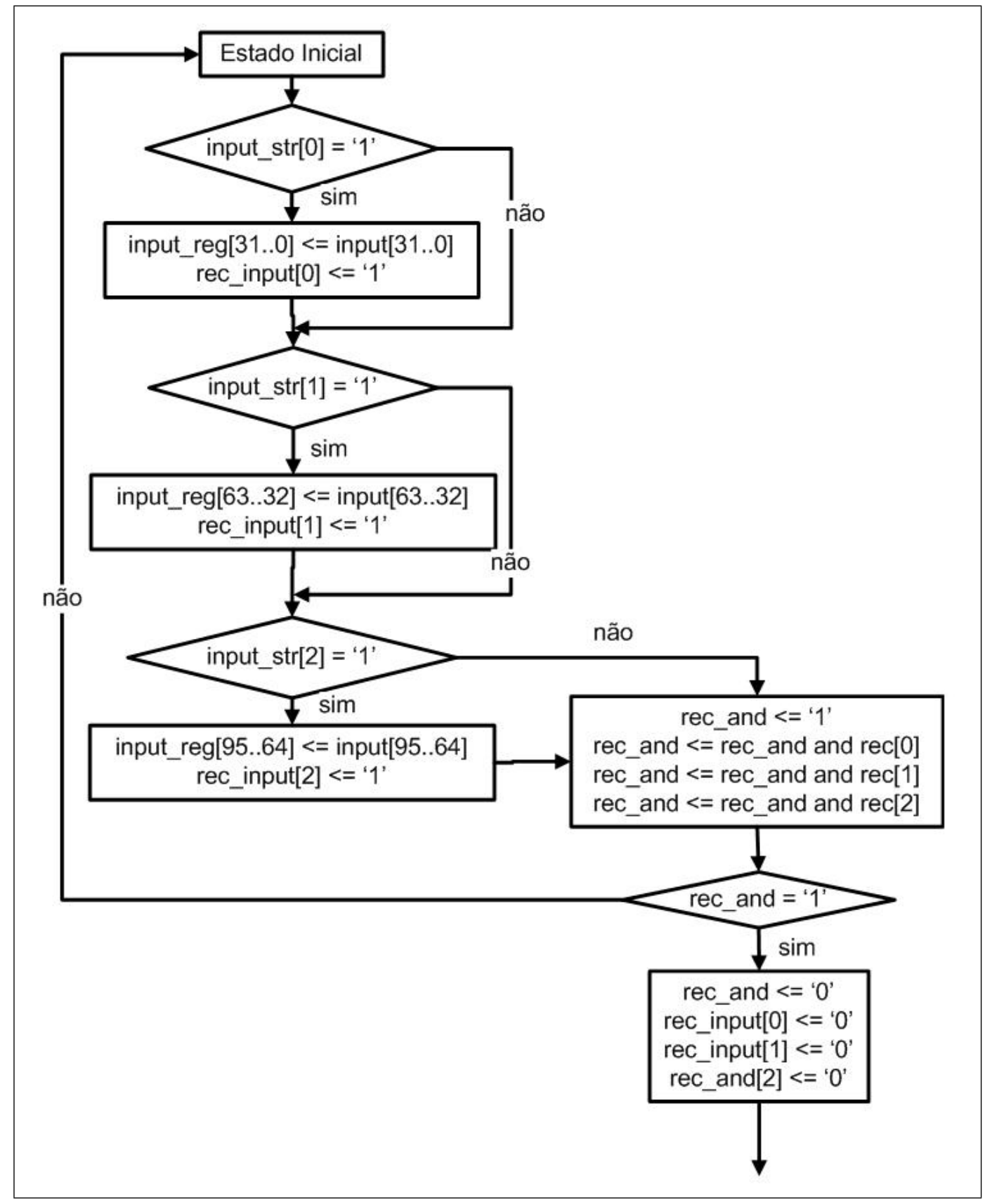

Figura 5.20: Diagrama de estados do operador NTM: recebimento dos dados de entrada. 


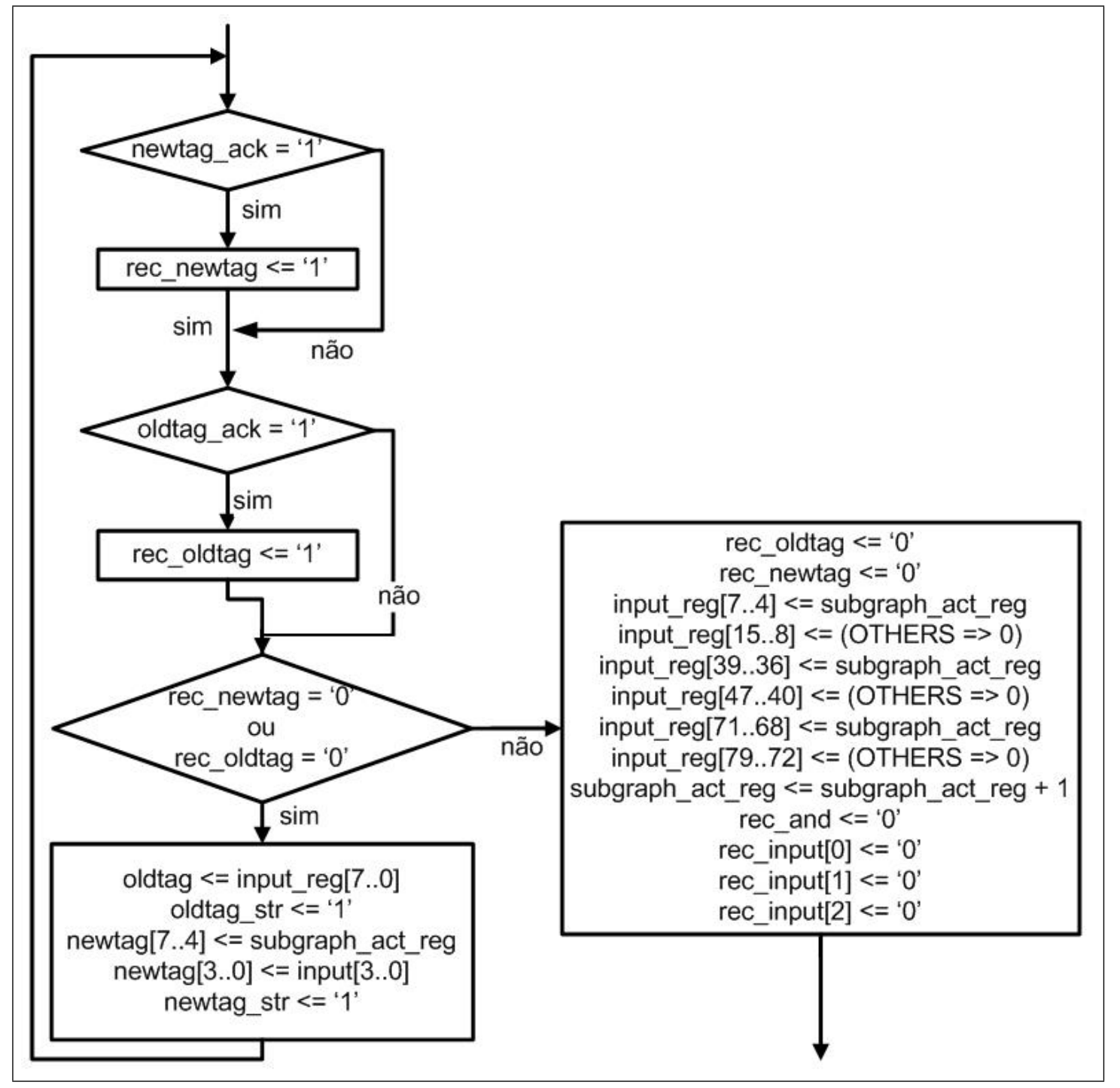

Figura 5.21: Diagrama de estados do operador NTM: geração de tags novas e envio de dados à OTT. 
Os valores de newtag e oldtag são enviados juntamente com seus sinais de handshake para a OTT. Quando a OTT recebe os sinais do protocolo avisando que os dados estão disponíveis, ela responde pelo protocolo avisando que já recebeu e armazenou. No diagrama de estados da Figura 5.21, primeiramente é testado se newtag_ack é igual a 1. Na primeira vez que este teste é feito o resultado é FALSO, pois o valor newtag ainda não foi enviado para a OTT. Em seguida, é testado se oldtag_ack é igual a 1 e, como oldtag também não foi enviado ainda na primeira vez que o teste é feito, o resultado também é FALSO. Quando a primeira condição é VERDADEIRA, rec_newtag recebe 1 para indicar que a OTT já recebeu o valor de newtag. Quando a segunda condição é VERDADEIRA, rec_oldtag recebe 1 para indicar que a OTT já recebeu o valor de oldtag. Um terceiro teste é feito para verificar se rec_newtag ou rec_oldtag ainda é igual a zero. Se algum deles ainda é igual a zero, significa que a OTT ainda não recebeu todos os valores, então a máquina de estado disponibiliza os valores de oldtag e newtag na saída, sinaliza que estão disponíveis por meio do protocolo de comunicação e volta para a primeira condição (newtag_ack = 1), recomeçando as verificações. Se ambos os valores rec_newtag e rec_oldtag são iguais a 1, rec_newtag e rec_oldtag recebem zero e a nova tag para o token armazenado em input_reg é gerada. O campo ativação de subgrafo de cada entrada (input_reg[7..4], input_reg[39..36] e input_reg[71..68]) recebe o valor do registrador subgraph_act_reg, responsável por armazenar a ativação de subgrafo que deve ser atribuída a cada novo conjunto de entradas. O campo iteração atual de cada entrada (input_reg[15..8], input_reg[47..40] e input_reg[79..72]) recebe zero, o campo ativação de grafo e o dado propriamente dito permanecem inalterados. Os registradores para controle do recebimento das entradas (rec_and, rec_input[0], rec_input[1] e rec_input[2]) também recebem zero. Neste momento, o operador passa para o último estágio, que é o envio do resultado para a saída.

No estágio de envio de resultados, todos os resultados são colocados em output assim como o aviso para o próximo operador de que os dados estão prontos. Quando todas as entradas são recebidas pelo operador seguinte, o operador NTM volta ao seu estado inicial. No diagrama de estados da Figura 5.22, os três primeiros testes (output_ack[O]=1, output_ack[1] $=1$ e output_ack[2] = 1) não resultam VERDADEIRO pois a saída output ainda não está disponível para o operador seguinte, portanto ele não pode reconhecer o recebimento. Caso alguma destas condições seja VERDADEIRA, significa que o token enviado pela saída foi recebido e a posição de send_output referente ao token recebe 1 para indicar que este dado já foi recebido. Após passar pelas três condições, a máquina de estados realiza um conjunto de operações lógicas (E lógico), armazenadas em send_and, que irá resultar em 1 caso todos os va- 


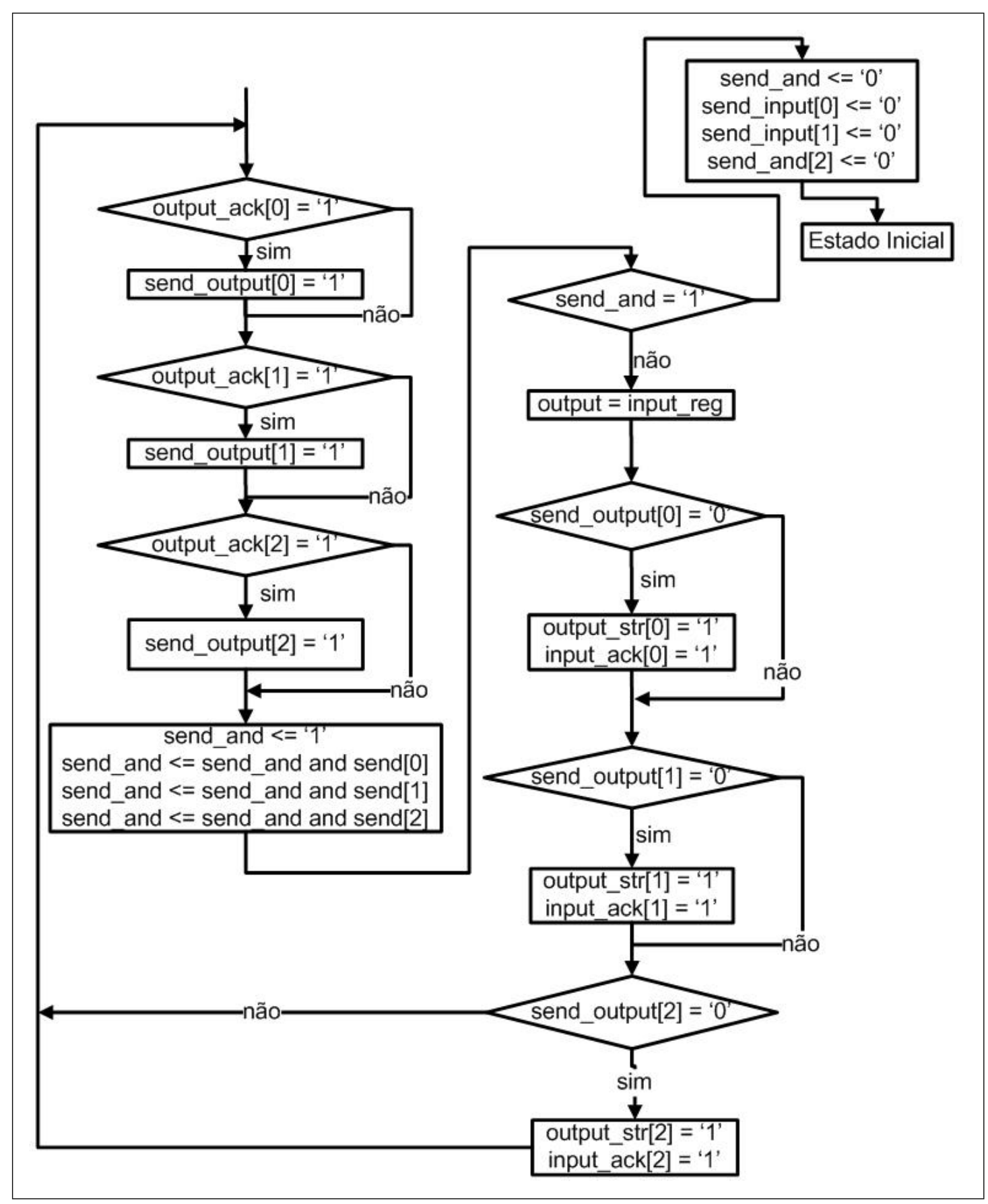

Figura 5.22: Diagrama de estados do operador NTM: envio do resultado para a saída. 
Tabela 5.4: Resultados da sintese do operador NTM na Xilinx Spartan 3E 3s500efg320-4.

\begin{tabular}{c|c} 
& Utilização dos Elementos do Dispositivo \\
\hline Operador & NTM \\
\hline Número de Slices & 159 de $4656(3 \%)$ \\
\hline Número de Slices FFs & 243 de $9312(2 \%)$ \\
\hline Número de LUTs de 4 entradas & 122 de $9312(1 \%)$ \\
\hline Número de bounded IOBs & 229 de $232(98 \%)$ \\
\hline Número de GCLKs & 1 out of $24(4 \%)$ \\
\hline \hline Período Mínimo & $4.786 \mathrm{~ns}$ \\
\hline Frequência Máxima & $208.923 \mathrm{MHz}$ \\
\hline
\end{tabular}

lores de send_output sejam iguais a 1, ou seja, caso todas as entradas tenham sido recebidas. Então, se send_and não é igual a 1, output recebe input_reg. Em seguida, se send_output $[0]=0$, output_str[O] recebe 1 para indicar que a saída zero está disponivel para o operador seguinte e, input_ack[O] recebe 1 para indicar para o operador antecedente que o NTM recebeu e processou adequadamente aquele dado. Os outros valores de send_output são testados e o mesmo processo ocorre com os outros dados. Por fim, se send_and é igual a 1, os registradores para controle do envio de dados (send_and, send_input[0], send_input[1] e send_input[2]) recebem zero e a máquina de estados volta ao seu estado inicial, podendo então receber novos conjuntos de entradas. A Tabela 5.4 apresenta os resultados da síntese do operador NTM.

A Figura 5.23 apresenta a simulação do operador NTM após a síntese e o place and route utilizando a ferramenta ISE da Xilinx. A figura mostra o operador NTM recebendo primeiramente um conjunto de entradas com três dados: $<0.2 .00, F F F F>h,<0.2 .00, E E E E>h$ e $<0.2 .00, D D D D>h$. Após receber os dados de entrada, as tags antigas e novas são enviadas para a OTT, no caso $<2.00>h$ e $<0.0>h$ respectivamente. Em seguida, é gerada a saída com a nova tag, e os tokens passam a ser $<0.0 .00, F F F F>h$, $<$ 0.0.00, EEEE $>h$ e $<0.0 .00, D D D D>h$. Um segundo conjunto de entradas foi simulado também de maneira similar ao caso explicado acima, porém no segundo caso fica evidente o uso do registrador interno para diferenciar dados de diferentes conjuntos de entradas, pois o novo valor de subgrafo das tags passa a ser 1 já que o registrador foi incrementado na execução anterior. Os sinais de handshake também podem ser visualizados na simulação.

\subsubsection{New Tag Destructor (NTD)}

O operador NTD é responsável por recuperar a tag antiga de um token que está saindo de uma construção iterativa e necessita voltar para ser proces- 


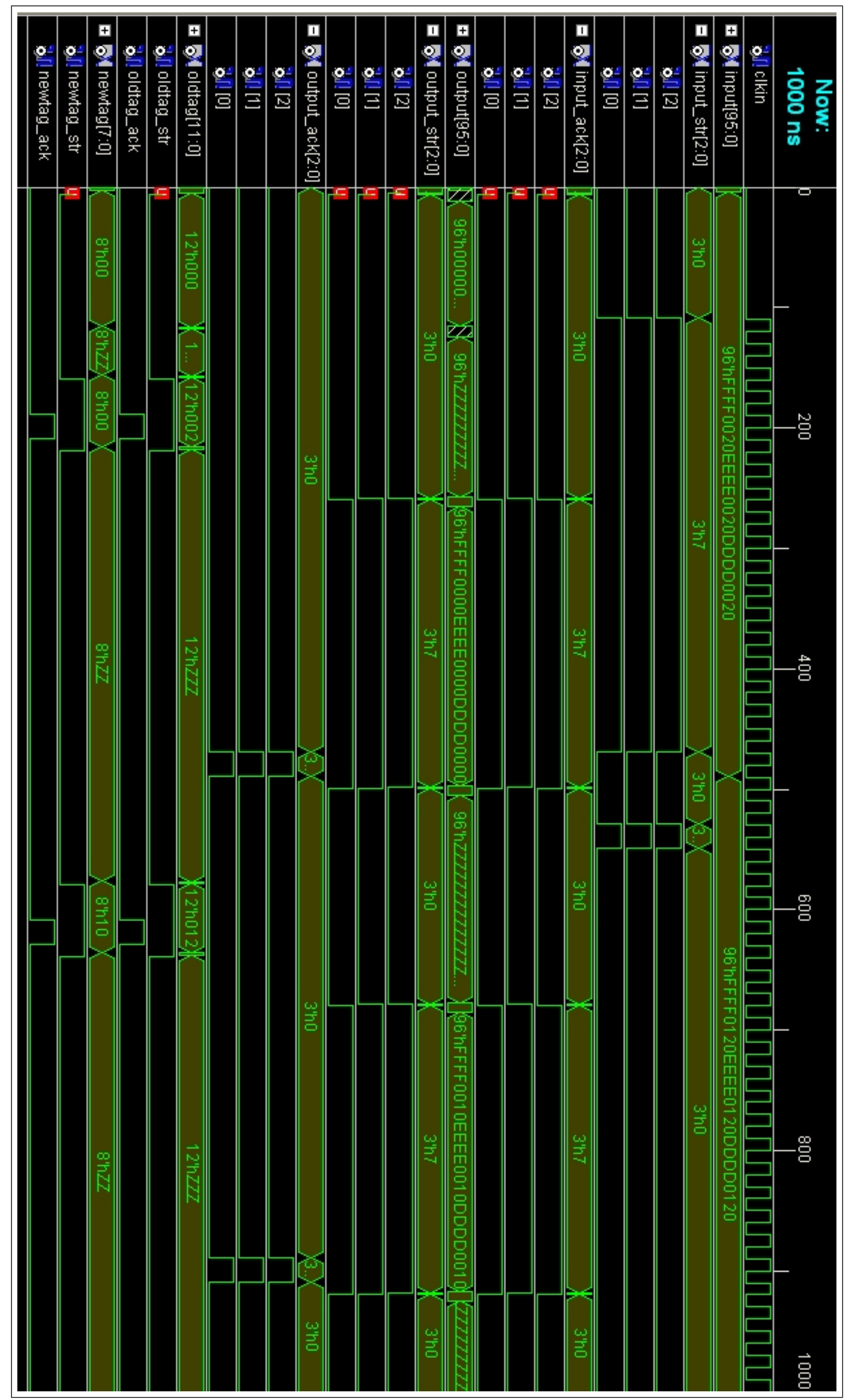

Figura 5.23: Simulação do operador NTM após síntese e place and route. 
sado no nível de aninhamento mais externo. A Figura 5.24 apresenta o bloco esquemático do NTD juntamente com sua representação gráfica.

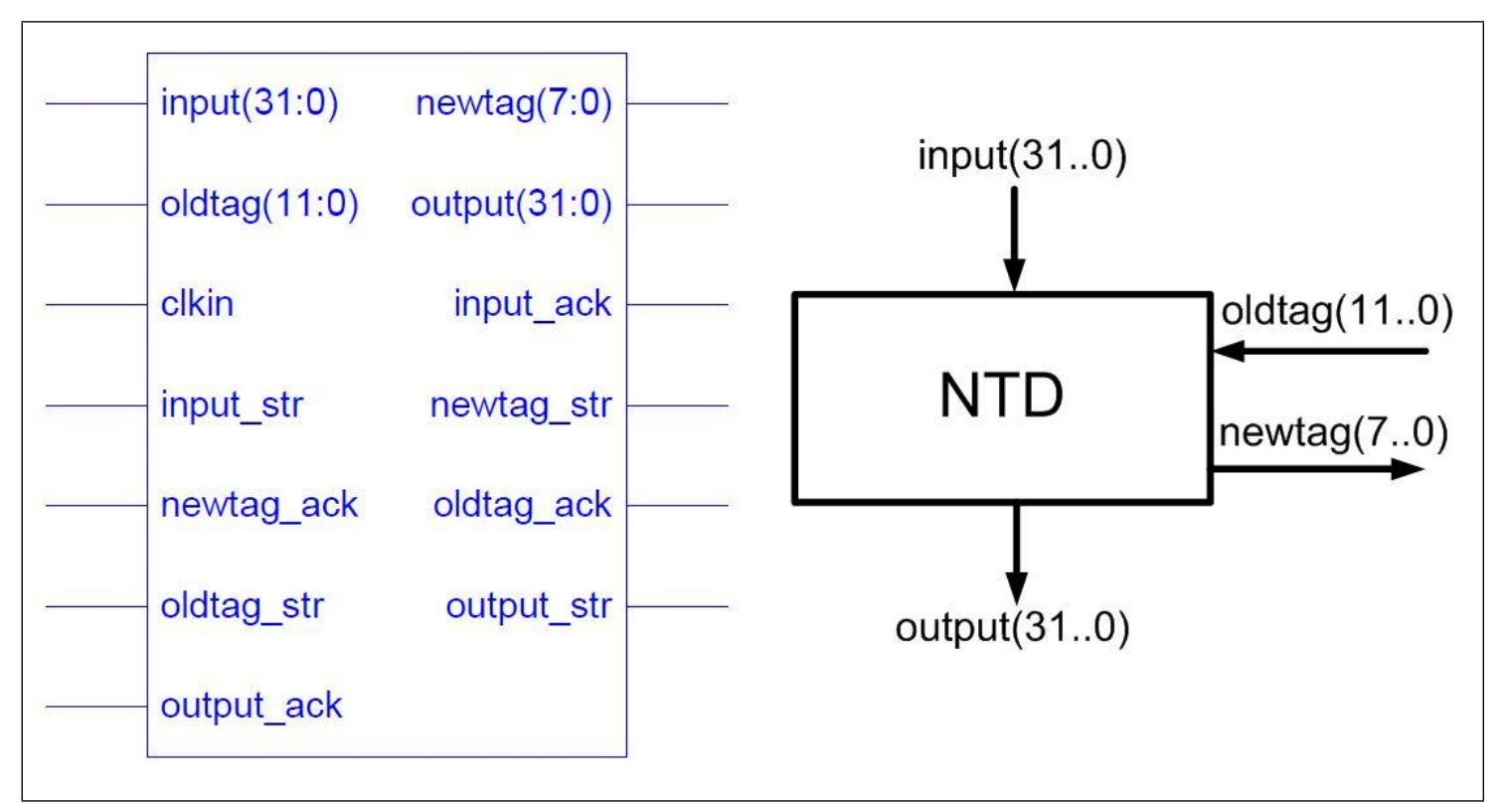

Figura 5.24: Bloco esquemático do operador NTD e sua representação gráfica.

Os sinais input, clkin, input_str, output_ack, newtag_ack, oldtag e oldtag_ack são sinais de entrada e os sinais output, input_ack, output_str, newtag, newtag_str e oldtag_str são sinais de saída. O token entra pelo sinal input e os sinais input_str e input_ack são os sinais de handshake para o sinal input. $\mathrm{O}$ NTD envia a nova tag para a OTT através da saída newtag seguindo o protocolo de comunicação por meio dos sinais newtag_str e newtag_ack e a tag antiga é recebida através da entrada oldtag utilizando os sinais oldtag_str e oldtag_ack para o protocolo de comunicação. O resultado da operação é enviado para a saída output que possui os sinais de handshake output_str e output_ack. A Figura 5.25 apresenta o diagrama de estados do operador NTD.

Inicialmente, é testado se input_str é igual a 1. Se não é, o teste se repete até que um dado chegue e input_str seja 1. Quando input_str se torna 1, input_reg recebe input. Neste momento, o NTD deve enviar a tag atual do token recebido para a OTT a fim de que ela envie de volta a tag antiga daquele token. Isto é feito pelos comandos newtag <= input_reg[7..0] e newtag_str <= '1'. Se a OTT recebe o dado, newtag_ack se torna 1. Após enviar o dado, o NTD fica esperando a OTT enviar a tag antiga e sinalizar por meio de oldtag_str que ela já está disponível. Enquanto os sinais de handshake não sinalizam o envio e recebimento das tags, os dados permanecem disponíveis. Então, quando oldtag_str é igual a 1, input_reg[15..8] recebe oldtag e, portanto, os campos iteração atual e ativação de subgrafo que o token possuía antes de entrar no loop são recuperados. A condição seguinte testa se output_ack é igual a 1. Caso não é, output recebe input_reg, output_str recebe 1 para indicar 


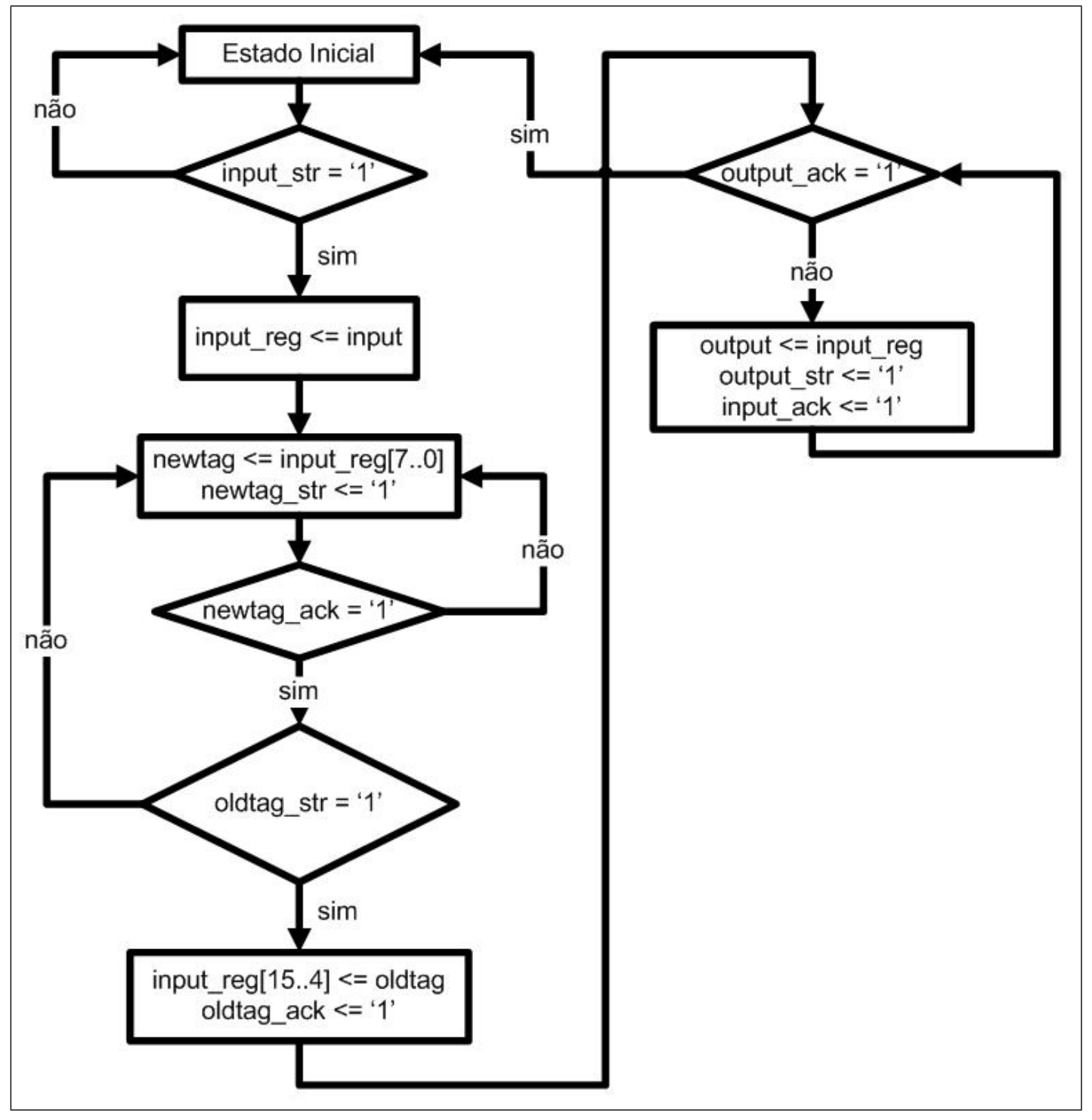

Figura 5.25: Diagrama de estados do operador NTD. 
Tabela 5.5: Resultados da síntese do operador NTD na Xilinx Spartan 3E 3s500efg320-4.

\begin{tabular}{c|c} 
& Utilização dos Elementos do Dispositivo \\
\hline Operador & NTD \\
\hline Número de Slices & 47 de $4656(1 \%)$ \\
\hline Número de Slices FFs & 81 de $9312(0 \%)$ \\
\hline Número de LUTs de 4 entradas & 57 de $9312(0 \%)$ \\
\hline Número de bounded IOBs & 93 de $232(40 \%)$ \\
\hline Número de GCLKs & 1 out of $24(4 \%)$ \\
\hline \hline Período Mínimo & $3.523 \mathrm{~ns}$ \\
\hline Frequência Máxima & $283.889 \mathrm{MHz}$ \\
\hline
\end{tabular}

ao operador seguinte que o dado está disponível e input_ack recebe 1 para indicar ao operador antecedente que o dado enviado foi recebido e processado adequadamente. Finalmente, quando output_ack é igual a 1, significa que o operador seguinte recebeu o dado e o NTD volta para o estado inicial, pronto para receber outro token. A Tabela 5.5 apresenta os resultados da síntese do operador NTD.

A Figura 5.26 apresenta a simulação do operador NTD após a síntese e o place and route utilizando a ferramenta ISE da Xilinx. A figura mostra o operador NTD recebendo primeiramente o dado $<1$.A.FF, $0000>h$. O operador requisita a leitura utilizando a ativação de grafo e ativação de subgrafo $(<1 . A>$ h). Após algum tempo, recebe a tag antiga $\langle C . C C\rangle$. Então, o dado é gerado na saída com sua tag antiga recuperada. O mesmo processo acontece para o token seguinte $<2 . A . F F, 0000>h$, que ao final se torna $<2 . B . B B, 0000>h$. Os sinais de handshake também podem ser visualizados na simulação.

\subsubsection{Old Tag Table (OT)}

A OTT é uma estrutura de memória responsável por armazenar as tags antigas dos dados que entram em construções iterativas e que ao final da construção iterativa necessitarão recuperar suas tags antigas para voltarem a executar corretamente em um nível de aninhamento anterior. A Figura 5.27 apresenta o bloco esquemático da OTT juntamente com sua representação gráfica.

Os sinais data_in, clkin, data_in_str, data_out_ack, addr_rd, addr_rd_str, $a d d r \_w r$ e $a d d r \_w r \_s t r$ são sinais de entrada e os sinais data_out, data_in_ack, $a d d r \_r d \_a c k, a d d r \_w r \_a c k$ e data_out_str são sinais de saída. A OTT implementa uma memória dual channel, ou seja, é possível realizar uma leitura e uma escrita simultaneamente desde que os endereços sejam diferentes. Os endereços de leitura são enviados para o sinal addr_rd e os de escrita para 


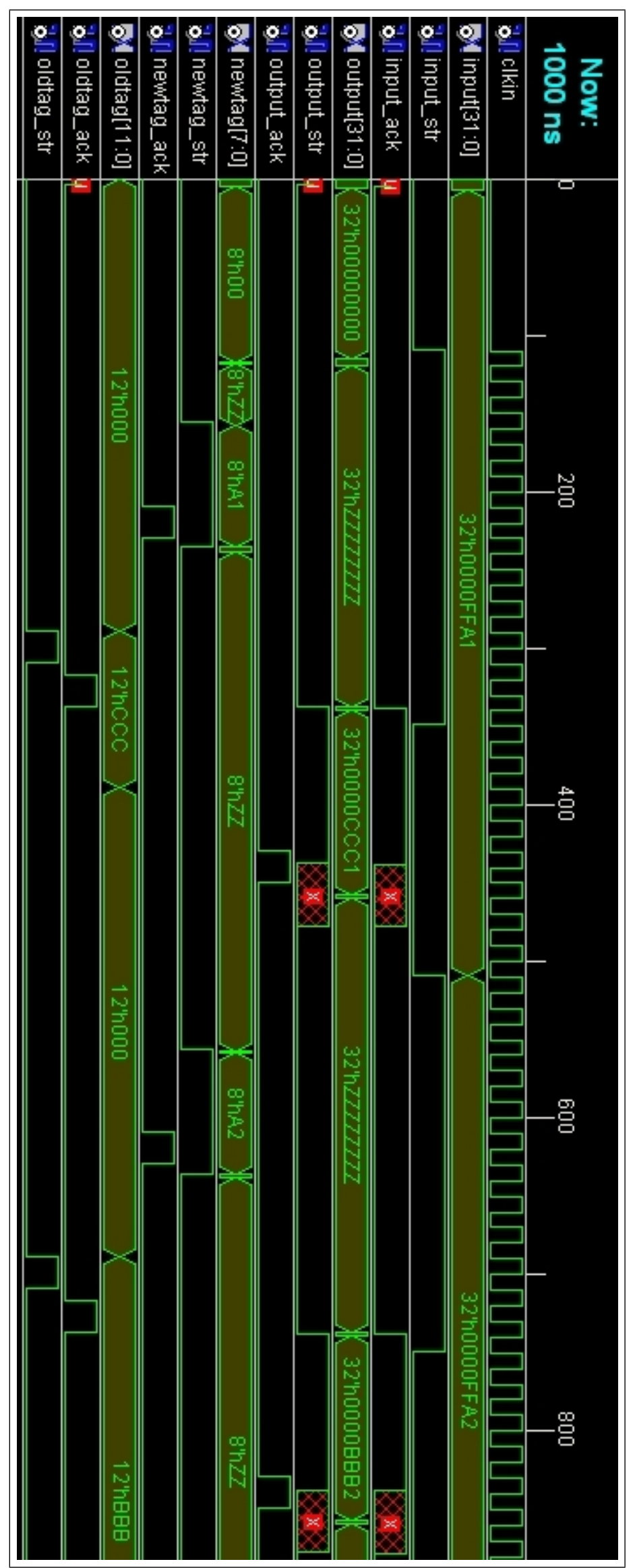

Figura 5.26: Simulação do operador NTD após sintese e place and route. 


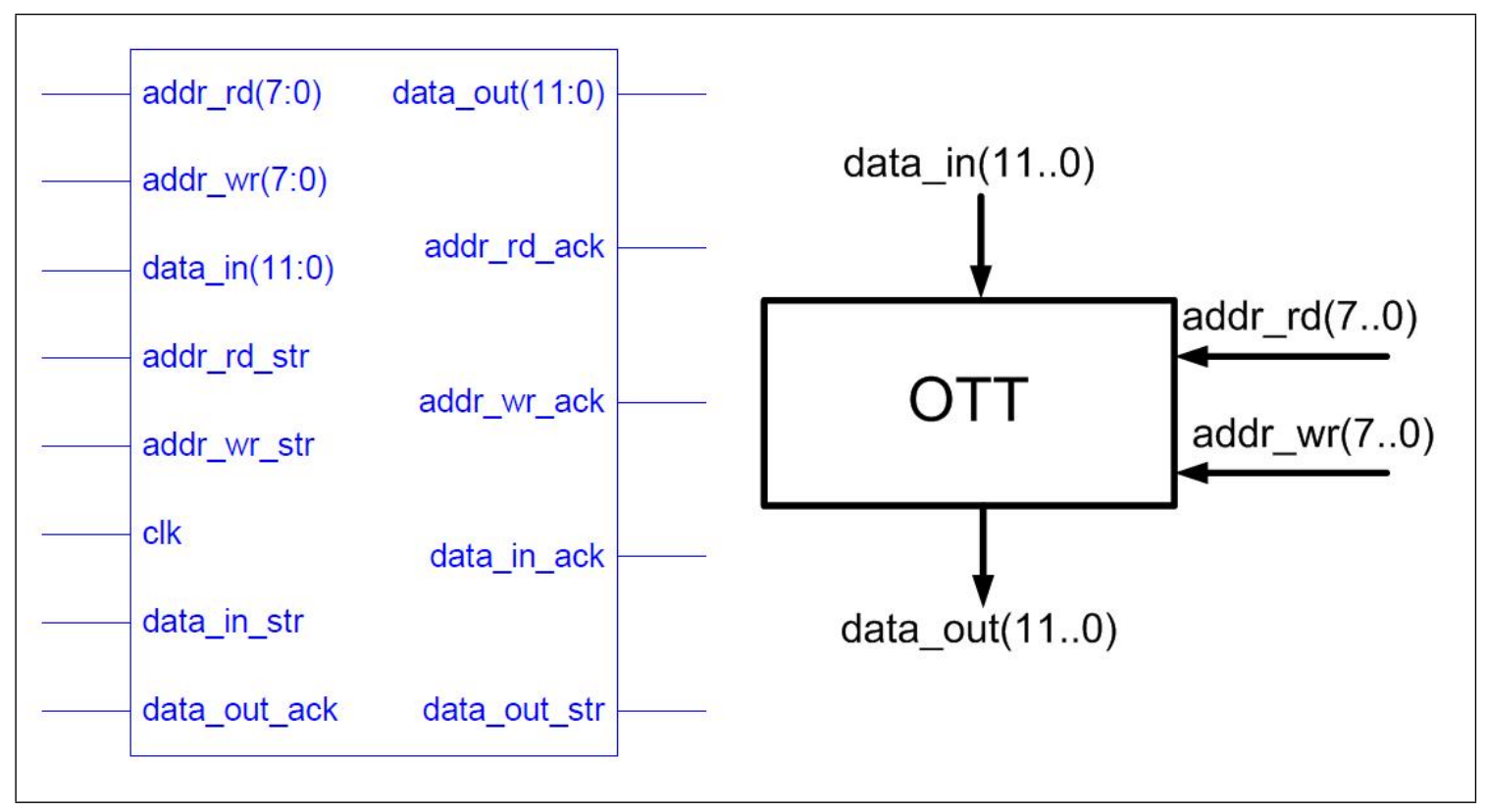

Figura 5.27: Bloco esquemático da OTT e sua representação gráfica.

$a d d r \_w r$. Quando a operação é de escrita, o dado a ser armazenado no endereço indicado pelo sinal $a d d r \_w r$ é o valor que está no sinal data_in. Quando a operação é de leitura, o dado a ser lido é colocado no sinal data_out. Todos os sinais de dados seguem o protocolo handshake. A Figura 5.28 apresenta o diagrama de estados da OTT referente ao processo de escrita. Já a Figura 5.29 apresenta o diagrama de estados da OTT referente ao processo de leitura.

O processo de escrita funciona da seguinte maneira: quando addr_wr_str e data_in_str são iguais a 1, significa que $a d d r \_w r$ e data_in estão disponíveis. Então, $a d \_w r$ recebe $a d d r \_w r, r e c \_a d d r \_w r$ recebe $1, d \_$in recebe data_in e rec_data_in recebe 1 . Em seguida, se rec_addr_wr ou rec_data_in não são iguais a 1, significa que algum dado não foi recebido e volta-se para o estado inicial. Se todos os dados foram recebidos, os valores para controle do recebimento dos dados recebem zero, os valores addr_wr_ack e data_in_ack recebem 1 e o endereço de memória $a d \_w r$ recebe o valor armazenado em d_in. Após isto, a máquina de estados volta ao estado inicial.

Já no processo de leitura, quando addr_rd_str é igual a 1 significa que a entrada $a d d r$ rd está disponível. A partir de então, o endereço de escrita recebido por $a d d r \_r d$ é copiado para ad_rd e enquanto data_out_ack não for igual a 1, o dado a ser lido fica disponível em data_out por meio do comando data_out $<=$ memory(conv_integer(add_rd)). Após data_out_ack se tornar 1 , indicando que o operador seguinte recebeu o dado, o processo de leitura da OTT volta ao seu estado inicial, pronta para receber novos dados. A Tabela 5.6 apresenta os dados de síntese da OTT.

A Figura 5.30 apresenta a simulação da OTT após a síntese e o place and route utilizando a ferramenta ISE da Xilinx. Inicialmente o valor $<A . A A\rangle h$ 


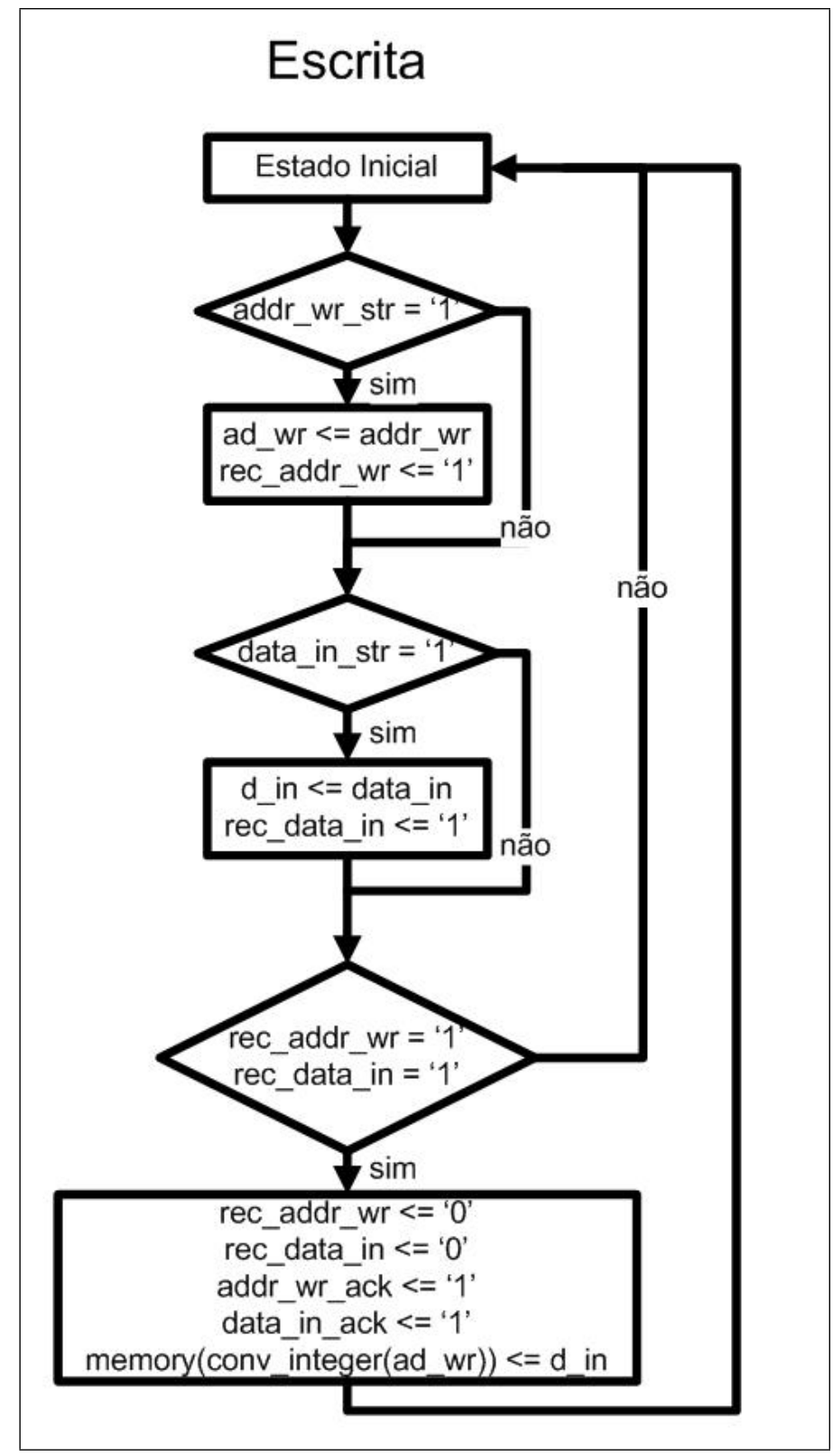

Figura 5.28: Diagrama de estados da OTT: Escrita.

Tabela 5.6: Resultados da sintese da OTT na Xilinx Spartan 3E 3s500efg3204.

Utilização dos Elementos do Dispositivo

\begin{tabular}{c|c}
\hline Operador & OTT \\
\hline Número de Slices & 13 de $4656(0 \%)$ \\
\hline Número de Slices FFs & 18 de $9312(0 \%)$ \\
\hline Número de LUTs de 4 entradas & 10 de $9312(0 \%)$ \\
\hline Número de bounded IOBs & 49 de $232(21 \%)$ \\
\hline Número de BRAMs & 1 de $20(5 \%)$ \\
\hline Número de GCLKs & 1 out of $24(4 \%)$ \\
\hline \hline Período Mínimo & $3.561 \mathrm{~ns}$ \\
\hline Frequência Máxima & $280.824 \mathrm{MHz}$ \\
\hline
\end{tabular}




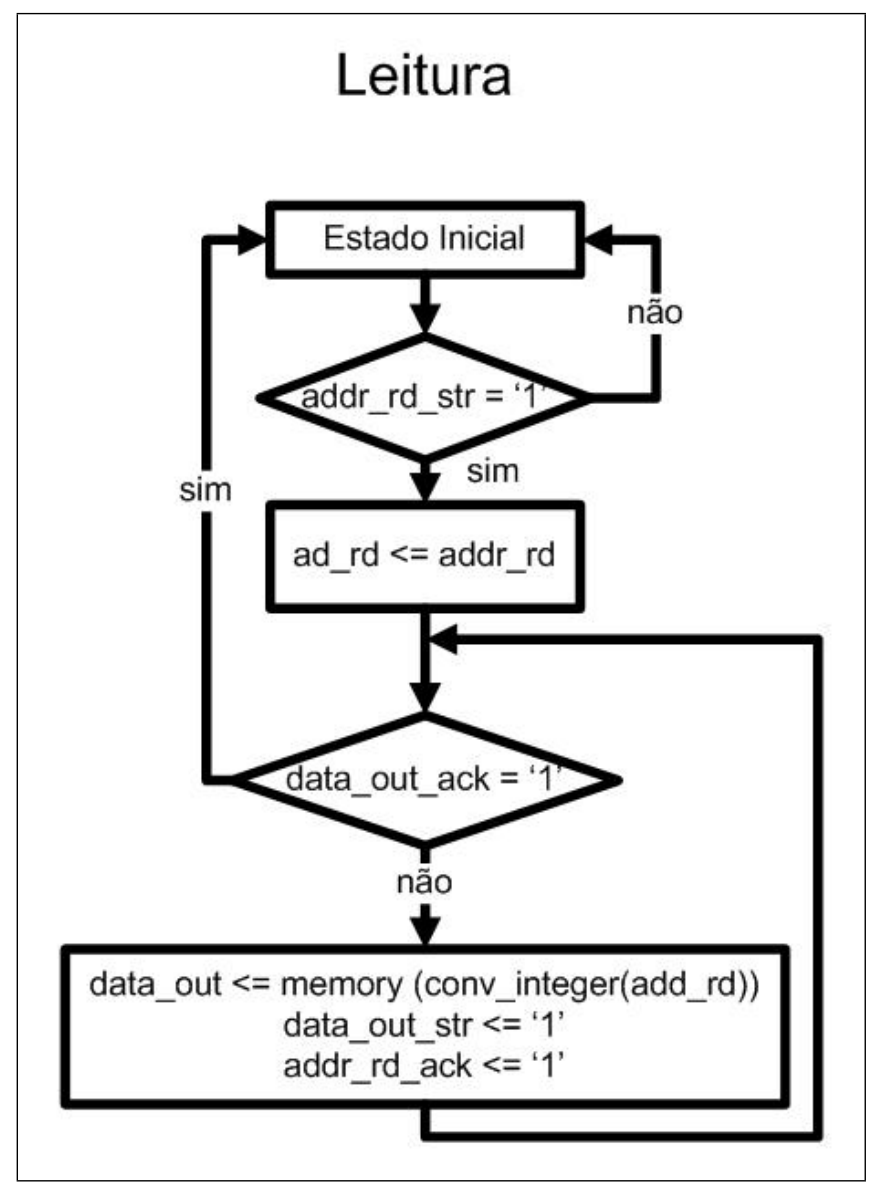

Figura 5.29: Diagrama de estados da OTT: Leitura.

é escrito no endereço $<0.0>h$. Em seguida, o valor $<B . B B>h$ é escrito no endereço $<0.1>h$ ao mesmo tempo em que uma leitura do endereço $<0.0>h$ está sendo realizada. Por fim, o endereço $<0.1>h$ é lido. Os sinais de handshake também podem ser visualizados na simulação.

Nesta implementação da OTT, a tag antiga é a informação armazenada e o endereço representa a tag nova, desta forma a busca da tag antiga é facilitada. Porém, questões de implementação, as limitações e vantagens serão discutidas nas próximas seções.

\subsubsection{Testes de integração}

Além dos testes do funcionamento de cada operador separadamente, também foram realizados testes integrando os operadores. Dois testes de integração serão apresentados a seguir.

O grafo do primeiro teste está representado na Figura 5.31.

Como pode ser visto na Figura 5.31, este grafo recebe um dado como entrada no operador ITG. Após receber sua tag, o token entra no subgrafo, que representa qualquer conjunto de operadores que não manipulam tags. Após passar pelo NTM, o token entra em um subgrafo e, por fim, o token sai do grafo através do operador TR. Dois sinais foram acrescentados no grafo para 


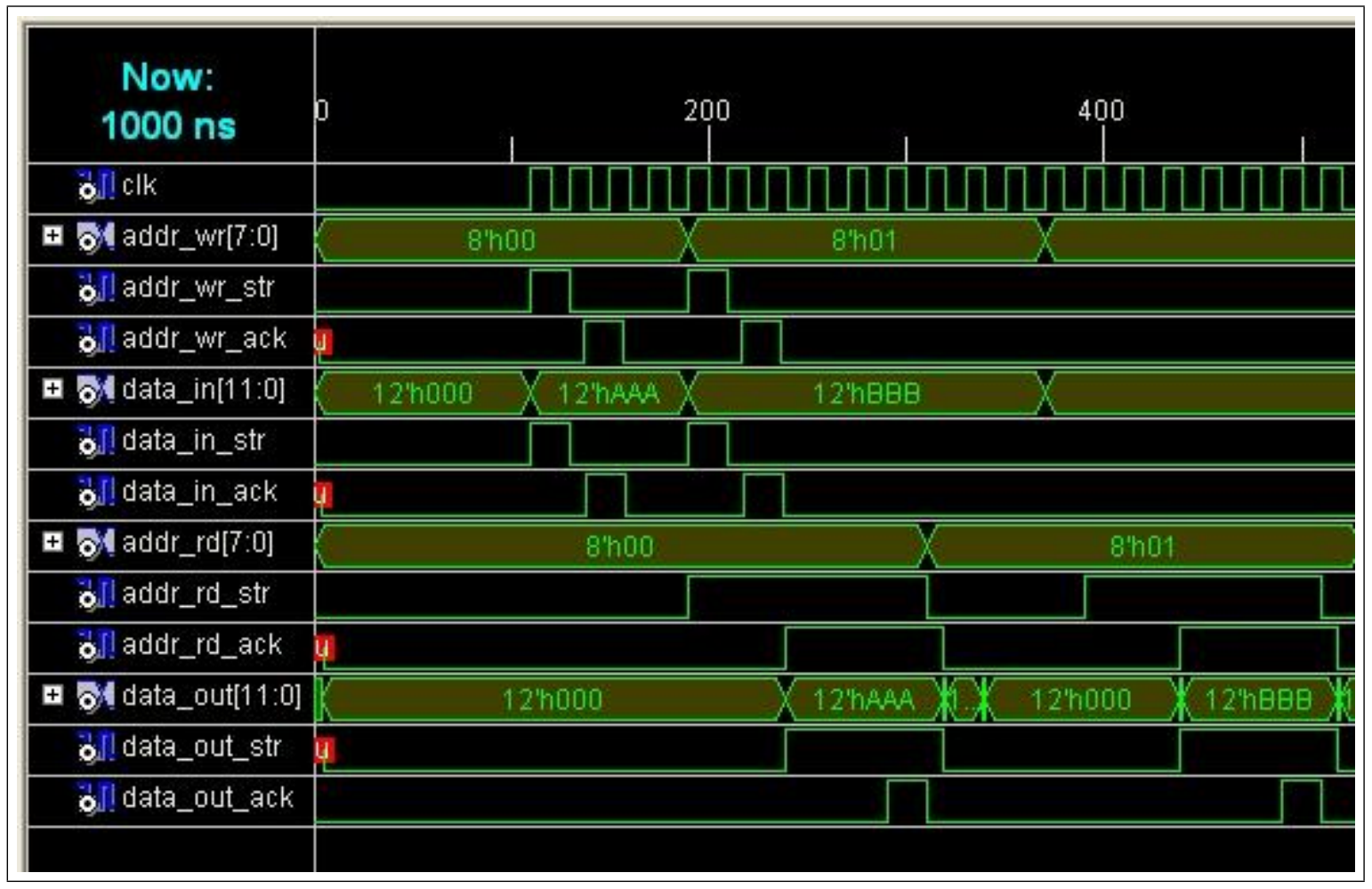

Figura 5.30: Simulação da OTT após síntese e place and route.

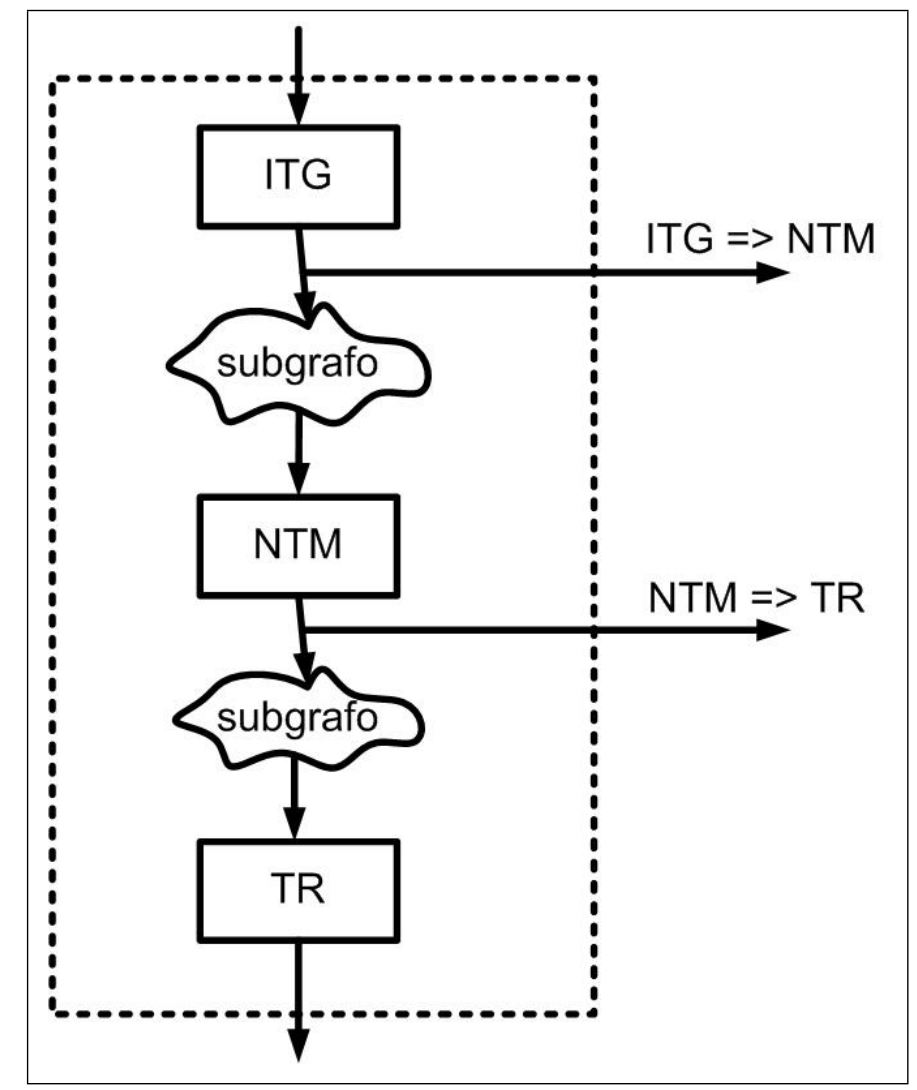

Figura 5.31: Grafo de teste integrando ITG, NTM e TR. 
visualizar os valores intermediários do token (ITG $=>$ NTM e NTM $=>$ TR). As Figuras 5.32 e 5.33 mostram a simulação deste teste na ferramenta ISE da Xilinx.

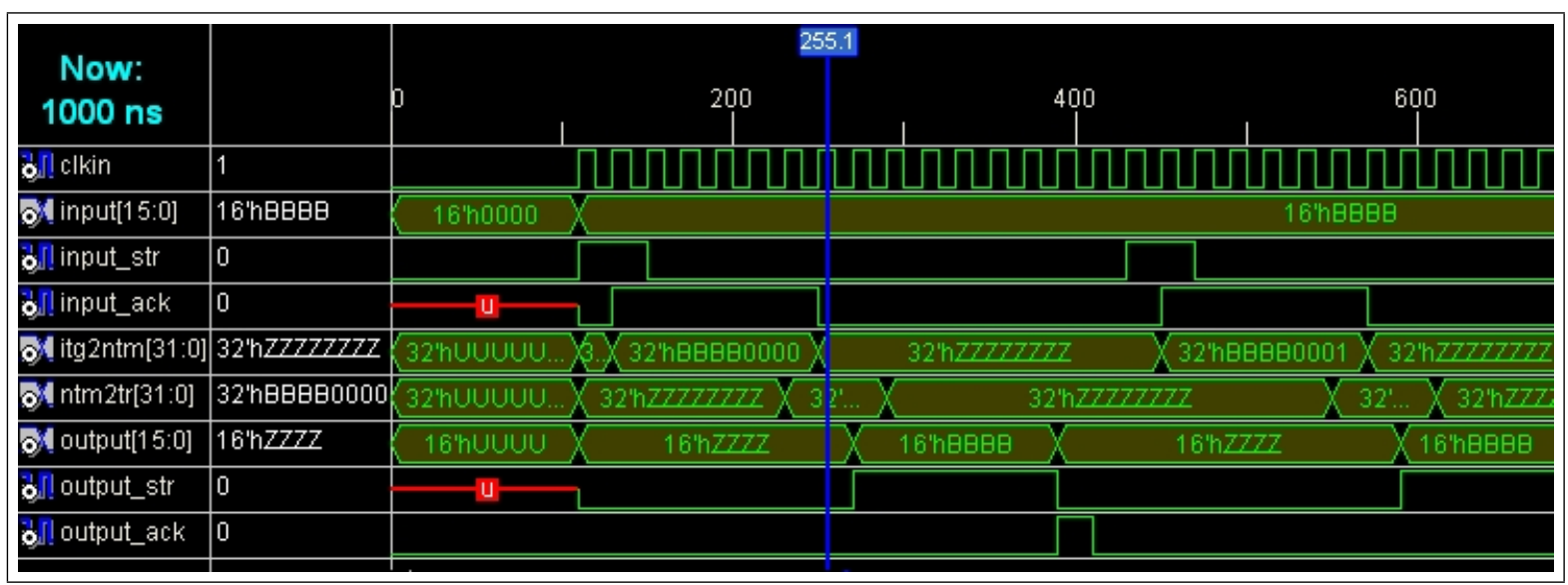

Figura 5.32: Simulação ITG, NTM e TR parte 1.

A Figura 5.32 mostra quando um primeiro dado valendo $<B B B B>h$ chega ao ITG. Podemos ver através do sinal itg2ntm (ITG $=>$ NTM) que após receber suas tags, o token passa a valer $<0.0 .00, B B B B>h$. No instante $255.1 \mathrm{~ns}$, o token já passou pelo NTM e o sinal ntm2tr (NTM => TR) mostra que o token vale $<0.0 .00, B B B B>h$. Finalmente, ao passar pelo TR, o token perde sua tag e passa a ser novamente apenas $<B B B B>h$.

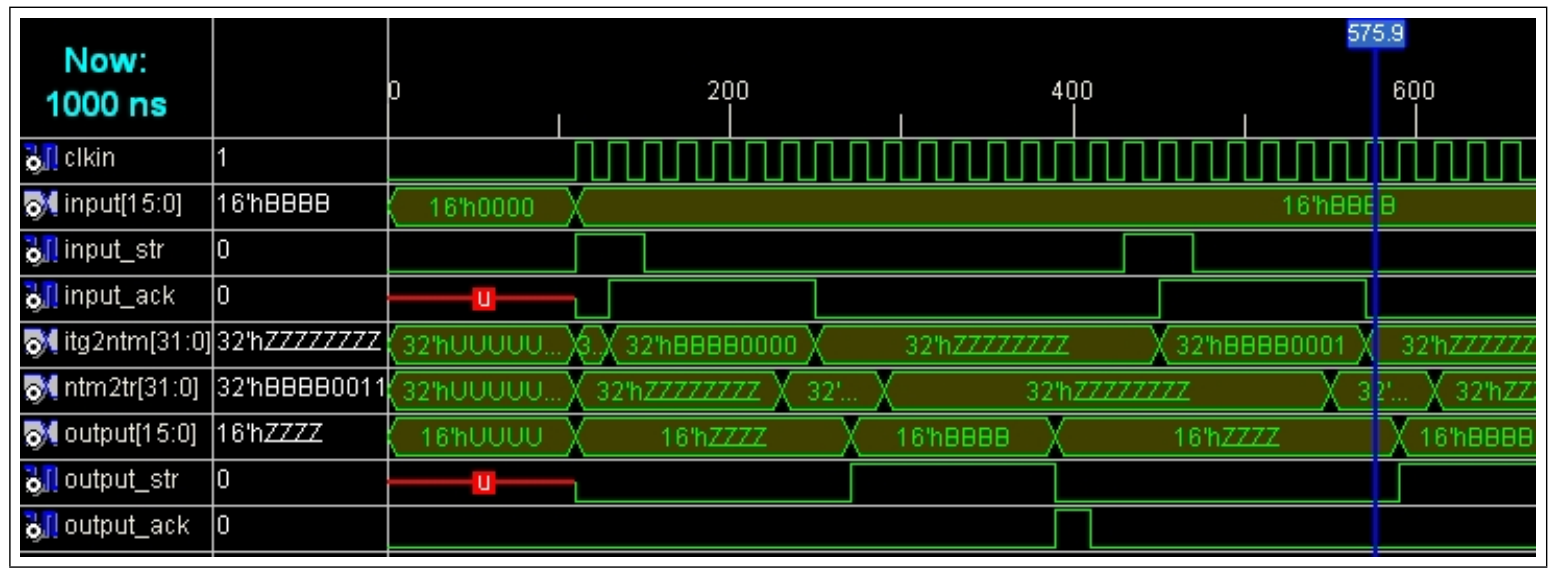

Figura 5.33: Simulação ITG, NTM e TR parte 2.

Já a Figura 5.33 mostra a mesma simulação, porém com foco no segundo dado que chega ao ITG. Tal dado, também valendo $<B B B B>h$, chega ao ITG por volta de $420 \mathrm{~ns}$ chegando ao ITG. Por ser o segundo dado, ao passar pelo ITG, o dado recebe uma segunda ativação e se torna $<1.0 .00, B B B B>h$, que pode ser visto pelo sinal itg2ntm. Por volta de $575.9 \mathrm{~ns}$, o token já passou pelo NTM e recebeu uma segunda ativação de subgrafo e passou a ser $<1.1 .00, B B B B>h$. Por fim, ao passar pelo TR, volta a ser simplesmente $<B B B B>h$. 
O segundo teste de integração realizado simula um subgrafo de uma construção iterativa. Neste grafo é possível verificar o funcionamento da OTT, juntamente com o NTM, NTD e o NIG. A Figura 5.34 ilustra este caso.

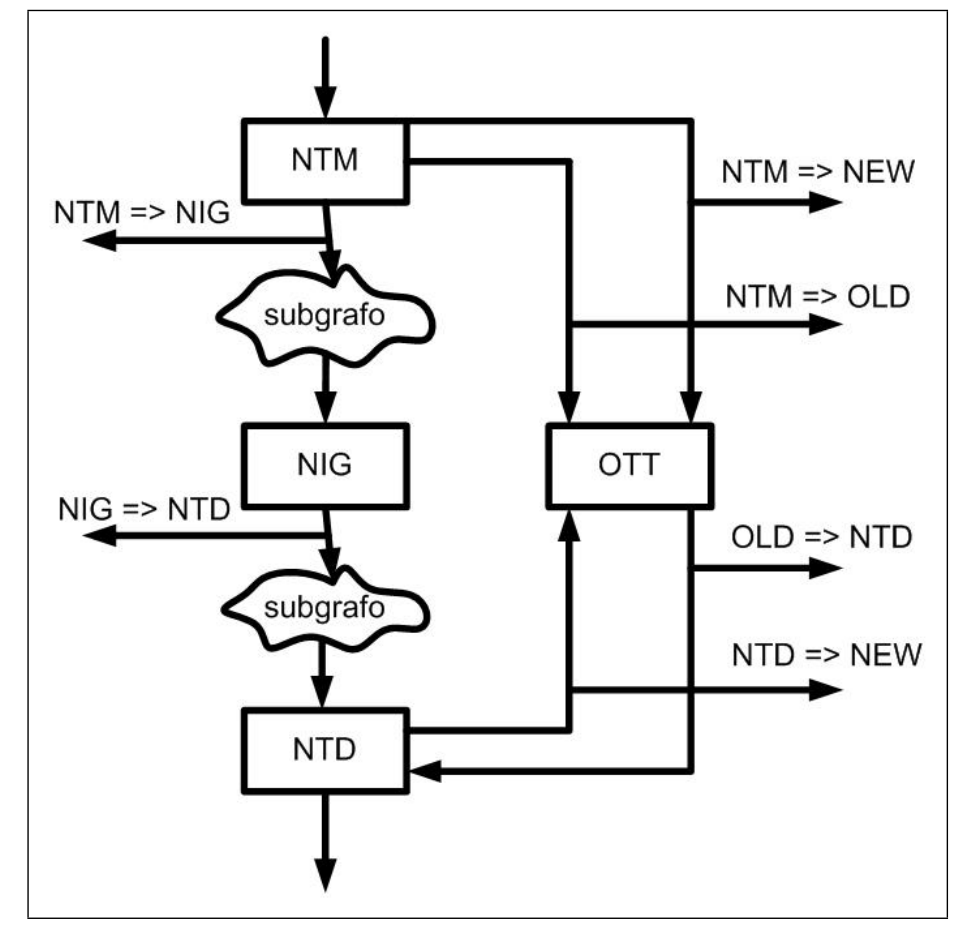

Figura 5.34: Grafo de teste integrando NTM, NIG, NTD e OTT.

Inicialmente, o token chega ao NTM. Neste momento, uma tag nova é gerada e a tag antiga juntamente com a gerada são enviadas para a OTT. O token segue pelo subgrafo e passa pelo NIG. Ao chegar ao NTD, o NTD solicita a tag antiga do token a OTT. Após recuperar sua tag antiga, o token sai da construção iterativa. Alguns sinais de saída foram adicionados para que fosse possivel verificar os resultados intermediários da simulação. NTM => NIG para visualizar o valor do token entre o NTM e o NIG; $N T M=>N E W$ para visualizar o valor da tag nova enviada do NTM para a OTT; $N T M=>$ OLD para visualizar o valor do tag antiga enviada do NTM para a OTT; NIG => NTD para visualizar o valor do token entre o NIG e o NTD; $N T D=>N E W$ para visualizar o valor da tag nova enviada do NTD para a OTT; OLD => NTD para visualizar o valor do tag antiga enviada da OTT para o NTD. A Figura 5.35 ilustra uma simulação desta construção iterativa.

$\mathrm{O}$ token que chega ao NTM na simulação vale $<A . A \cdot A A, A A A A>h$. $\mathrm{O}$ NTM gera um valor novo para ativação de subgrafo (no caso, zero) e zera o campo iteração atual. Em seguida, a tag antiga $(<A . A A>h)$ e a tag nova $(<A .0>h)$ são enviadas para a OTT perto dos $150 \mathrm{~ns}$. Estes valores podem ser vistos através dos sinais ntm2old (NTM => OLD) e ntm2new (NTM $=>$ NEW) respectivamente. O token chega ao operador NIG valendo $<A .0 .00, A A A A>h$ por volta de $250 \mathrm{~ns}$. O NIG incrementa o campo da iteração atual do dado e no 


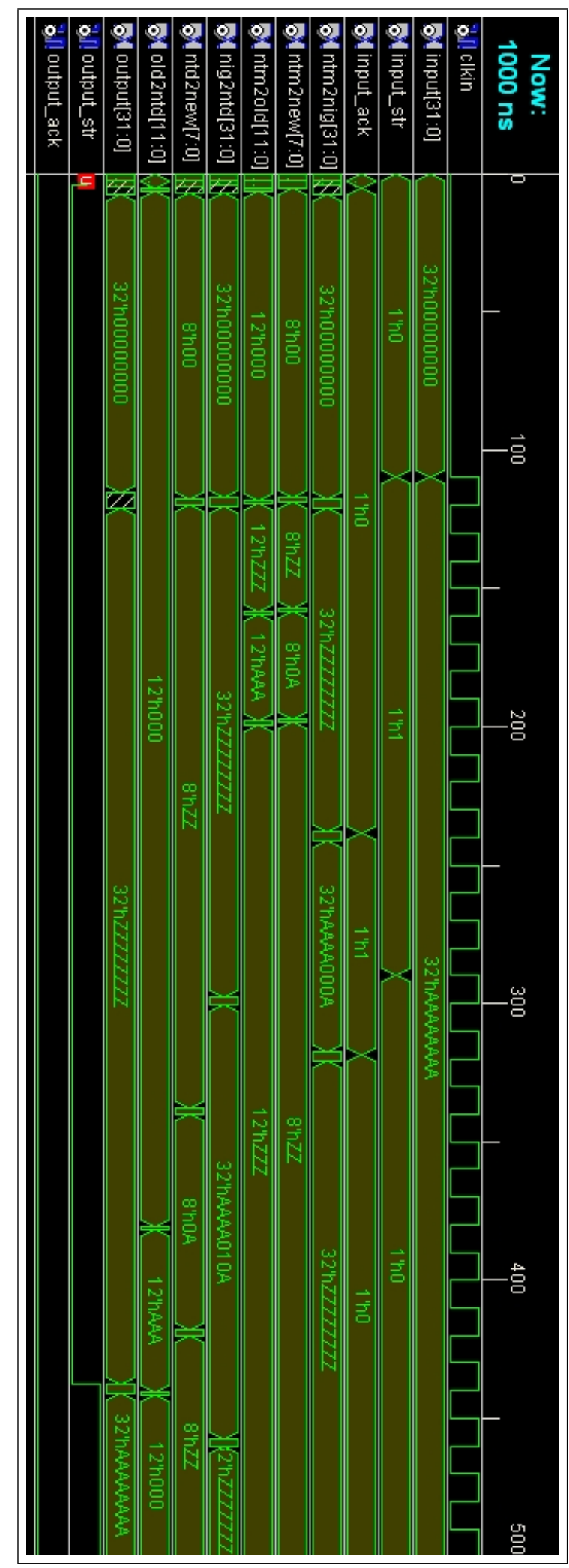

Figura 5.35: Simulação NTM, NIG, NTD e OTT. 
sinal nig2ntd (NIG $=>$ NTD) é possivel notar que o valor do token passa a ser $<A .0 .01, A A A A>h$ por volta dos 300ns. Quando o token chega ao NTD, o NTD solicita a tag antiga a OTT. Após a recuperação da tag antiga, o token deixa a construção iterativa com a mesma tag que possuia antes entrar no loop, ou seja, o token se torna $<A$.A.AA, $A A A A>h$ por volta dos $400 n s$. Além da saída

final gerada pelo NTD, todos os outros sinais intermediários podem ser vistos na simulação.

\subsection{CONSIDERAÇÕES FINAIS}

Neste capítulo foram apresentados o modelo teórico das tags para a arquitetura ChipCflow dinâmica, o modelo teórico dos operadores para gerenciamento das tags, a implementação, simulação e testes dos operadores utilizando VHDL e a ferramenta ISE da Xilinx. O próximo capítulo irá apresentar as conclusões deste trabalho, algumas discussões e trabalhos futuros. 


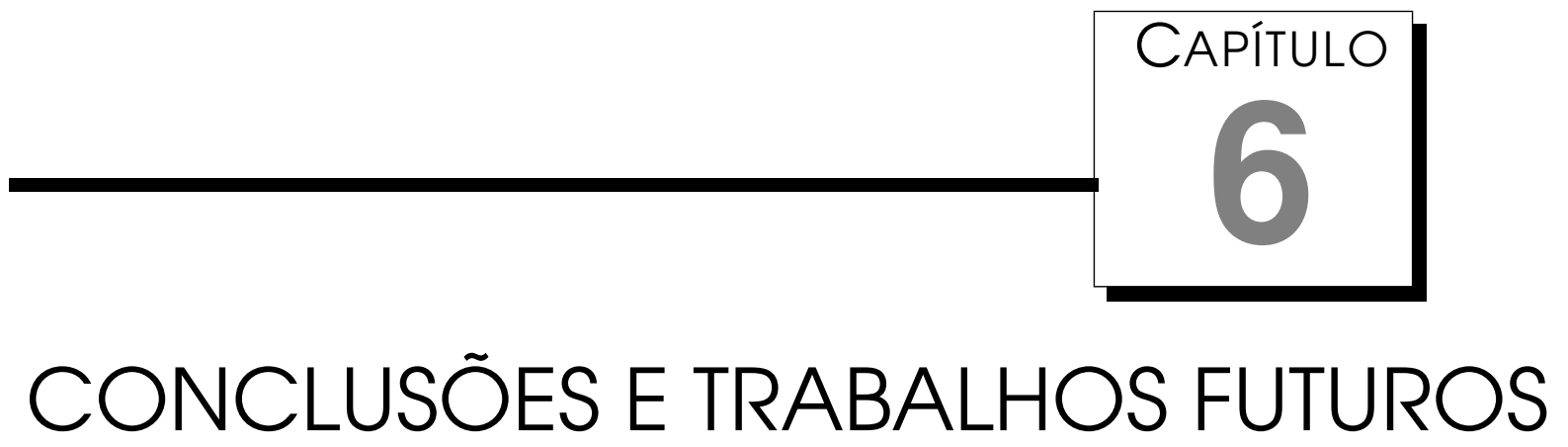

A ferramenta ChipCflow surge com o intuito de propor soluções para o paralelismo em hardware reconfigurável utilizando o modelo a fluxo de dados dinâmico, cujo paralelismo é considerado intrínseco ao modelo e como alternativa para as arquiteturas tradicionais multicore. No modelo a fluxo de dados dinâmico utilizando tagged-token, várias questões estão envolvidas: matching de dados, instâncias dos operadores, gerenciamento de tags, organização de memória, etc. Esta dissertação de mestrado teve por objetivo investigar arquiteturas a fluxo de dados dinâmico tagged-token, propor e implementar um modelo para gerenciamento de tags em FPGA para a arquitetura ChipCflow a fim de obter a PROVA-DE-CONCEITOS para esta questão.

Na Tabela 6.1, é apresentado um comparativo das informações contidas nas tags das máquinas tagged-token apresentadas no Capítulo 3 , além do ChipCflow em sua proposta inicial (ChipCflow1) apresentado na seção 4.3 e o ChipCflow atual (ChipCflow2) apresentado na seção 4.5 utilizando os operadores para gerenciamento de tags como proposto no capítulo 5 deste trabalho.

O campo iteração (iteration ID, current iteration, wave number, iteration level) é utilizado nas máquinas de Manchester, TTDA, WaveScalar, ChipCflow1 e ChipCflow2 para identificar a qual iteração um dado pertence quando está em um loop. O campo subgrafo (invocation ID, activation name, subgraph activation) é usado nas máquinas Manchester, TTDA e ChipCflow2 para identificar de qual ativação de uma construção iterativa, procedimento ou função um dado faz parte em determinado momento. O campo grafo (graph activation) foi utilizado em ChipCflow1 e ChipCflow2 para armazenar de qual ativação de um grafo um dado faz parte, caso o grafo faça parte de uma arquitetura híbrida, como CPU-FPGA. O campo index é utilizado na máquina de Man- 
Tabela 6.1: Comparação de tags em arquiteturas tagged-token.

Arquiteturas tagged-token

\begin{tabular}{c|c|c|c|c|c}
\hline Informações & Manchester & TTDA & WaveScalar & ChipCflow 1 & ChipCflow2 \\
\hline Iteração & $\mathrm{X}$ & $\mathrm{X}$ & $\mathrm{X}$ & $\mathrm{X}$ & $\mathrm{X}$ \\
\hline Subgrafo & $\mathrm{X}$ & $\mathrm{X}$ & & & $\mathrm{X}$ \\
\hline Grafo & & & & $\mathrm{X}$ & $\mathrm{X}$ \\
\hline Index & $\mathrm{X}$ & & & & \\
\hline Endereço & & $\mathrm{X}$ & $\mathrm{X}$ & & \\
\hline Thread & & & $\mathrm{X}$ & & \\
\hline Tag antiga & & $\mathrm{X}$ & & $\mathrm{X}$ & $\mathrm{X}$ \\
\hline Aninhamento & & & & $\mathrm{X}$ & \\
\hline
\end{tabular}

chester para indicar qual é o índice da posição de um dado, caso este dado faça parte um vetor, por exemplo. O campo endereço (code block, instruction address, porta de destino e instruction ID) usados nas máquinas TTDA e WaveScalar foram utilizados para indicar para qual instrução o dado deve ir. O campo thread (thread ID) foi utilizado no WaveScalar para identificar dados de diferentes threads em uma arquitetura multi-threaded. A informação tag antiga usada em TTDA, ChipCflow1 e ChipCflow2 são essenciais para executar programas com loops ou funções aninhadas e são armazenadas para que o dado possa recuperar a tag que possuía enquanto estava sendo processado em um nível de aninhamento externo. O campo aninhamento foi proposto na máquina ChipCflow 1 para indicar em qual aninhamento de um código o dado está sendo processado.

O ChipCflow não necessita de um campo na tag para indicar o índice de um dado, caso o dado faça parte de um vetor, já que possui instruções de load e store que recebem o índice correto do vetor a ser acessado. Campos utilizados para indicar endereço de destino também não são necessários, uma vez que a comunicação no ChipCflow é local e ponto a ponto, com ligações montadas pelo compilador. Nesta dissertação, foi considerado que o ChipCflow executaria programas com uma única thread e, por isso, não foi utilizada uma tag específica para identificar de qual thread um dado faz parte. A tag antiga deve ser armazenada para que seja possível executar loops, funções e procedimentos aninhados. Uma das limitações do WaveScalar é não executar loops aninhados, pois as tags antigas não são armazenadas e, como consta em Swanson et al. (2007), os waves não podem conter loops. O campo aninhamento foi proposto inicialmente para o ChipCflow, porém, nos casos estudados e verificados, tal campo não se mostrou útil.

Na proposta inicial do ChipCflow, a tag deveria conter a iteração atual, aninhamento e ativação de grafo. Os campos iteração e ativação de grafo continu- 
aram existindo na versão atual do ChipCflow. Porém, o campo aninhamento foi substituído pelo campo ativação de subgrafo. Esta mudança foi necessária para que fosse possível diferenciar dados de várias chamadas (ativações) de uma mesma função ou procedimento que fizessem parte de um mesmo aninhamento, mesma iteração e mesma ativação de grafo. Neste caso, o campo aninhamento seria o mesmo para todas as chamadas e, consequentemente, os dados das diferentes chamadas se misturariam.

O campo ativação de grafo é utilizado para diferenciar os dados em uma arquitetura CPU-FPGA, entretanto, nos casos onde sabe-se que o programa executa apenas uma vez ou executa inteiramente no FPGA, este campo poderia ser descartado. Especulativamente, poderia ser utilizado como thread ID, porém um estudo mais aprofundado desta questão deve ainda ser realizado.

As demais arquiteturas apresentadas, como CHiMPS (PUTNAM et al., 2008) e CASH (BUDIU, 2003), são arquiteturas baseadas no fluxo de dados estático, não possuem tags e exploram menos paralelismo do que as arquiteturas dinâmicas.

Uma primeira questão sobre a implementação apresentada que merece ser esclarecida é com relação ao número de bits utilizado para cada campo da tag. Nas implementações feitas neste trabalho, a tag possui 16 bits, quatro para ativação de grafo, quatro para ativação de subgrafo e oito para iteração atual. Como foi dito anteriormente, tais valores foram definidos arbitrariamente apenas para testes. Se o tamanho das tags é fixo, poderia ocorrer overflow e consequentemente haveria a possibilidade de conflito dos tokens. Porém, a ideia na arquitetura ChipCflow é que o compilador analise o código e, ao gerar o grafo a fluxo de dados em VHDL, defina o tamanho das tags de modo que a capacidade seja adequada para a aplicação em questão. Para isto, é necessário que o compilador tenha a informação sobre quantas iterações/ativações um grafo ou subgrafo irá executar. Casos onde esta informação não está disponível em tempo de compilação não foram considerados, mas se fossem considerados seria necessário um mecanismo para gerenciamento de overflow da tag.

Uma limitação que ocorre em relação às tags é que elas foram implementadas considerando apenas programas single-threaded. Um estudo mais aprofundado sobre arquiteturas a fluxo de dados multi-threaded precisa ser feito para concluir se o modelo de tags implementado neste trabalho também se enquadra neste tipo de arquitetura.

Como foi mencionado na introdução deste trabalho, alguns trabalhos essenciais para o modelo do ChipCflow dinâmico ainda estão em desenvolvimento como a unidade de matching, instâncias e o próprio compilador da ferramenta ChipCflow. Portanto, não foi possivel testar os operadores em uma 
máquina a fluxo de dados real. Para verificar seu funcionamento, implementouse em VHDL os operadores realizando apenas a sua função básica e, como não havia unidade de matching e nem instâncias, a versão dos operadores funcionam de forma estática. Tal implementação teve por objetivo desenvolver o núcleo destes operadores. Sendo assim, no momento em que as outras estruturas estiverem prontas, basta integrar este núcleo às estruturas para se ter uma implementação dinâmica.

Embora não se tenha alcançado nenhum resultado quantitativo do overhead dos operadores para gerenciamento de tags, é possível afirmar que ele irá existir, uma vez que todo o processamento que não é o cálculo realizado sobre os dados da aplicação propriamente ditos são considerados overhead. Entretanto, os operadores de manipulação de tags foram projetados para que realizassem computações simples. De qualquer forma, um estudo deve ser realizado para verificar a relação do overhead inserido por tais operadores e o paralelismo existente em uma aplicação. Programas com pouco ou nenhum paralelismo não são ideais para se utilizar tags já que não haverá concorrência para o processamento dos tokens nos operadores. A real vantagem oferecida pelo uso de tagged-token surge em aplicações massivamente paralelas com vários tokens sendo processados simultaneamente dentro dos operadores.

Com a proposta da OTT (Old Tag Table) para armazenamento das tags antigas dos tokens, a arquitetura ChipCflow passa a ter dois tipos de memória: uma memória para os dados propriamente ditos e a memória para as tags antigas, que é formada pelo conjunto de todas as OTTs espalhadas pelo grafo. A implementação da OTT feita neste trabalho não pretende ser a implementação otimizada da estrutura. Foi implementada uma memória dual-channel para permitir que ao mesmo tempo em que um NTM escreve na tabela, um NTD pode ler. Em casos reais em uma máquina a fluxo de dados dinâmica, é provável que várias escritas sejam realizadas simultaneamente por várias instâncias de um mesmo NTM. Além disso, várias solicitações de leituras também podem acontecer ao mesmo tempo pelos vários NTDs e suas instâncias. Consequentemente, é necessário um gerenciador de acesso a estas memórias, para tratar isto de alguma maneira. A concorrência de memória que acontece nas OTTs é semelhante a concorrência que acontece na memória de dados com as instruções load e store.

O fato das OTTs serem distribuídas ao longo do grafo, reduzem o gargalo que acontece em memórias totalmente centralizadas. O gerenciamento de tags também acontece de forma distribuída e é realizado somente sobre os dados que necessitam alterar suas tags.

Com relação aos dados de síntese dos operadores, pode-se concluir que os resultados foram satisfatórios. Com exceção do NTM, que ocupou 3\% no 
número de slices, $2 \%$ do número de slices flip-flops e 1\% das LUTs, todos os operadores ocuparam menos de 1\% destes três recursos do FPGA, indicando que é possível colocar vários destes operadores em um DFG implementado em um FPGA. O período mínimo maior apresentado foi do NTM (4.786ns) e ainda assim foi satisfatório, uma vez que um operador completo do ChipCflow com unidade de matching, instâncias, entre outras estruturas possui período mínimo de aproximadamente 6ns (SILVA and LOPES, 2010).

Alguns dos trabalhos futuros que se seguem imediatamente após a realização deste trabalho estão relacionados com as discussões feitas acima e são:

- Implementação de uma estrutura otimizada da OTT para gerenciar a concorrência no acesso a esta memória;

- Implementar a máquina a fluxo de dados dinâmica do ChipCflow para aplicações multi-threaded;

- Integração da unidade de matching, instâncias dos operadores e gerenciamento de tags;

- Análise de desempenho e overhead no ChipCflow por meio da execução de benchmarks; 


\section{REFERÊNCIAS BIBLIOGRÁFICAS}

AGARWAL, V., HRISHIKESH, M. S., KECKLER, S. W., and BURGER, D. (2000). Clock rate versus ipc: the end of the road for conventional microarchitectures. In Proceedings of the 27th annual international symposium on Computer architecture, ISCA 'O0, pages 248-259, New York, NY, USA. ACM.

ALTERA (2007). Nios II C2H Compiler Users Guide. Altera Corporation.

ARVIND (2005). Dataflow: Passing the token. In ISCA 06 Keynote Talk Paper, Madison, WI.

ARVIND, K. and NIKHIL, R. S. (1990). Executing a program on the mit taggedtoken dataflow architecture. IEEE Trans. Comput., 39(3):300-318.

ASTOLFI, V. F. (2009). Chipcflow - em hardware dinamicamente reconfigurável. Dissertação de Mestrado, Universidade de São Paulo, Instituto de Ciências Matemáticas e de Computação - ICMC - USP, Brasil.

ASTOLFI, V. F. and SILVA, J. L. (2007). Execution of algorithms using a dynamic dataflow model for reconfigurable hardware - commands in dataflow graph. In III Southern Conference on Programmable Logic.

BHATTACHARYYA, S. S., BREBNER, G., JANNECK, J. W., EKER, J., VON PlATEN, C., MATTAVELli, M., and RAUlET, M. (2008). Opendf: a dataflow toolset for reconfigurable hardware and multicore systems. SIGARCH Comput. Archit. News, 36(5):29-35.

BOBDA, C. (2007). Introduction to Reconfigurable Computing: Architectures, Algorithms, and Applications. Springer.

BUDIU, M. (2003). Spatial Computation. PhD thesis, Carnegie Mellon University, Computer Science Department. Technical report CMU-CS-03-217. 
BUDIU, M., ARTIGAS, P. V., and GOLDSTEIN, S. C. (2005). Dataflow: A complement to superscalar. In In IEEE International Symposium on Performance Analysis of Systems and Software (ISPASS, pages 177-186.

BURGER, D., KECKLER, S. W., MCKINLEY, K. S., DAHLIN, M., JOHN, L. K., LIN, C., MOORE, C. R., BURRILL, J., MCDONALD, R. G., YODER, W., and TEAM, T. T. (2004). Scaling to the end of silicon with edge architectures. Computer, 37(7):44-55.

CAPPELLI, A., LODI, A., MUCCI, C., TOMA, M., and CAMPI, F. (2004). A dataflow control unit for c-to-configurable pipelines compilation flow. FieldProgrammable Custom Computing Machines, Annual IEEE Symposium on, 0:332-333.

COMPTON, K. and HAUCK, S. (2002). Reconfigurable computing: a survey of systems and software. ACM Comput. Surv., 34(2):171-210.

COMPTON, K., HAUCK, S., and COMPTON, K. (2000). An introduction to reconfigurable computing. IEEE Computer.

CORREIA, V. M. (2009). Chipcflow - uma ferramenta para execução de algoritmos utilizando o modelo a fluxo de dados dinâmico em hardware reconfigurável - operadores em grafos a fluxo de dados. Dissertação de Mestrado, Universidade de São Paulo, Instituto de Ciências Matemáticas e de Computação - ICMC - USP, Brasil.

COSTA, K. A. P. (2009). Chipcflow - uma ferramenta para execução de algoritmos utilizando o modelo a fluxo de dados dinâmico em hardware reconfigurável: Módulo de conversão c em grafo a fluxo de dados. Tese Doutorado, Universidade de São Paulo, Escola de Engenharia de São Carlos, Brasil.

CULLER, D. E., SAH, A., SCHAUSER, K. E., VON EICKEN, T., and WAWRZYNEK, J. (1991). Fine-grain parallelism with minimal hardware support: a compiler-controlled threaded abstract machine. In ASPLOS-IV: Proceedings of the fourth international conference on Architectural support for programming languages and operating systems, pages 164-175, New York, NY, USA. ACM.

DAVIS, A. L. (1978). The architecture and system method of ddm1: A recursively structured data driven machine. In ISCA '78: Proceedings of the 5th annual symposium on Computer architecture, pages 210-215, New York, NY, USA. ACM. 
DENNIS, J. B. (1974). First version of a data flow procedure language. In Programming Symposium, Proceedings Colloque sur la Programmation, pages 362-376, London, UK. Springer-Verlag.

DENNIS, J. B. (1980). Data flow supercomputers. Computer, 13(11):48-56.

DENNIS, J. B. and MISUNAS, D. P. (1975). A preliminary architecture for a basic data-flow processor. In In Proceedings of the 2nd Annual Symposium on Computer Architecture, pages 126-132.

EL-GHAZAWI, T., EL-ARABY, E., HUANG, M., GAJ, K., KINDRATENKO, V., and BUELL, D. (2008). The promise of high-performance reconfigurable computing. Computer, 41(2):69-76.

GEBHART, M., MAHER, B. A., COONS, K. E., DIAMOND, J., GRATZ, P., MARINO, M., RANGANATHAN, N., ROBATMILI, B., SMITH, A., BURRILL, J., KECKLER, S. W., BURGER, D., and MCKINLEY, K. S. (2009). An evaluation of the trips computer system. In ASPLOS '09: Proceeding of the 14th international conference on Architectural support for programming languages and operating systems, pages 1-12, New York, NY, USA. ACM.

GRAFE, V. G., DAVIDSON, G. S., HOCH, J. E., and HOLMES, V. P. (1989). The epsilon dataflow processor. SIGARCH Comput. Archit. News, 17(3):36-45.

GURD, J. R., KIRKHAM, C. C., and WATSON, I. (1985). The manchester prototype dataflow computer. Commun. ACM, 28(1):34-52.

HAUCK, S. (1998). The roles of fpgas in reprogrammable systems. In Proceedings of the IEEE, pages 615-638.

JÚNIOR, F. S. (2011). Chipcflow - validação e implementação do modelo de partição e protocolo de comunicação no grafo a fluxo de dados dinâmico. Dissertação de Mestrado, Universidade de São Paulo, Instituto de Ciências Matemáticas e de Computação - ICMC - USP, Brasil.

JOHNSTON, W. M., HANNA, J. R. P., RICHARD, and MILLAR, J. (2004). Advances in dataflow programming languages. ACM Comput. Surv, 36:1-34.

KIRK, D. B. and HWU, W.-M. W. (2010). Programming Massively Parallel Processors: A Hands-on Approach. Morgan Kaufmann, 1 edition.

KISHI, M., YASUHARA, H., and KAWAMURA, Y. (1983). Dddp-a distributed data driven processor. SIGARCH Comput. Archit. News, 11(3):236-242.

LEE, B. and HURSON, A. R. (1993). Issues in dataflow computing. Advances in Computers, 37:285-333. 
LEE, W., BARUA, R., FRANK, M., SRIKRISHNA, D., BABB, J., SARKAR, V., and AMARASINGHE, S. (1998). Space-time scheduling of instruction-level parallelism on a raw machine. SIGOPS Oper. Syst. Rev., 32(5):46-57.

MAI, K., PAASKE, T., JAYASENA, N., HO, R., DALLY, W. J., and HOROWITZ, M. (2000). Smart memories: a modular reconfigurable architecture. In ISCA 'OO: Proceedings of the 27th annual international symposium on Computer architecture, pages 161-171, New York, NY, USA. ACM.

MARTINS, C. A. P., ORDONEZ, E. D. M., CORREAA, J. B. T., and CARVALHO, M. B. (2003). Computação reconfigurável: conceitos, tendências e aplicações. In XXII Jornada de Atualização em Informática (JAI) - Livro Texto, volume XXII, pages 339-388, Campinas. Sociedade Brasileira de Computação.

MERIBOUT, M. and MOTOMURA, M. (2004). Efficient metrics and high-level synthesis for dynamically reconfigurable logic. IEEE Trans. Very Large Scale Integr. Syst., 12(6):603-621.

MÖHL, S. (2005). The mitrion-c programming language. Technical report, Lund, Sweden.

MOORE, G. E. (2000). Readings in computer architecture. chapter Cramming more components onto integrated circuits, pages 56-59. Morgan Kaufmann Publishers Inc., San Francisco, CA, USA.

NAGARAJAN, R., SANKARALINGAM, K., BURGER, D., and KECKLER, S. W. (2001). A design space evaluation of grid processor architectures. In MICRO 34: Proceedings of the 34th annual ACM/IEEE international symposium on Microarchitecture, pages 40-51, Washington, DC, USA. IEEE Computer Society.

PAPADOPOULOS, G. M. and CULLER, D. E. (1998). Monsoon: an explicit token-store architecture. In ISCA '98: 25 years of the international symposia on Computer architecture (selected papers), pages 398-407, New York, NY, USA. ACM.

PUTNAM, A. (2009). Microarchitectures and Synthesis Compilers for Efficiently Executing Imperative Language Programs. PhD thesis, University of Washington, Computer Science and Engineering.

PUTNAM, A. R., BENNETT, D., DELlingeR, E., MASON, J., and SUNDARARAJAN, P. (2008). Chimps: a high-level compilation flow for hybrid cpu-fpga architectures. In FPGA '08: Proceedings of the 16th international 
ACM/SIGDA symposium on Field programmable gate arrays, pages 261261, New York, NY, USA. ACM.

RANGANATHAN, N., BURGER, D., and KECKLER, S. W. (2009). Analysis of the trips prototype block predictor. In ISPASS 2009: Proceedings of the IEEE International Symposium on Performance Analysis of Systems and Software, pages 195-206. IEEE.

REDAELli, F., SANTAMBROGIO, M. D., and ScIUTO, D. (2008). Task scheduling with configuration prefetching and anti-fragmentation techniques on dynamically reconfigurable systems. In DATE '08: Proceedings of the conference on Design, automation and test in Europe, pages 519-522, New York, NY, USA. ACM.

SAKAI, S., YAMAGUCHI, Y., HIRAKI, K., KODAMA, Y., and YUBA, T. (1989). An architecture of a dataflow single chip processor. SIGARCH Comput. Archit. News, 17(3):46-53.

SANCHES, L. B. (2010). Chipcflow - partição e protocolo de comunicação no grafo a fluxo de dados dinâmico. Dissertação de Mestrado, Universidade de São Paulo, Instituto de Ciências Matemáticas e de Computação - ICMC - USP, Brasil.

SANKARALINGAM, K., NAGARAJAN, R., LIU, H., KIM, C., HUH, J., BURGER, D., KECKLER, S. W., and MOORE, C. R. (2003). Exploiting ilp, tlp, and dlp with the polymorphous trips architecture. In ISCA '03: Proceedings of the 30th annual international symposium on Computer architecture, pages 422-433, New York, NY, USA. ACM.

SANKARALINGAM, K., NAGARAJAN, R., MCDONALD, R., DESIKAN, R., DROLIA, S., GOVINDAN, M. S., GRATZ, P., GULATI, D., HANSON, H., KIM, C., LIU, H., RANGANATHAN, N., SETHUMADHAVAN, S., SHARIF, S., SHIVAKUMAR, P., KECKLER, S. W., and BURGER, D. (2006). Distributed microarchitectural protocols in the trips prototype processor. In MICRO 39: Proceedings of the 39th Annual IEEE/ACM International Symposium on Microarchitecture, pages 480-491, Washington, DC, USA. IEEE Computer Society.

SHIMADA, T., HIRAKI, K., NISHIDA, K., and SEKIGUCHI, S. (1986). Evaluation of a prototype data flow processor of the sigma-1 for scientific computations. In ISCA '86: Proceedings of the 13th annual international symposium on Computer architecture, pages 226-234, Los Alamitos, CA, USA. IEEE Computer Society Press. 
SILVA, B. A. (2010). Chipcflow assembly - um código inerentemente paralelo entre linguagens de alto nível e o hardware. Relatório Técnico, Universidade de São Paulo - Laboratório de Computação Reconfigurável (LCR) ICMC, USP - São Carlos, Brasil.

SILVA, J. L. (1992). Processamento a fluxo de dados tolerante a falhas em um computador paralelo. Tese Doutorado, Universidade Estadual de Campinas, UNICAMP, Brasil.

SILVA, J. L. (2006). Execution of algorithms using a dynamic dataflow model for reconfigurable hardware - a purpose for matching data. In The 6th International Workshop on System on Chip for Real Time Applications.

SILVA, J. L., COSTA, K. A. P., and RODA, V. O. (2009). The c compiler generating a source file in vhdl for a dynamic dataflow machine. In WSEAS.

SILVA, J. L. and LOPES, J. J. (2010). A dynamic dataflow architecture using partial reconfigurable hardware as an option for multiple cores. W. Trans. on Comp., 9(5):429-444.

SILVA, J. L. and MARQUES, E. (2006). Executing algorithms for dynamic dataflow reconfigurable hardware - the operators protocol. In In: RECONFIG 06: The 3st International Conference on Reconfigurable Computing and FPGAs.

SKLIAROVA, I. and FERRARI, A. B. (2003). Introdução à computação reconfigurável. REVISTA DO DETUA, 2(6).

SMITH, A., GIBSON, J., MAHER, B., NETHERCOTE, N., YODER, B., BURGER, D., MCKINLE, K. S., and BURRILL, J. (2006). Compiling for edge architectures. In Proceedings of the International Symposium on Code Generation and Optimization, CGO '06, pages 185-195, Washington, DC, USA. IEEE Computer Society.

SWANSON, S., MICHELSON, K., SCHWERIN, A., and OSKIN, M. (2003). Dataflow: The road less complex. In In Workshop on Complexity-effective Design.

SWANSON, S., SCHWERIN, A., MERCALDI, M., PETERSEN, A., PUTNAM, A., MICHELSON, K., OSKIN, M., and EGGERS, S. J. (2007). The wavescalar architecture. ACM Trans. Comput. Syst., 25(2):1-54.

TAYLOR, M. B., KIM, J., MILLER, J., WENTZLAFF, D., GHODRAT, F., GREENWALD, B., HOFFMAN, H., JOHNSON, P., LEE, J.-W., LEE, W., MA, A., SARAF, A., SENESKI, M., SHNIDMAN, N., STRUMPEN, V., FRANK, M., 
AMARASINGHE, S., and AGARWAL, A. (2002). The raw microprocessor: A computational fabric for software circuits and general-purpose programs. IEEE Micro, 22(2):25-35.

VEEN, A. H. (1986). Dataflow machine architecture. ACM Comput. Surv., 18(4):365-396.

VERONESI, R. (2005). Rtrassoc51 - módulo de comunicação i2c reconfigurável ri2c. Defesa de Dissertação Apresentada ao Programa de Pós-Graduação em Ciência da Computação do UNIVEM para obtenção do título de Mestre, Marilia, S.P., 2005.

XILINX (2011). Documentation. http://www.xilinx.com/support/documenta tion/index.htm. acesso: 23/02/2011. 